

\title{
Interiority of a Disconnected Mind
}

\author{
Sarah Cheetham
}

A 120-point thesis

submitted to the Victoria University of Wellington

in partial fulfilment of the requirements for the

degree of Master of Interior Architecture

Victoria University of Wellington

School of Architecture 


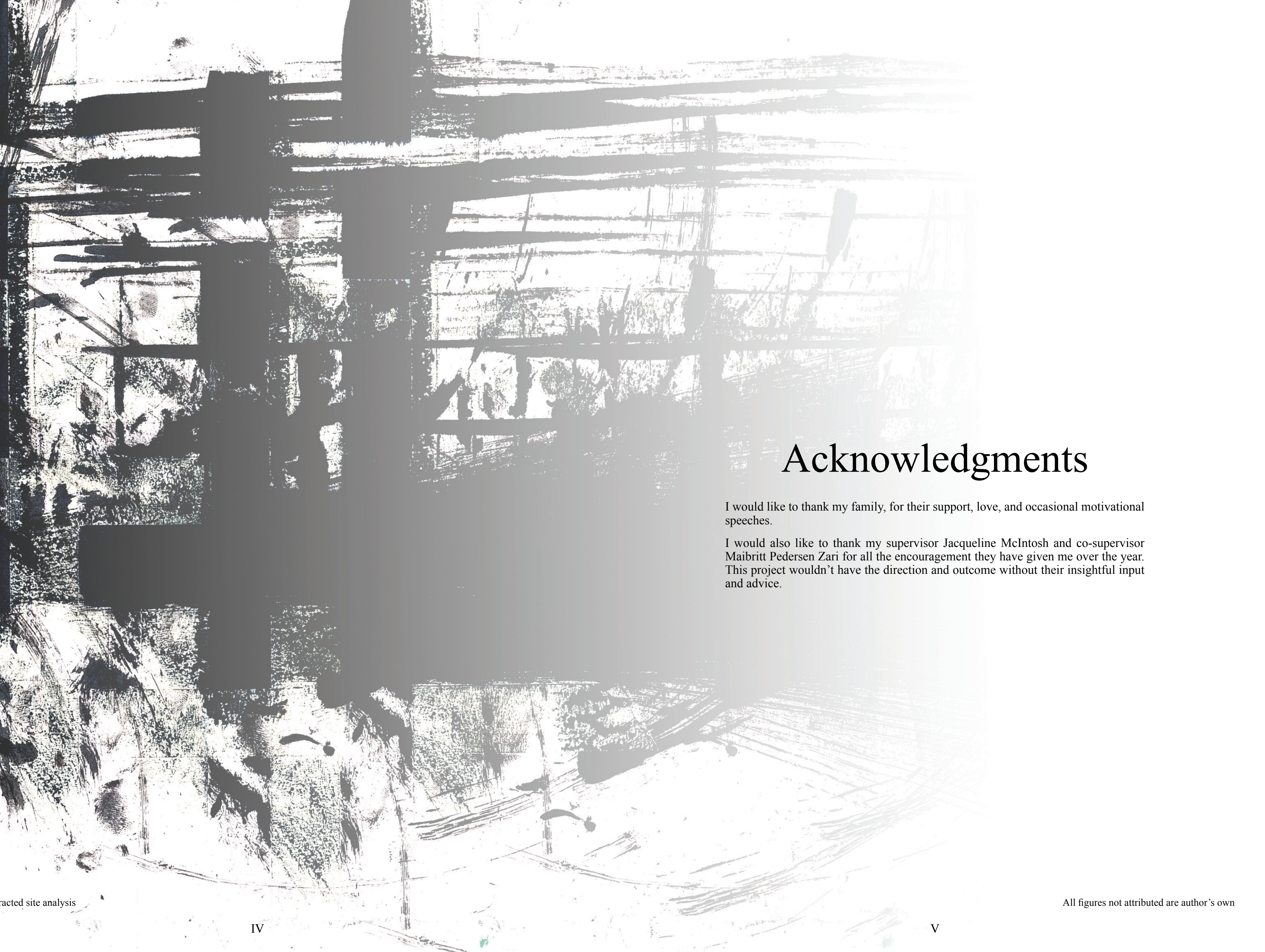





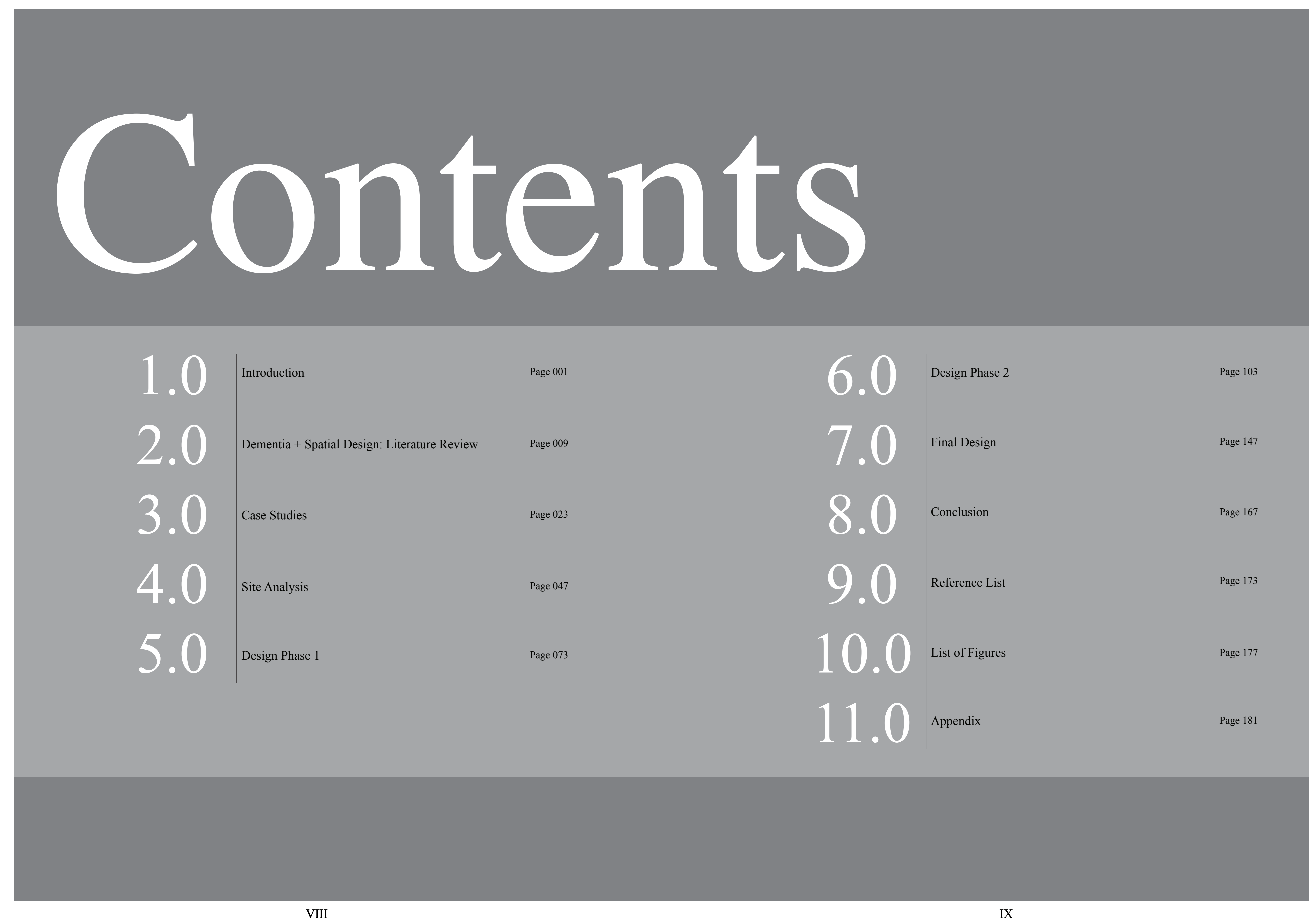




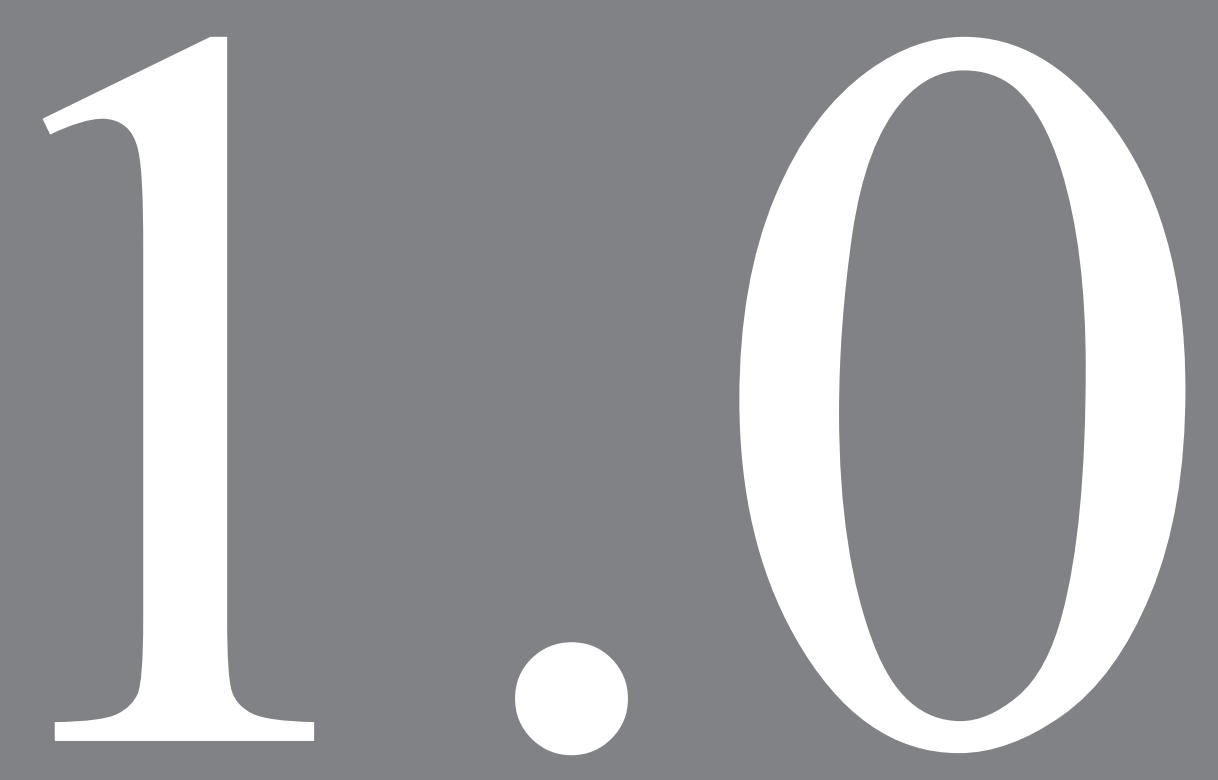

Introduction 


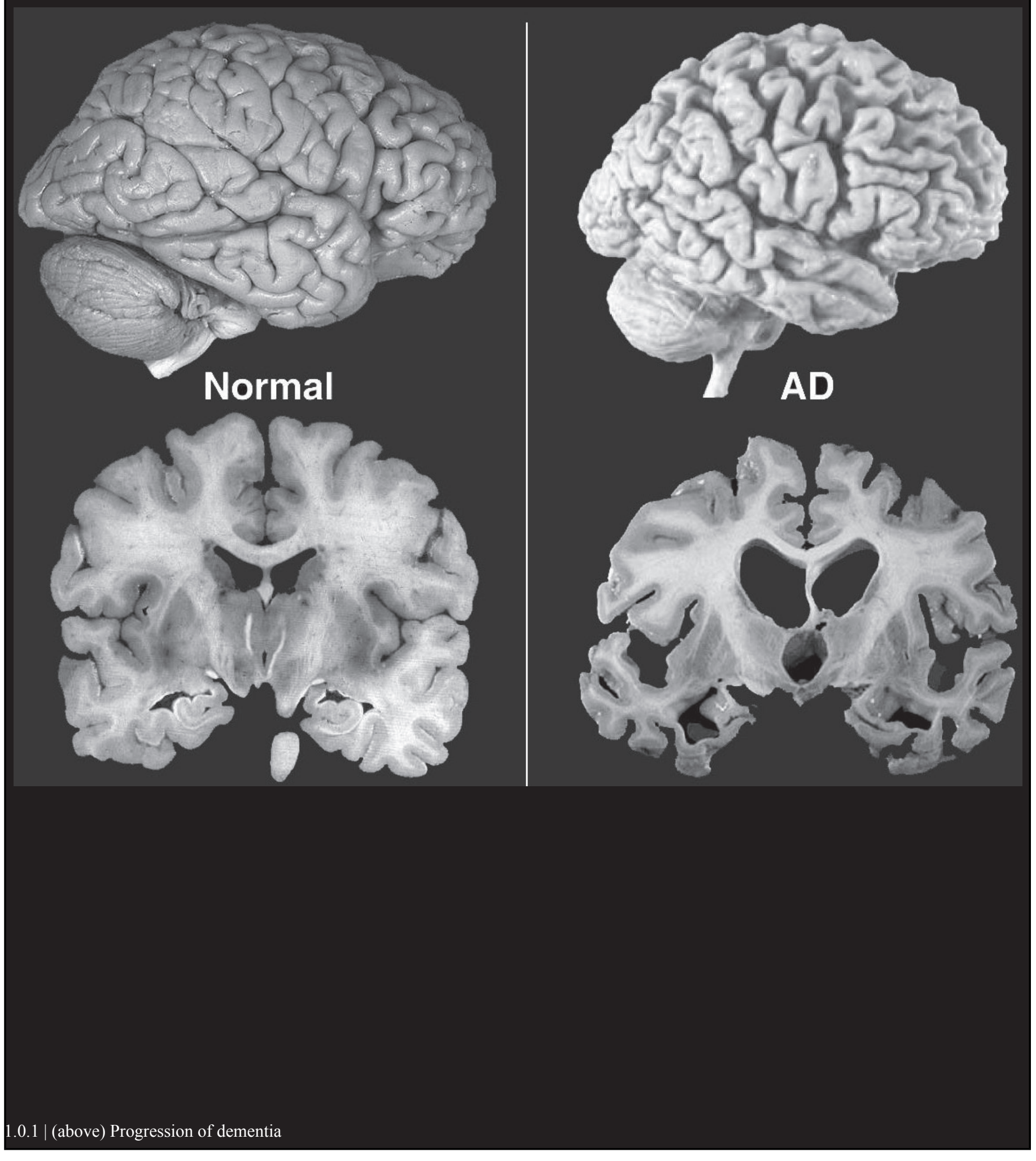

002
The thought of losing yourself while you're still living is a hard concept to grasp but this kind of loss is a reality for people with dementia. This process of loss commonly comes in the form of memory loss, but also affects 'language, attention, problem solving, planning and organising, and judgment' (Mental Health Foundation of New Zealand and Peters). Dementia is a colloquial term used to describe people Zealand and Peters), causing the brain's pathways and connections to die over time.

\section{MMPMPMM 2011

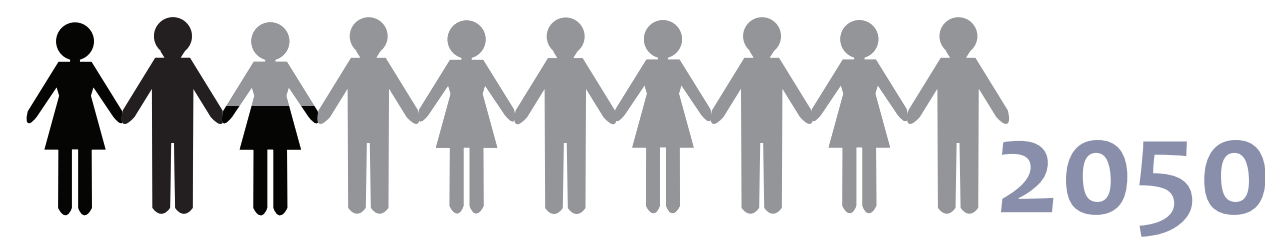

New Zealand as a whole has an increasing rate of people with dementia (Alzheimers New Zealand). Since the 2008 Dementia Economic Impact Report, the number of people with dementia has increased by 18\% (Deloitte Access Economics i). Dementia affects $1.1 \%$ of the tota New Zealand population, and is said to triple by 2050 (Deloitte Access Economics i). As an increasing numbers of New Zealanders become affected by dementia, the need for specialised care and support is becoming a prominent issue that needs to be addressed. There are a number of New Zealand facilities that provide care for people with dementia, but only a limited number of specialised facilities where all aspects of the condition are explored and addressed through design. This problem becomes apparent when families struggle to look after their loved ones at home rather than put them in an institutionalised aged-care
facility.
The New Zealand Ministry of Health has set up a Dementia Care Framework which is in the process of being implemented by local District Health Boards (DHB's) (Ministry of Health). The framework suggested by the Ministry seeks to address the stigma around Dementia and the care facilities, while developing low budget activities within the community (Ministry of Health). These activities promote the connection of people with dementia to the community in an effort to bring back some of the normality of their life, which loss of memory has taken away. The Ministry of Health 'recognises that dementia care needs to be improved nationwide in a way that maximises the independence and wellbeing of the person with dementia and their family and whanau while ensuring safety and affordability of
services' (Ministry of Health 1). 


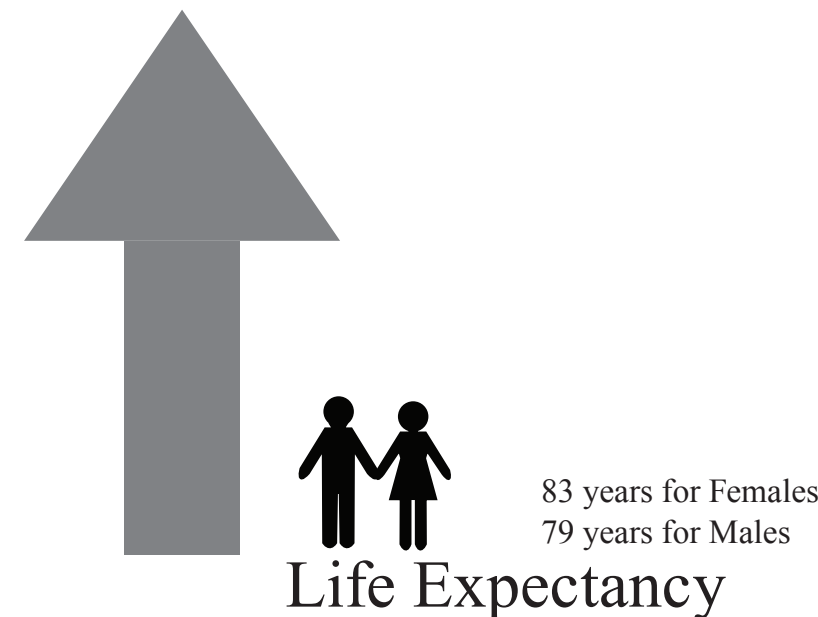

Life Expectancy

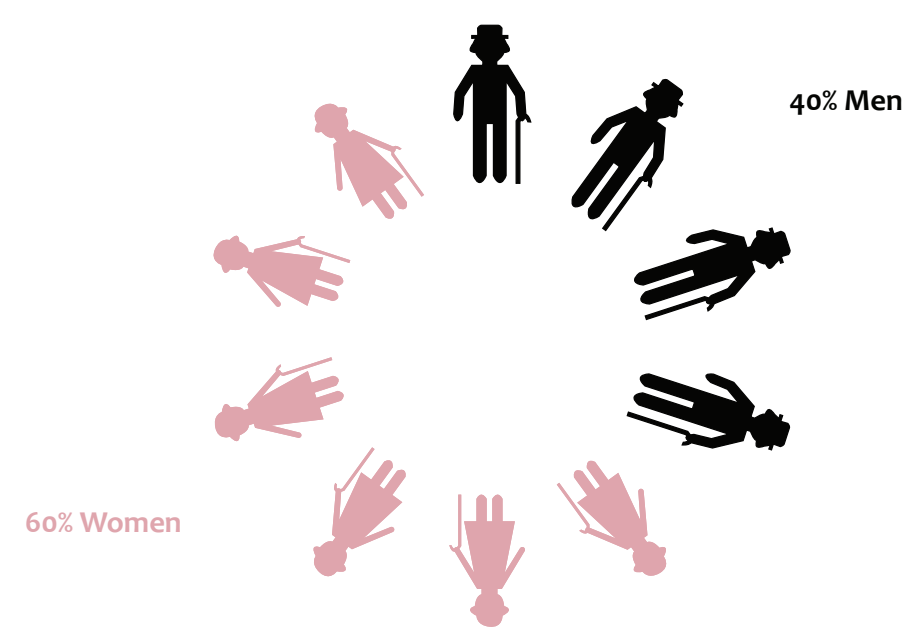

Successful aged-care facilities rely on clear demographic and geographic cues (Reynolds and Beamish 34). Due to the large increase in elderly needing institutional care, facilities focus on providing small rooms in multi-storey buildings often with limited outlook onto environments. These

environments can be particularly confusing for people with dementia as the majority of New Zealanders do not come from high density urban environinonts. This situation is particularly problematic for people from a rural background as they are unable to regulate environmental changes.
With a growing and ageing population, the need for dementia care centres in rural communities will become increasingly important. New Zealand has an opportunity to develop a rural dementia centre that fosters connectiveness and familiarity for the person with dementia and the facility, but still upholds all aspects of appropriate healthcare through design. This thesis proposes to design a dementia care facility for people from a rural community
that reflects the lifestyle they have come from. The design proposes an environment that is both familiar and stimulating for the residents, while ensuring therapeutic and dementiaspecific benefits. 


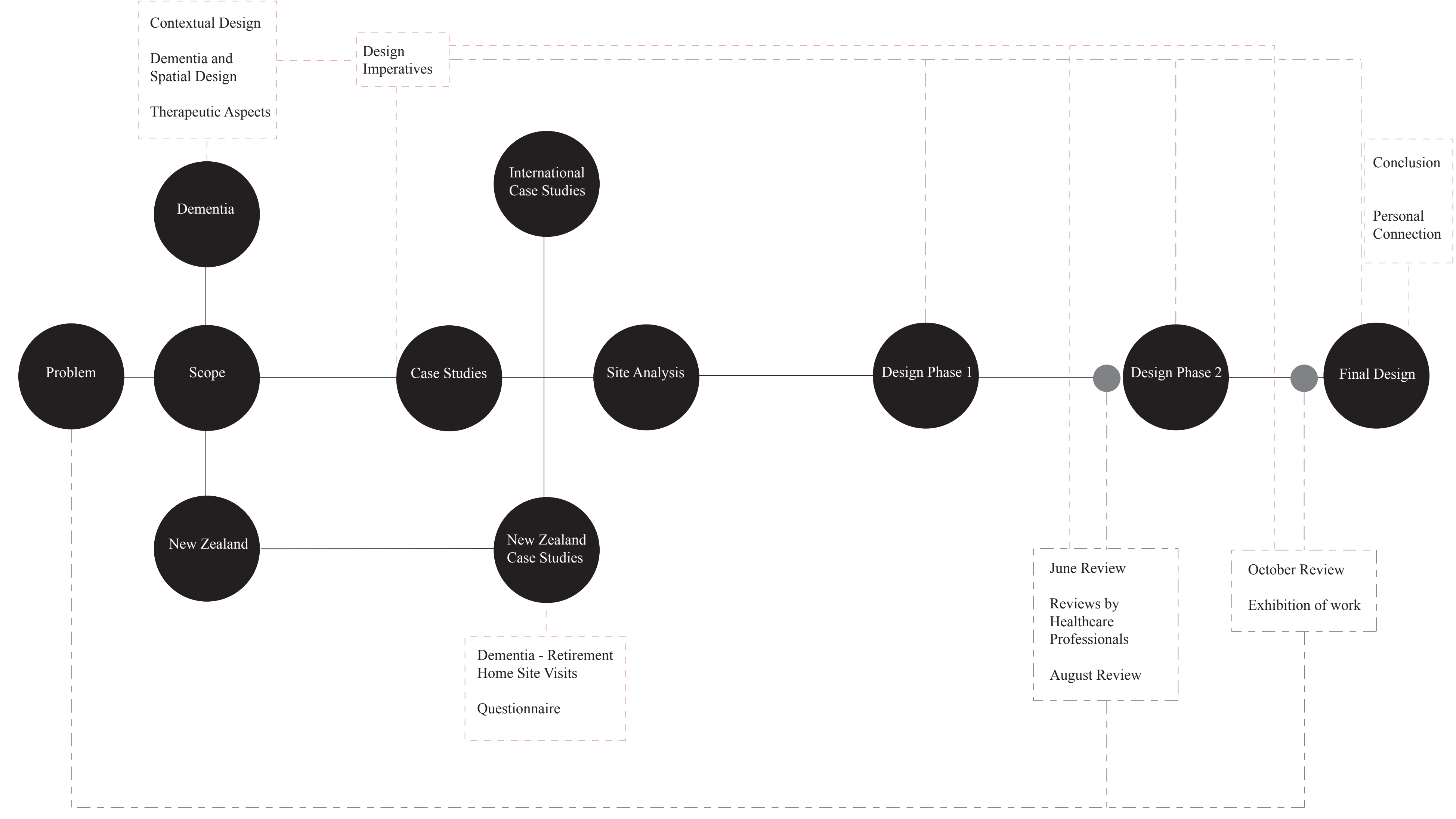



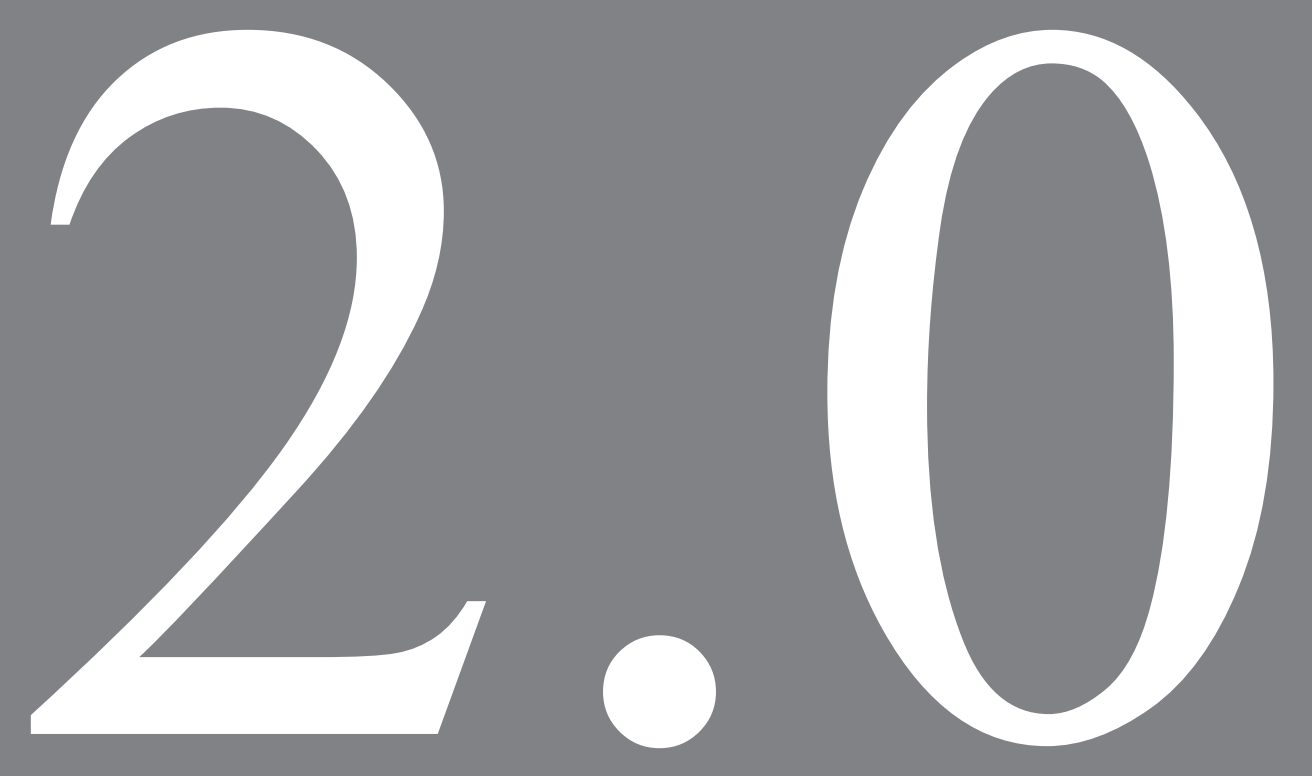

Dementia + Spatial Design: Literature Review 


\section{Dementia}

\section{Categorisation}

People with dementia face the following issues that are relevant to a spatial context.

\section{Lighting issues:}

Sensitivity to lighting - florescent lighting is too bright and clinical for a home-like dementia centre.

Causes sleep deprivation - sleep becomes disrupted as dementia progresses. With the addition of light therapy, the circadian rhythm can begin to go back to normal. This increases sleep at night, and reduces daytime napping and 'sundown syndrome ${ }^{1}$, wandering.

Too much light - if a room has too much light this reduces the contrast between fixtures, furniture and surface materials. This creates confusion for someone with objects becomes difficult (Victorian
Material/surface treatment issues:

Level changes - large level changes become a challenge when the majority of residents have low mobility. Small level changes such as a lip between two materials, or the frame of a door become hazardous as residents tend to trip on these features.

Surface changes - changes with materials create confusion for residents. They can feel the texture underfoot, and can get a fright when this changes.

Contrast of materials - to ensure that residents can see objects, fixtures, and fittings, there should be a contrast between them. When the comes too large however dark colours should be avoided, and reasonably dark colours shouldn't be placed right next to very light colours (Victorian Government Health

\begin{tabular}{|c|c|c|c|c|c|}
\hline & Stage 1 & Stage 2 & Stage 3 & Stage 4 & Stage 5 \\
\hline Orientation & $\begin{array}{c}\text { Fully } \\
\text { orientated in } \\
\text { time and } \\
\text { place }\end{array}$ & $\begin{array}{l}\text { Struggle with } \\
\text { challenging } \\
\text { problems and } \\
\text { timing }\end{array}$ & $\begin{array}{l}\text { Becoming } \\
\text { disorientated } \\
\text { geographically }\end{array}$ & $\begin{array}{l}\text { Disorientation to } \\
\text { both time and } \\
\text { space }\end{array}$ & $\begin{array}{l}\text { No orientation } \\
\text { in time or } \\
\text { geography }\end{array}$ \\
\hline Memory & $\begin{array}{c}\text { No } \\
\text { signific ant } \\
\text { memory } \\
\text { problems }\end{array}$ & $\begin{array}{l}\text { Minor memory } \\
\text { inconsistencies }\end{array}$ & $\begin{array}{l}\text { Short term } \\
\text { memory is almost } \\
\text { gone }\end{array}$ & $\begin{array}{l}\text { Short term } \\
\text { memory is } \\
\text { seriously impaired }\end{array}$ & $\begin{array}{l}\text { Extreme } \\
\text { memory loss }\end{array}$ \\
\hline $\begin{array}{l}\text { Home and } \\
\text { Hobbies }\end{array}$ & $\begin{array}{l}\text { Have a well } \\
\text { maintained } \\
\text { home life }\end{array}$ & $\begin{array}{l}\text { Problem } \\
\text { remembering daily } \\
\text { activities }\end{array}$ & $\begin{array}{l}\text { Some chores may } \\
\text { be forgotten }\end{array}$ & $\begin{array}{c}\text { Can accomplish } \\
\text { chores but may } \\
\text { need help - and } \\
\text { be reminded }\end{array}$ & $\begin{array}{l}\text { Impossible to } \\
\text { perform daily } \\
\text { activities }\end{array}$ \\
\hline Personal Care & $\begin{array}{c}\text { Fully able to } \\
\text { take care of } \\
\text { their } \\
\text { personal } \\
\text { needs }\end{array}$ & $\begin{array}{c}\text { Capable of } \\
\text { personal hygiene }\end{array}$ & $\begin{array}{l}\text { Reminders for } \\
\text { some personal } \\
\text { hygiene }\end{array}$ & $\begin{array}{l}\text { Need help taking } \\
\text { care of hygiene }\end{array}$ & $\begin{array}{l}\text { Full assistance is } \\
\text { needed }\end{array}$ \\
\hline Community & $\begin{array}{l}\text { Can function } \\
\text { out in the } \\
\text { world }\end{array}$ & $\begin{array}{l}\text { Sometimes have } \\
\text { difficulties with } \\
\text { social activities }\end{array}$ & $\begin{array}{l}\text { Needs some } \\
\text { assistance in } \\
\text { public areas }\end{array}$ & $\begin{array}{l}\text { Accompanied to } \\
\text { social events }\end{array}$ & $\begin{array}{l}\text { Impossible to } \\
\text { engage with } \\
\text { community }\end{array}$ \\
\hline Level of Care & $\begin{array}{l}\text { Able to care } \\
\quad \text { for } \\
\text { themselves }\end{array}$ & $\begin{array}{l}\text { Possible extra } \\
\text { home care }\end{array}$ & Dementia Facility & Dementia Facility & Hospital Care \\
\hline
\end{tabular}

Within dementia there are five stages that aim to categorise a person by their symptoms. This is shown in the table. 


\section{Contextual Design}

"Contextual Design is a customer-centreed design process that uses extensive field data as the foundation for understanding users'needs, tasks, intents, and processes

The way in which individuals react to or understand situations is based on how they perceive these experiences or places. Perception influences and shapes an individual based on their past experiences and upbringing. The way in which we perceive space also affects how we react within the built environment. The individual
relies on past 'percepts, memories, relies on past 'percepts, memories,
attitudes, and preferences' to create connections to a new space, or to orientate themselves within an old space. These perceptions are also the links that make people feel secure when entering unknown territory. The connections we attribute to a space are more often defined by objects and reference points and the relationship we have with them (Pop 212-215). As memory fails, these perceptions become more important for people with denentia because they become
the connections with belongings and familiar environments.
The familiar environment of a home is not a luxury for peop a home dementia who are in care facilities. This familiarity is essential for dementia, yet when they reach the point where they need the most assistance, they are often placed in an institution with no familiarity whatsoever (Wildevuur et al. 22). For rural community members with dementia, these institutions do not provide the necessary perceptions of 'things rural'. The dwelling is a major part of understanding identification and orientation and as such is the "central place of human existence' (Haddad 90). Modern homes and institutions do not possess qualities that are congruent with rural typology and perceived as homelike (Haddad 96). For this reason, the psychosocial design of the physical environment is becoming a more researched aspect of health and wellbeing in dementia care patients (Morgan et al. 257; FISCHL).

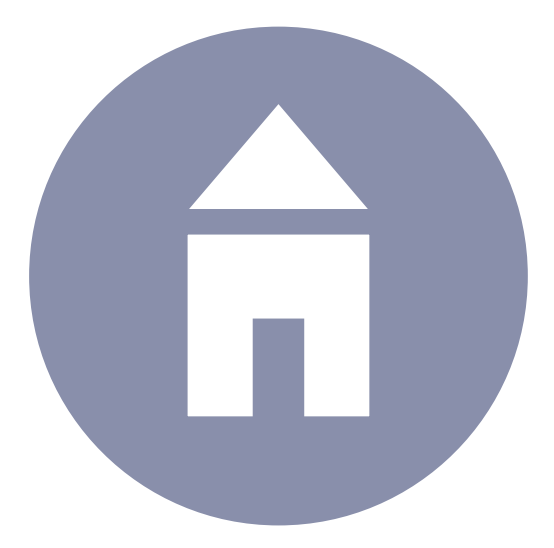

Furthermore, as elderly people look for 'personal interaction, informality, little social differentiationge, and communities are becoming rura communities are becoming more popular places to retire in New People are returning to the familiarity of a rural community they grew up

in. This in turn increases the need for rural nursing homes and dementia to rural typology. The connection to a farming typography of grass, simple wooden dwellings, and animals may provide the congruent aspects that rural elderly require. 


\section{Wayfinding}

Wayfinding is described as a visual representation to aid people in reaching their destination successfully (Passini et al. 685).

As dementia progresses, wayfinding ability is increasingly diminished or lost, along with the ability to process spatial configurations (Passini et al. 687). This interferes with the way in which people get from one destination to another, and in turn, can cause them to get lost in familiar or their agitation, confusion and anxiety (Passini et al. 694). A normal brain allows people to recognise and understand environmental cues, using them to orientate themselves within spaces, and anticipate impending environments. People with dementia struggle with processing many things at once, making the task of spatial orientation and remembering the destination too difficult (Passin et al. 694). These feelings become multiplied when a patient is in new surroundings (Marquardt and Schmieg 337). Environments such as nursing homes and dementia care centres can implement design techniques which aid the process of wayfinding to make reaching a destination for people with dementia less stressful.

In addition, the inclusion of central communal spaces to orientate oneself has been proven to enhance the wayfinding abilities of people with dementia (Passini et al. 698; Marquardt and Schmieg 335). The person with dementia can use these spaces along with multiple reference points to get from one destination to another and from one decision point to the next (Passini et al. 698) Reference points should occur in a sequential and linear order to prevent confusion (Passini et al. 697). These reference points are commonly large visual cues such as architectural elements, fixtures, fittings, and furniture (Passini et al. 698, Marquardt and Schmieg 338). In particular Marquardt and Schmieg points at directional changes rerence points at directional changes which to bupport "alloced and remembered (Marquardt and Schmieg 338).

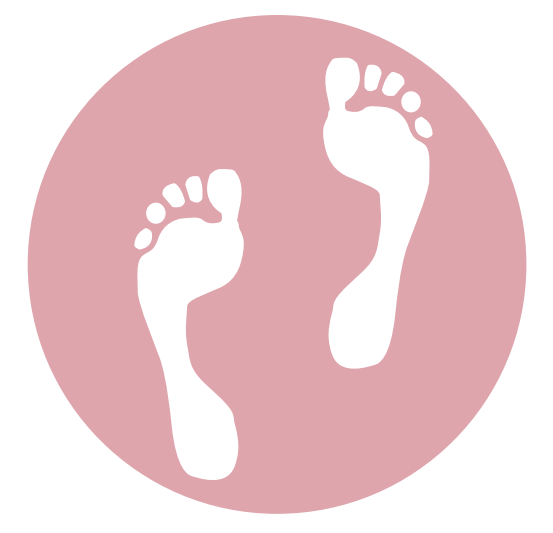
Another of the more documented difficulties is in the nature of the journey, such as the size and shape journey, such as the size and shape and Schmieg 335). Advantages af having minimal to no diretion of having minimal to no direction changes improves residents the 'direct visual access to all places relevant to the resident' (Marquardt and Schmieg 335). This design and Schmieg 335). This design strategy requires less reliance on
allocentric orientation or reference points (Marquardt and Schmieg 338). The narrowness of corridors has also been raised as a problem with clear wayfinding (Passini et al. 696). If corridors become a place for medical or maintenance equipment, they can cause circulation issues leading to disorientation and anxiety (Passini et al. 696). This increase in anxiety can 1 there is a large group of residents requiring more equipment and more corridors connecting spaces. The size of the facility significantly influences awareness, orientation, safety, security and regulation of stimulation. The smaller the centre the more beneficial for people with dementia (Morgan et al. 262).

Care facilities can be designed to reduce anxiety and disorientation. These methods of spatial design align with the cognitive ability of someone with dementia who has minimal spatial orientation. 


\section{Therapeutic Design}

Therapeutic design recognises peoples need's for connectedness. 'Connectedness is the state of being connected or related. It refers to the relationships people build with others and the benefits they bring to individuals as well as to society.' (Wildevuur et al. 52)

Loss of memory and deterioration of cognitive function causes people with dementia to feel a loss in connection with society. ?ankns have strong desires to be "acknowledged and useful, playing a part in the development of society and who they used to be' (Wildevuur et al. 110). Addressing this aspect in dementia care the this aspect in dectia care through design

A designed environment that facilitates spontaneous social interaction and an 'attractive' appearance has been proven to enhance the mental wellbeing of people with dementia (The Eden Alternative; Reynolds and Beamish 37). Social encounters also help maintain a relationship to the community, and prevent the feeling of isolation and loneliness (Wildevuur et al. 52). The 'Eden Alternative' suggests including the residents in the decision process in care facilities, or encouraging them to take part in the maintenance of gardens and grounds. This can provide people with a purpose, reducing the boredom with a pursidents and can be a way of replacing the job that they performed et al. 110; The Eden Alte (Wildever

In a rural community animals have usually influenced a person's life. The therapeutic qualities of animals have also been seen as hugely beneficial to the wellbeing of elderly and people with dementia (Baun and McCabe 42; Walsh 473). Animals provide companionship, comfort, and security, while also decreasing (Walsh 437). The human-animal companion bond has been recognised and plays an integral part in the 'Eden Alternatives' (Baun and McCabe 44, The Eden Alternative). For people with dementia, animals provide an outlet for 'sundown syndrome' and wandering (Walsh 44; Baun and McCabe 474) which can take pressure off caregivers and enhance the relationship between animal and human (Baun and McCabe 48).

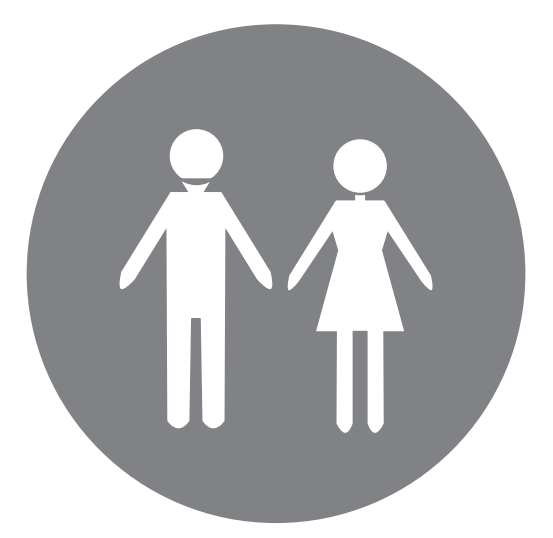

Designing the physical environment to increase connections between people with dementia the between landscapes, and animals has become an important aspect an important aspect of therapeutic The principles used ale explored through 'The 10 Eden Alternatives' to eliminate loneliness, helplessness, and boredom (The Eden Alternative). The 'Eden Alternatives' were devised by Dr. Bill and Jude Thomas and seek to provide a therapeutic environment for elderly to live in comfortably (The Eden Alternative). They place importance on providing elderly with connections to life outside institutionalised care and give meaning and psychosocial significance to residents.

However, alongside these specific connections is the more general connection between humans and nature. Biophilic design explores how nature captivates us and provides Green). The notion that Green). The notion that nature can to problem solving and an aide harmonisation within our minds is explained through the 14 Biophilic aspects. Biophilic design is broken into three groups; natural analogues, and nature of the space (Terrapin Bright Green). Nature in the space refers to how affected by nature Natural analogues is how nature can be abstracted to be used in building form, or through perterns. Nuture of the or through patterns. Nature of the space is about to generate an emotional response.

Therapeutic design is becoming an influential practice that looks at environment and how it can become a source of benefit for people in healthcare. This is important as it reduces the confusion and agitation in people with dementia (Day et al. 397). By using aspects of biophilic design alongside the Eden alternative, the connection between nature, community, animals, and the dementia centre will allow for a design that stimulates and benefits the residents. The design of nature within a space also provides a connection between therapeutic of a rural setting. Exploring and or a rual setting. Exploning and will seek to provide connections to past memories for rural people with dementia. 


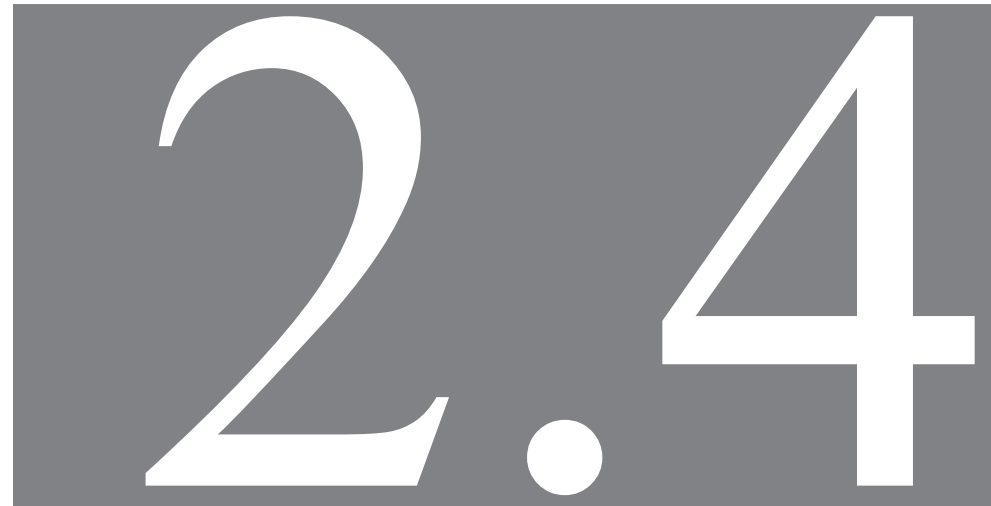

14 Patterns of Biophilia

Dementia Spatial Aspects

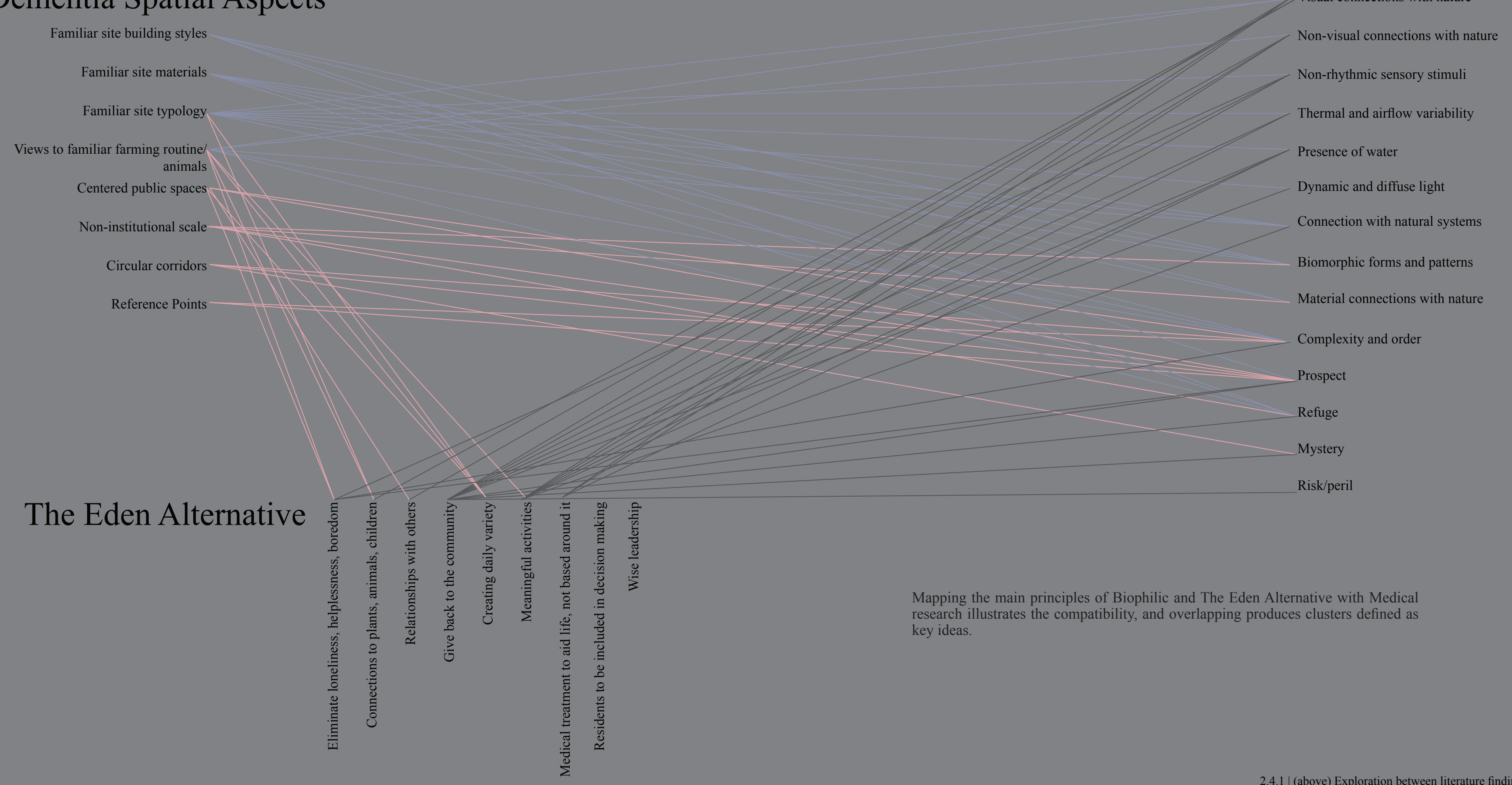


From the connections diagram, twelve factors have been chosen to measure both
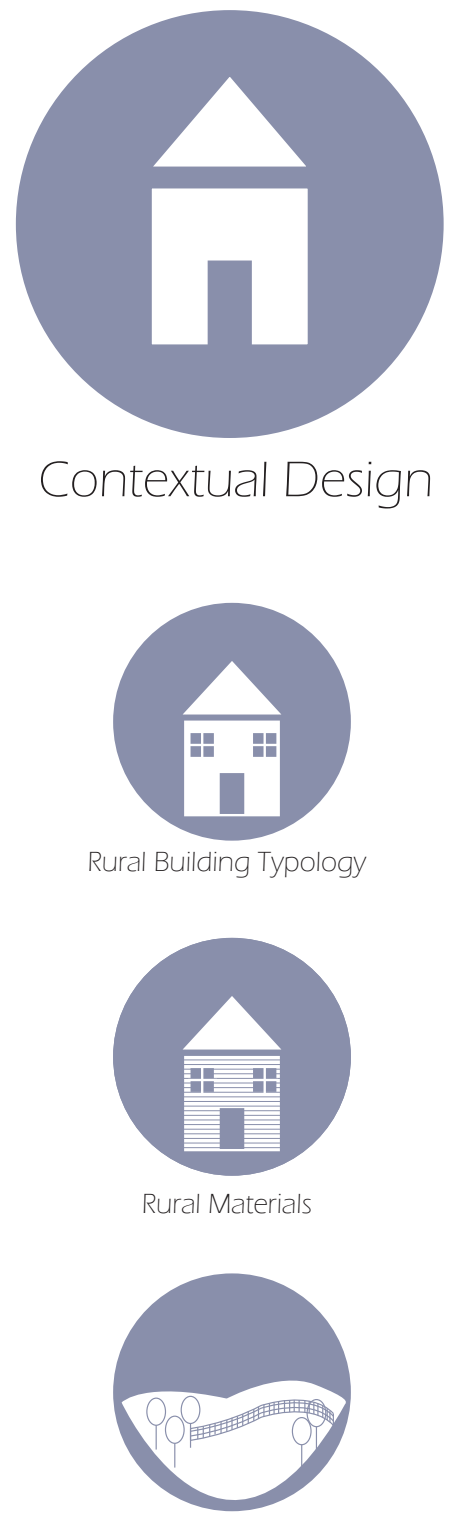

Rural Landscape Typology

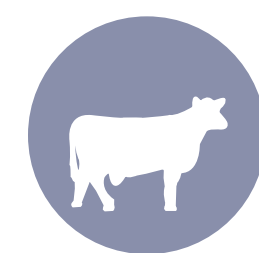

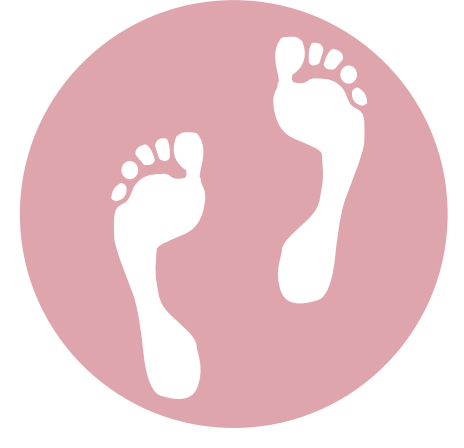

Wayfinding
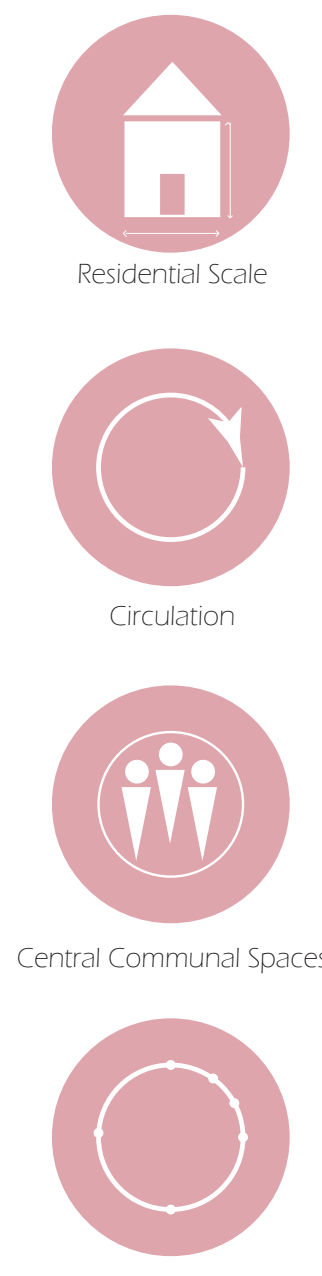

Reference points

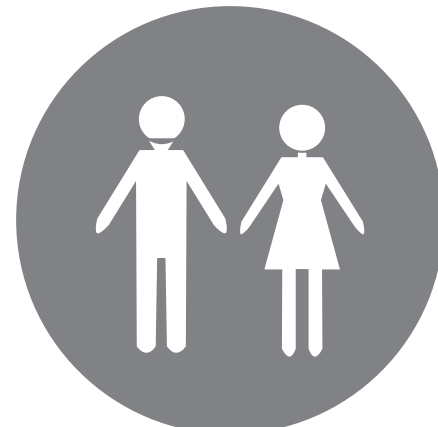

Therapeutic Design
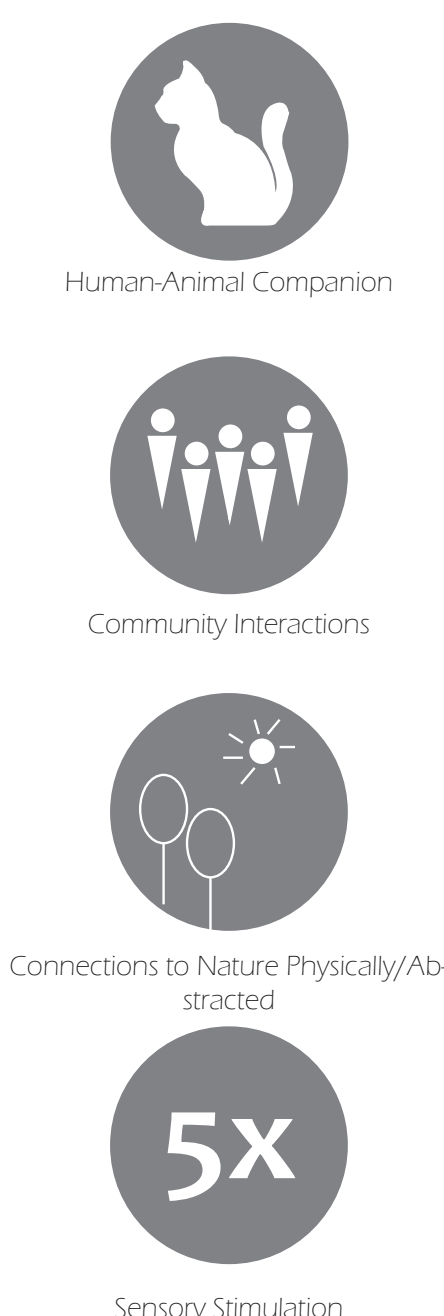

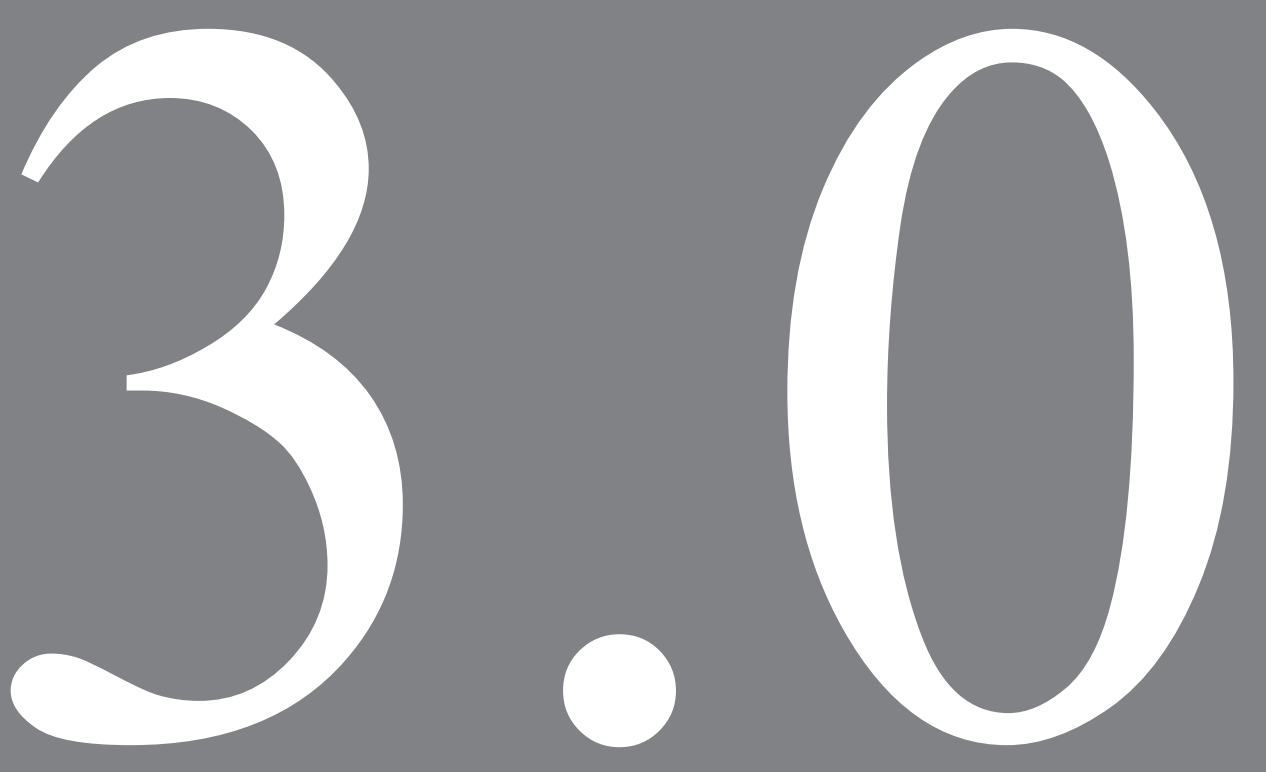

Case Studies 
To explore best practice, a number of case studies in New Zealand have been reviewed, and provide an insight into the facilities currently available for people with dementia. The author visited each facility during 2015, conducted a serie of informal interviews with staff and observed residents' behaviours to determine issues with design that are not recorded in the literature. This chapter explore three case studies in New Zealand that were chosen by their location and thei pecialised dementia building refurbishments.

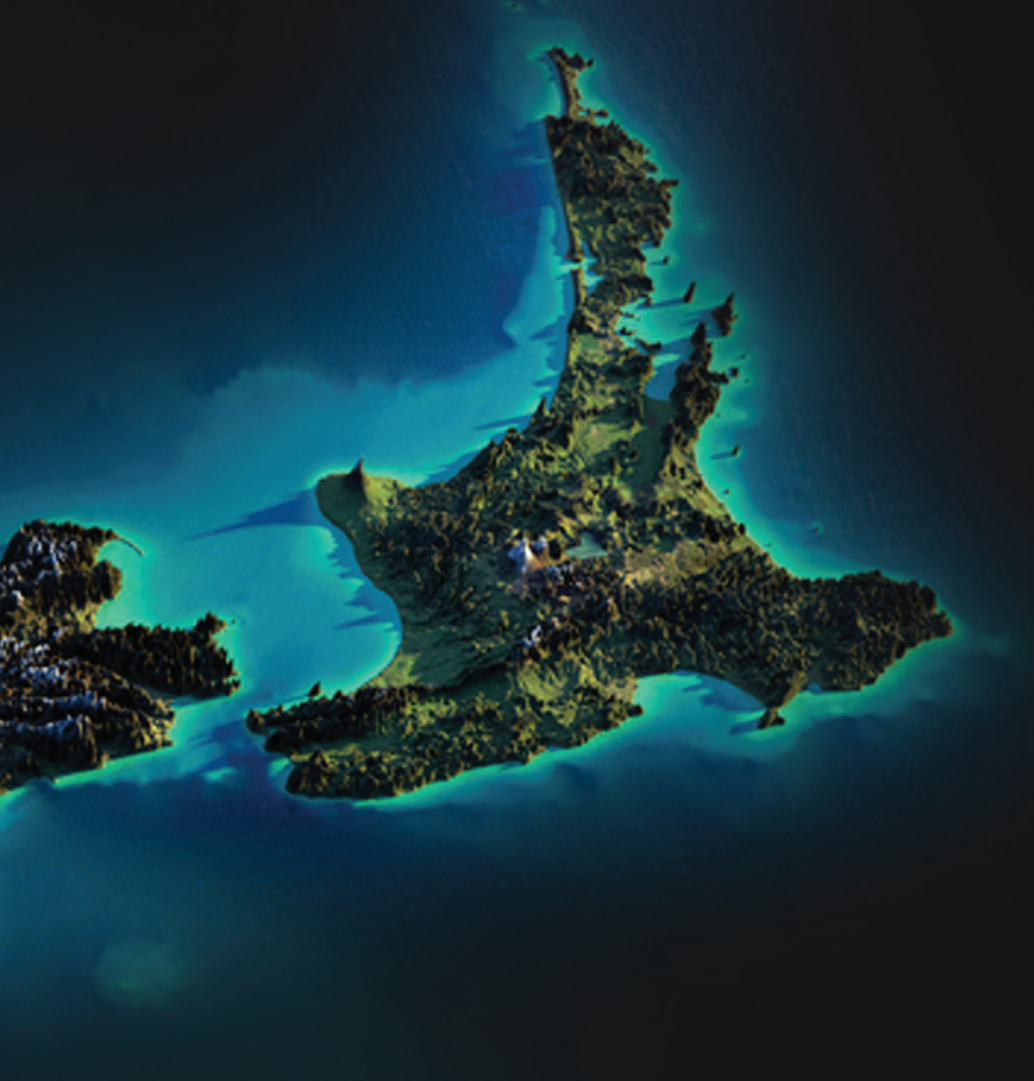




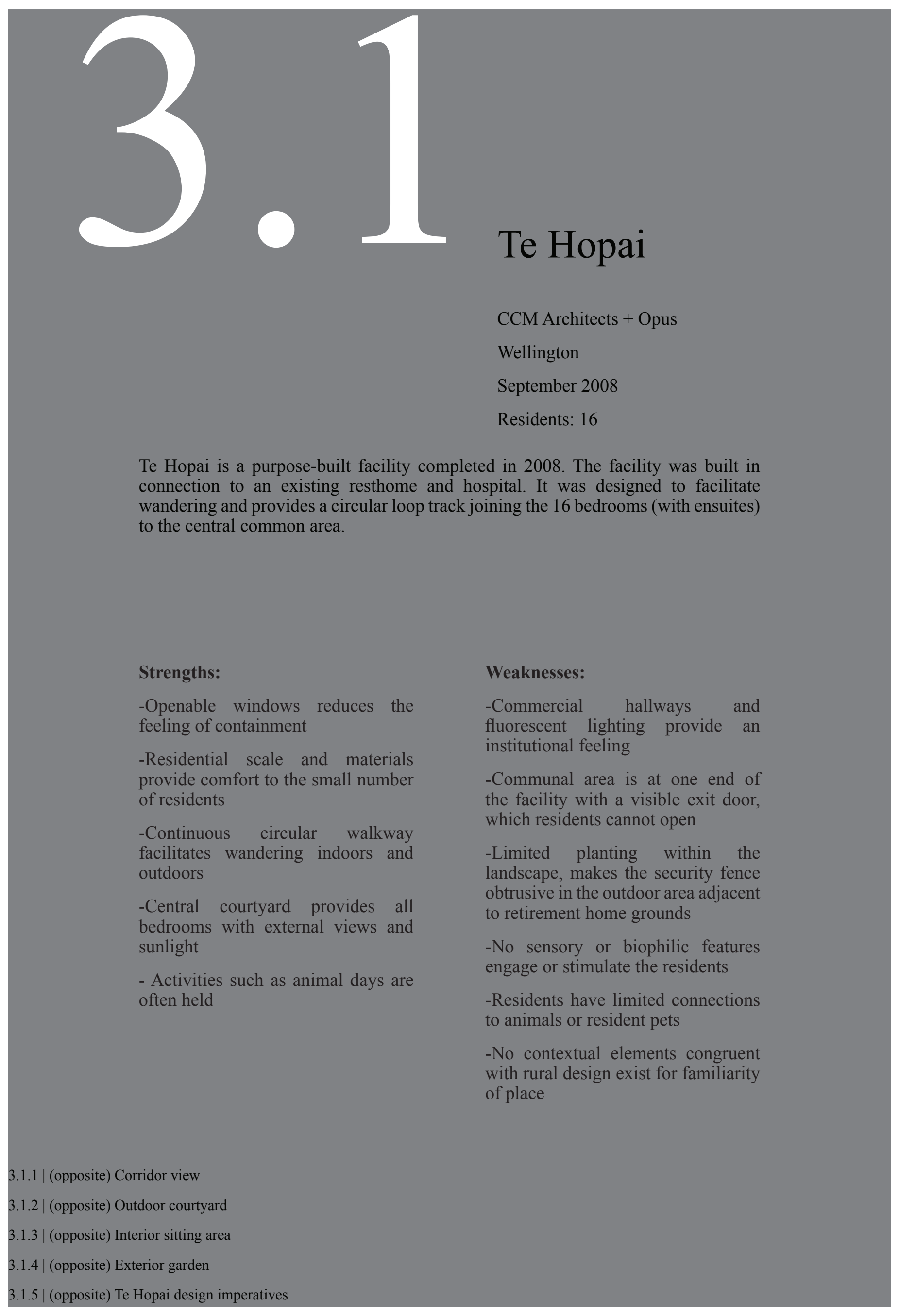
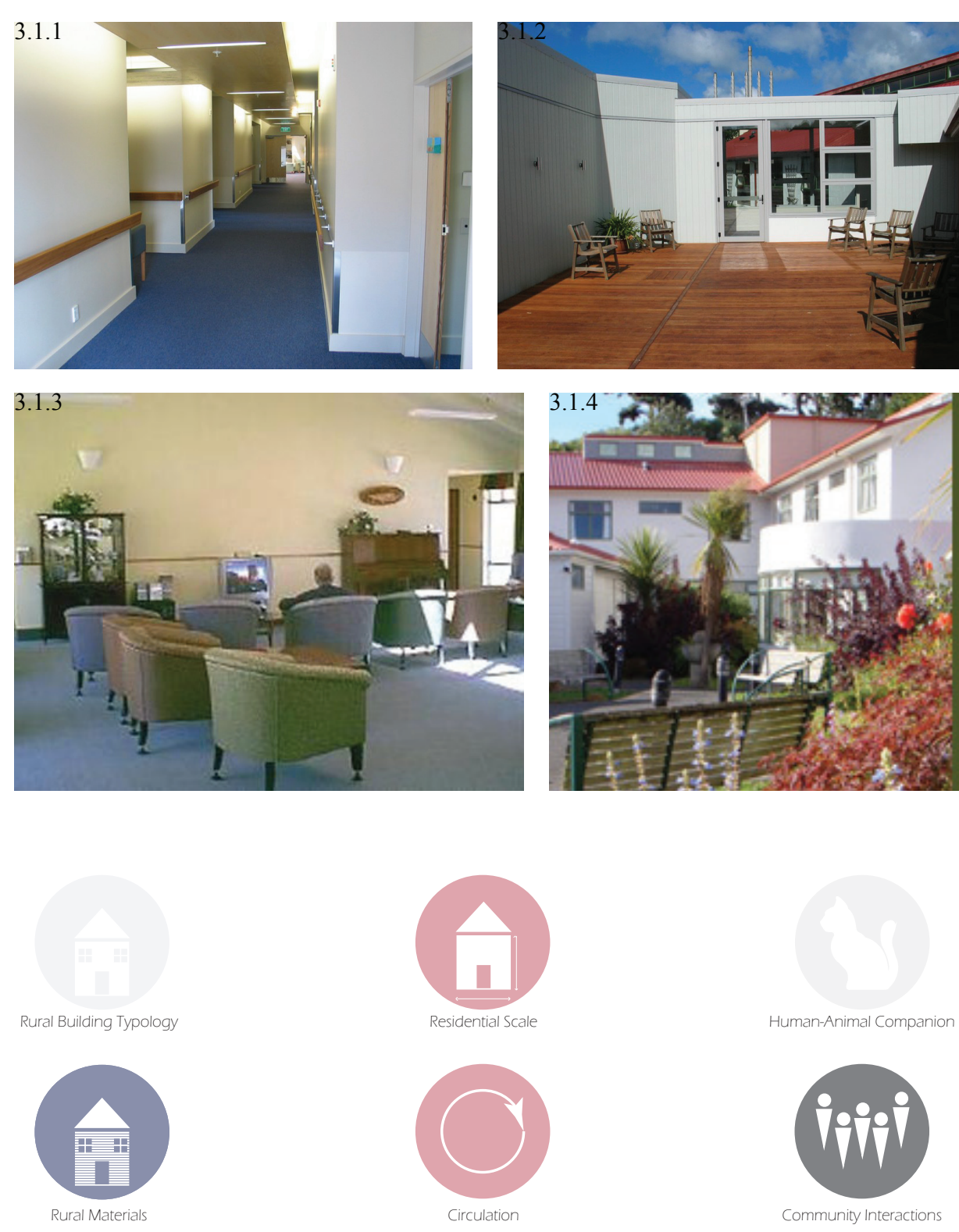

(19in)
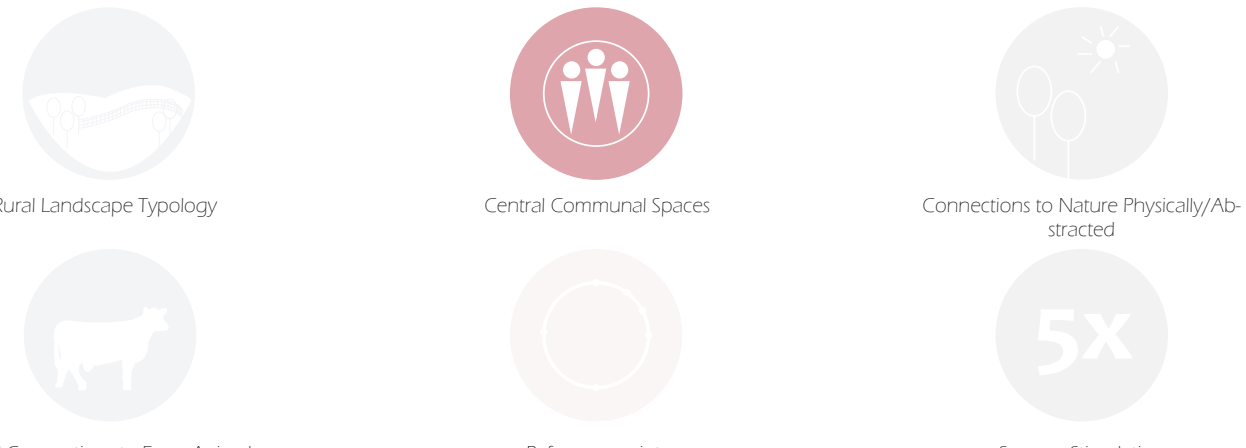


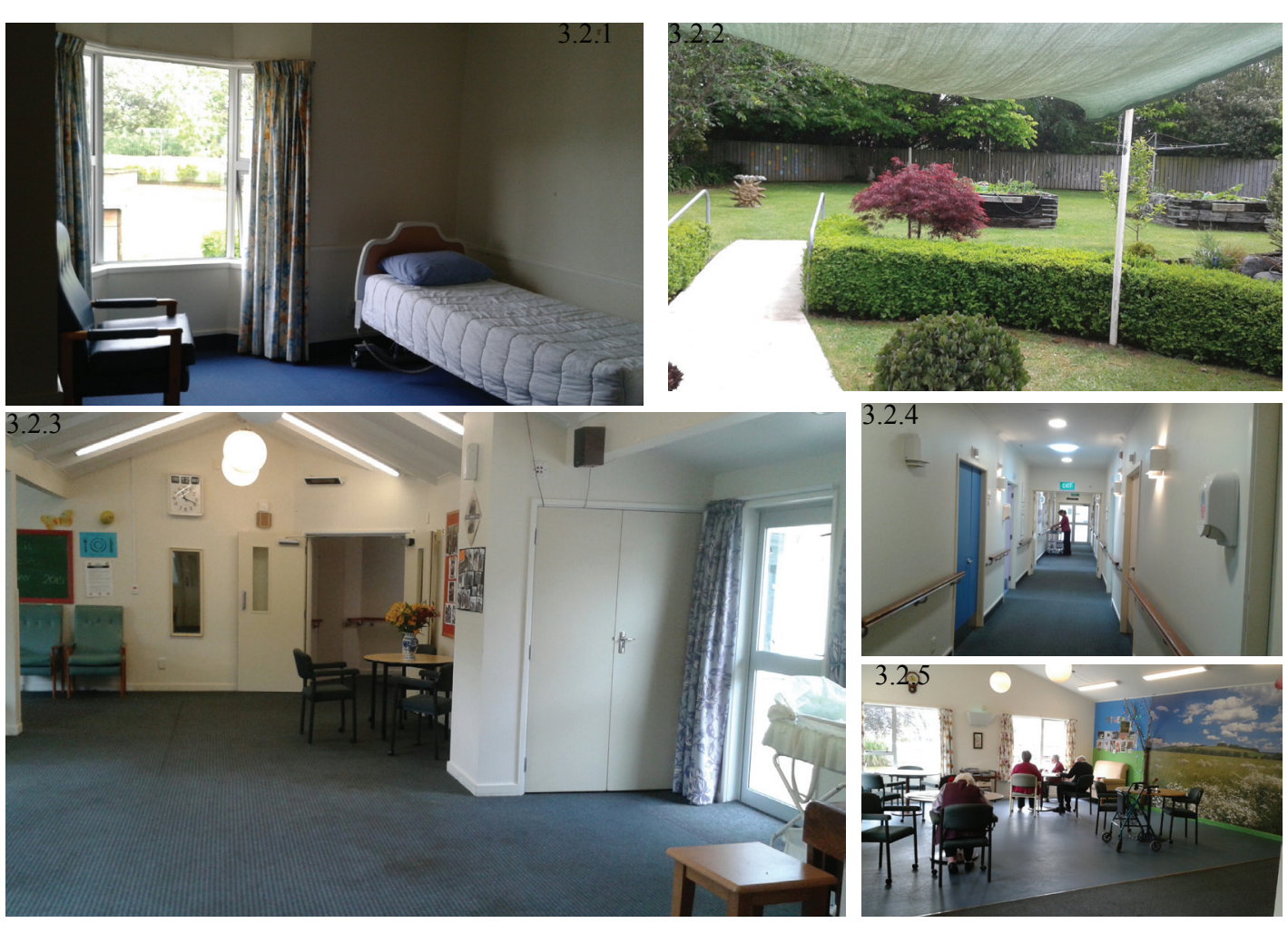

-Visual view

is not entirely suitable
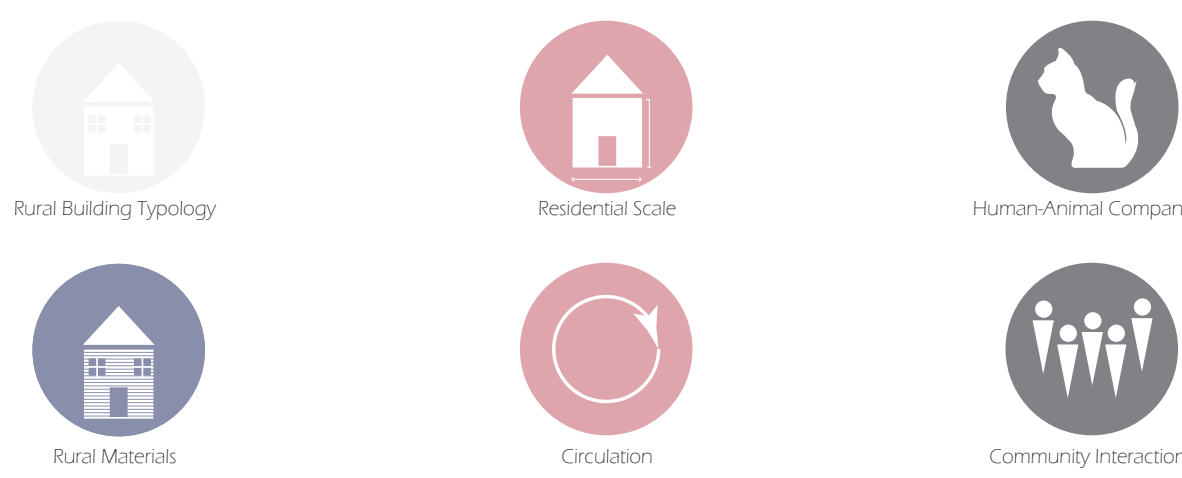

(Bini)
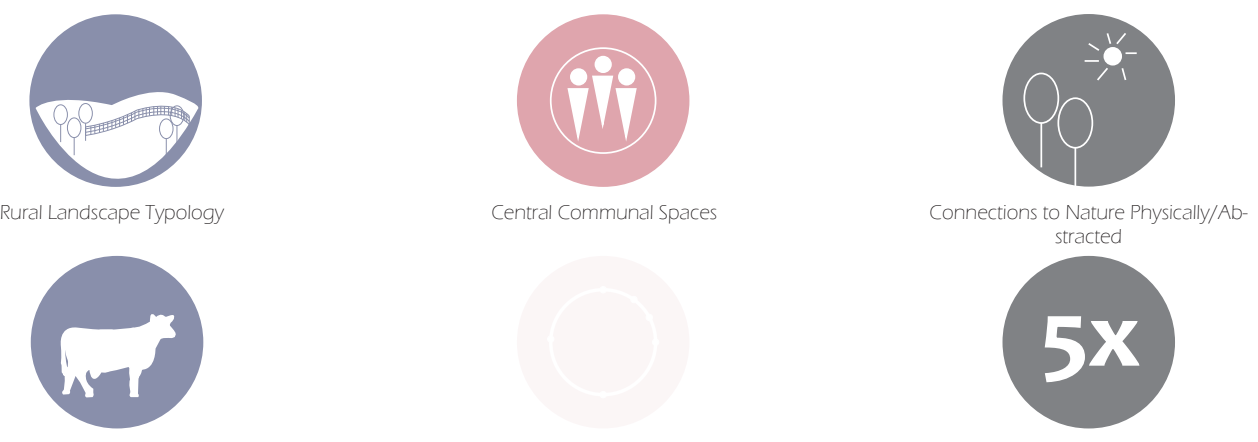

$5 x$
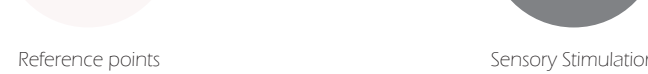

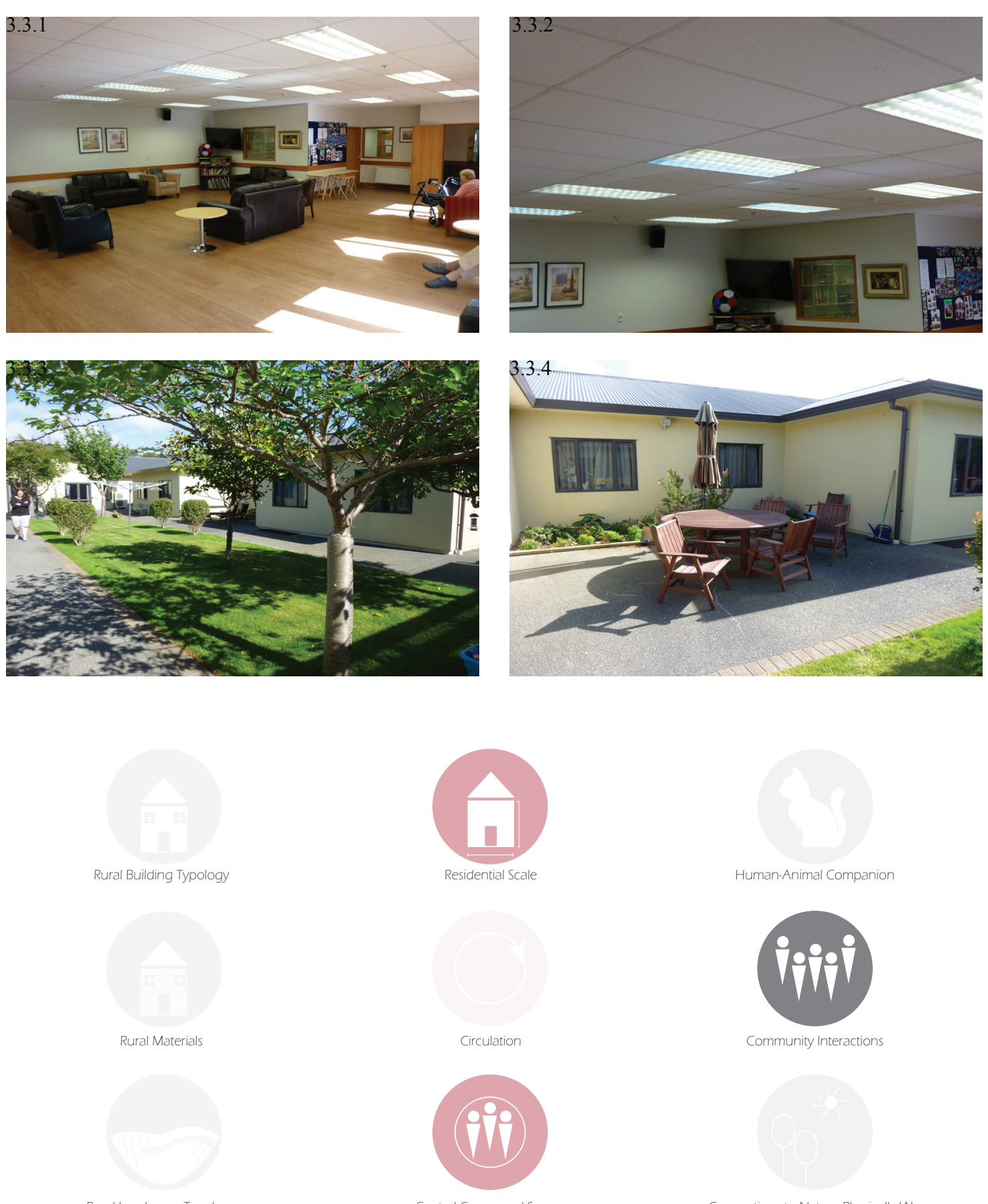

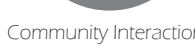

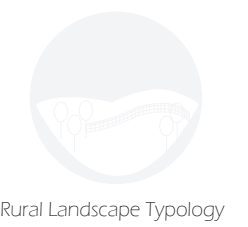

(iii)

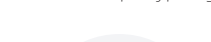

centrat Communal S S paces

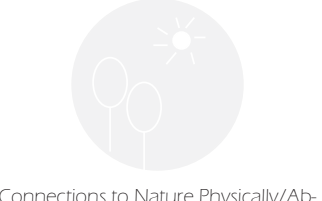




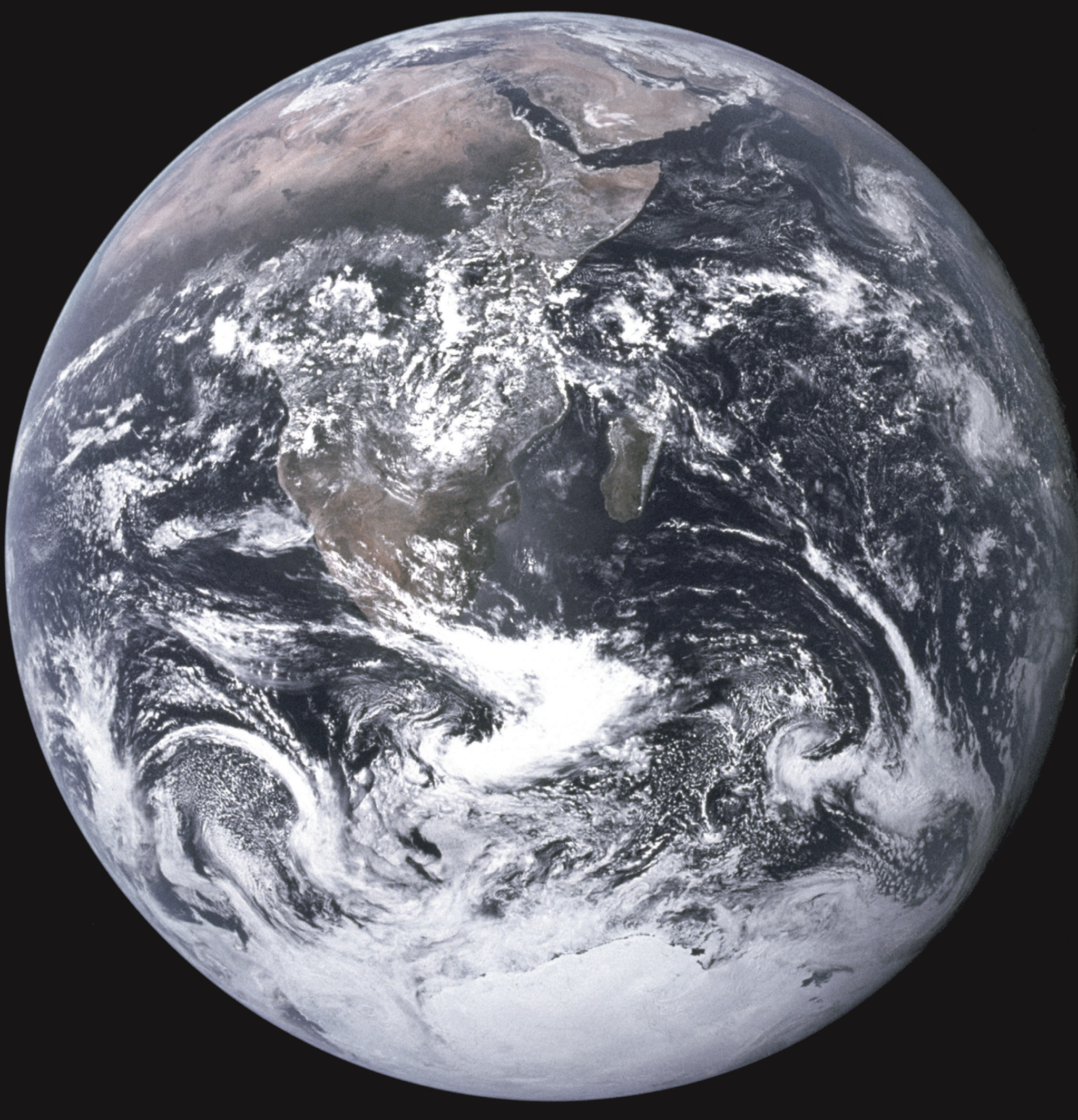

International case studies provide leading design solutions and current experiments in design for dementia. 


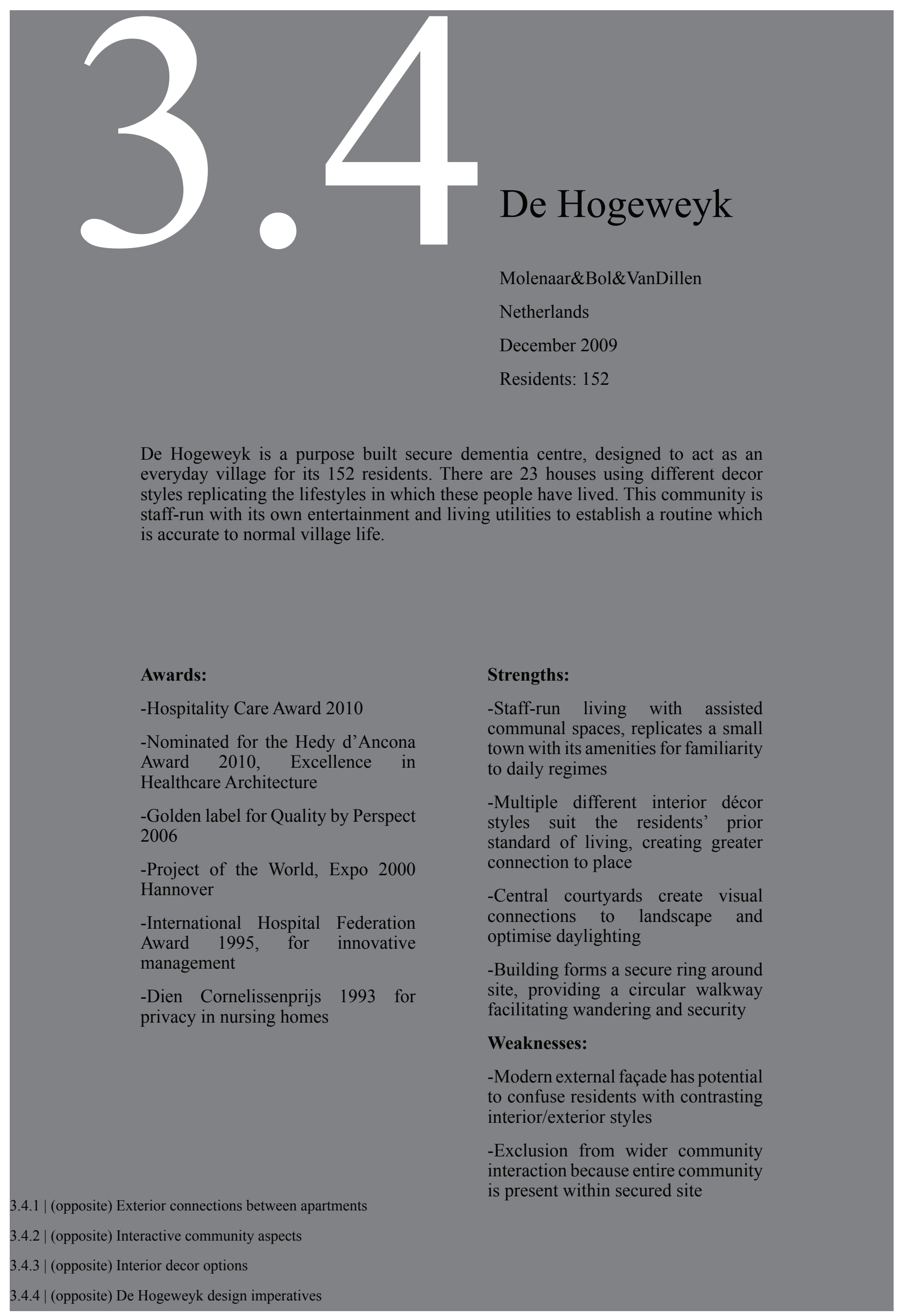
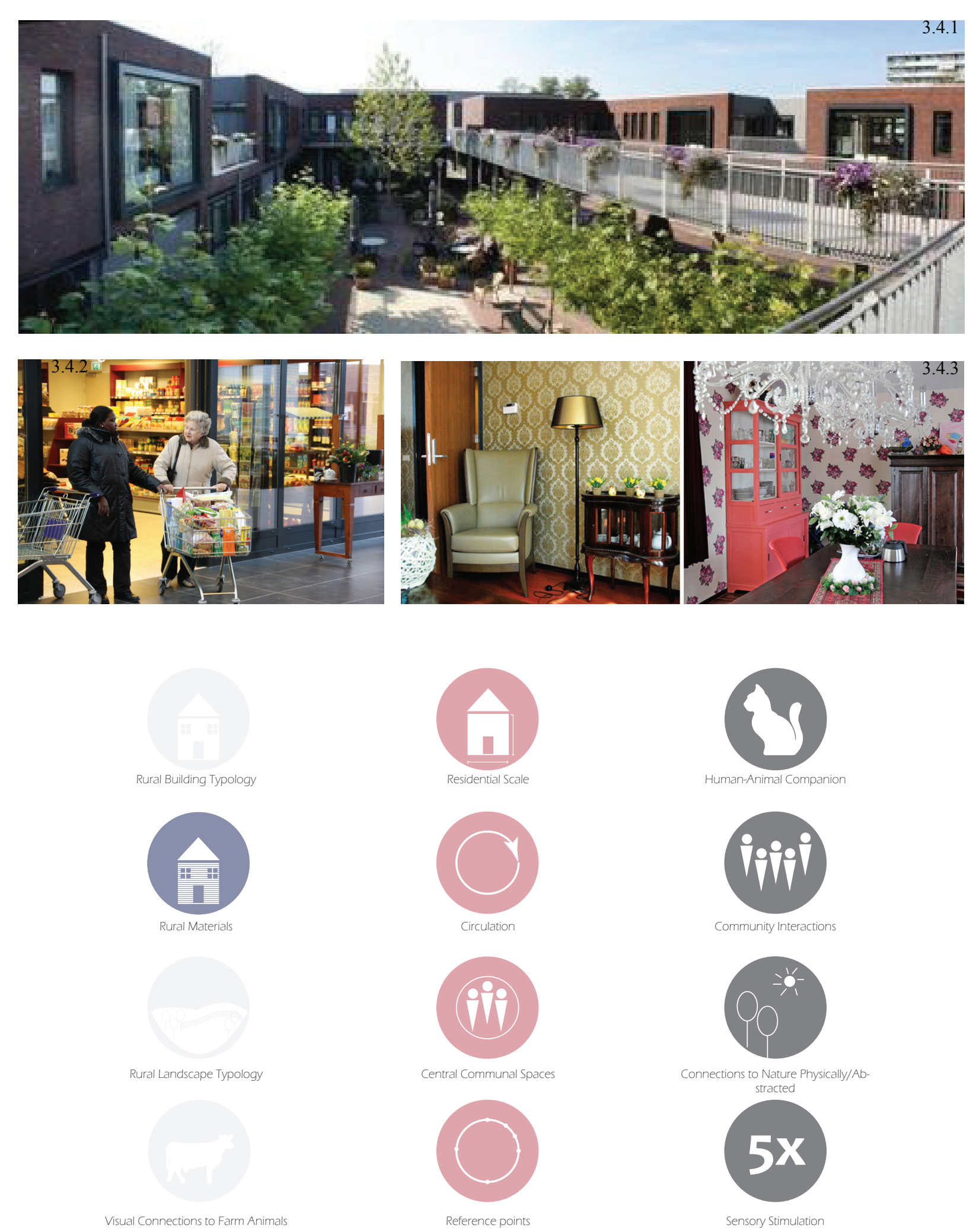


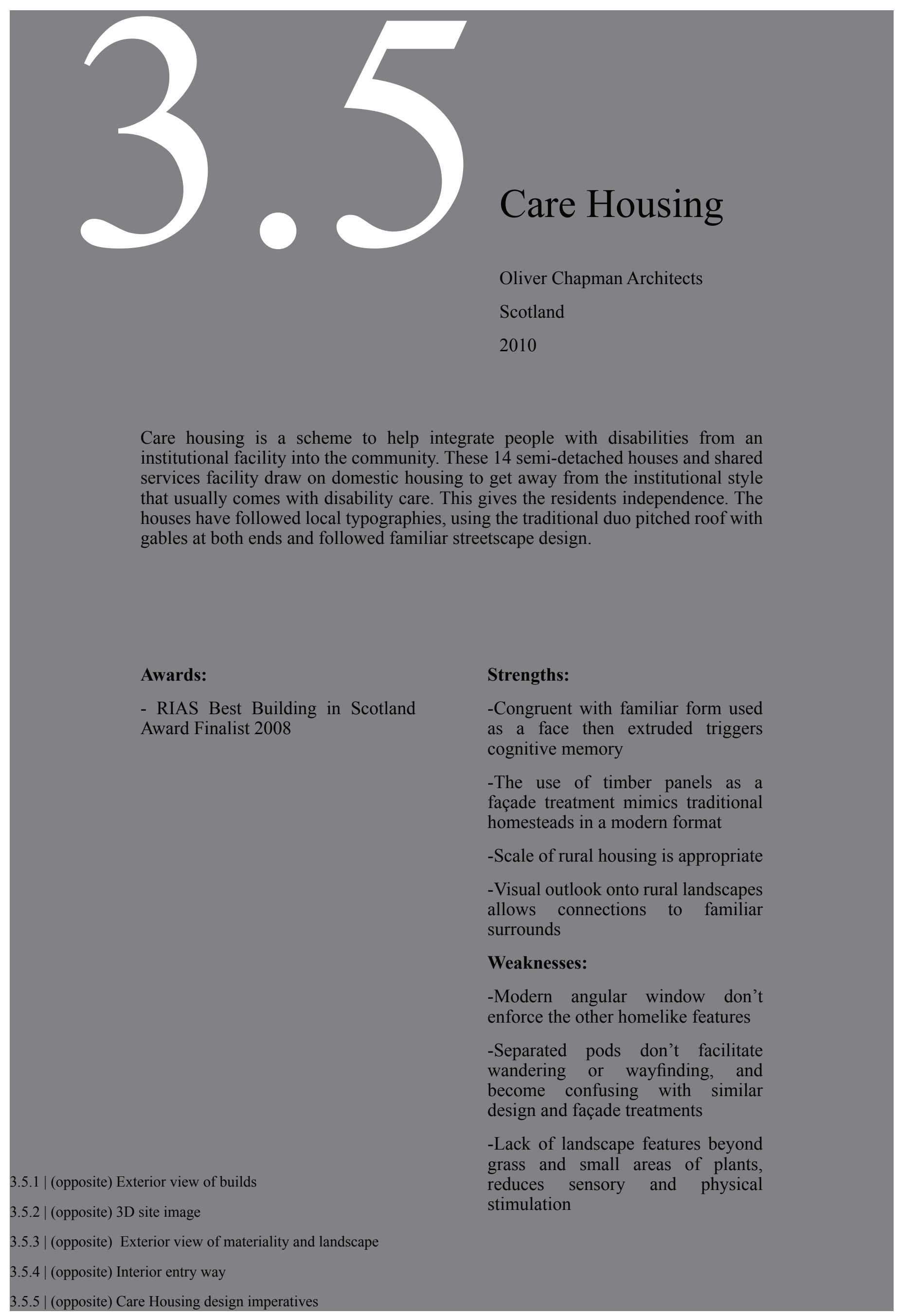
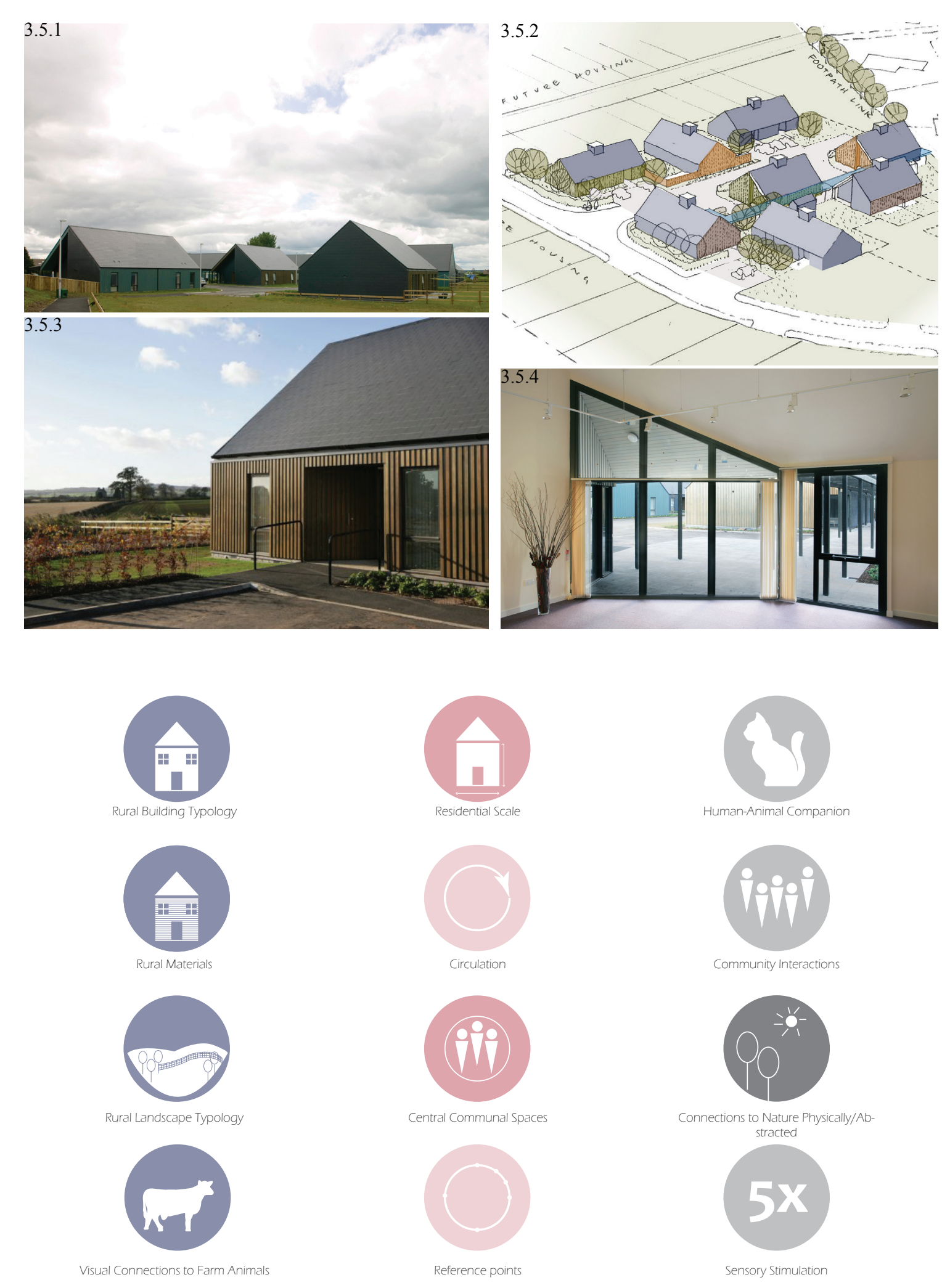

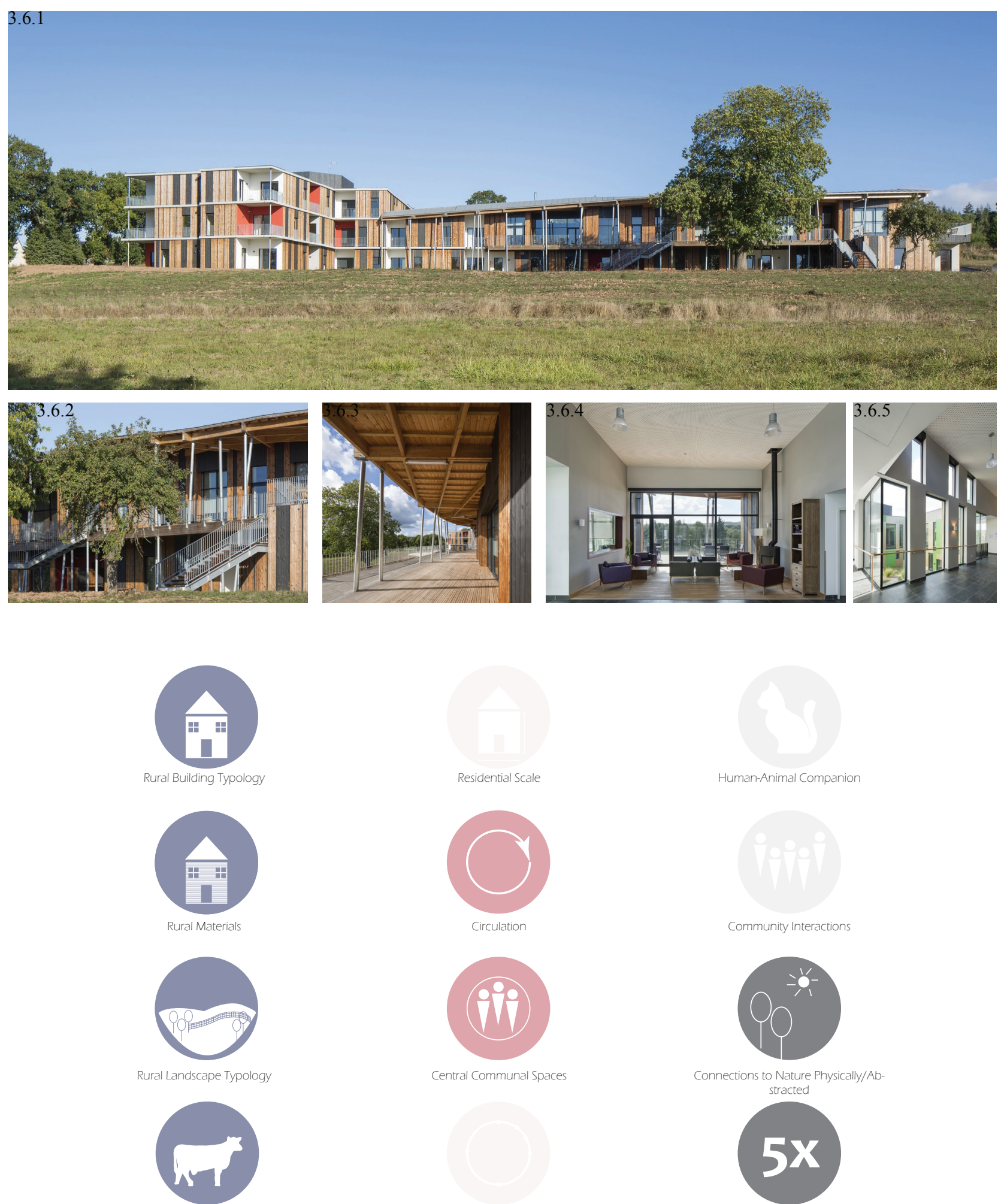

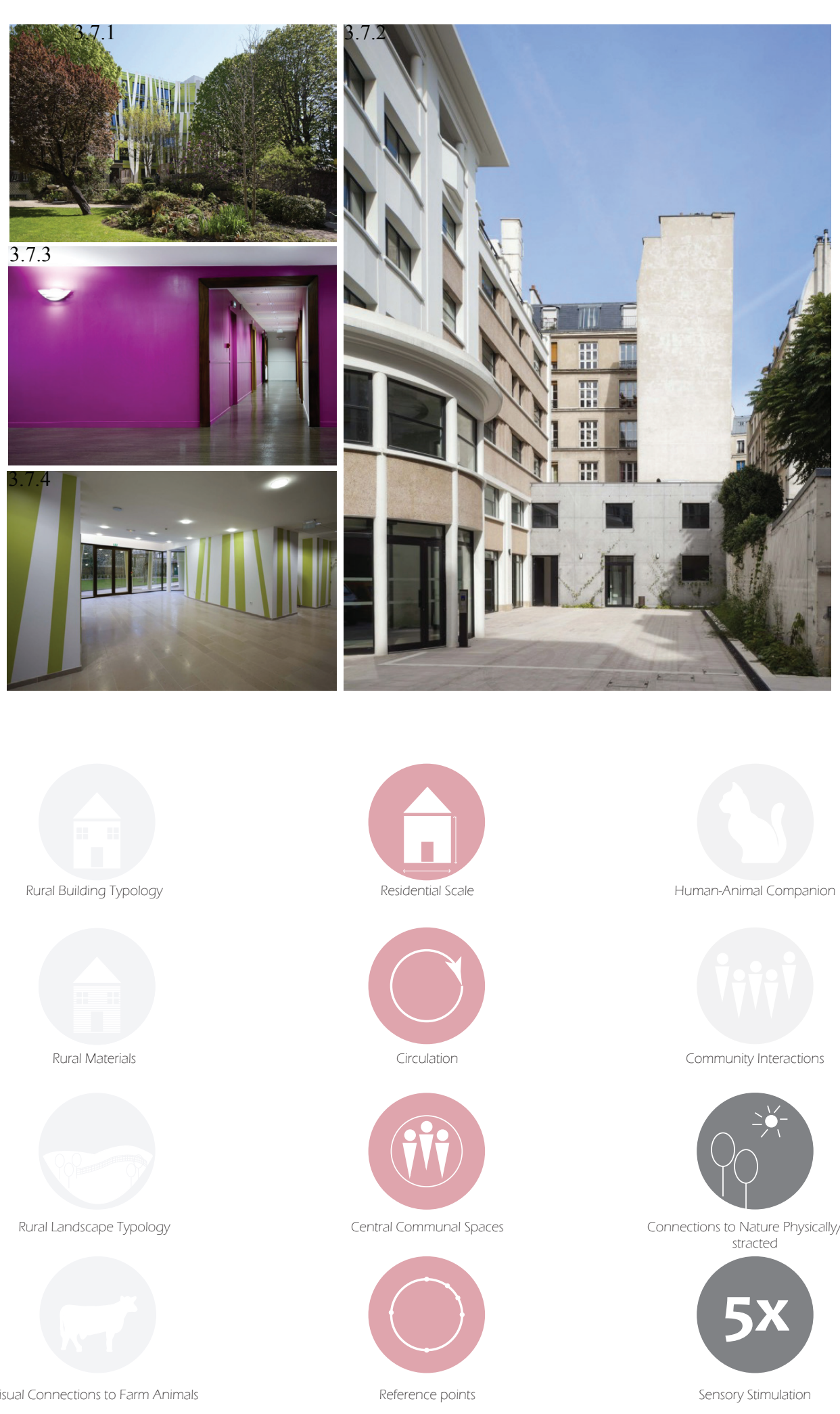

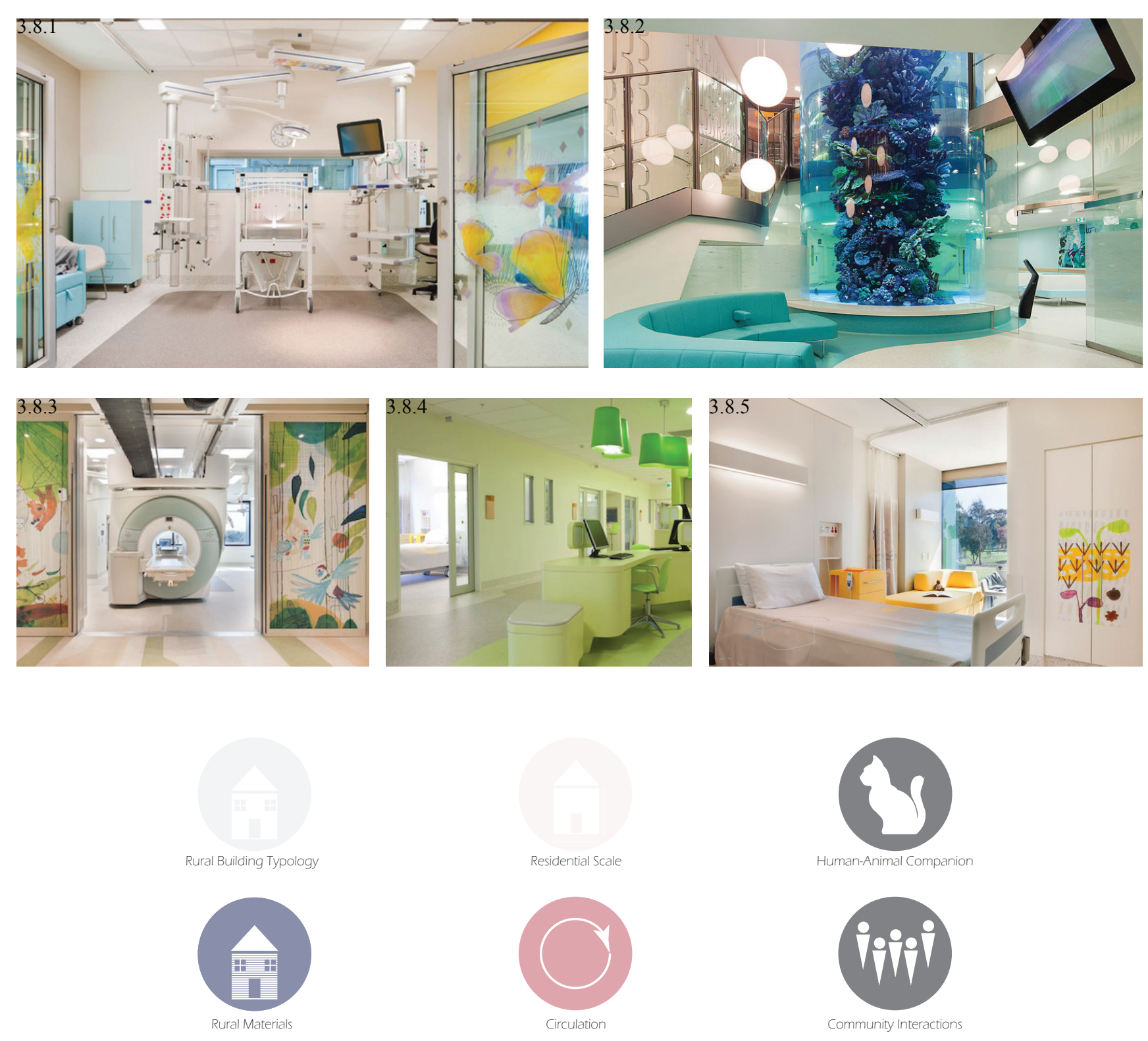

(Pinit)
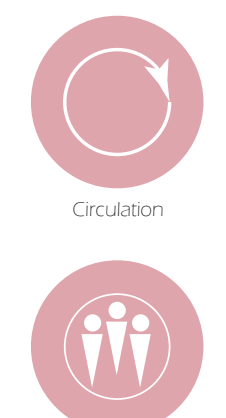

Rural Landscape Typology
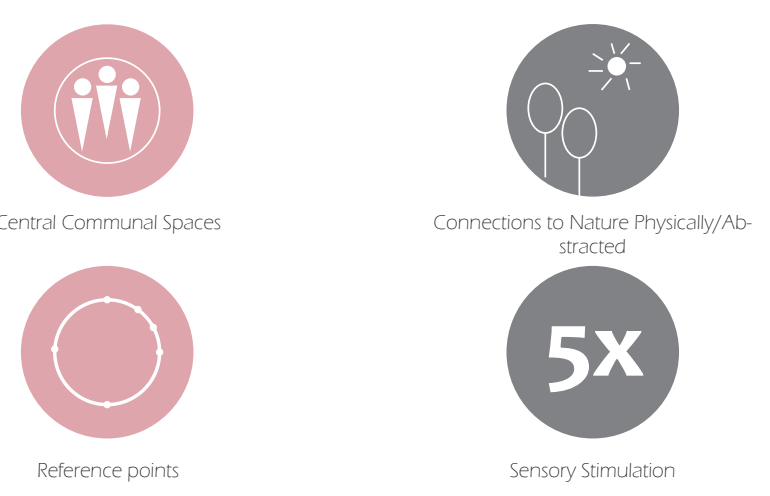

$5 x$ 
Local and international case studies have identified which aspects of design need more exploration to function at a higher standard. These are rural scale, rural typology, community interactions, reference points, connections to animals, human animal companions, and sensory stimulation. There were also design aspects which can be taken and implemented, as they provide acceptable solutions to dementia visits has provided a greater understanding of dementia and the issues that people with dementia face. This knowledge will inform design iterations and explorations to aid in the process of creating a specialised rural dementia centre which meets resident and staff requirements.

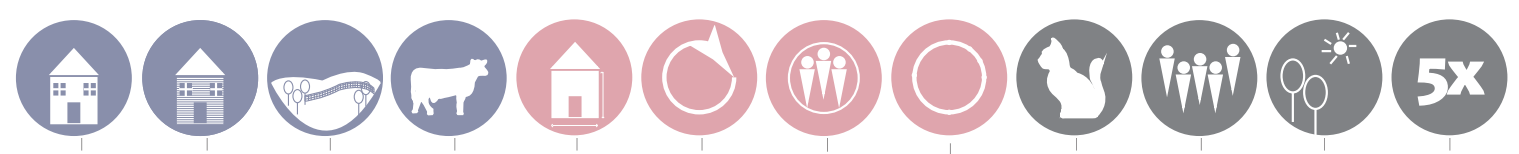

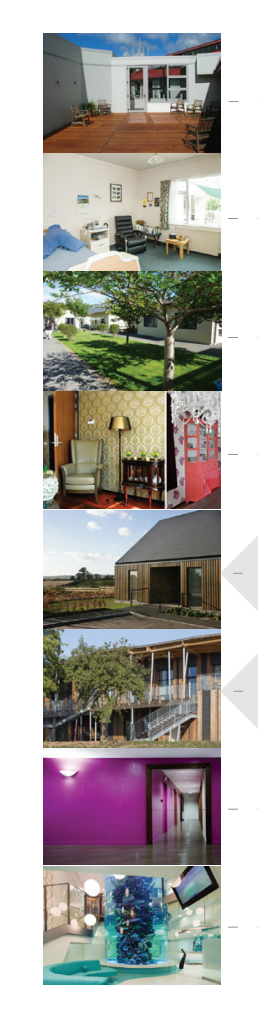

2

$\begin{array}{lllllllllll}6 & 3 & 3 & 6 & 6 & 8 & 3 & 3 & 5 & 6 & 5\end{array}$ 


$$
4.0
$$




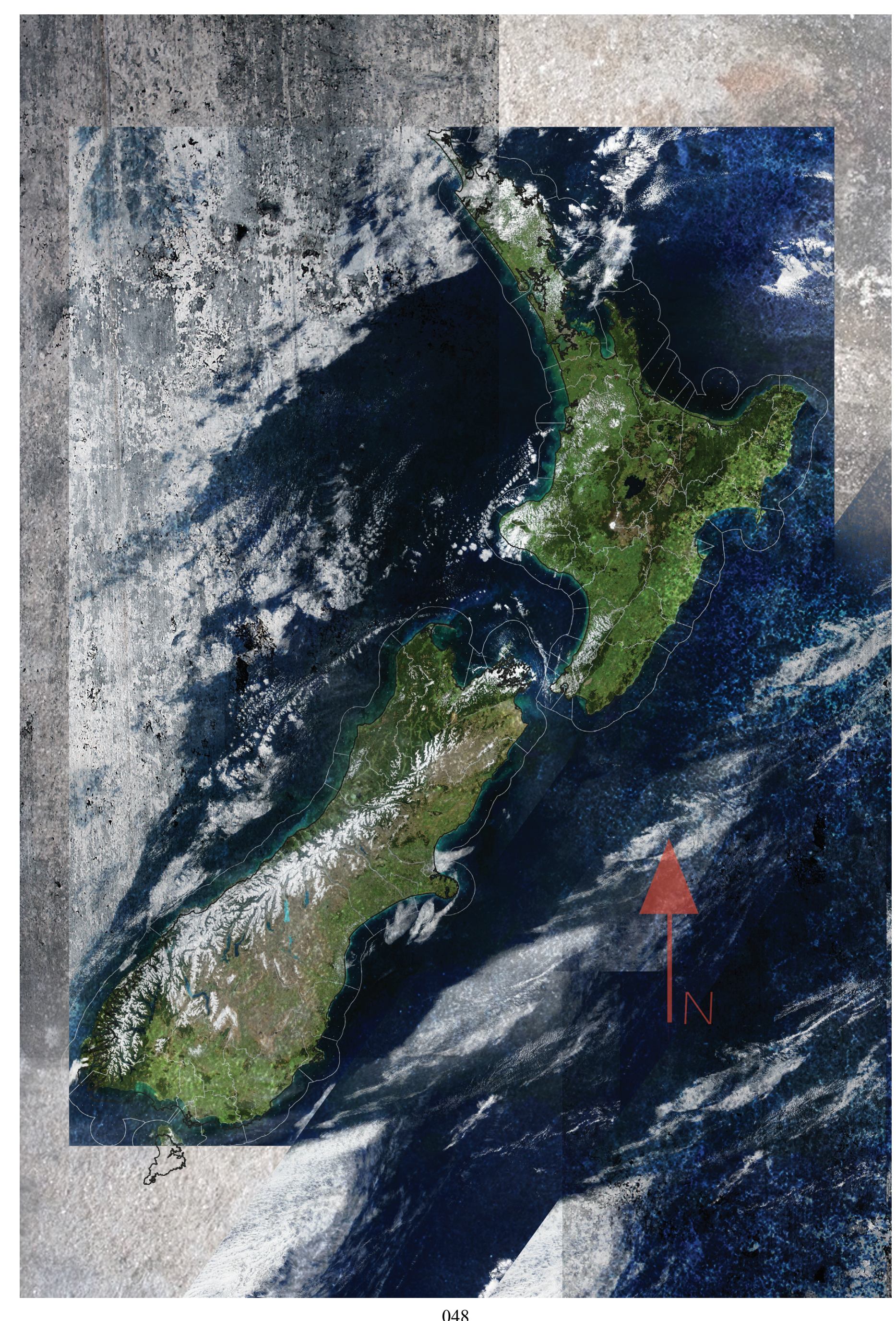

Of, relating to, or characteristic of the country, country life, or country people; living in the country: the rural population; of or relating to agriculture.

One of the most important aspects of designing for people with dementia is creating visual connections between the environment they are in now and the past they have returned to when losing monory and cognitive ability. Using elements such as routine, lifestyle and familiar geographical environments can generate qualities of design that residents feel comfortable using and orientating themselves within. 


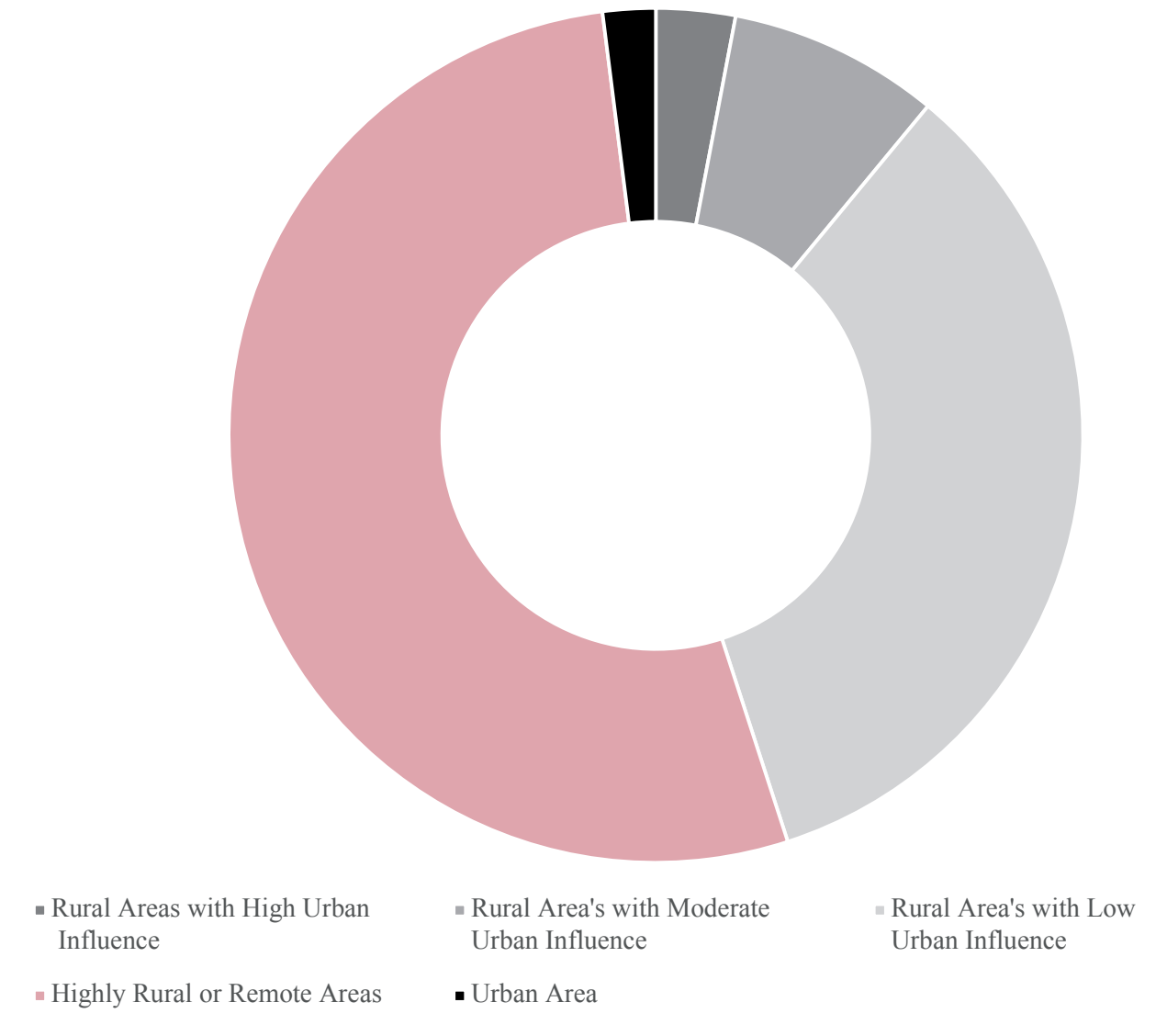

The site plays a major role in creating a contextual connection between people from a rural community, and the proposed dementia centre. It requires a place that is congruent with features of typical rural typologies and landscapes. These features differ depending on where in New Zealand people have typically lived, and with this the design would also change. New Zealand as a whole is known for its large agricultural influences, where over $50 \%$ of the land area is classified as highly rural or remote areas ('Highly Rural/Remote Areas')(see fig.4.0.2). The Manawatu is the second largest region by area in the North Island, making it an ideal location to design a rural dementia centre (Statistics New Zealand 9).

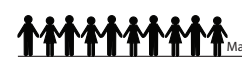

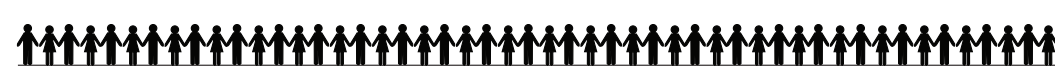
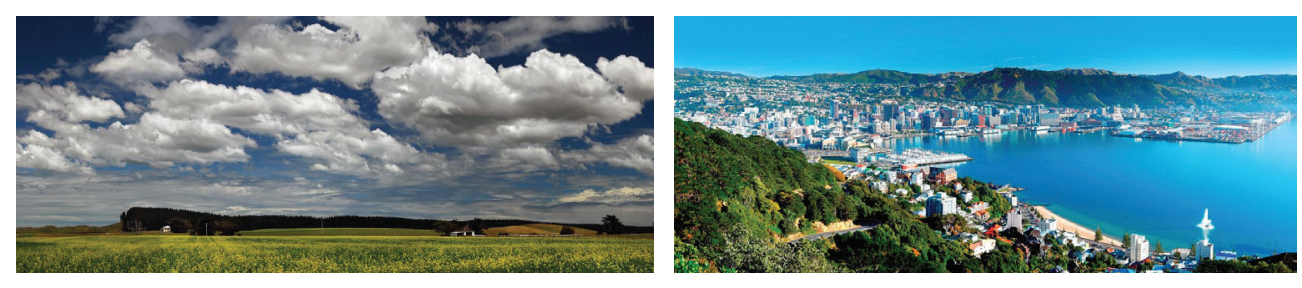

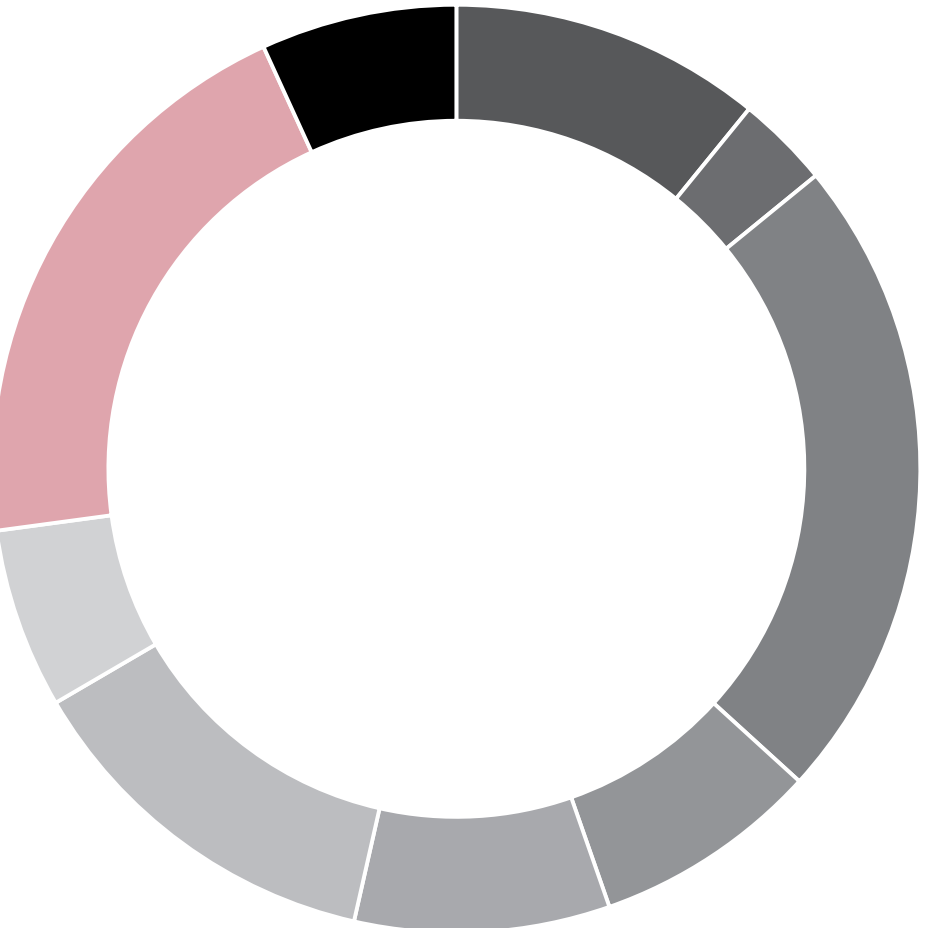

- Northland

- Auckland

- Waikato

- Bay of Plenty

- Hawke's Bay $\square$ Taranaki

- Wellington

- Manawatu-Wanganu

The Manawatu is dominated by agriculture. The extreme contrasts between the rural communities of the Manawatu and the urban setting of, say Wellington results in drastic difference in both visual elements and the density of people per square meter (see fig.4.0.3-4.0.5). The large, mostly flat expanse of the Manawatu allows for extensive views in al directions. The sense of freedom expressed in this landscape helps reduce the anxiety of being trapped, unlike the secured dementia centres in urban areas.
The Manawatu currently has a higher percentage of elderly compared with other regions in New Zealand. It also has a high percentage of people classed as middle aged, which provides a large number of people who will transition into the elderly age bracket in the immediate future (see fig.4.0.7) (Statistics New Zealand 17). This creates a market for current and future users of a dementia centre in the Manawatu.

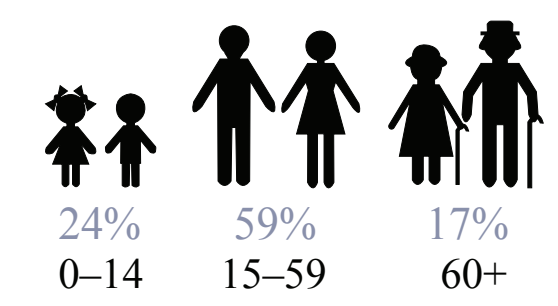

4.0.2 | (above) Percentage of rural and urban land area in New Zealand

4.0.3 | (above) Comparison of people per square meter Manawatu (rural) - Wellington (urban)

4.0 .4 | (above) Manawatu scenic views

4.0 .5 | (above) Wellington scenic views 

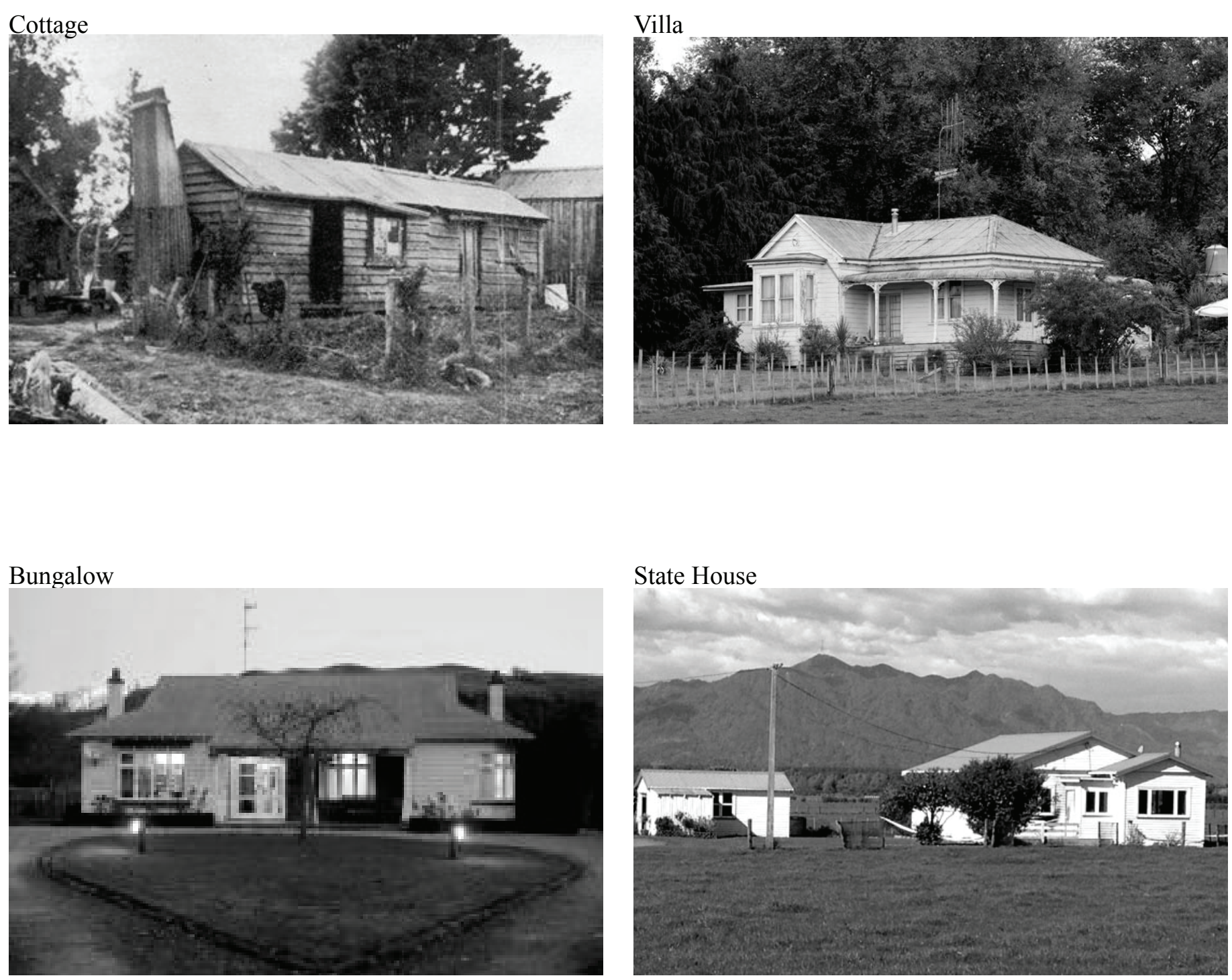

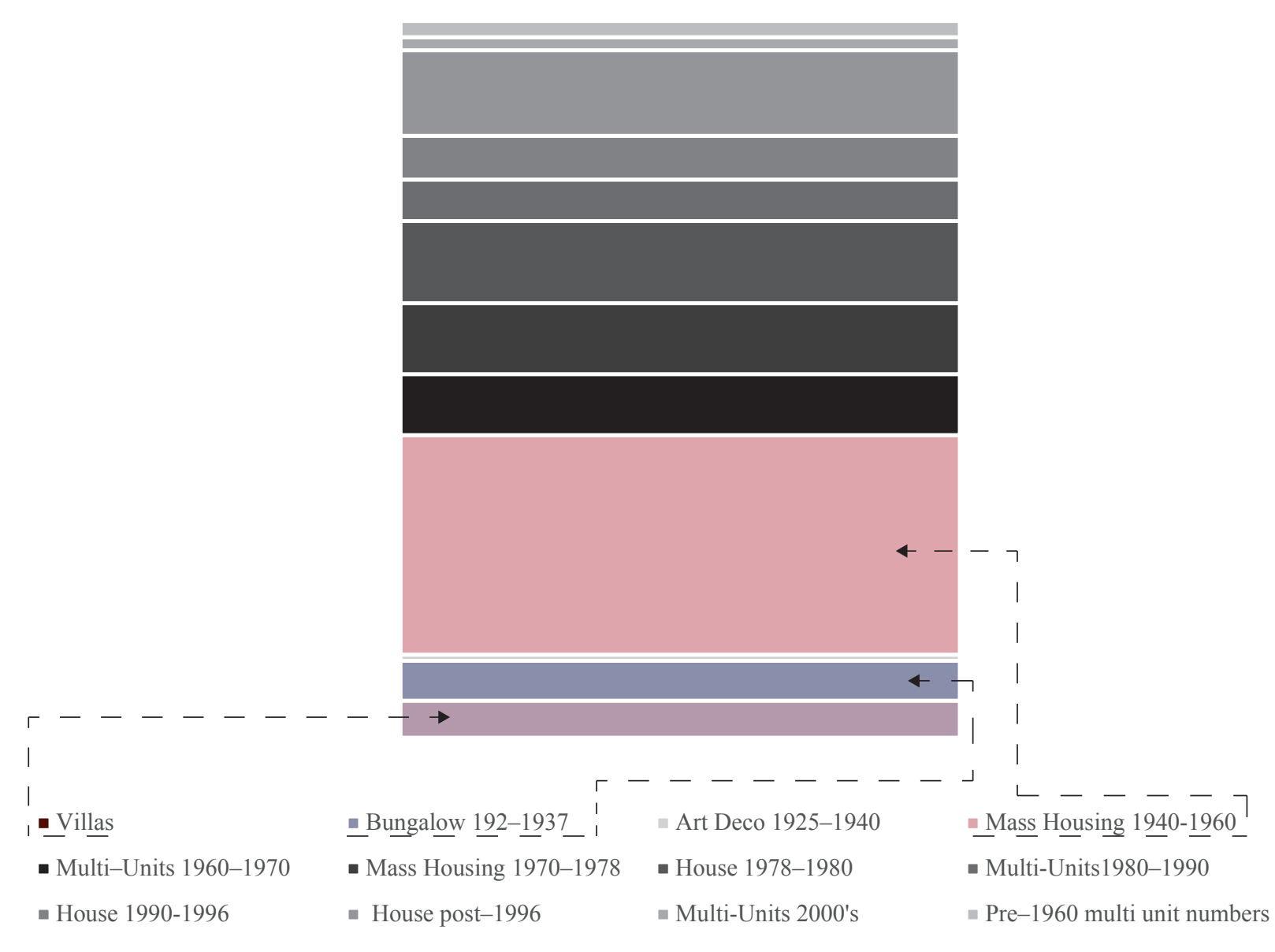

The Manawatu holds many styles of buildings, some of which are visually consistent with what could be considered rural design. The most common architectural types are cottages, villas, bungalows, and state housing. With lower labour skill level and between rural and urban design. typo logies were onginally easily distinguishable 

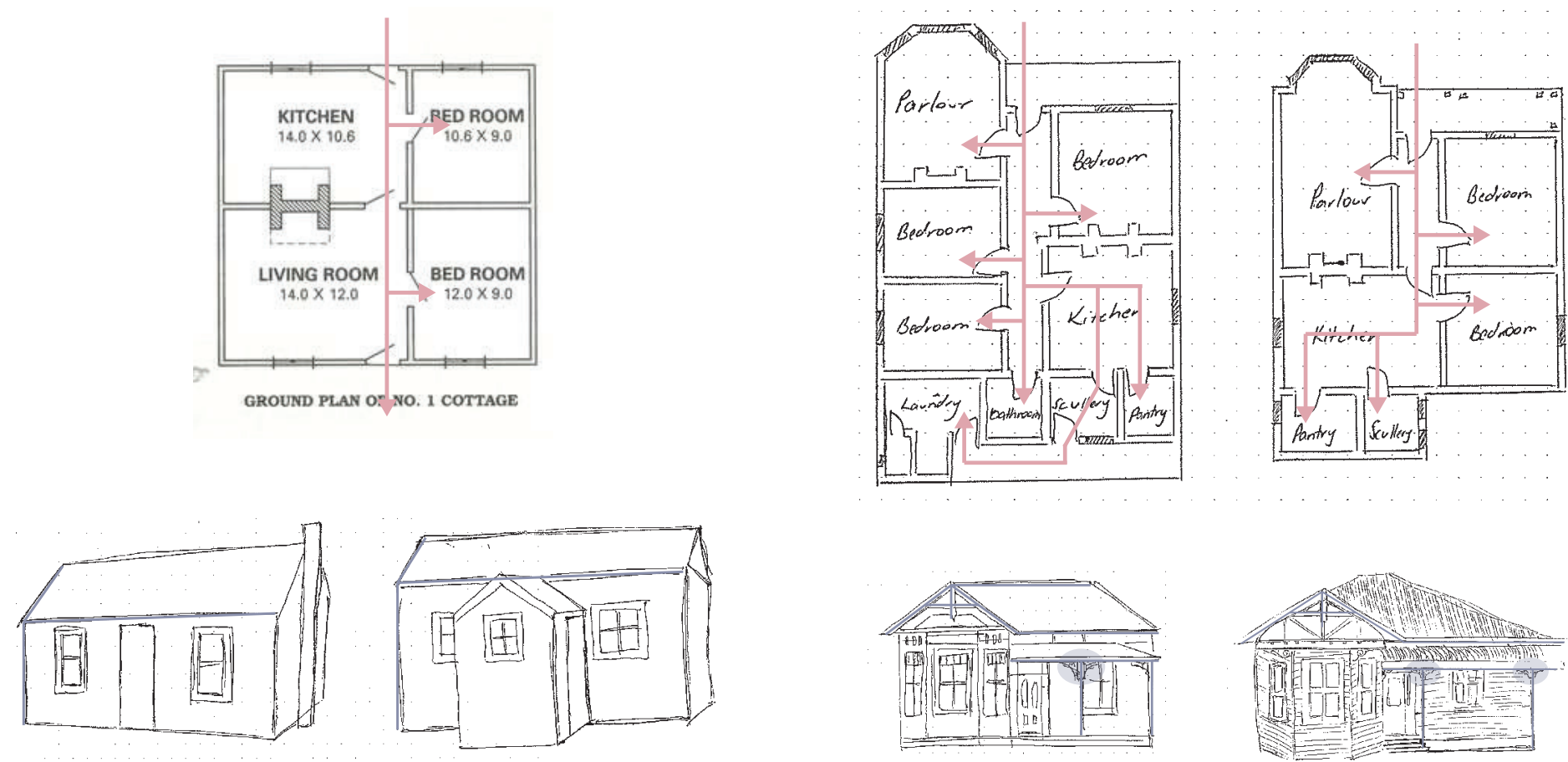
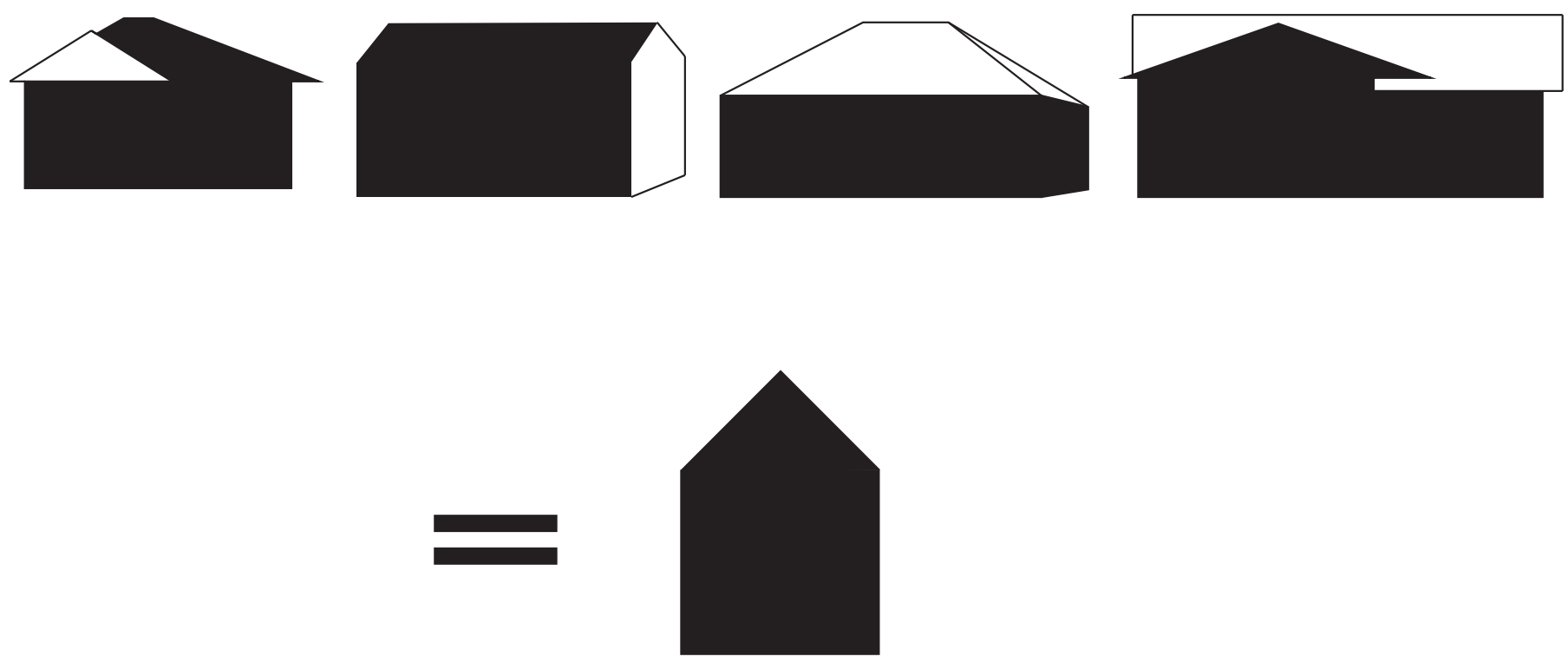

Bungalow

State Housing
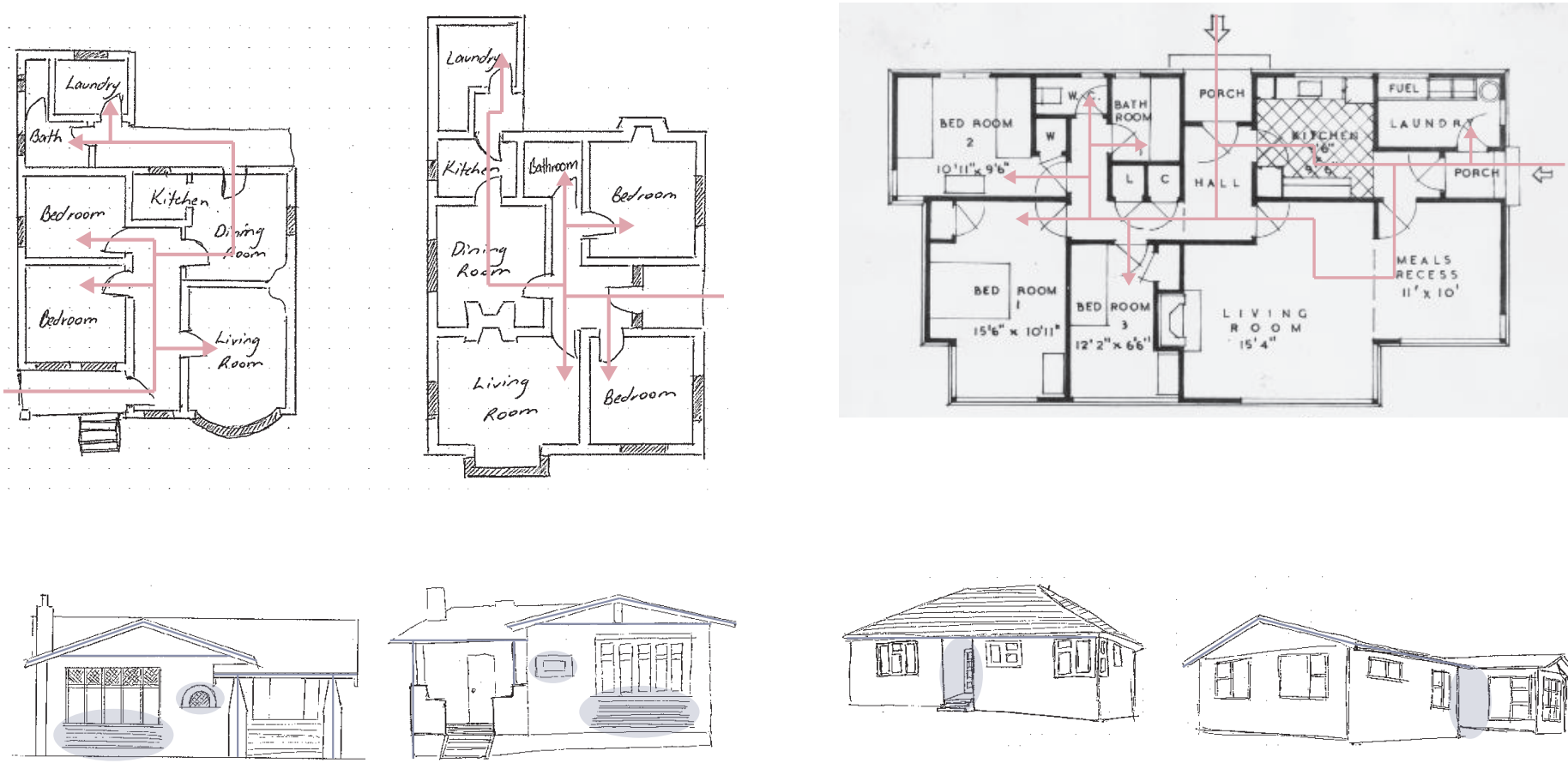

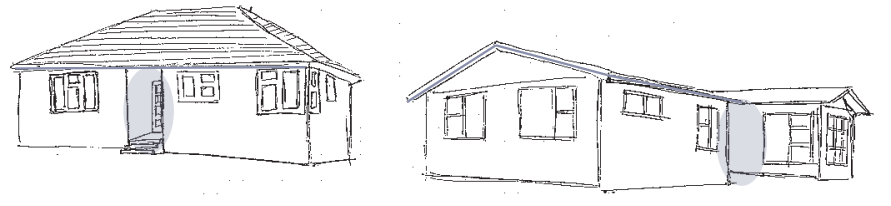

What has been established visually and through an evaluation of plans is that these buildings all hold similar design characteristics while still maintaining their own individuality. Similar aspects include the duo-pitched roof, gable ends, locally sourced materials, and closed plan living. However, the problen is not with designing to the typographical characteristics of a rural community, but rather including these features while still upholding the necessary features of a age-care facility. 


\begin{tabular}{|l|l|l|l|}
\hline Accommodation and Facilities - Planning Allowances - 8 Residents \\
\hline Residents & Single bedsitting rooms & $9.6-12 \mathrm{~m}^{2}$ & $96 \mathrm{~m}^{2}$ \\
\hline & Single room including WC & $15.3 \mathrm{~m}^{2}$ & - \\
\hline & Double bedsitting rooms & $14.8-16 \mathrm{~m}^{2}$ & - \\
\hline & Bathrooms and toilets & $8.8 \mathrm{~m}^{2}$ & $70.4 \mathrm{~m}^{2}$ \\
\hline & & & $166.4 \mathrm{~m}^{2}$ \\
\hline Communal Rooms & Lounges & $2.3 \mathrm{~m}^{2}$ per pers on & $18.4 \mathrm{~m}^{2}$ \\
\hline & Dining ro om & $1.5 \mathrm{~m}^{2} \mathrm{pp}$ & $12 \mathrm{~m}^{2}$ \\
\hline & Handcraft or sewing room & $15 \mathrm{~m}^{2}$ & $15 \mathrm{~m}^{2}$ \\
\hline & & & $45.4 \mathrm{~m}^{2}$ \\
\hline & Pantry & $12.15 \mathrm{~m}^{2}$ & $12.15 \mathrm{~m}^{2}$ \\
\hline & Food prep - cooking & $42.5 \mathrm{~m}^{2}$ & $42.5 \mathrm{~m}^{2}$ \\
\hline & Washing up & $15 \mathrm{~m}^{2}$ & $15 \mathrm{~m}^{2}$ \\
\hline & Cloakroom and staffroom & $12 \mathrm{~m}^{2}$ & $12 \mathrm{~m}^{2}$ \\
\hline & & & $81.65 \mathrm{~m}^{2}$ \\
\hline Additional Rooms & Sluice room & $6 \mathrm{~m}^{2}$ & $6 \mathrm{~m}^{2}$ \\
\hline & Laundry & $20 \mathrm{~m}^{2}$ & $20 \mathrm{~m}^{2}$ \\
\hline & Linen store & $8 \mathrm{~m}^{2}$ & $8 \mathrm{~m}^{2}$ \\
\hline & Cleaners store & $4 \mathrm{~m}^{2}$ & $4 \mathrm{~m}^{2}$ \\
\hline & & & $110 \mathrm{~m}^{2}$ \\
\hline & & & $331.45 \mathrm{~m}^{2}$ \\
\hline & & & \\
\hline
\end{tabular}

Sizing is based on typical 40-person institution
In an urban setting a facility with 16 to 35 residents is considered large due to the number of staff required to take care of the residents at an optimal ratio of $1: 4$ in New Zealand (Harper 7). If this is then reduced to half ( 8 residents), the facility can be maintained in a smaller rural homestead without institutional aspects and sizing. This may create an aura of home care and appropriate context. The diagrams explore the programmatic specifications required to ensure that sufficient space is allocated per resident, and that additional staffing requirements are met (see fig. 4.015-4.016).

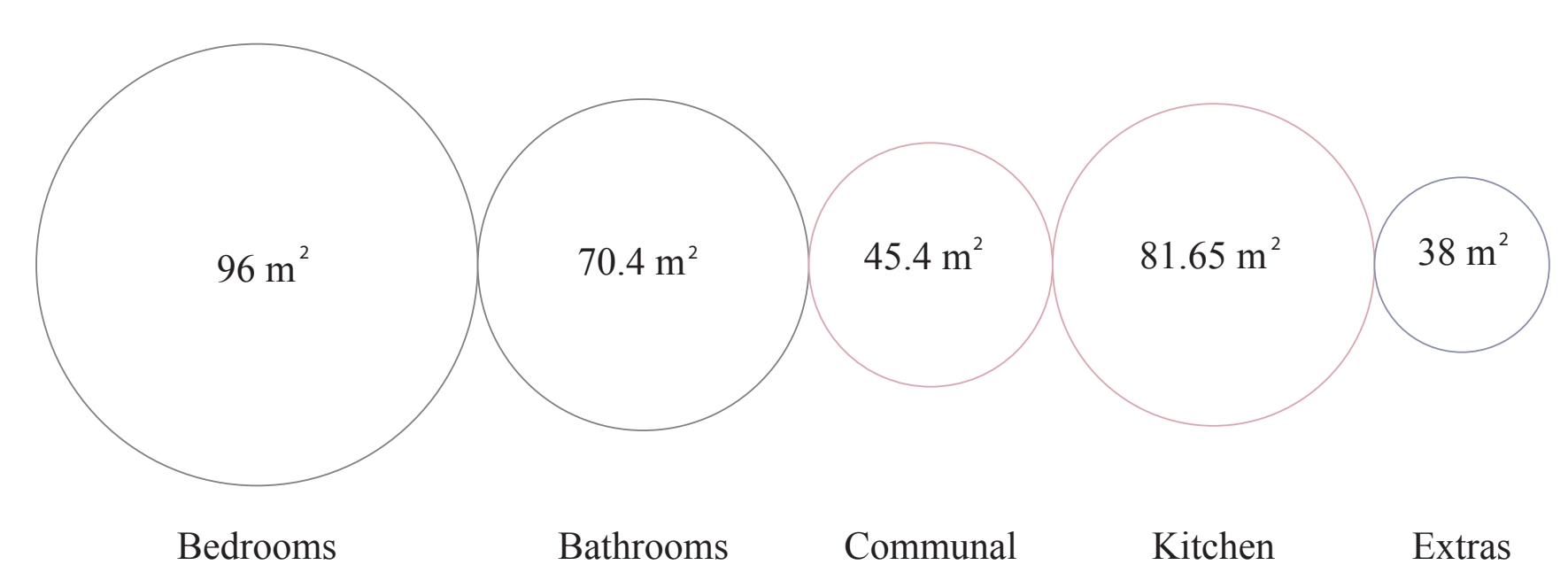


Currently dementia centres within the Manawatu are limited. Over the region there are scattered clusters, but none which are situated within a rural typology. The diagrams show the

overall numbers of dementia centres

and how these are placed in the region

(see fig 4.0.18). From this analysis it

is clear that there is an opportunity

for a dementia centre to be situated

around the rural town of Bulls (see

fig 4.0.19). Within this section of the

Manawatu there is a former

institution named Flock House,

which provided agricultural training

for people from 1923 to the 1980's

(Heritage New Zealand). The site

is situated $14 \mathrm{kms}$ away from the

town centre of Bulls, located close

to State Highway 1, and between

the two cities of Palmerston North

and Wanganui. This provides an

accessible location for people using

the state highway which bypasses the

general site area and the proposed

dementia centre. It is also beneficial

in terms of health and safety, because

it is close to local hospitals.

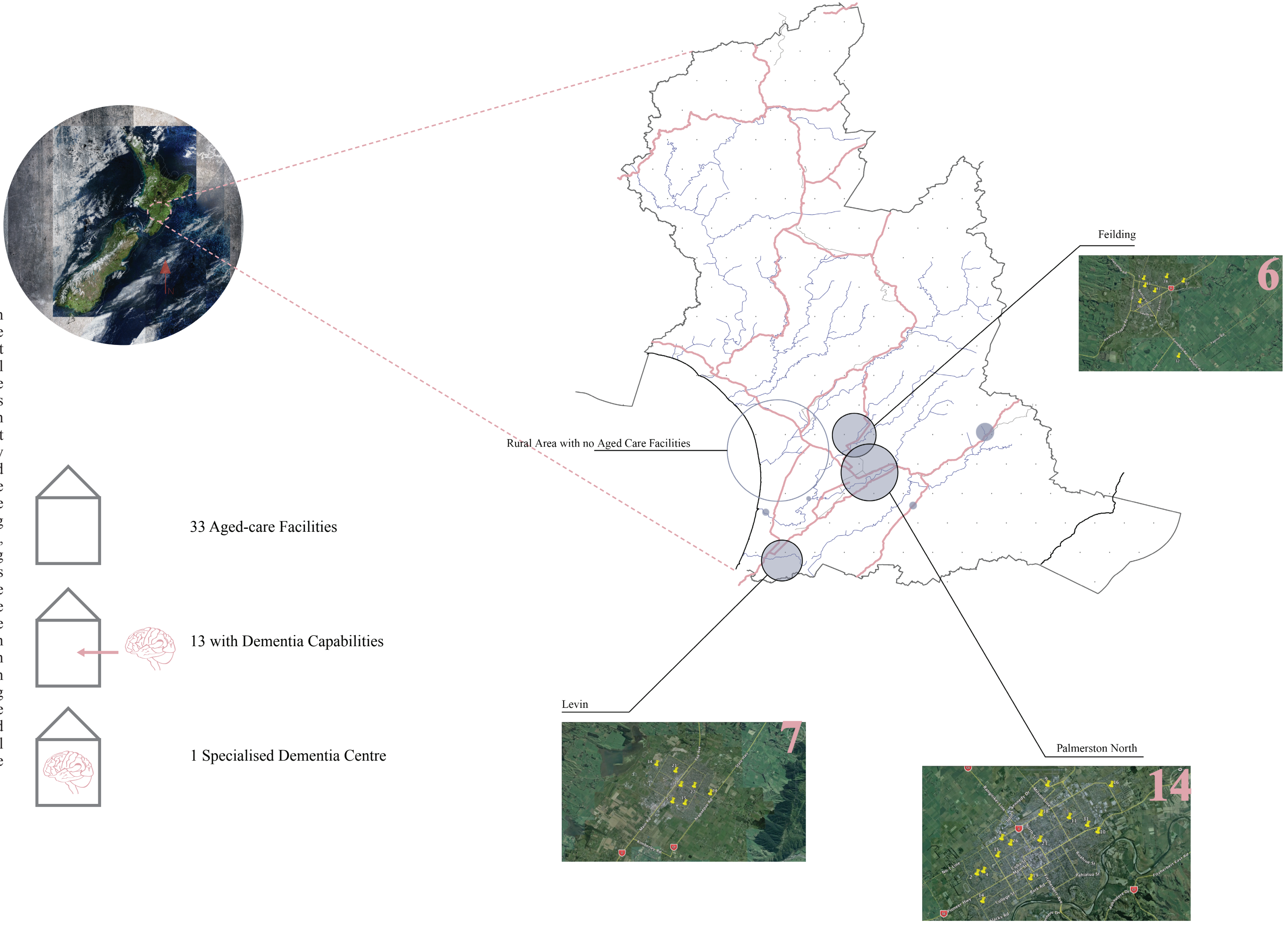

4.0.17| (above) New Zealand 


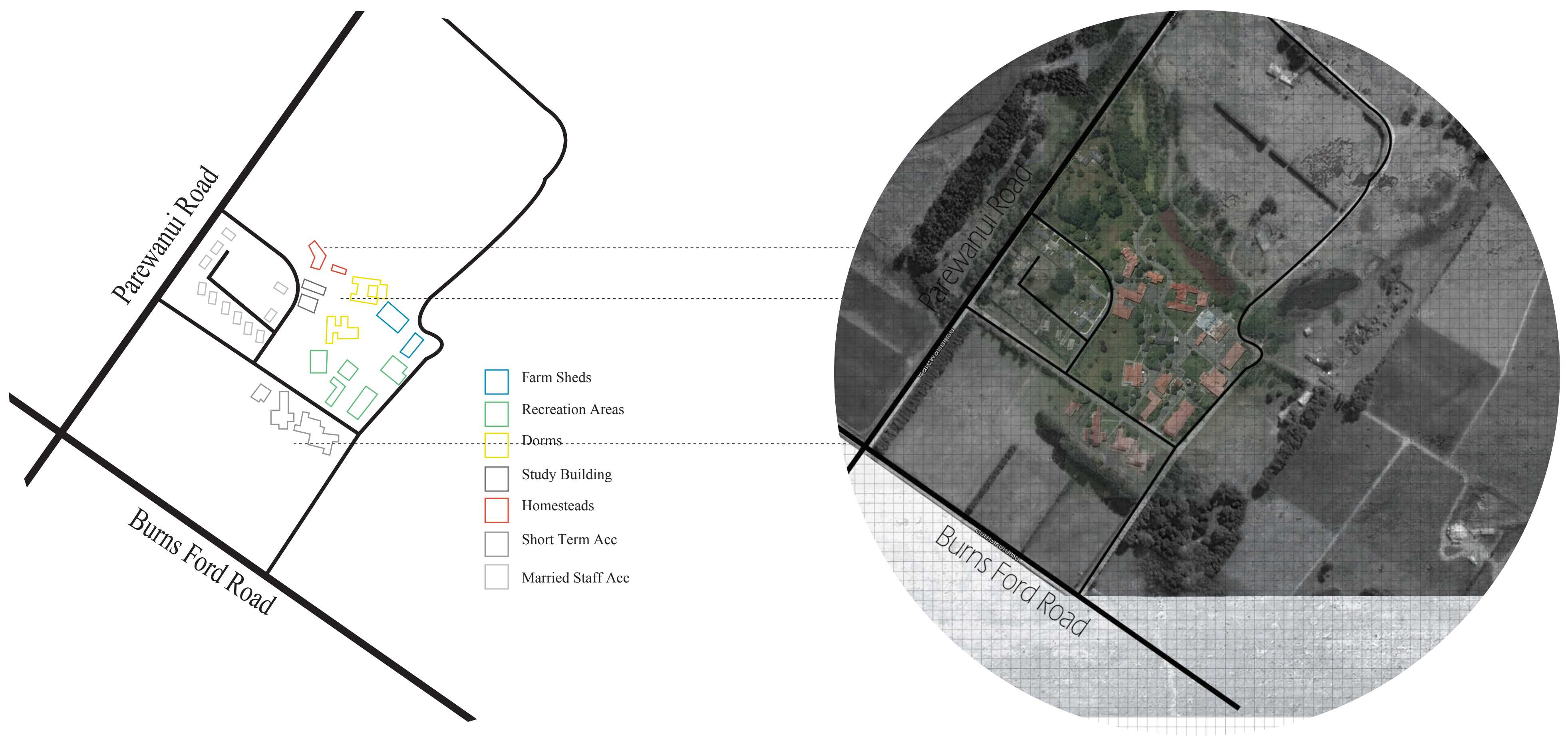

4.0.20 Flock House site building footprints and areal view

060

061 

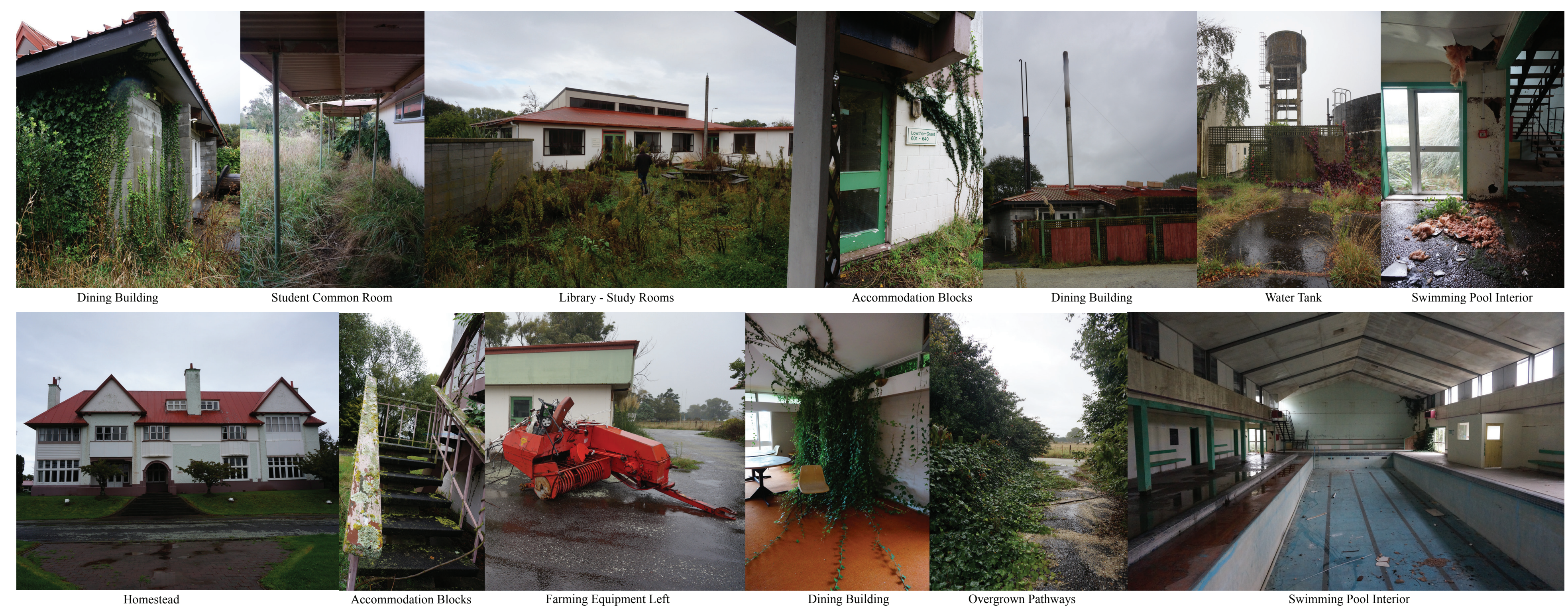

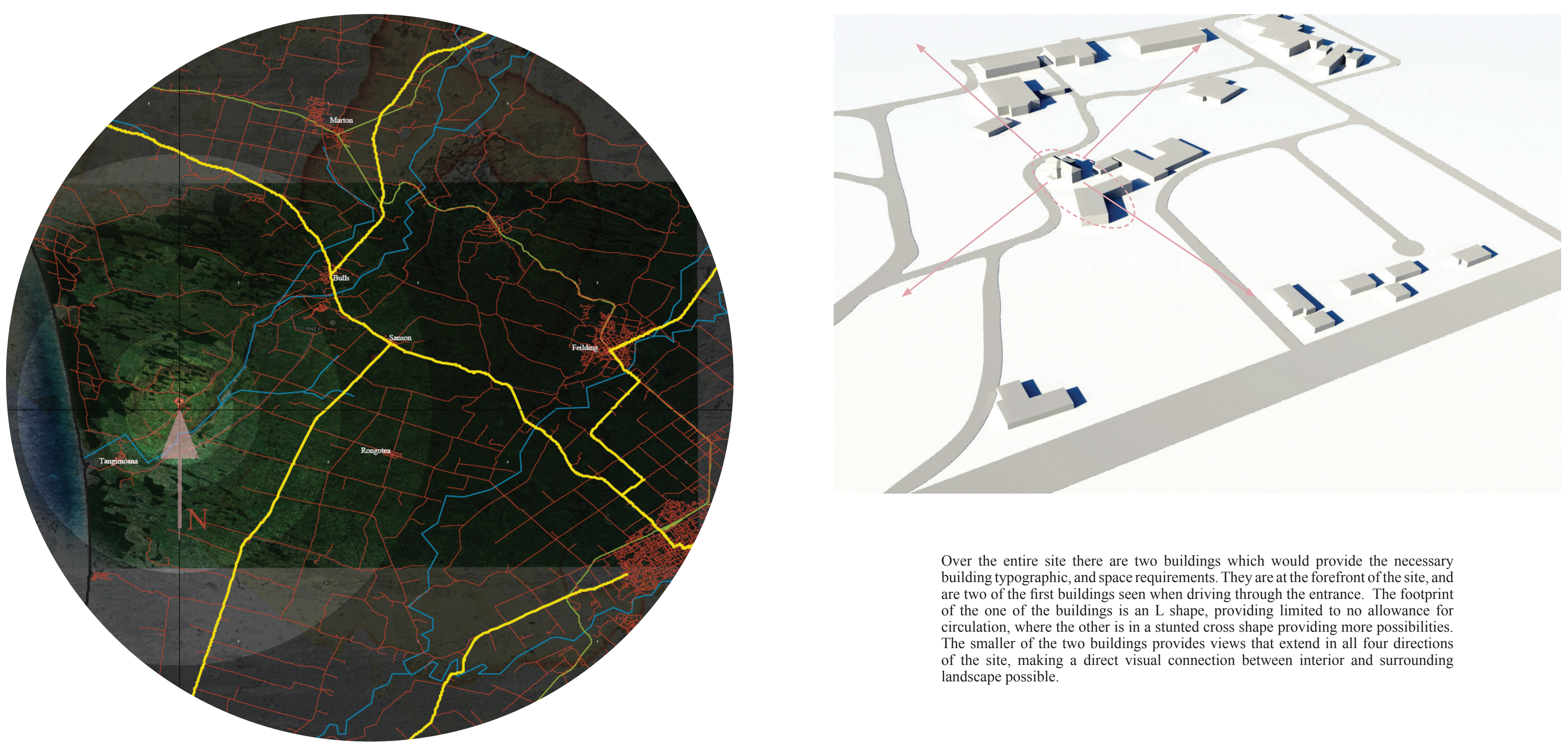

In the last 30 years the institution has become privately owned, and has changed ownership several times (Patsy McMillan). In this time some buildings have been sold, pulled down, or have become derelict. As a result, some of the buildings on site have been taken over by the local landscape, and are no longer usable. What is still present on the site are the historic homesteads, and some of the recreational buildings, such as the swimming pool, gymnasium, and training farm sheds (see fig.4.0.20)
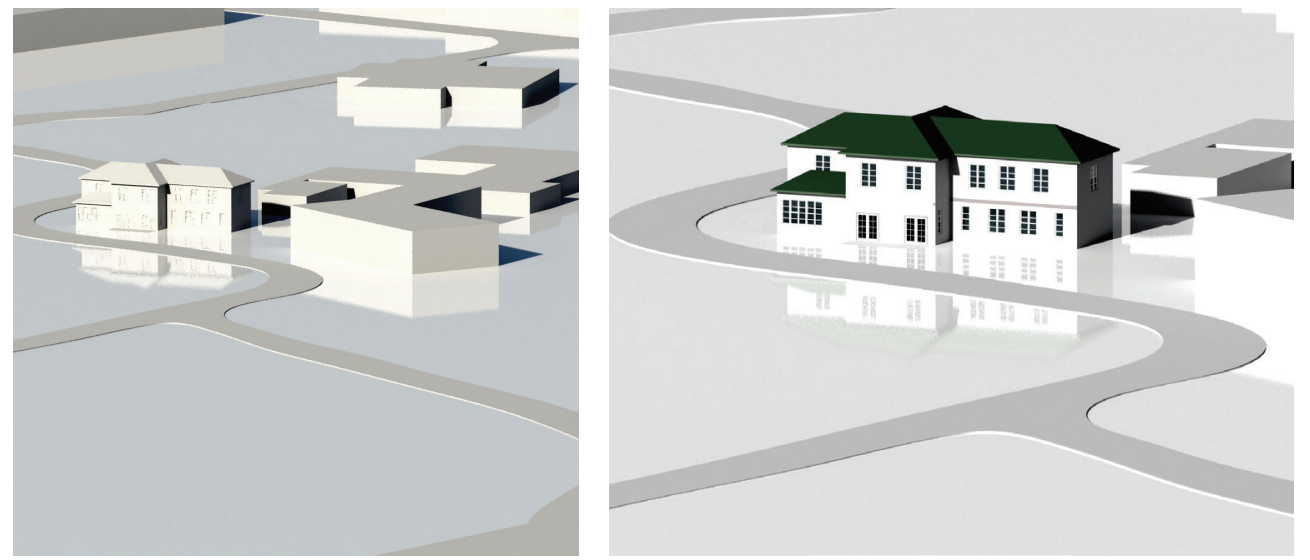

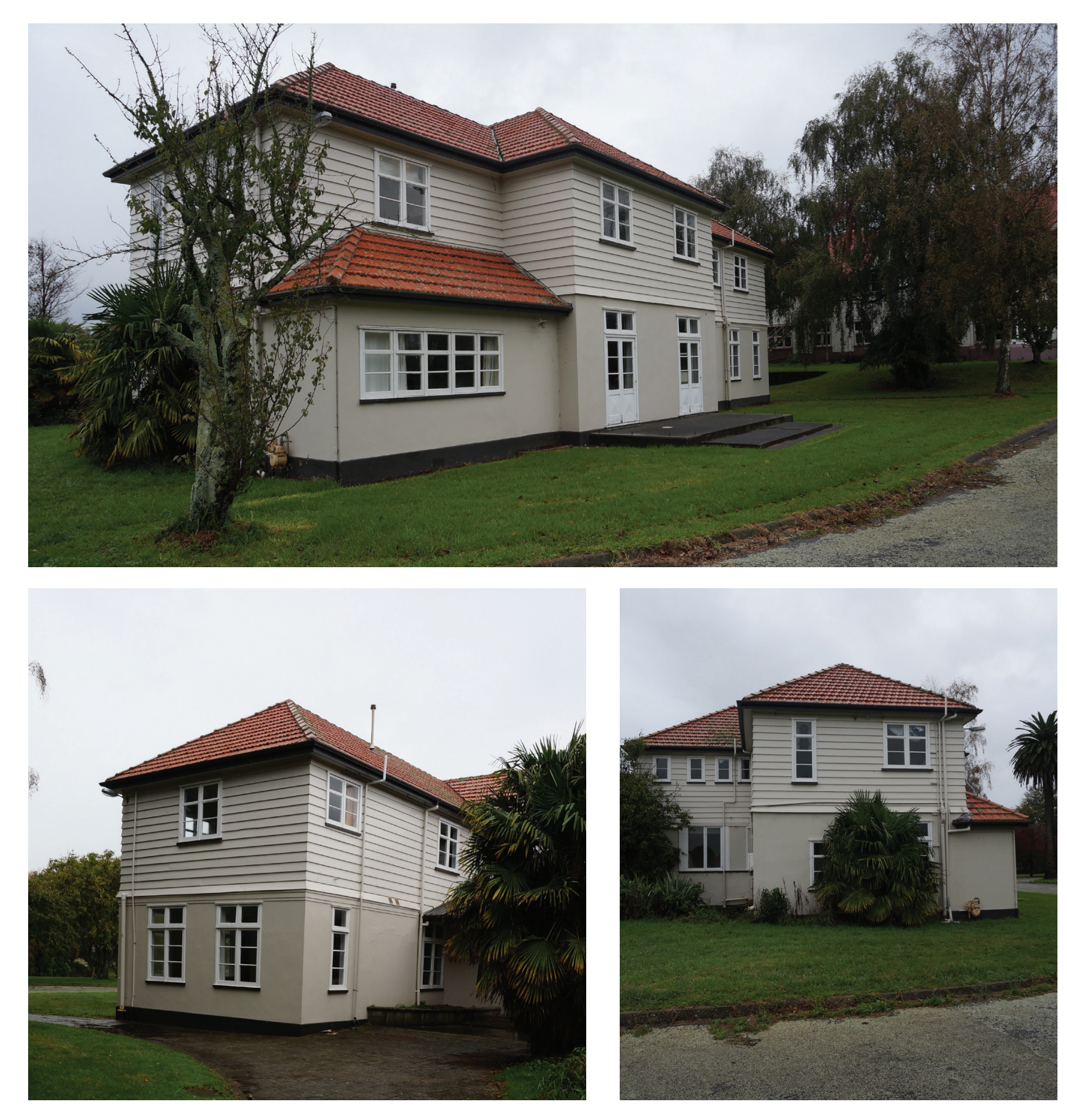
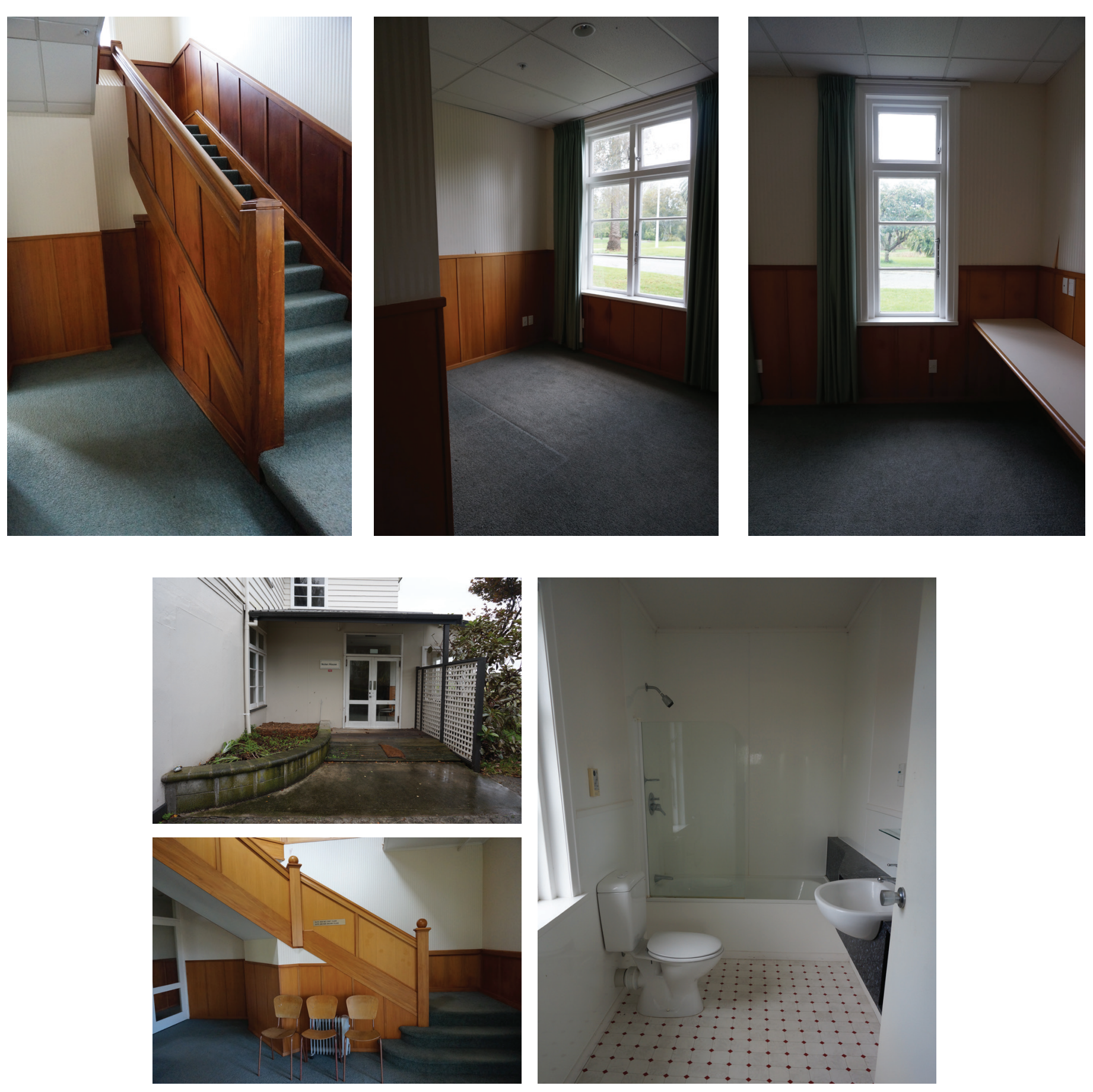


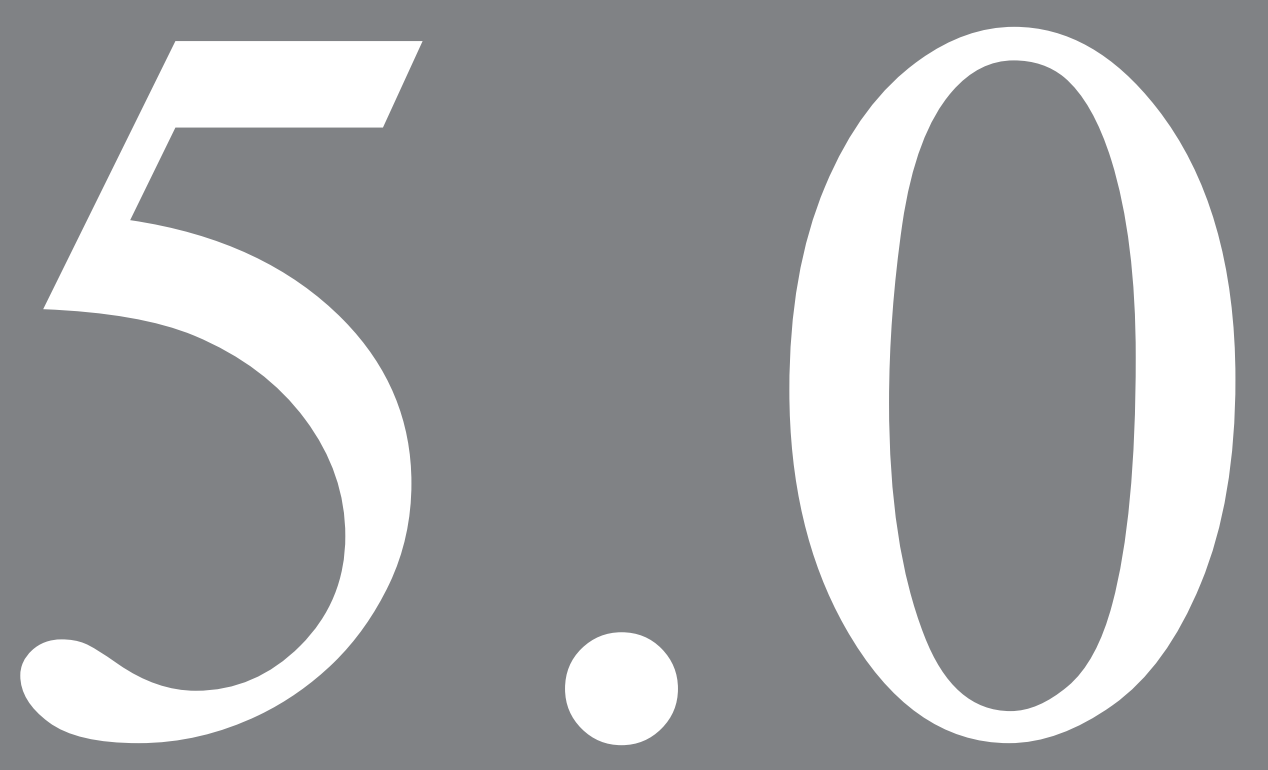

Design Phase 1 
With the proposed area located in the surrounding farmscapes on the outskirts of the rural town of Bulls, there is limited visual and close contact to community influences to expel the sense of isolation, or increased random community interaction. The possibility of another program to support the dementia centre and provide life to the sie has the oro been adopted. This also a dementia centre and a community hub for people from a rural community.

\begin{tabular}{|c|c|c|c|c|c|}
\hline & Rural activity & $\begin{array}{l}\text { Estimated amount } \\
\text { of space required }\end{array}$ & Age attracted & $\begin{array}{c}\text { Dementia } \\
\text { involvement }\end{array}$ & $\begin{array}{c}\text { Human-anima } \\
\text { interaction }\end{array}$ \\
\hline Garden centre & Yes & $\begin{array}{l}\text { One of the } \\
\text { existing buildings }\end{array}$ & Young adults + & $\begin{array}{l}\text { Residents can help } \\
\text { with planting up } \\
\text { pots, and with the } \\
\text { up keep of the } \\
\text { garden centre }\end{array}$ & No \\
\hline $\begin{array}{l}\text { Fix up of buildings } \\
\text { for prior purpose } \\
\text { (swimming pool, } \\
\text { squash courts, } \\
\text { gymnasium) }\end{array}$ & Yes & $\begin{array}{l}\text { Existing buildings } \\
\text { on site }\end{array}$ & All ages & $\begin{array}{l}\text { Potential for } \\
\text { aerobic swimming } \\
\text { or physical } \\
\text { therapy for the } \\
\text { residents }\end{array}$ & No \\
\hline Rural petting zoo & Yes & $\begin{array}{l}\text { Enclosed and } \\
\text { outdoor areas } \\
\text { (large or small } \\
\text { depending on } \\
\text { size/number of } \\
\text { animals) }\end{array}$ & All ages & $\begin{array}{l}\text { Residents can help } \\
\text { with feeding } \\
\text { animals. Routine of } \\
\text { feeding chickens } \\
\text { or lambs in spring } \\
\text { will bring back } \\
\text { memories from } \\
\text { past lifestyles }\end{array}$ & Yes \\
\hline $\begin{array}{l}\text { Horse riding } \\
\text { school and stables }\end{array}$ & Yes & $\begin{array}{l}\text { Large grass area- } \\
\text { enclosed building } \\
\quad \text { for stables }\end{array}$ & All ages & Help with feeding & Yes \\
\hline $\begin{array}{c}\text { Golfing } \\
\text { course/range }\end{array}$ & Yes & $\begin{array}{c}\text { Large grass area- } \\
\text { surrounding } \\
\text { paddocks }\end{array}$ & $\begin{array}{l}\text { Mainly middle- } \\
\text { aged }\end{array}$ & $\begin{array}{c}\text { No }- \text { mobility } \\
\text { issues }\end{array}$ & No \\
\hline Lawn bowls & Yes & $\begin{array}{c}\text { Small grass area- } \\
\text { with surrounding } \\
\text { club }\end{array}$ & Elderly & $\begin{array}{l}\text { With raised } \\
\text { bowling beds - an } \\
\text { activity for the } \\
\text { residents }\end{array}$ & No \\
\hline
\end{tabular}

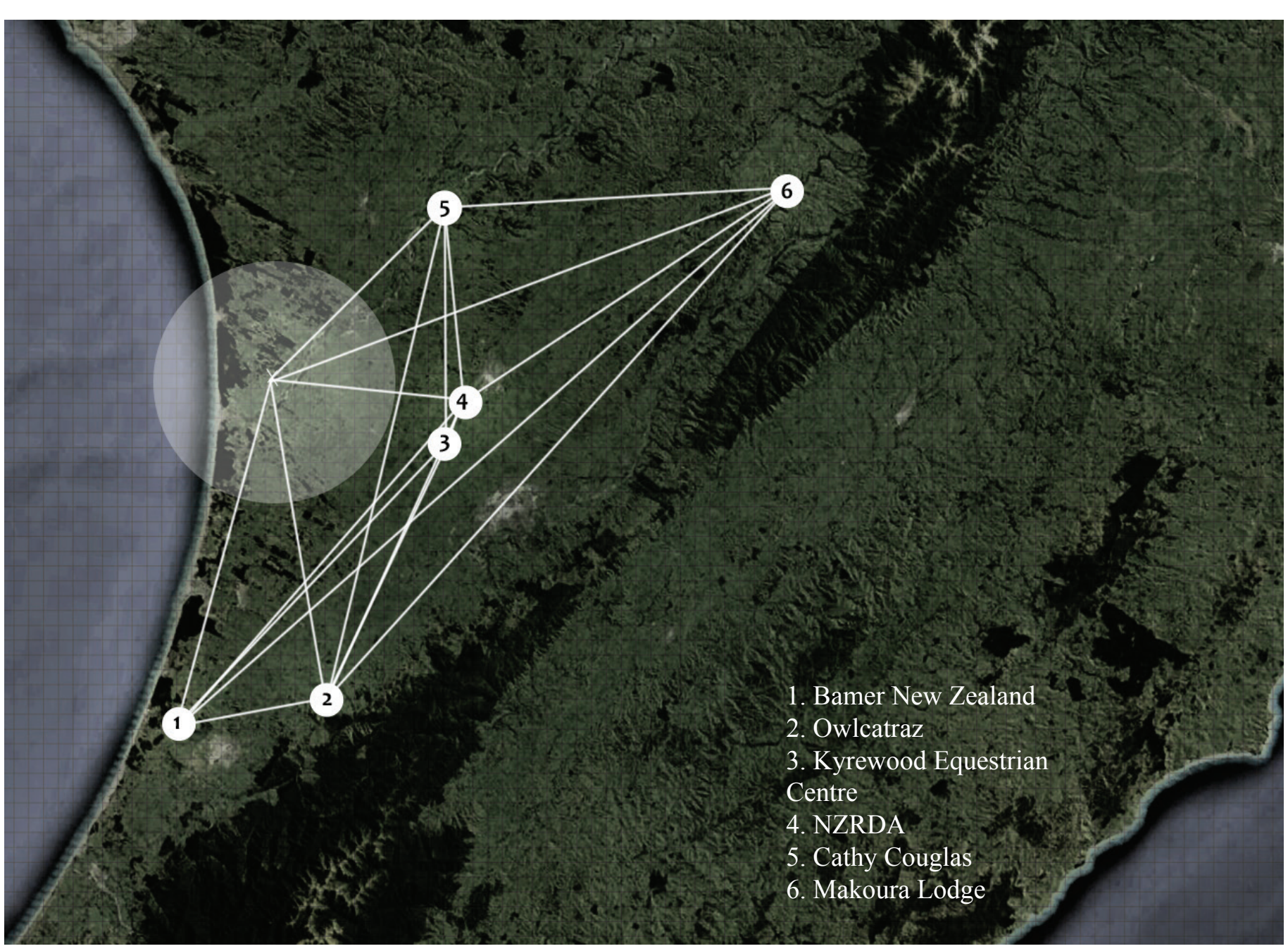

With limited agricultural community activities in the Manawatu, an acceptable programme to run alongside the dementia centre would be a petting zoo and horse
riding school (see fig. 5.0.1). These programmes will bring in people from both rural riding school (see fig.5.0.1). These programmes will bring in people from both rural input (see fig 5.0.2). With the influx of animals, engage the able dementia residents to help with feeding will provide a sense of worth and familiarity (Walsh 473). The ability to wander freely between community and dementia centre will enforce this aspect of freedom. 


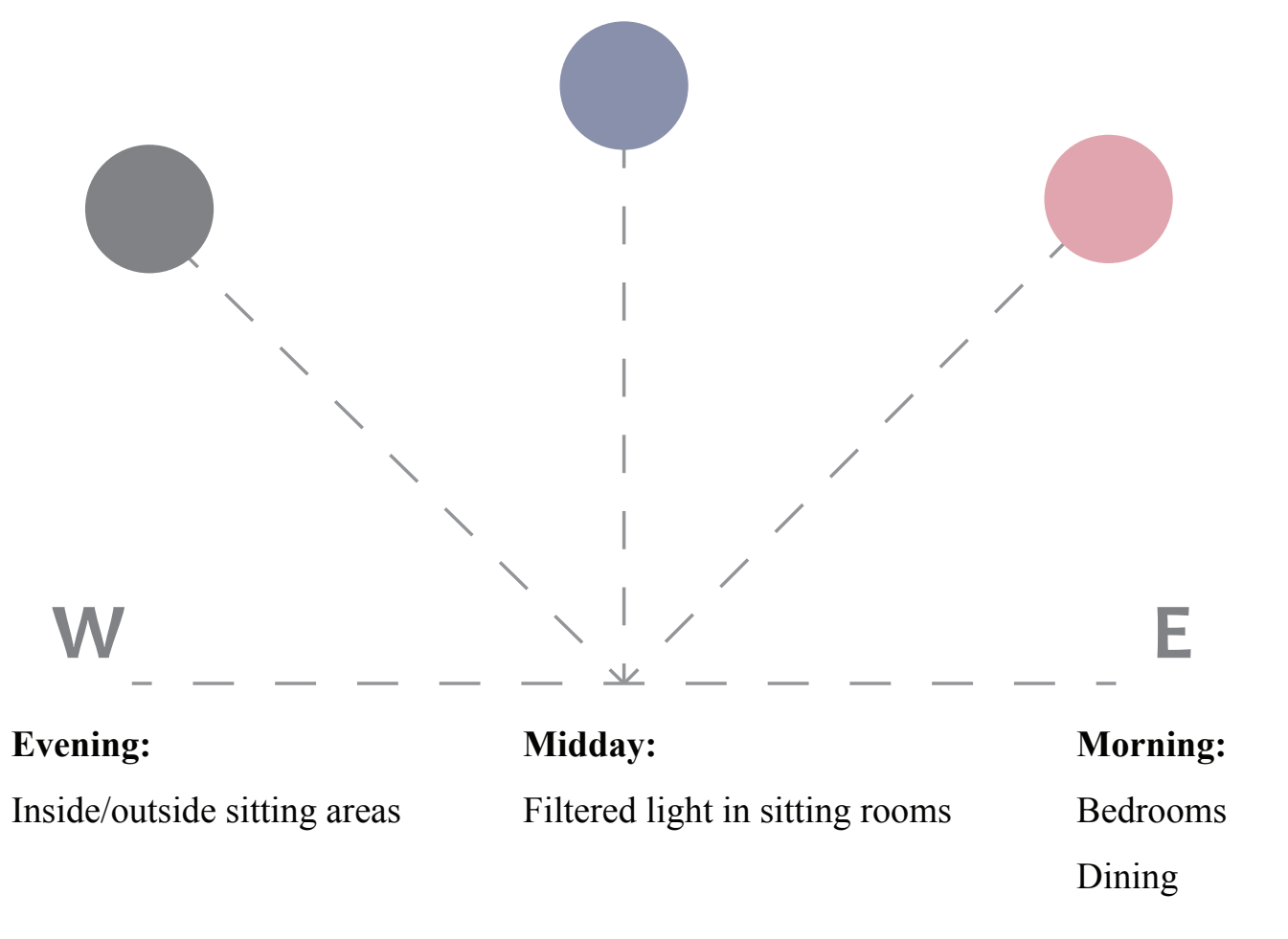

As lighting is directly related to our circadian rhythm, the importance of harnessing the natural light ensures a more normal circadian rhythm for people with dementia who typically suffer from sleep disruption. This influences the need for morning sun to be present where bedrooms are situated, and afternoon sun where living and communal areas are. This also encourages residents to get up in the morning and move through the building to enjoy both the sun and the company of others.

An initial sun study was conducted to evaluate the sun's path over the chosen building. This revealed that the longest side of the building faced north, capturing
the majority of the daylight. As this side would most likely hold the majority of the bedrooms, the longest side should face east for optimal use of natural light in the morning. This meant that this building will require repositioning on the site.

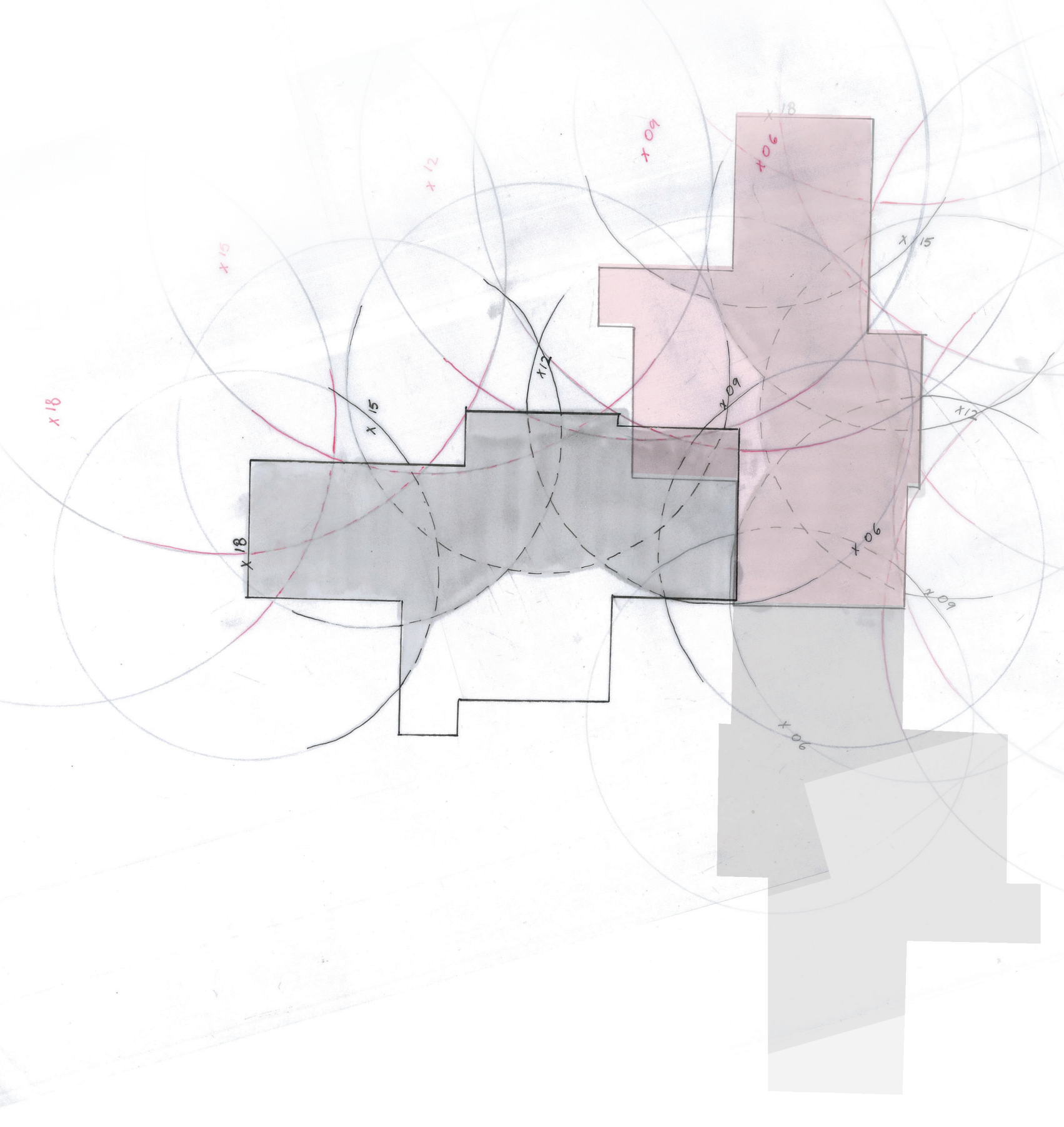




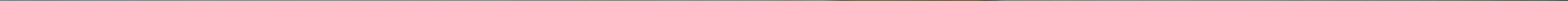




\subsection{Spatial Interaction}

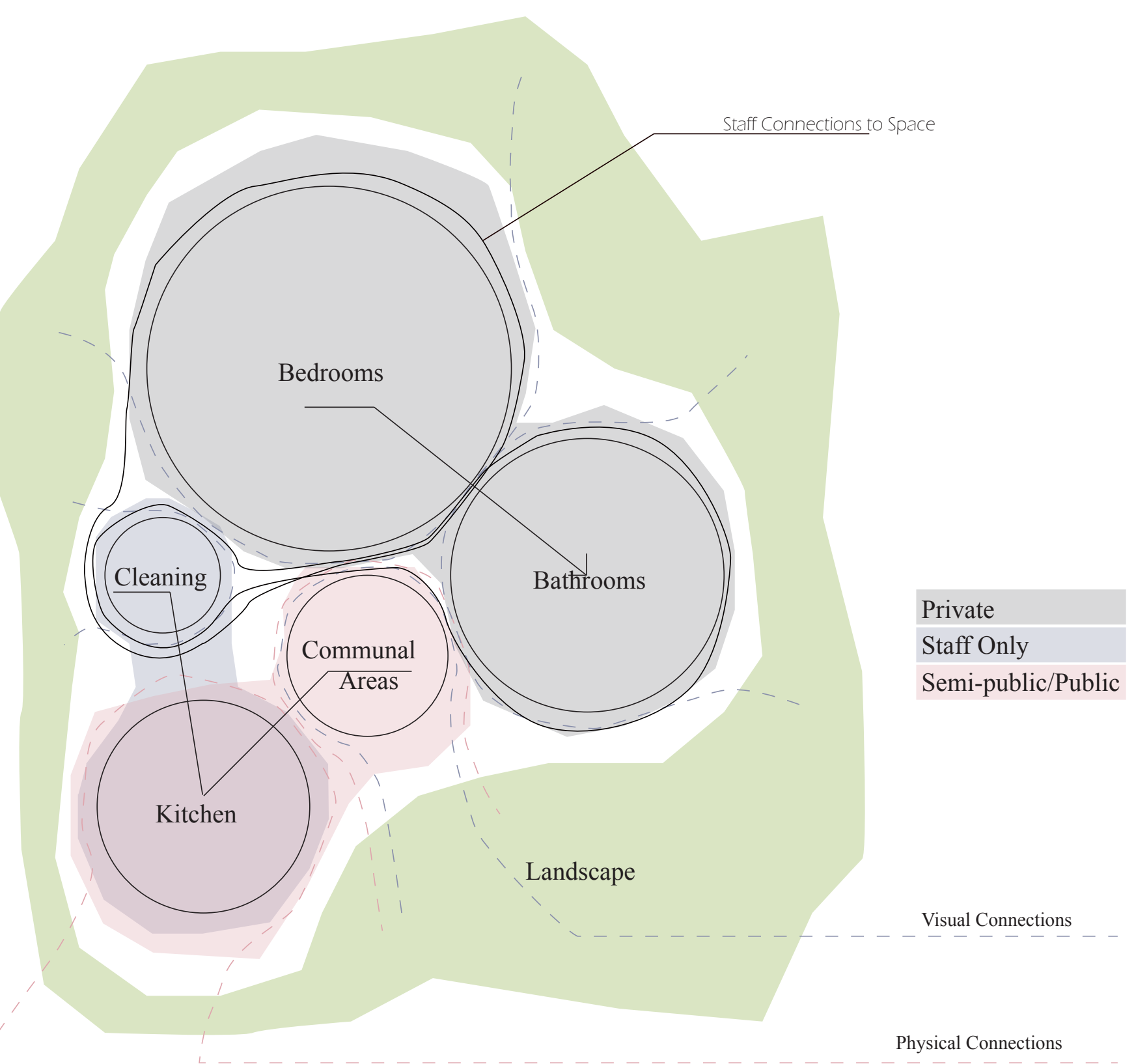

With importance on familiarity and easy wayfinding throughout the building, certain programmes need to be connected to establish a route that is both circular and memorable. Identifying which internal spaces need to connect with one another to avoid confusion and overlapping in circulation, while also providing a central space for staff to keep an eye on residents is important. Figure 5.3.1 shows how each space should connect with another and also the surrounding landscape. This was assessed with both visual and physical connections to establish the location of the various programmes bilding. 


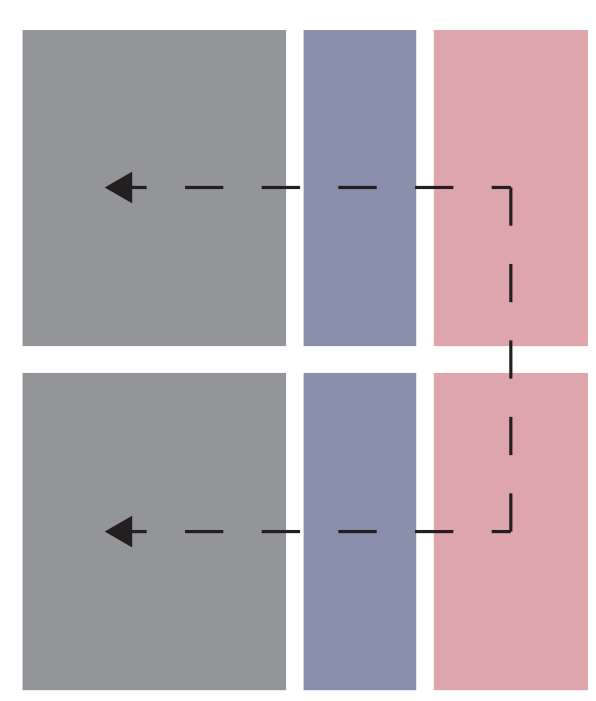

1. Double programmes over both levels. This splits up the residents into twe top level from the bottom.

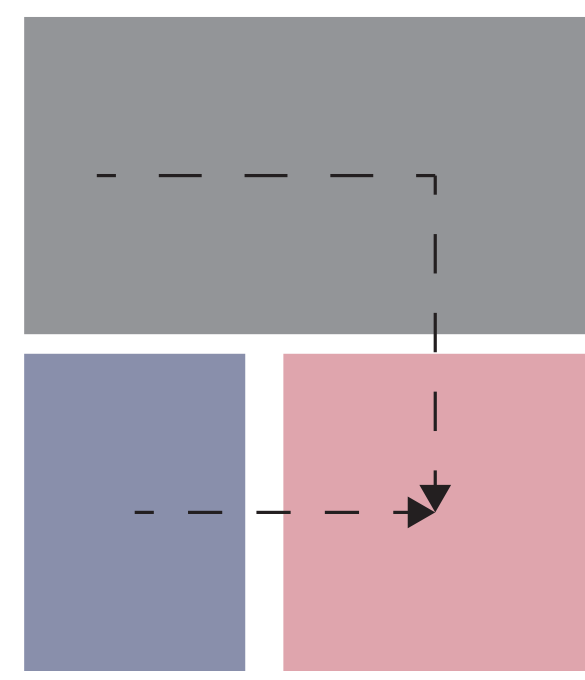

3. Centralising the staff observation area with a loop of public spaces inside the perimeter of the building facilitates safe wandering and minimises confusion.

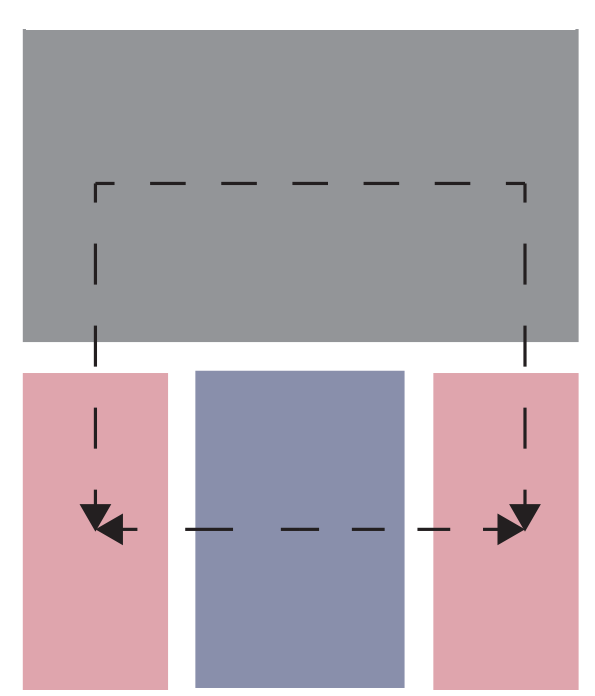

2. Locating bedrooms on upper level encourages the residents to spend time in the public and outdoor areas.

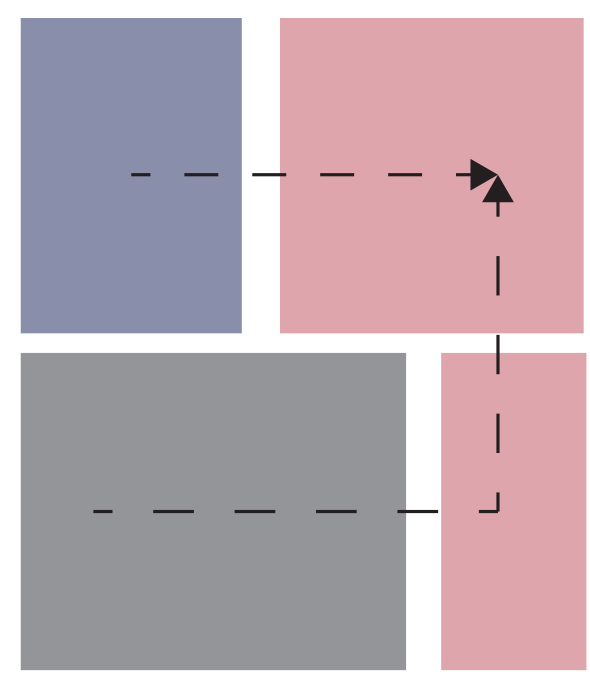

4. Staff areas are removed from the way of the residents and placed on the upper level, with bedrooms on the lower floor. Connection between resident and landscape is enhanced and mobility issues are reduced, with daytime activities centralised on one floor. This distances the staff and some public areas (such as the kitchen) from the residents.
Grouping the programmes into three categories (bedrooms, staff and communal areas) allowed for exploration of movement bosth horizontally and vertically. placing programmes within the existing building through sectios has established the optimal connections. The literature and case studies examined identified that for wellbeing, residents should spend minimal time in their rooms and that a focus should be put on public or semipublic spaces. By placing bedrooms on upper levels, a physical barrier has been created for people with dementia due to their lower mobility. Increasing their connection to other people and the possible activities can expel boredom. To address the concern of negotiating stairs, an elevator has been introduced. Key design moves have been to: 

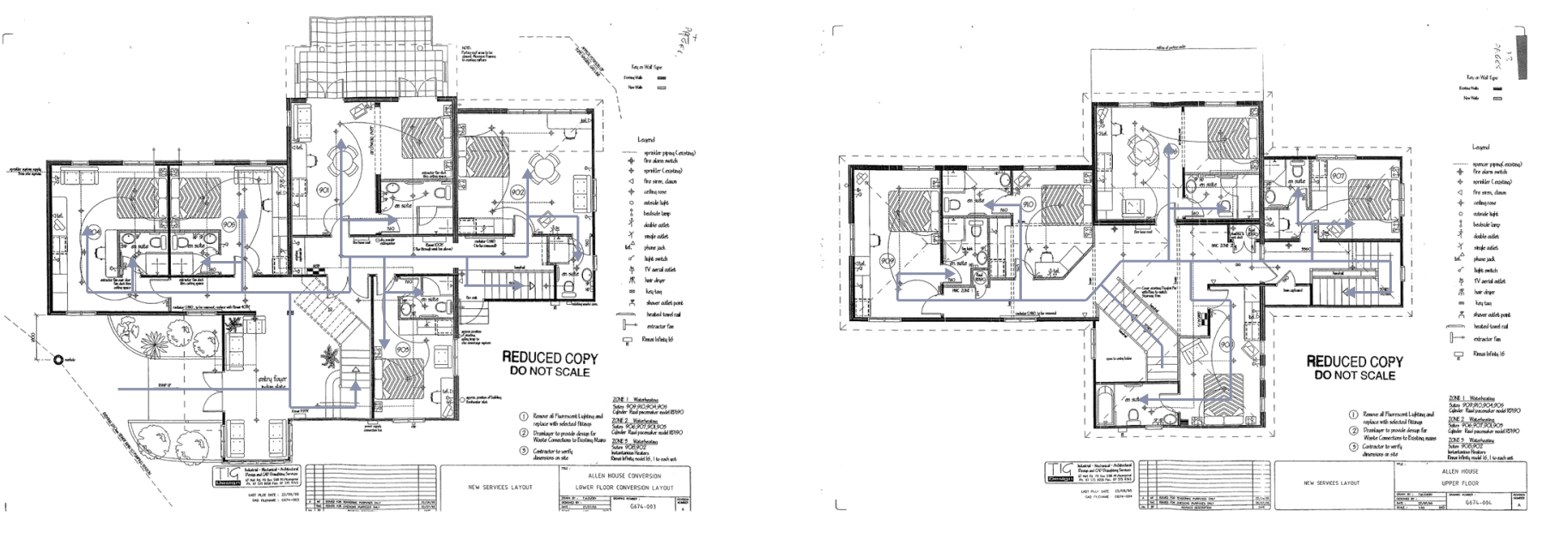

With these sizes and space allocations an initial study was undertaken to assess the existing building. The former use of the building had been as a short stay motel. This had similar programmatic requirements where every bedroom has its own bathing facilities. However, the historic layout lacked public spaces for residents to use during the day. Dual staircases allow for two methods of moving between levels and permitted a loop between them. The difference in materials and layout in the design of the stairs can allow them to become reference points when the interior of the space is opened up

By removing the internal walls, the shell of the building can be used to design dementia-specific circulation around the programmes. In keeping the existing building rather than demolishing it some of the agricultural heritage of the site is preserved and the building typology is familiar to local residents.

\section{Level 2}
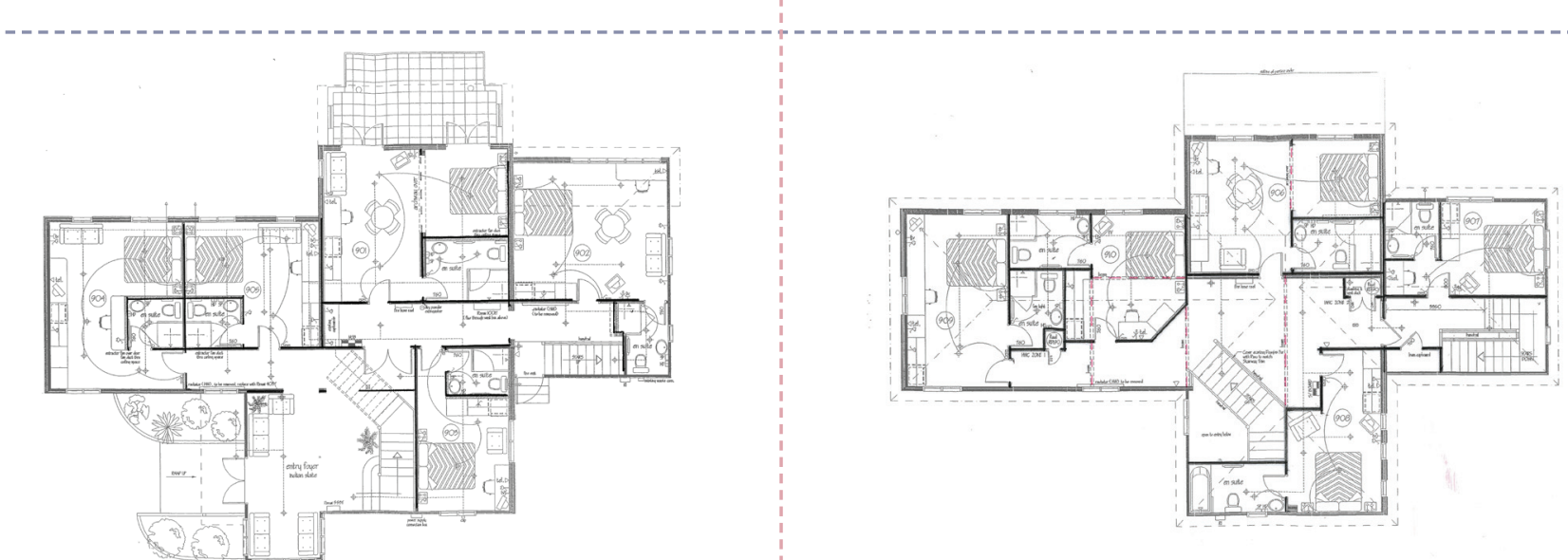

5.4.2 (above) Highlighting internal walls (current and removed)

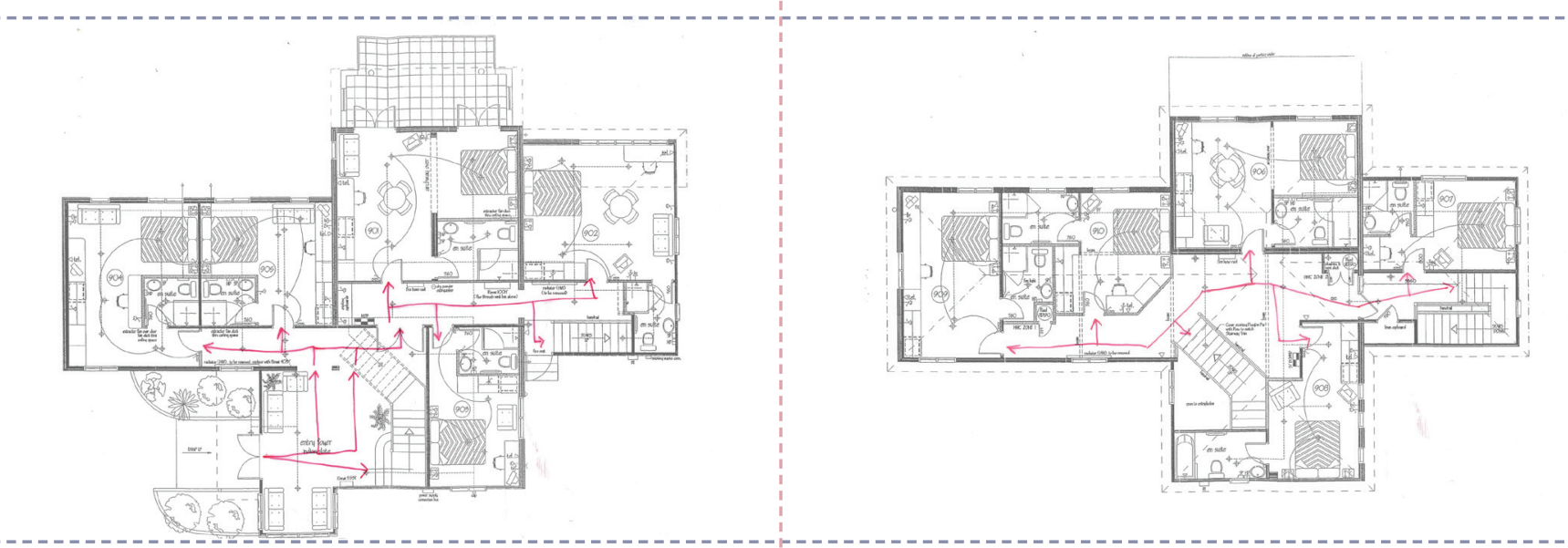

5.4.3 | (above) Possible methods of movement

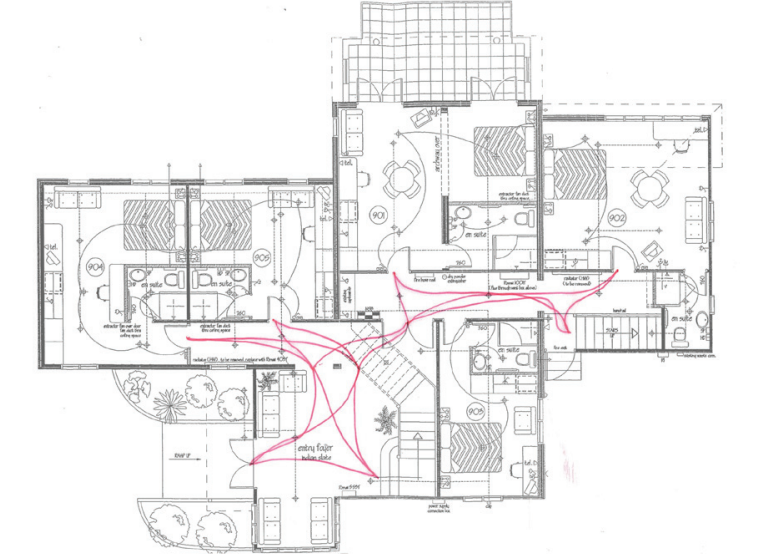



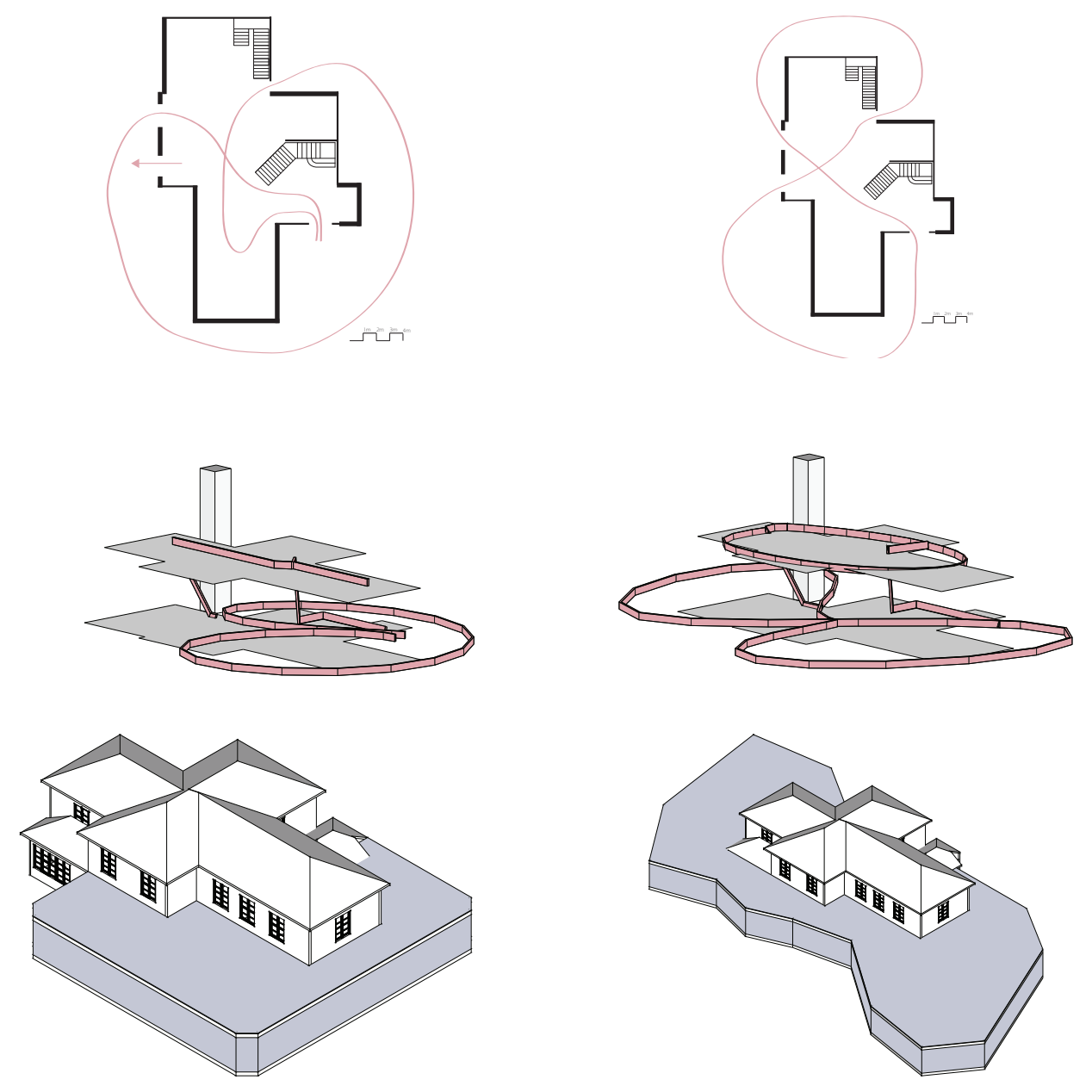
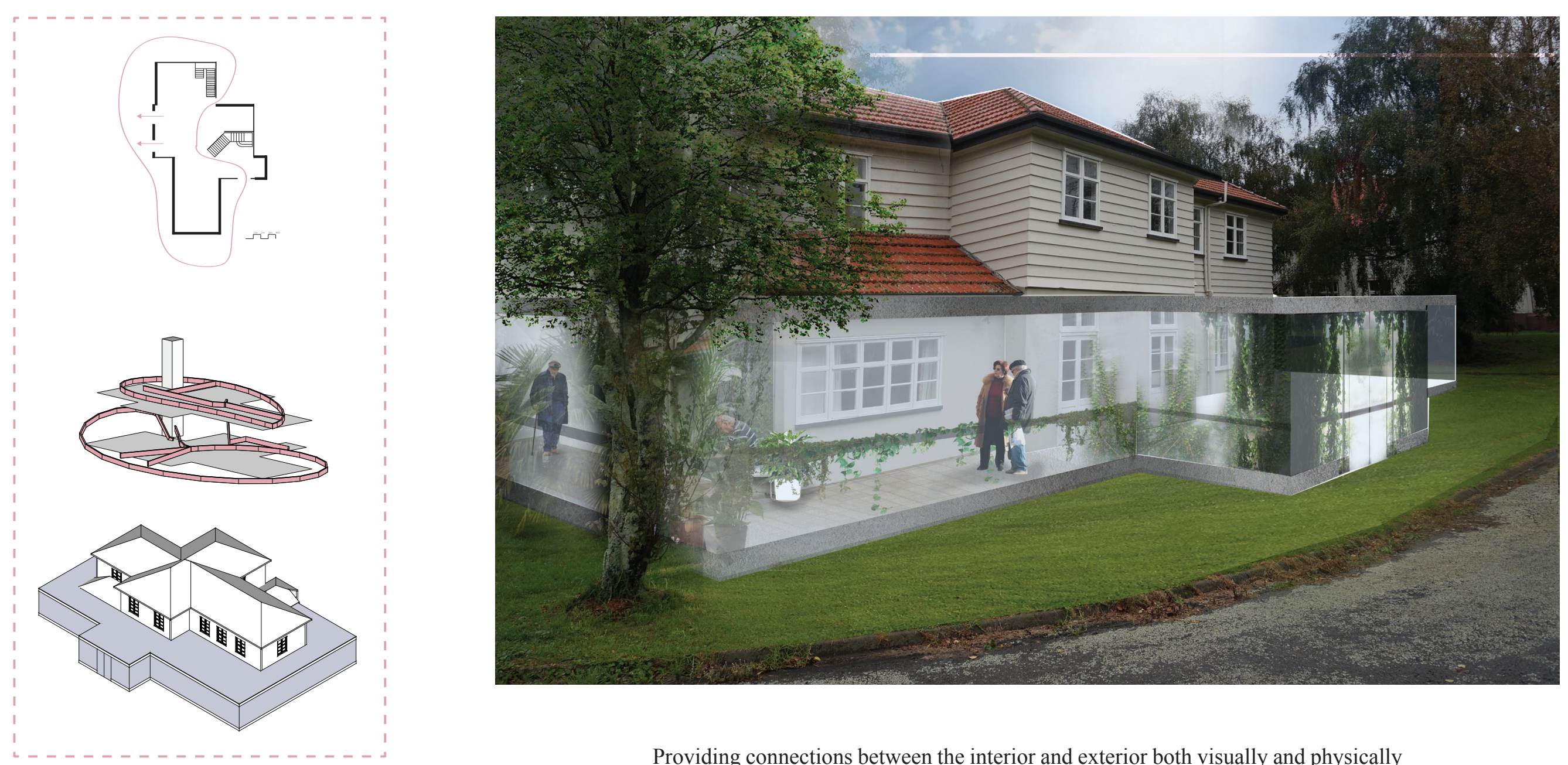

Providing connections between the interior and exterior both visually and physically Providing connections between the interior and exterior both visually and physically
is a key feature of the design. Using the current openings in the existing building, threshold between interior and exterior. People with dementia tend to enjoy filtered sunlight plants, and landscape, but not the exposed elements of sitting outside in some of the colder months. An exploration into creating an external form that doubles as a sun-room and indoor garden and that connects inside to outside reducing the exposure to the elements was conducted (see fig 5.5.1). The possible use of glass as a translucent skin ensures the visual connection to the surrounding landscape is not broken. However, the skin becomes an obtuse addition to the existing building, and would also be unusable as it would become too hot in summer (fig. 5.5.2). This addition needs further refinement to possess the same typographic style as the remainder of the building. 
A space study has been completed to determine sizing of programme elements and their possible positions in the building. As a circular loop is an important design feature, this has been examined to determine the most effective walkways around and through spaces. Keeping the existing staircases allows for vertical movement.

However, with the agility of the elderly residents in mind, additional support may

be needed. As the space requicents just meet the building footprint, additional

services will exceed this and require an extension to the existing building (see pink overlay on fig.5.5.4)
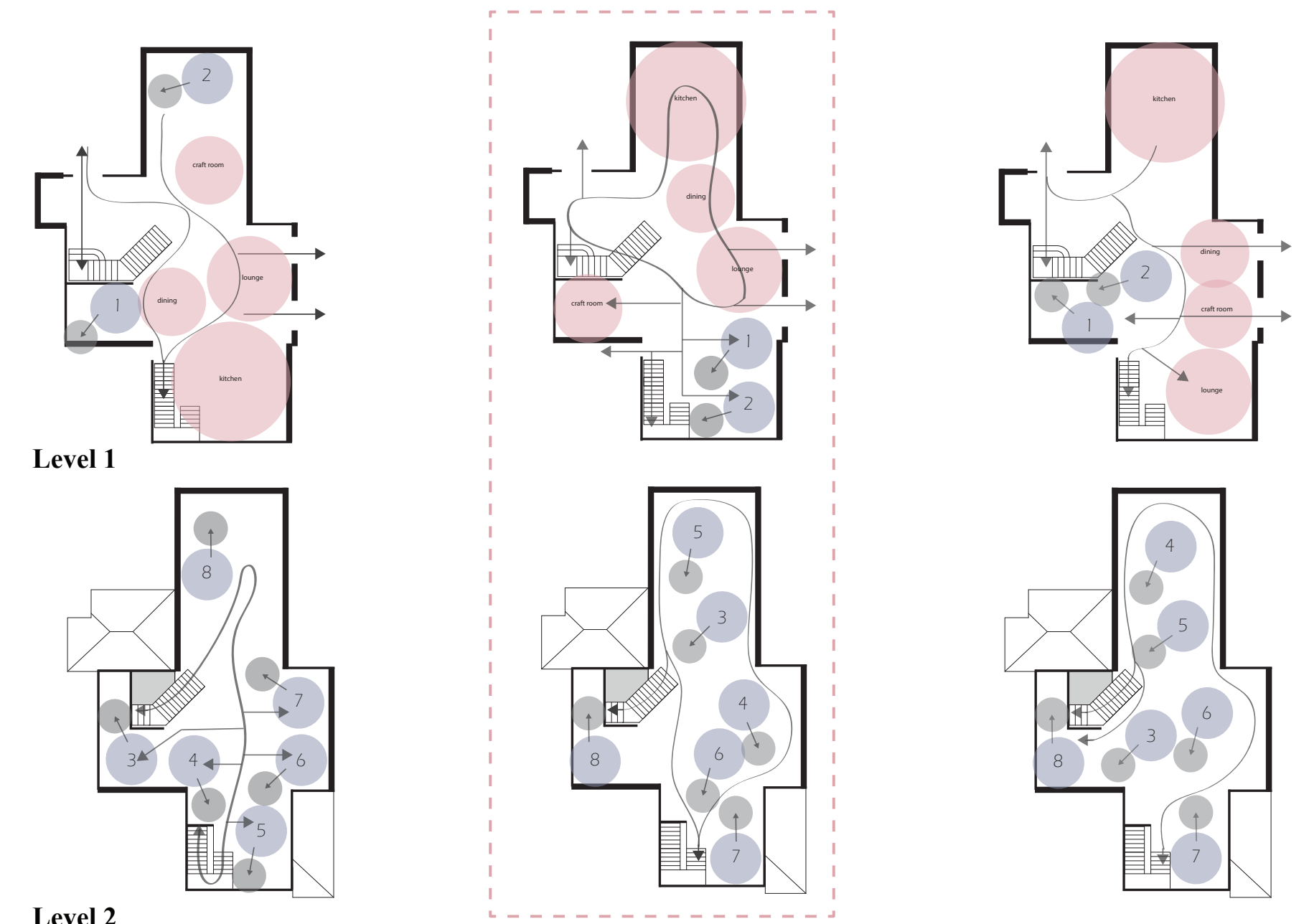

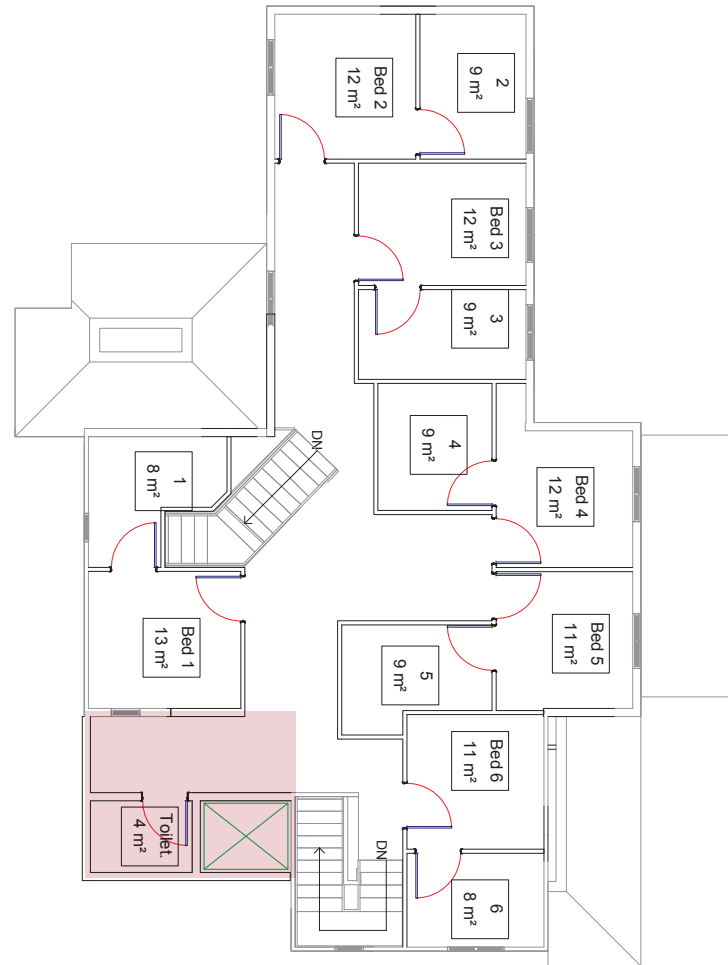

Level 2

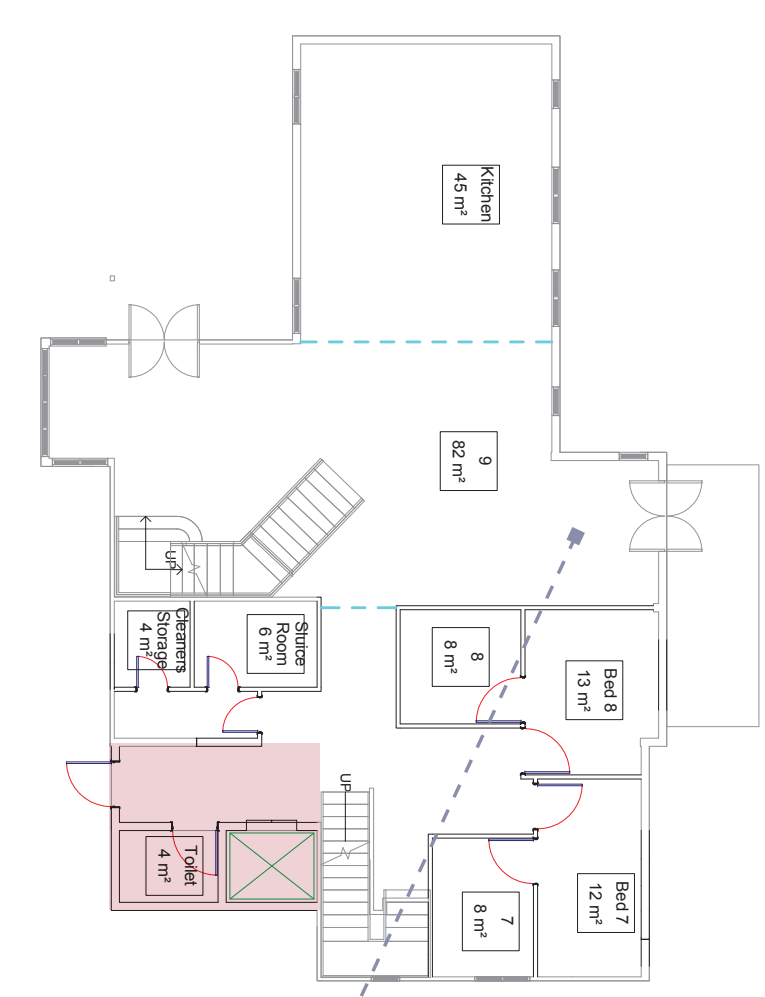

Level 1

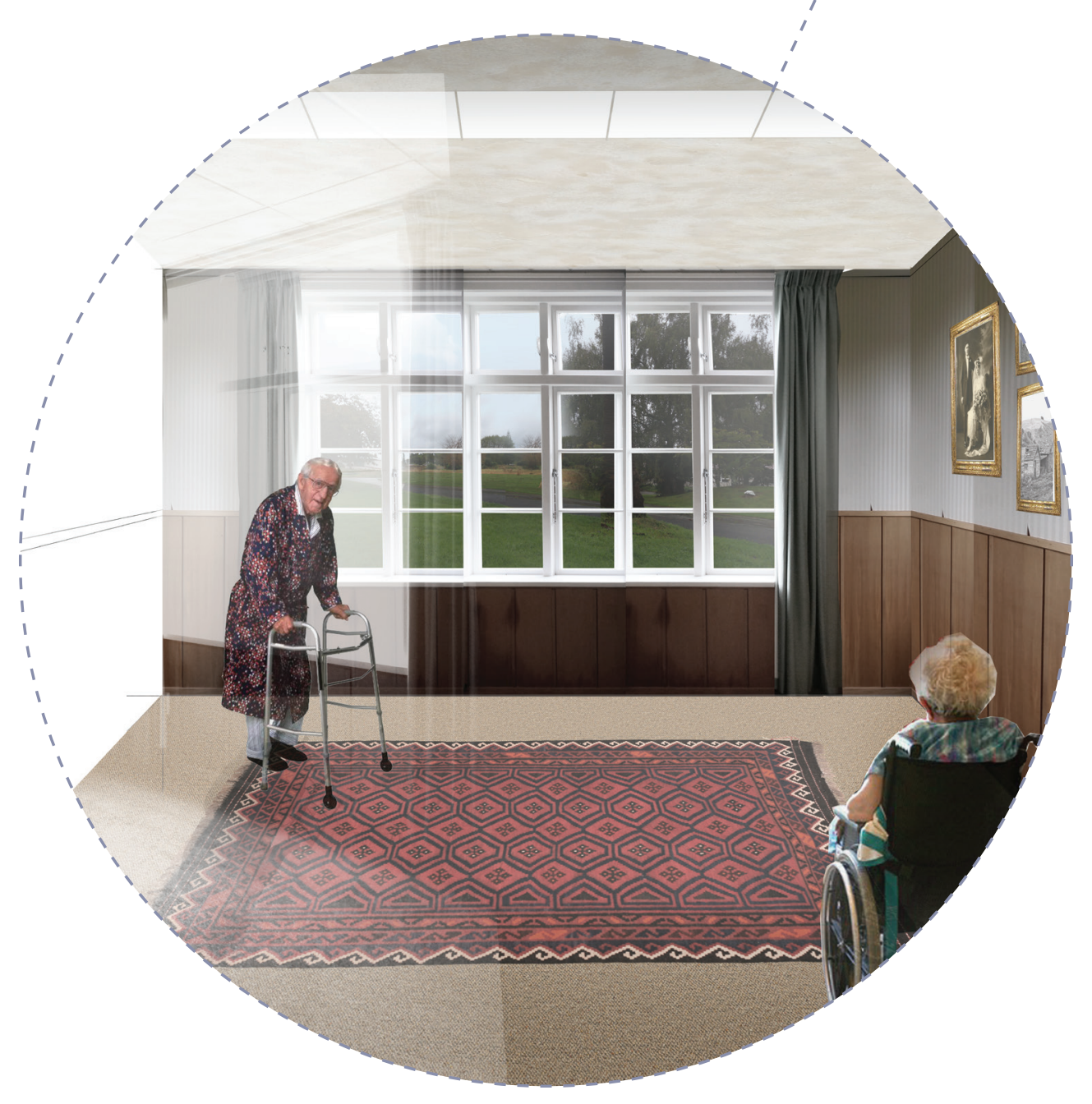

$5.5 .4 \mid$ (above) First devised floor plan

$5.5 \mid$ (above) Initial public space 


\subsection{Breakout Spaces}
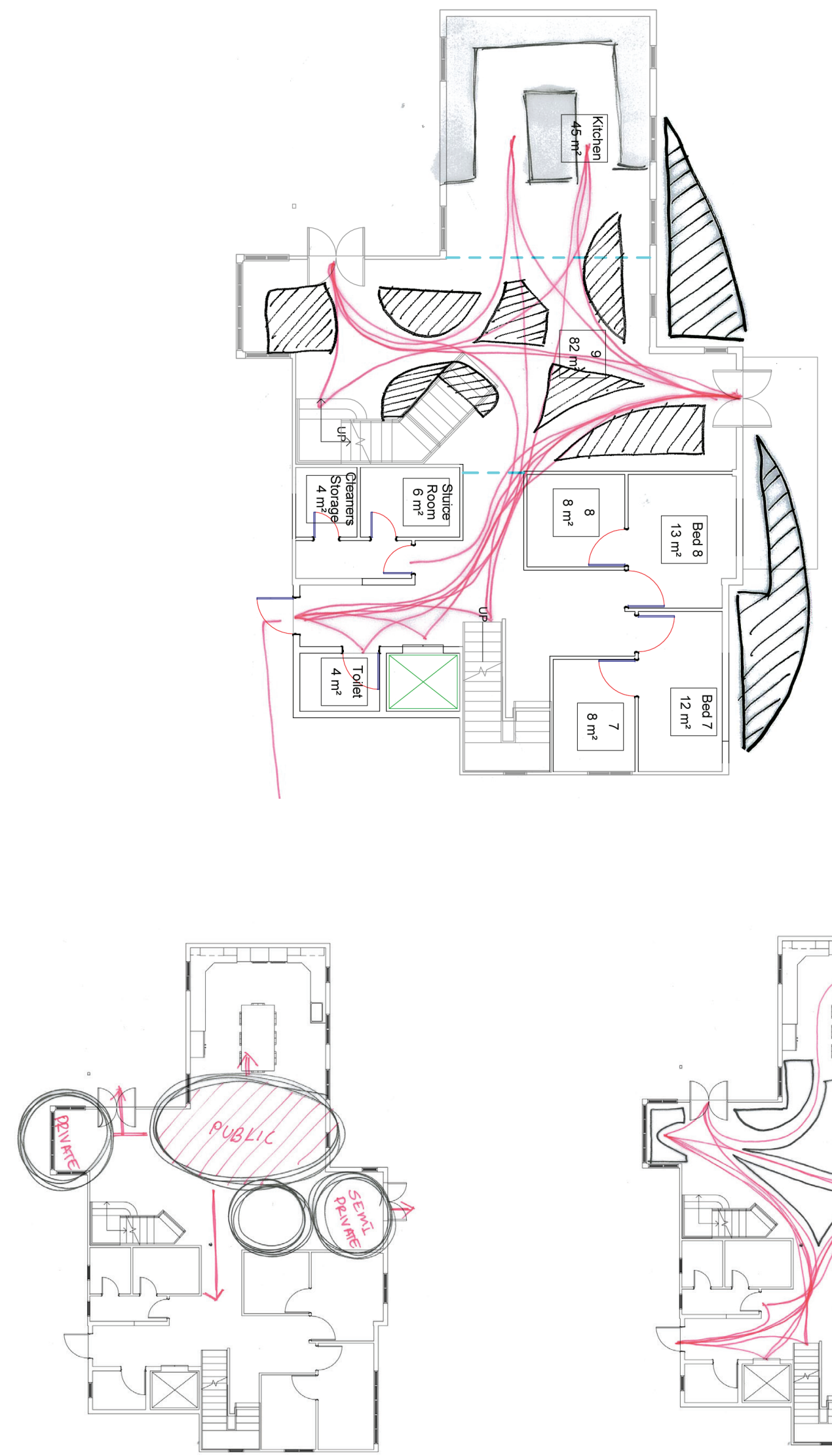

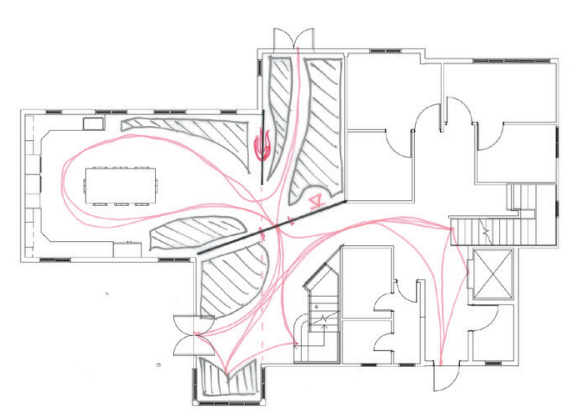

Layout 1

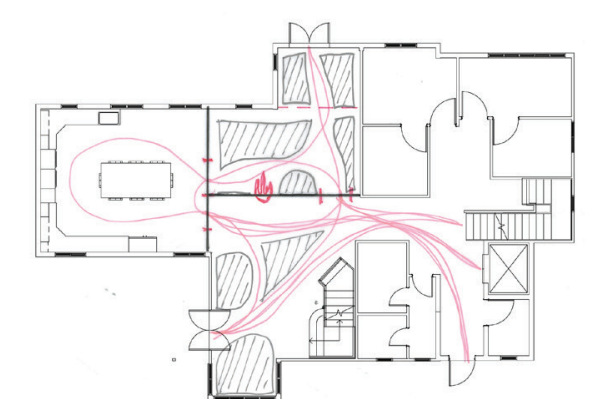

Layout 3

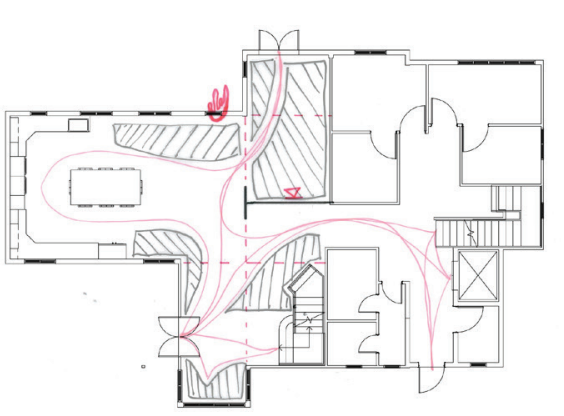

Layout 2

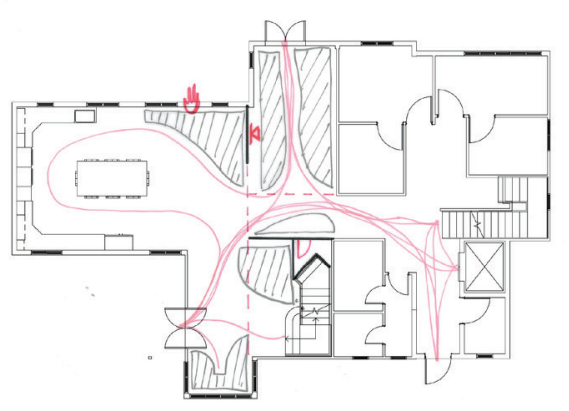

Layout 4

To provide spaces that cater for both social and individual activities and reflect an adapted version of rural interior design, barriers need to be introduced into the current open plan living. Through initial analysis of the open space, four layouts have been explored, which would allow for the necessary segregation of programme elements. These layouts look at both lange and small seang clusters, and prow activities would be performed within. Creating walls that entirely cut off rooms may also cause confusion to the residents. Walls that partially divide rooms would be best. 

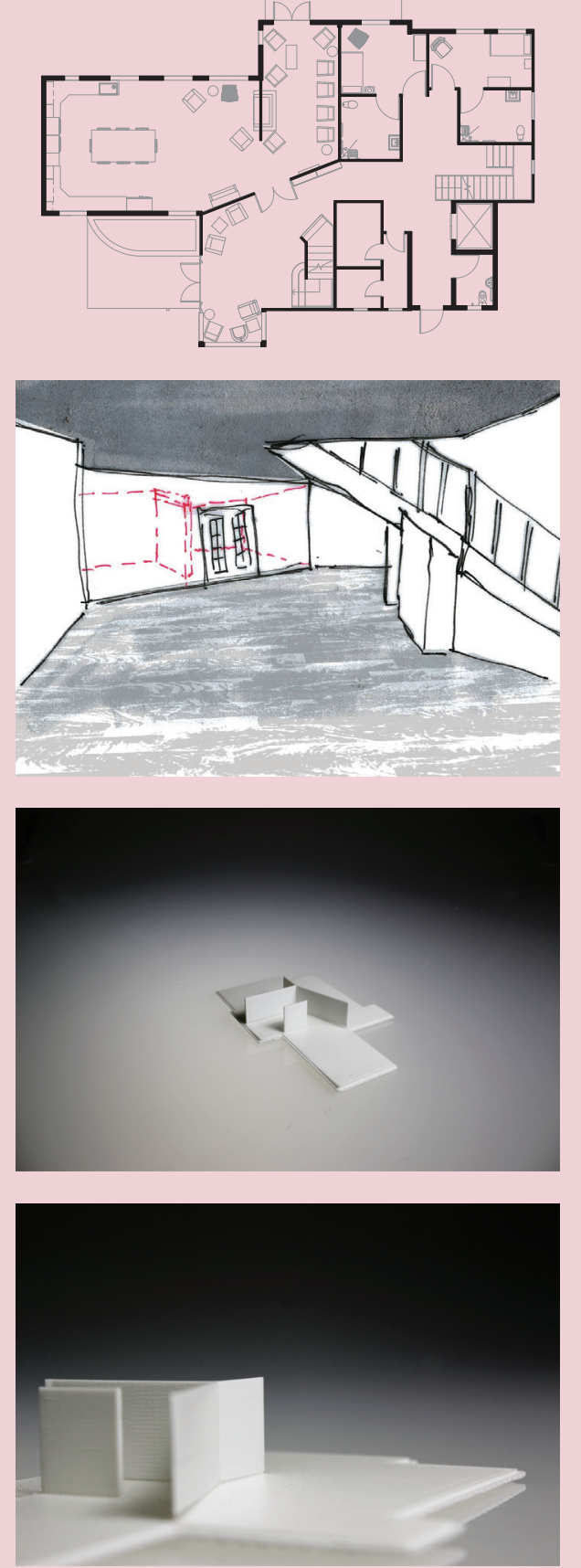

An angular wall drawing people from the entryway down the corridor aids in wandering between the two staircases, and avoids sharp corners. Main segregating wall could put off resident from wanting to enter kitchen area.
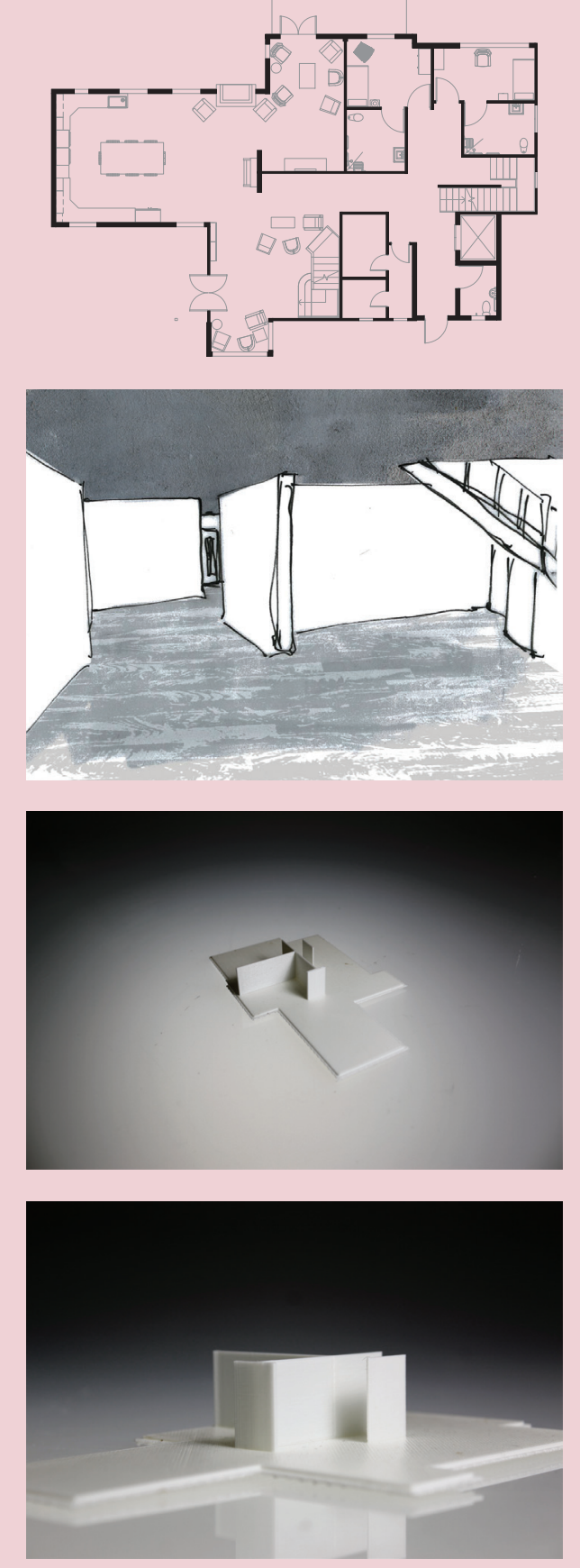

Partial segregation of spaces creates three areas still interlinked. This layout encourages wandering between inside and outside, and between the two staircases.
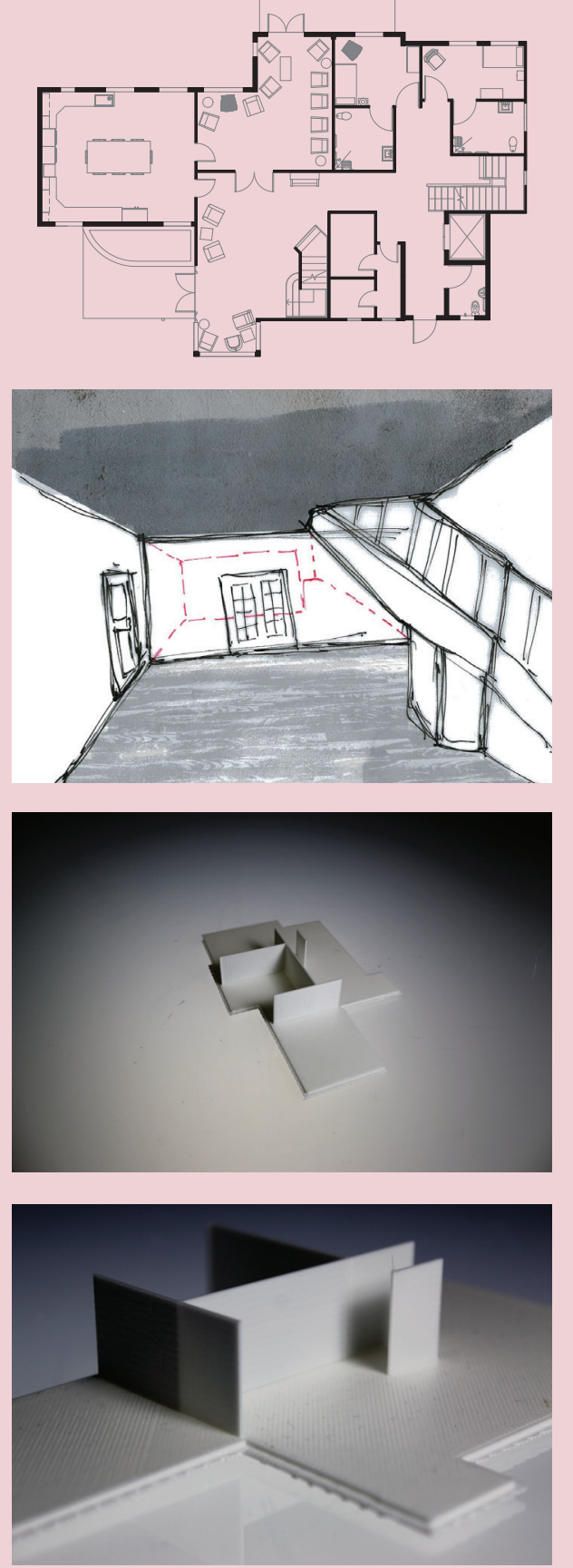

Full segregation of spaces. Kitchen area, and two living areas have no visual connection. Similar layout to

historic houses where corridor is used

to connect all rooms. Limits interaction between residents.
Layout 4
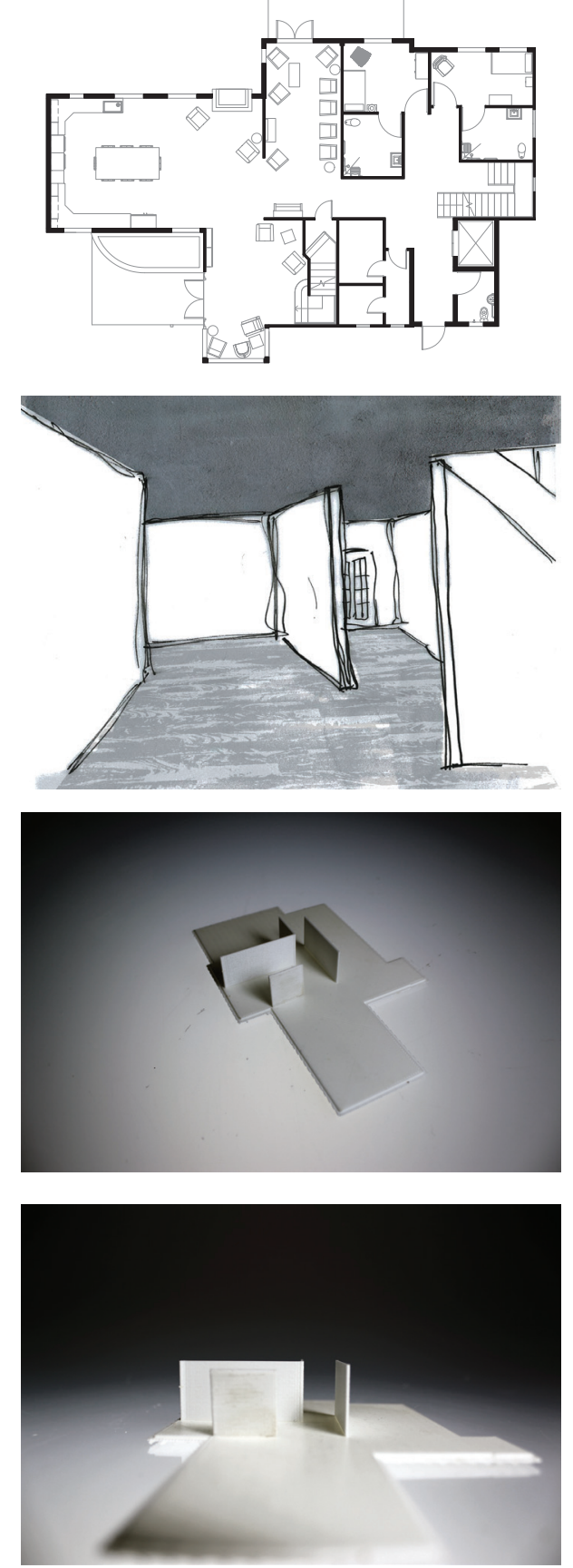

Semi-partitioned walls segregating spaces. These spaces have limited visual connections but can be seen when wandering down the centre of the facility. Partition walls create narrow spaces which become problematic when arranging furniture, and considering residents with walkers. 

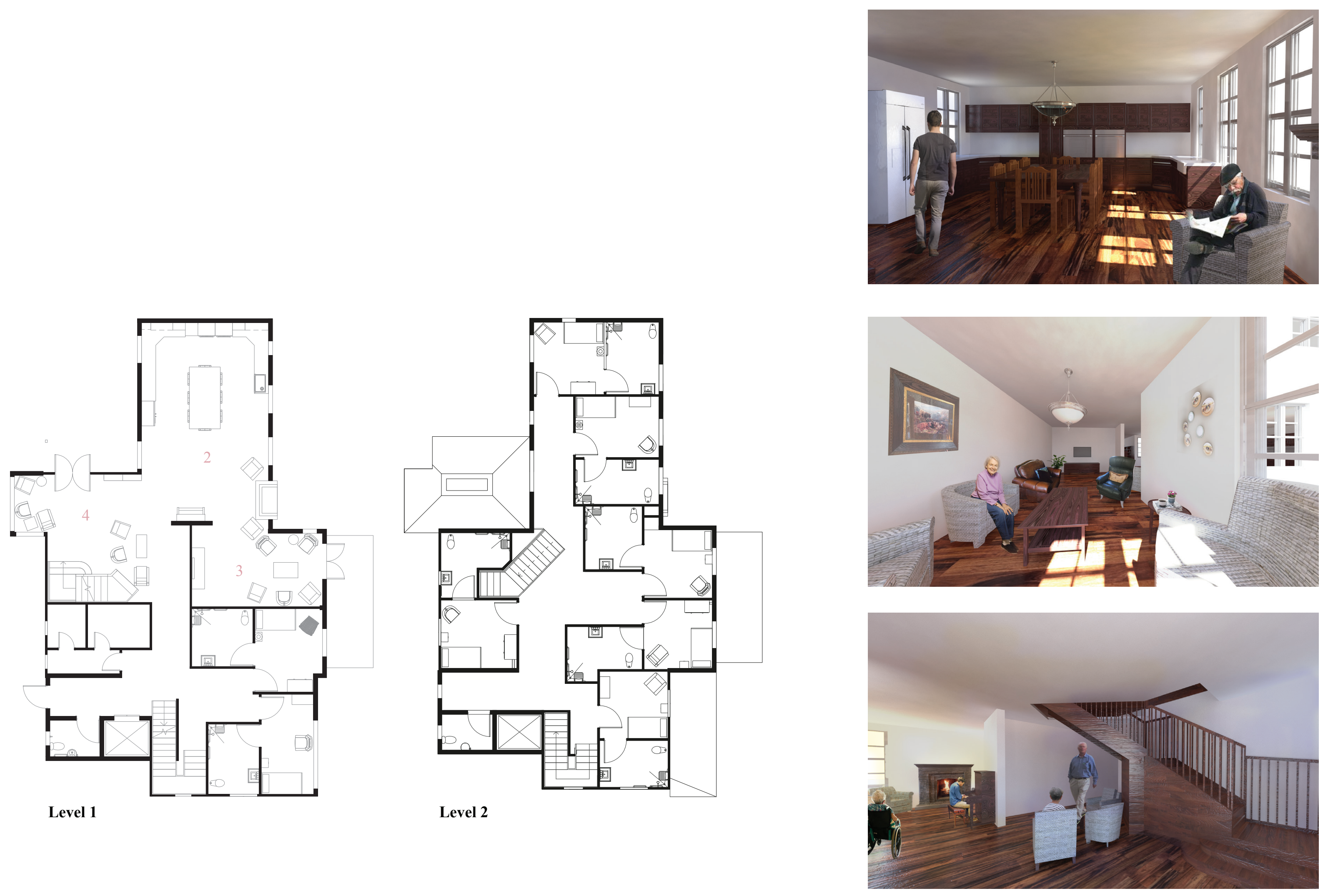

5.7.2 | (above) Kitchen design 5.7.3 | (above) Lounge design 5.7.4 | (above) Entry way
Rectangular table defines and another. Circular table allows a resident to reach around to grab someone else's

Wooden chairs allow ease with slideing from the side Material is easily cleaned.

With the limited number of residents there is no need for an industrial kitchen. An open kitchen encourages residents who are able to help with prep and get their own snack or cup of tea.

The option to bring residents' personal furniture makes a space more home-like, also provides them with a connection to past life.

With familiar objects such as fixtures, fittings, and decorations surrounding residents' the facility looks less like an institution and more home-like.

Timber flooring is a common feature in rural homesteads, and is present in the existing movement with wheelchairs, walking frames, and residents who shuffle. 


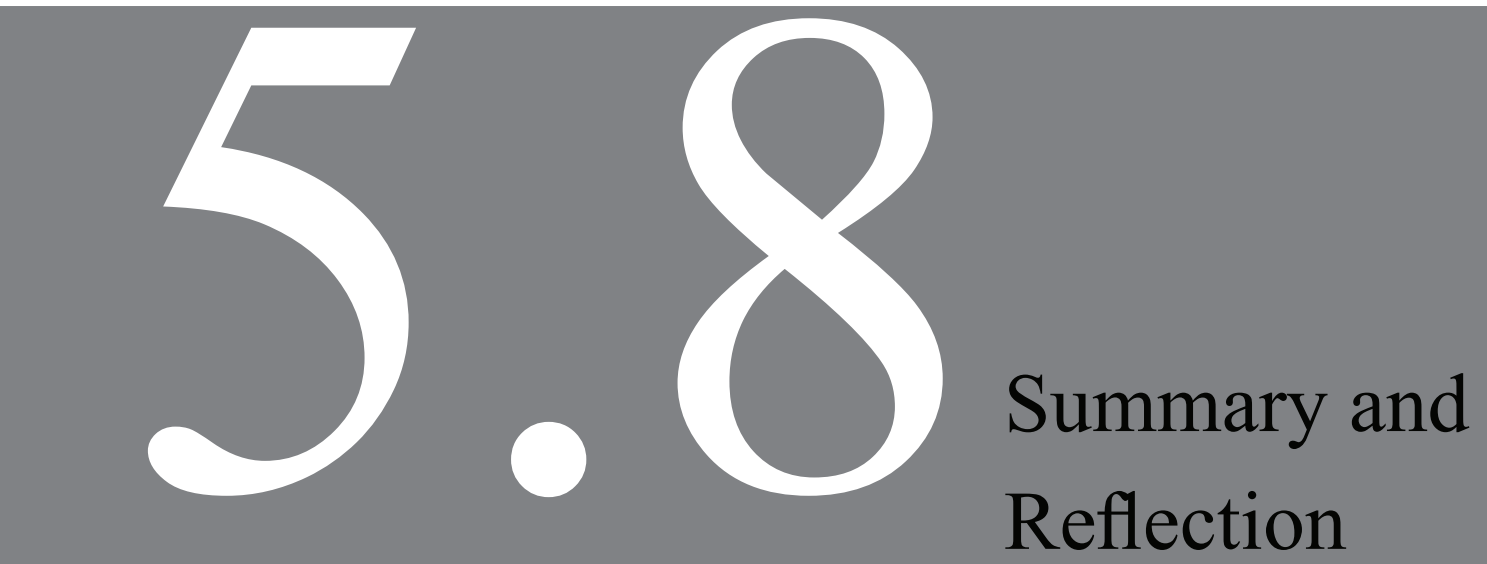

This initial design phase looked into the site in an in-depth manner to establish a connection between the existing buildings and those that are visually identified as 'rural design'. The outcome of this resulted in the choice to keep the historic context of the site and retrofit one of the buildings for use as a dementia centre. The selected building holds significant characteristics which are congruent with rural design, such as fenestration and design details, use of local materials, and interior layout. This re-enforces a connection with the residents' past lifestyles. The exploration of the surrounding landscapes to ensure visual stimulation for residents also provides connections to prior daily routines. The concept explores circulation options through tering and wayfinding.

Positives:

-Problem and programmatic requirements for design decisions are clear

-Spatial elemental gives consideration to facilitate circular wandering

-Choice of site provides building and landscape qualities congruent with that of a rural landscape

-The site is historically appropriate as prior uses also relate to the nurturing of these rural people

-Incorporates exploration into aspects of design which are determined by dementia

-Design highlights aspects of light to ensure wellbeing in residents

\section{Things to consider:}

-How far can the building be manipulated to benefit the residents with dementia, without losing the physical characteristics associated with rural design?

-How can the interior frame the landscape views more effectively, as if the farmer is looking out onto their farmland?

-How can the community/family visiting interact with the surrounding site as well as connect with residents and site?

-How can landscape techniques be used to create natural barriers between the dementia centre and the community aspects? -How can landscape be used indoors to create abstracted stimulation?

-How can aspects of the design be adjusted to incorporate features that relate to a personal scale?

-How can the addition of materials and colour benefit the residents?
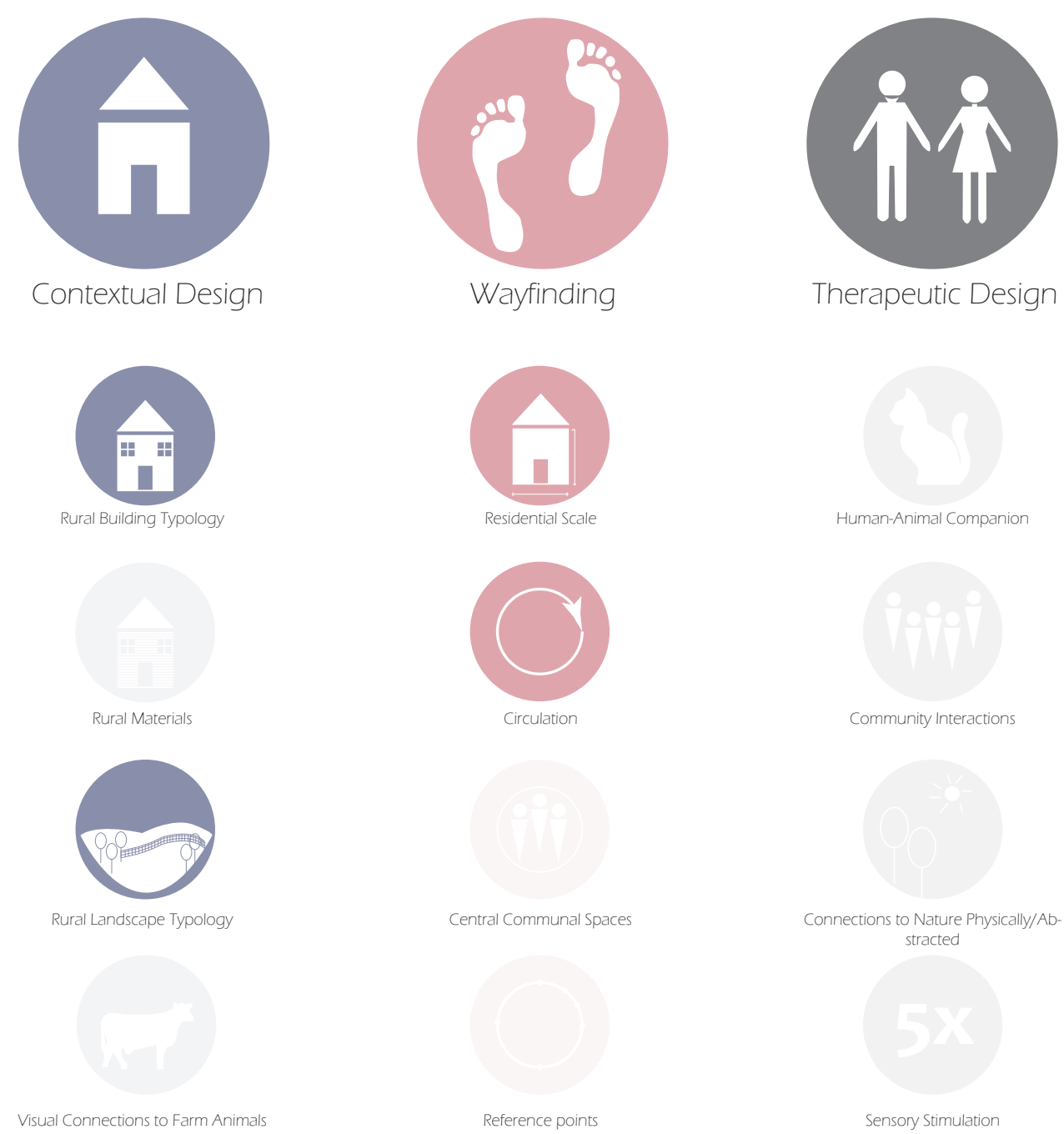

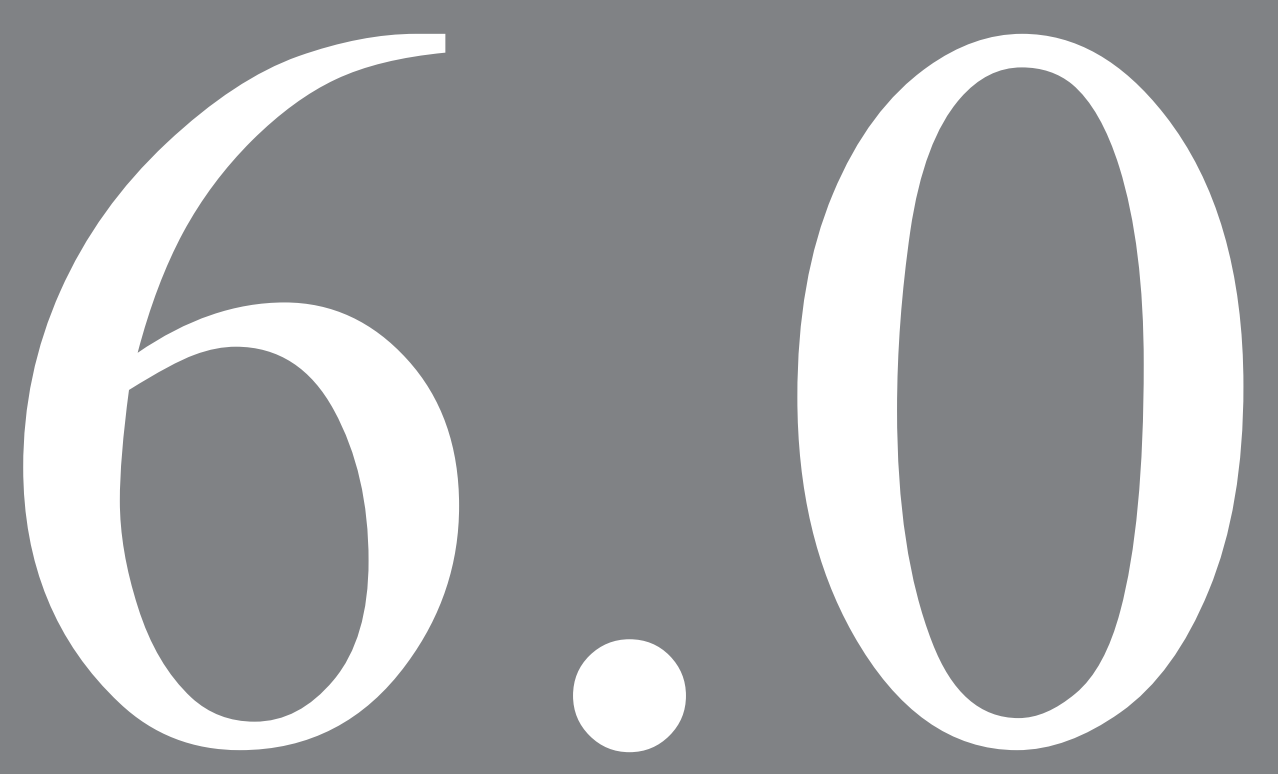

Design Phase 2 
<smiles>C1CC2CCC(C1)C2</smiles> 


$$
\begin{aligned}
& 80 \\
& \theta 0 \\
& =40
\end{aligned}
$$




\subsection{Bathroom Design}

The bathroom is a place that can either make a room feel like a home or like an institution. Materiality and familiar appliances will change the atmospheric qualities of the space. Features are required to assist the residents with less mobility and there must be room for staff in the bathroom. An exploration into types of sinks show which would best suit the bathroom for the programmatic purpose. The selected sink allows for ease of cleaning but also provides sufficient surface area on top for personal items.

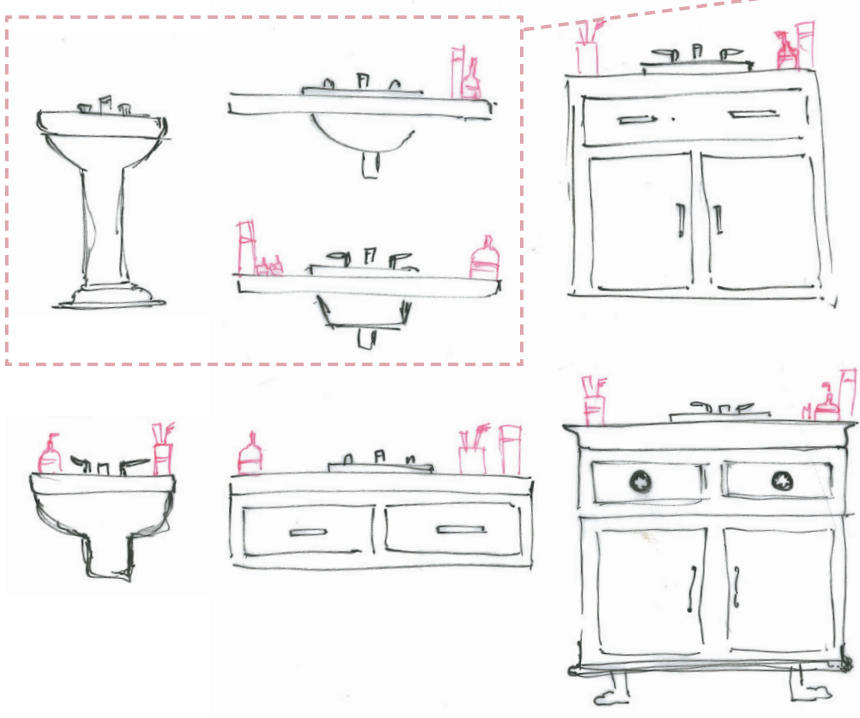

Deteriorating eyesight is commonly linked to dementia, impairing depth perception, spatial orientation, colour perception and the understanding of contrasts. To modern white bathroom design is not functional for the person with dementia. The toilet, flush buttroom design is not functional for the person with dementia. The low cognitive ability and failing eyesight. These features also need to hold some semblance to historic design to trigger memory and routine.

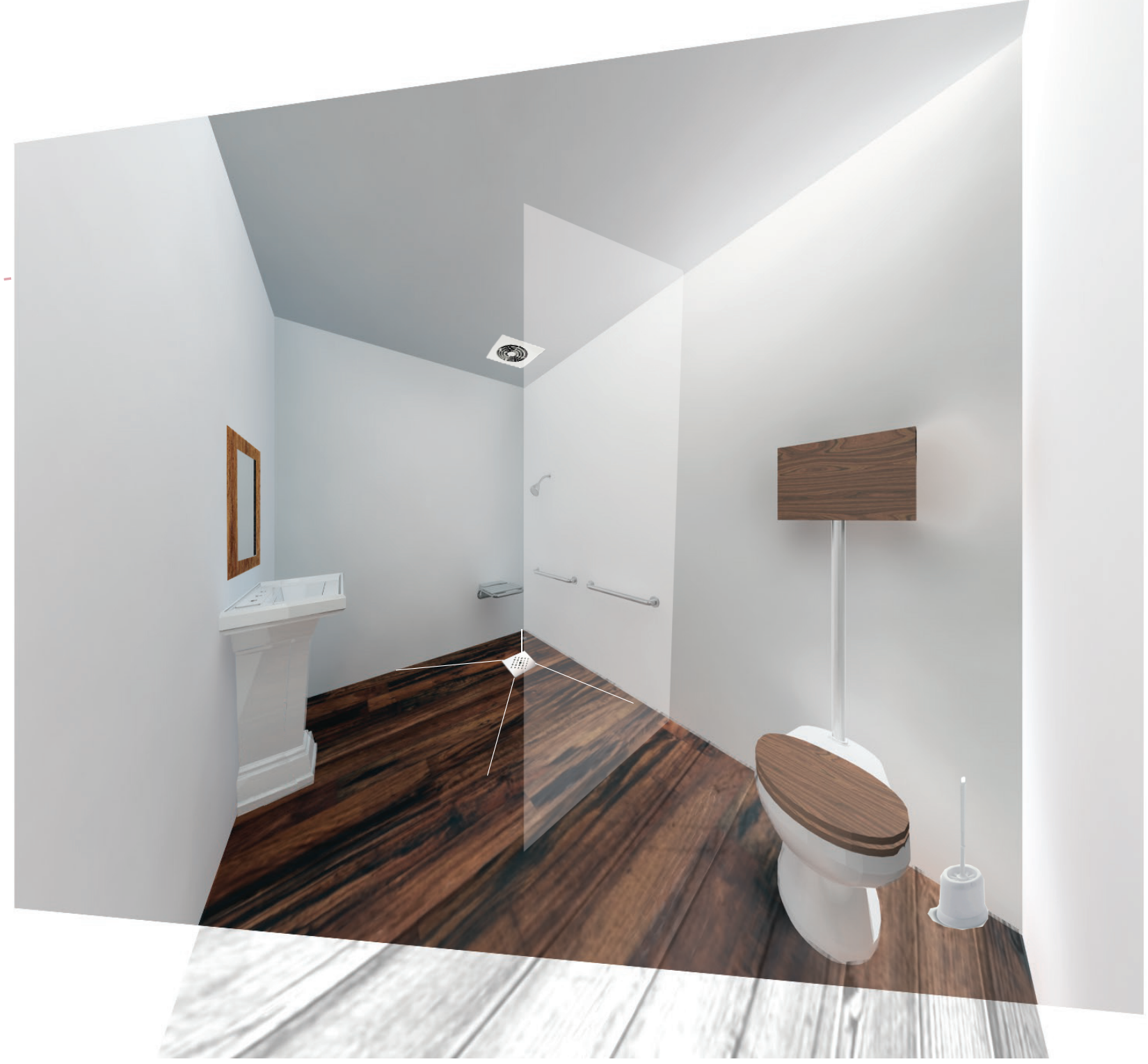

Our most successful bathroom has bright yellow walls that really distinguish the walls from the floor and in that bathroom we have a wooden toilet seat. They can all see that toilet and the comment has been "It's like home" probably from their childhood

- Questionnaire answer 


\subsection{Bathroom Visuals}

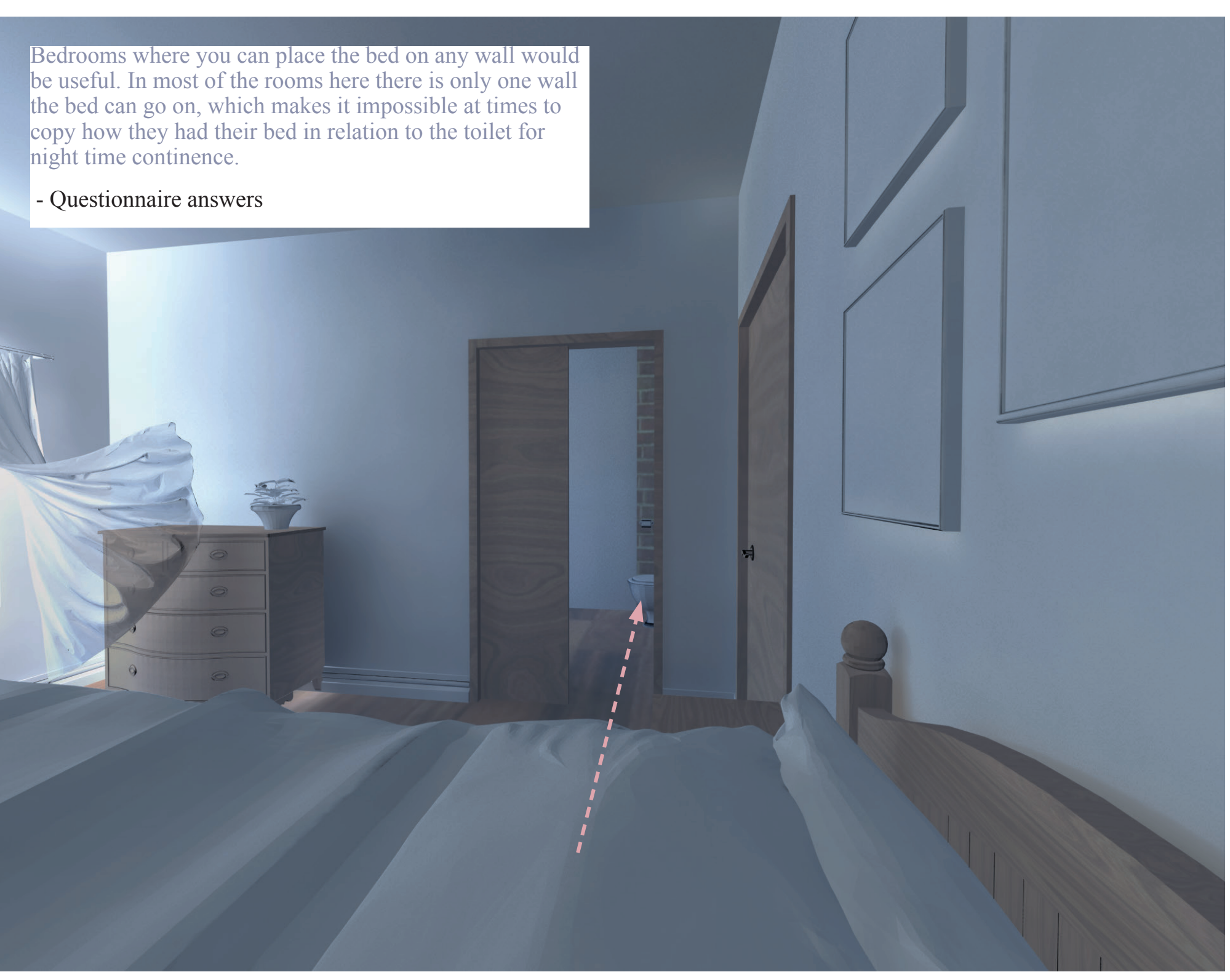
Ensuring that the bedroom layout provides physical features or clues that are familiar
to a person is important to the design of the room. With short term memory loss, to a person is important to the design of the room. With short term memory loss, the dementia resident is forced to rely on memory, which provides difficulties with

visual connection to the bathroom is important.

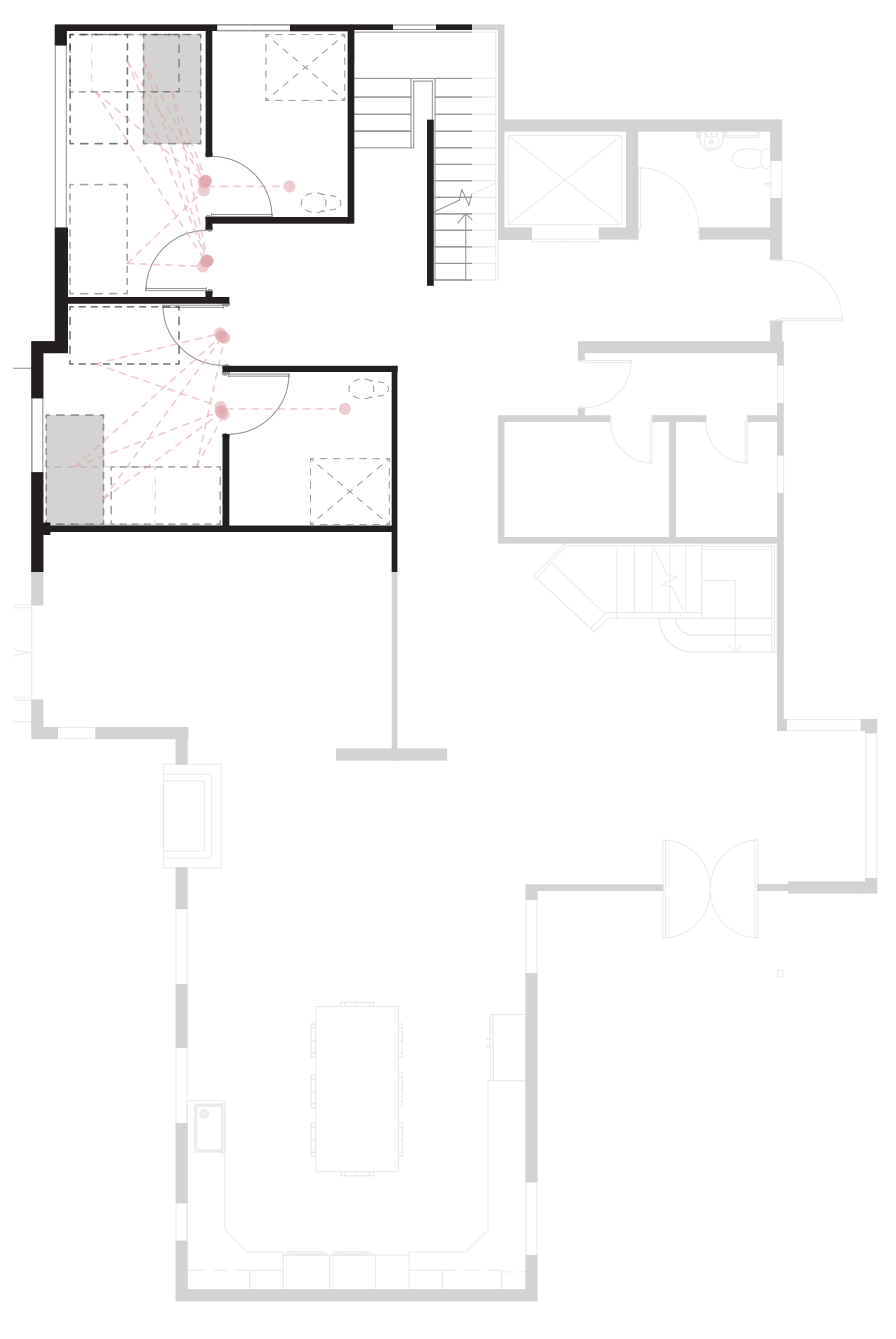

Bed (2000mm x 1200mm)

Shower

Toilet

Visuals to toilet from bed position

No visuals to toilet from bed position

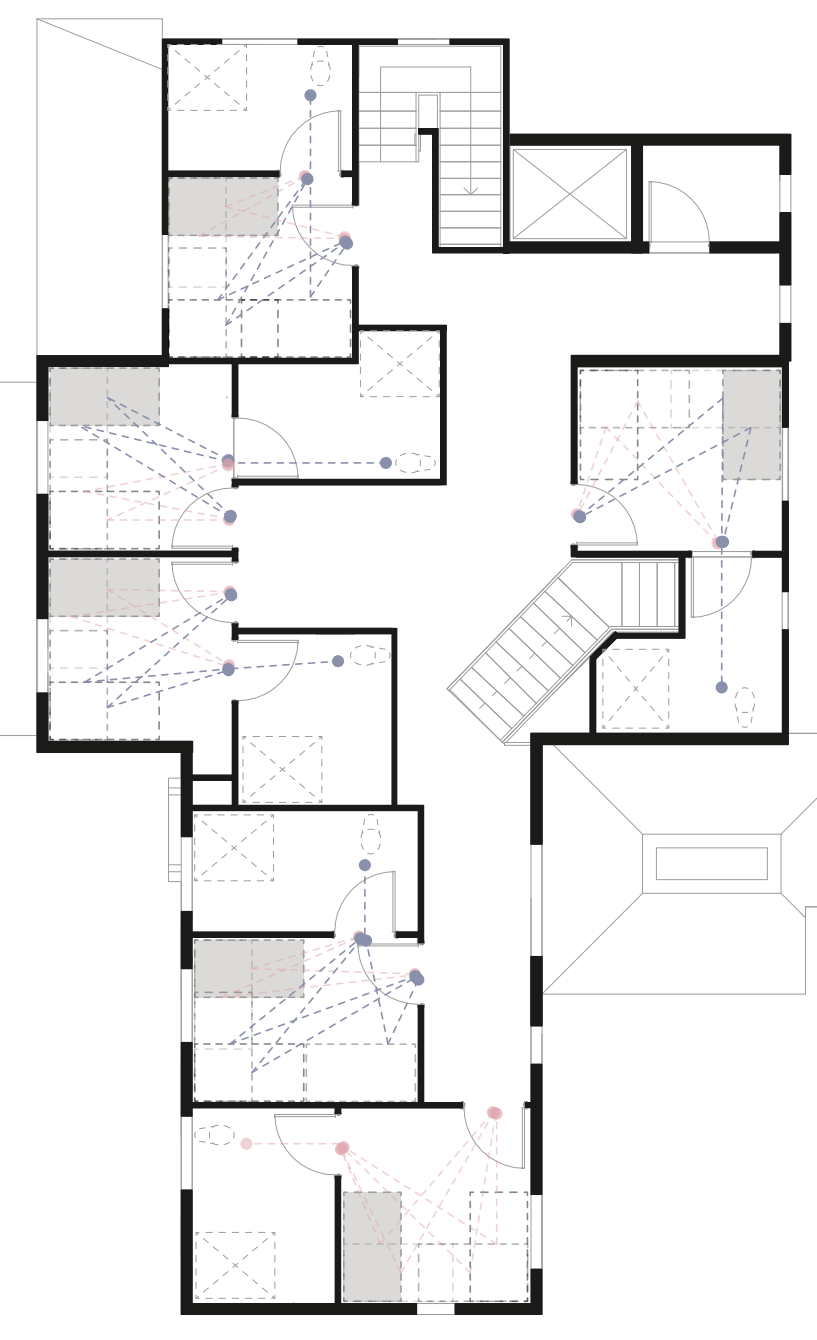



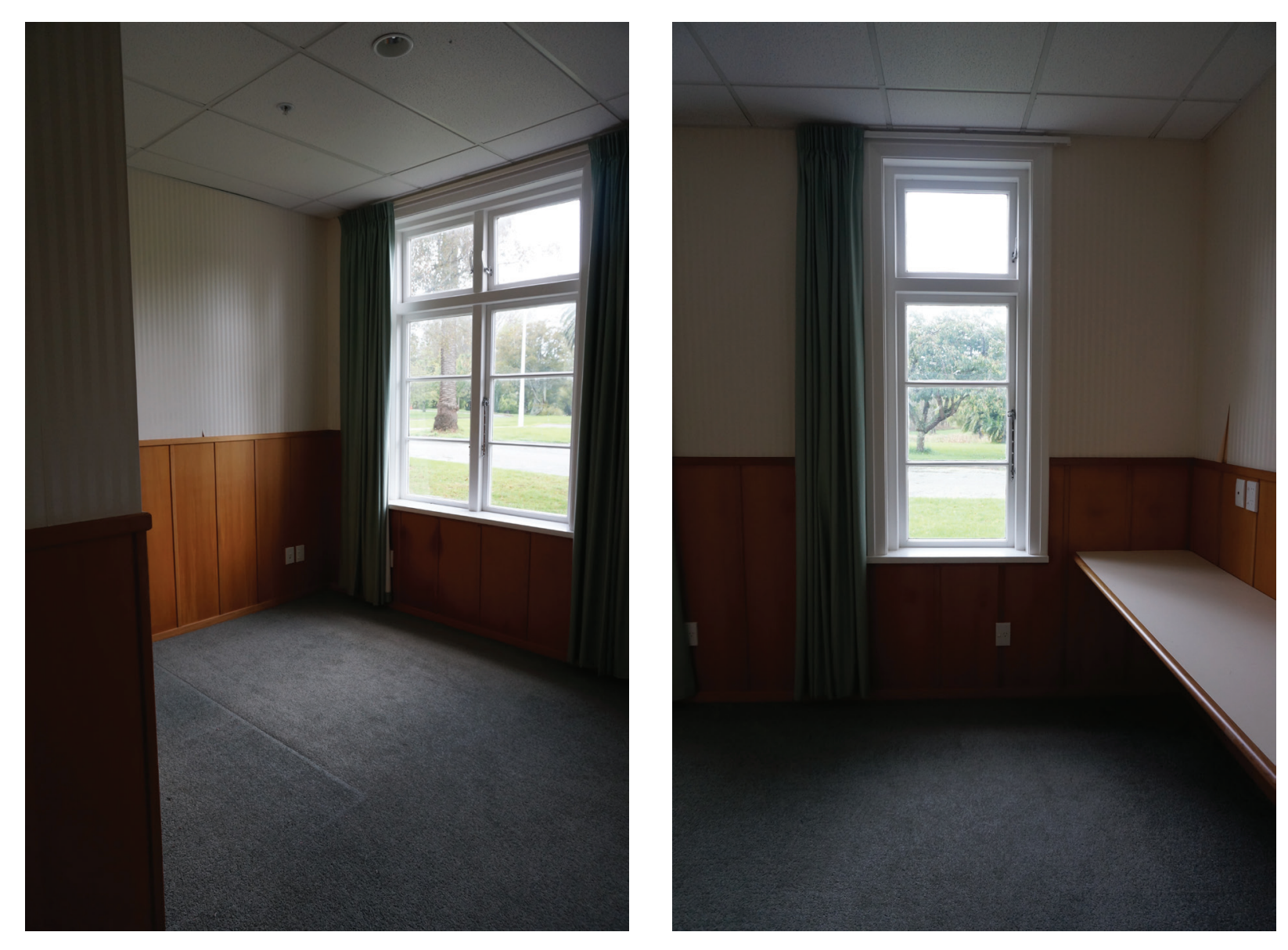
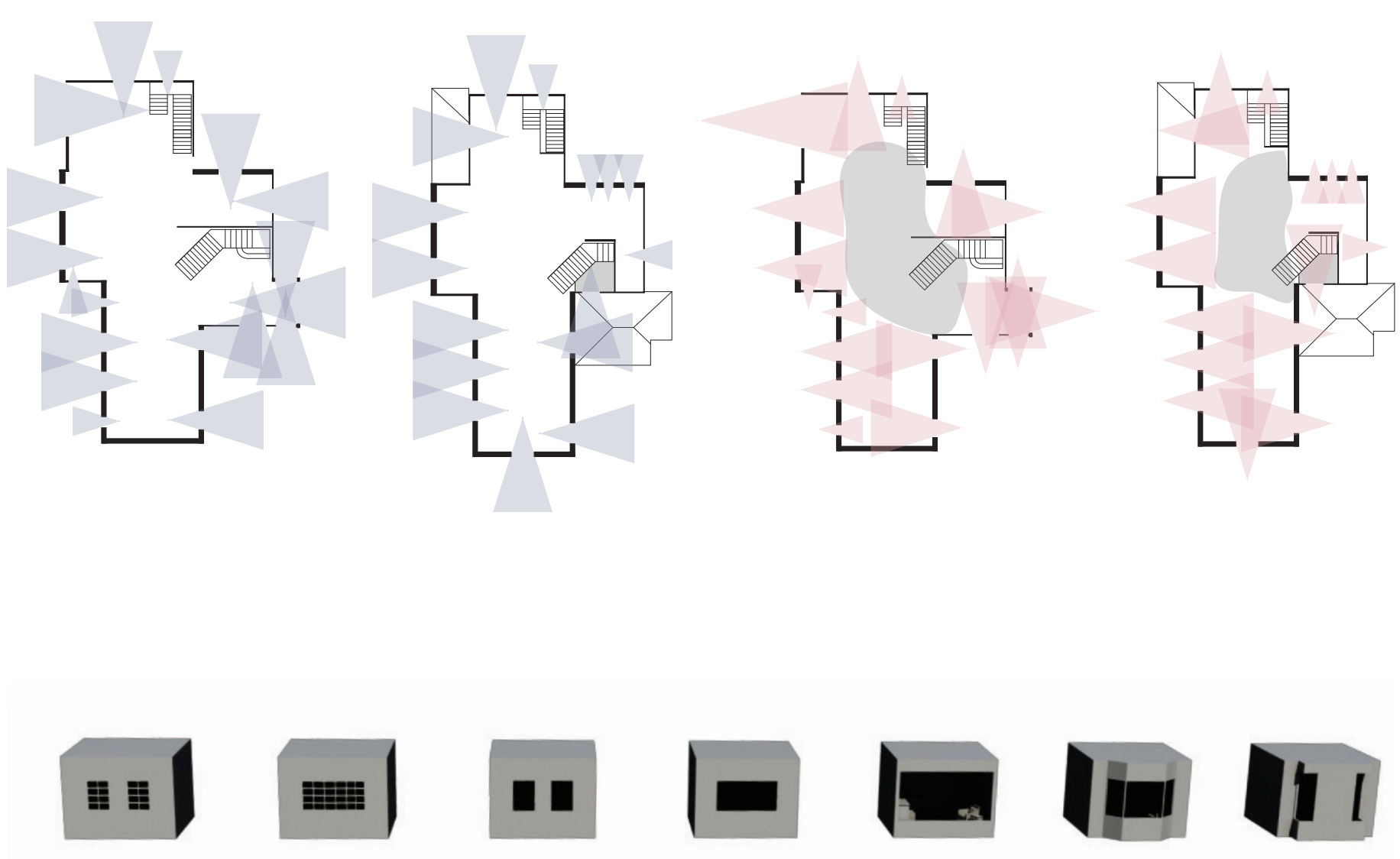

Another important aspect of designing for dementia is to ensure that people are receiving enough daylight, or can receive light therapy. The existing windows allow suit each bedroom and enter in the mornings. This will also increase the external viewing space for the residents, allowing them to see more of the surroundings. The design of the windows is congruent with the style of the house and acts as a familiar feature in the room. Ways in which the windows could be adapted to enhance this natural light have been explored and tested using a lighting analysis strategy. Figure 6.45 shows a series of iterations that encompass modern and historic window treatments to evaluate the lighting qualities inside an eastern-facing bedroom.

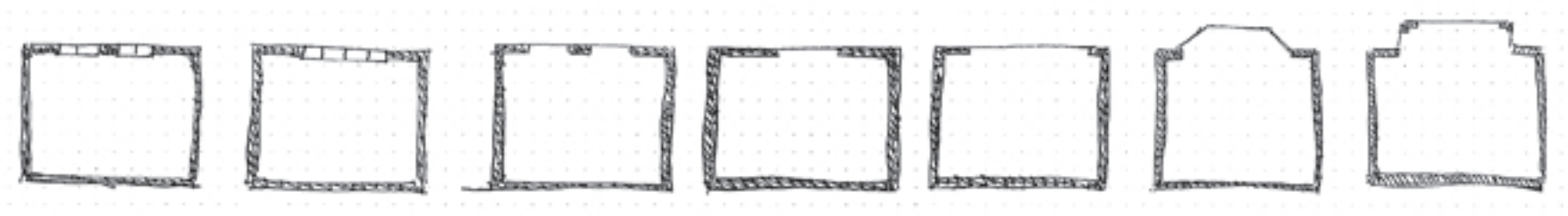




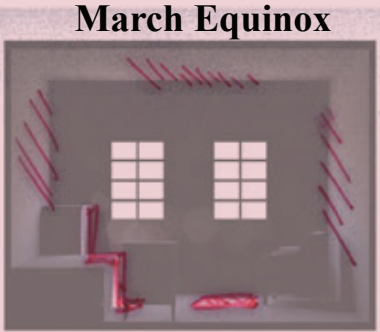

Current windows have low light levels, bu of windows

Similar design, larger opening allows more light in, and creates a bigger viewing port
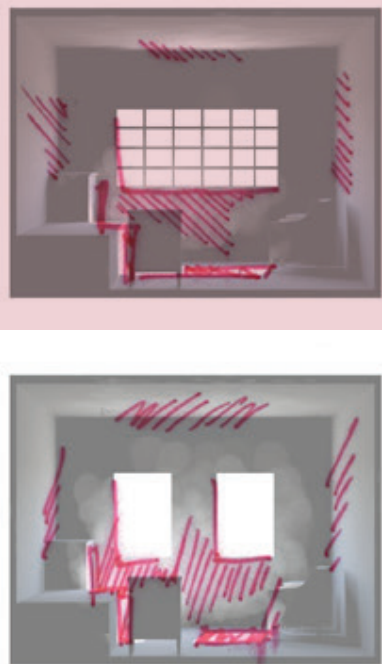

Same sized opening, single pane of glass lets in more light than the fram
windows; issues with ventilation.
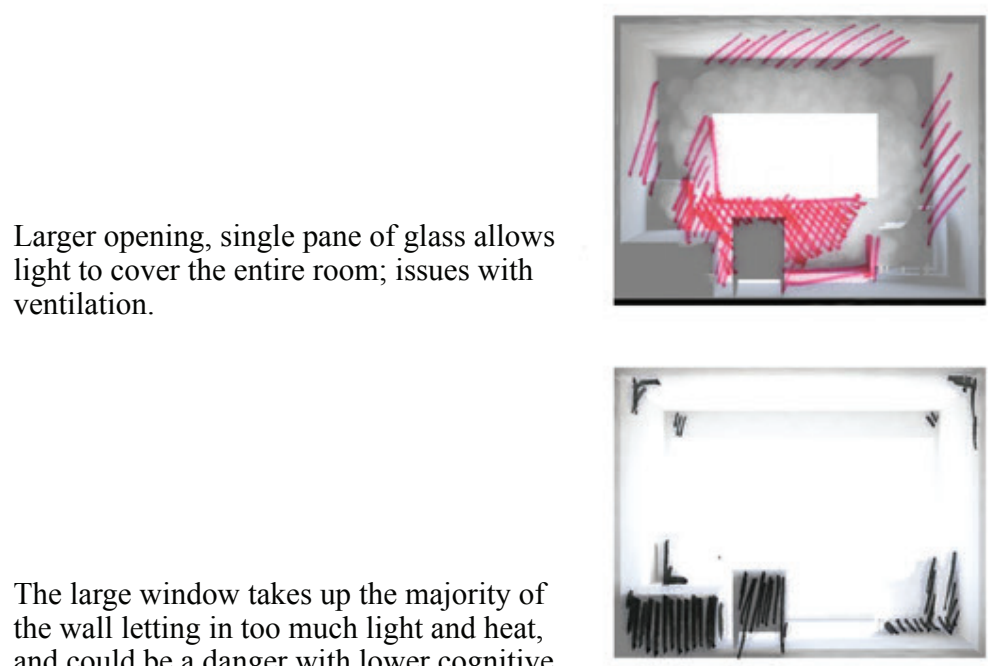

The large window takes up the majority of and cold be a too much light and heat,

Bay window design lets in too much light, and would make the room too warm in

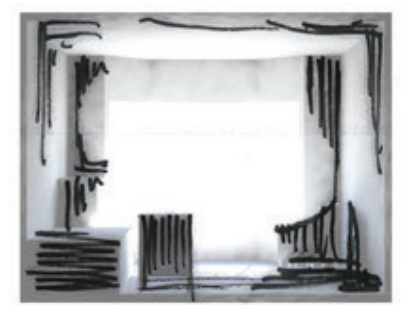

Corner windows let in light which covers the entire room; the design is a radical move for a rural typology, and would mean
giving each room a section sticking out of

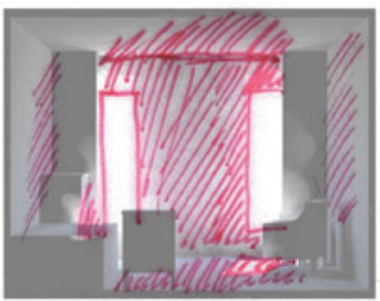

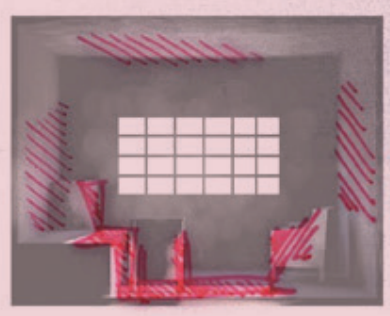

June Solstice

是
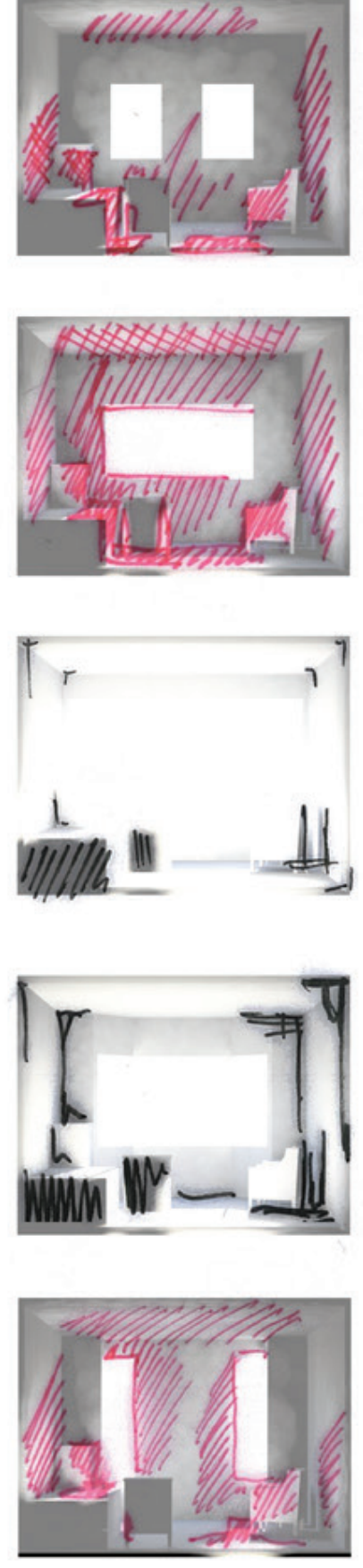

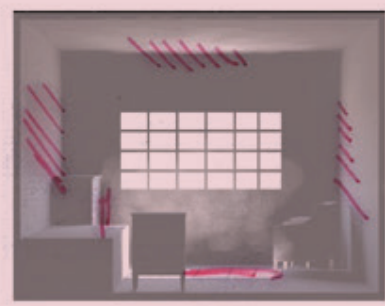

是

September Equinox

December Solstice

\#
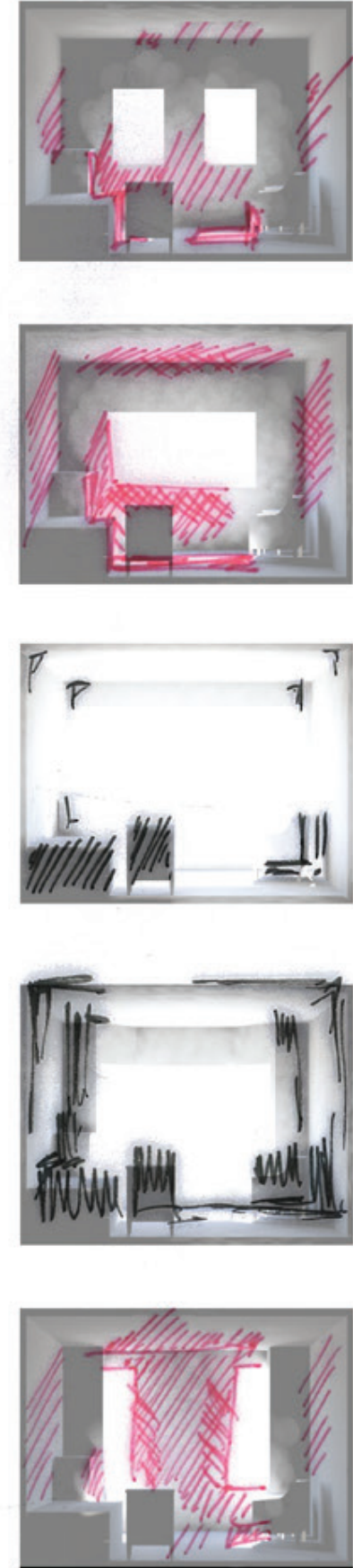

+ +
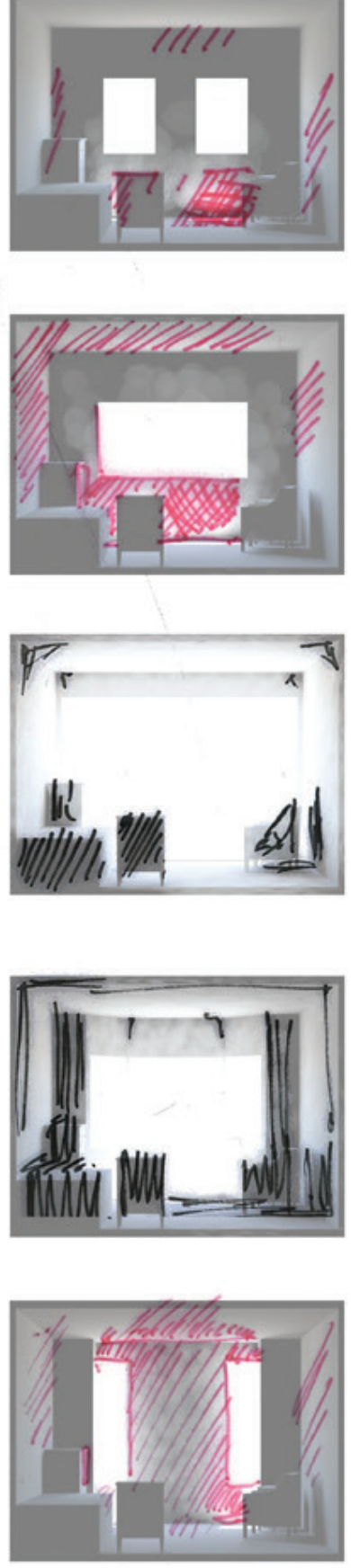


\subsection{Natural Ventilation}

A benefit of the existing windows is control over how they can be opened to allow natural ventilation. The windows all currently open with hinges on the side, creating a fall risk hazard for items that can fit out the window, or the possibility of a resident trying to get out a window. Ensuring that the windows cannot be opened to such an extent will prevent such hazards. Possible alternatives

have been explored to maximise the release of hot air out, and the entry of cool air in, without blocking the view of the surroundings. A combination of fixed and opening window panels will ensure the room is appropriately ventilated in all seasons.
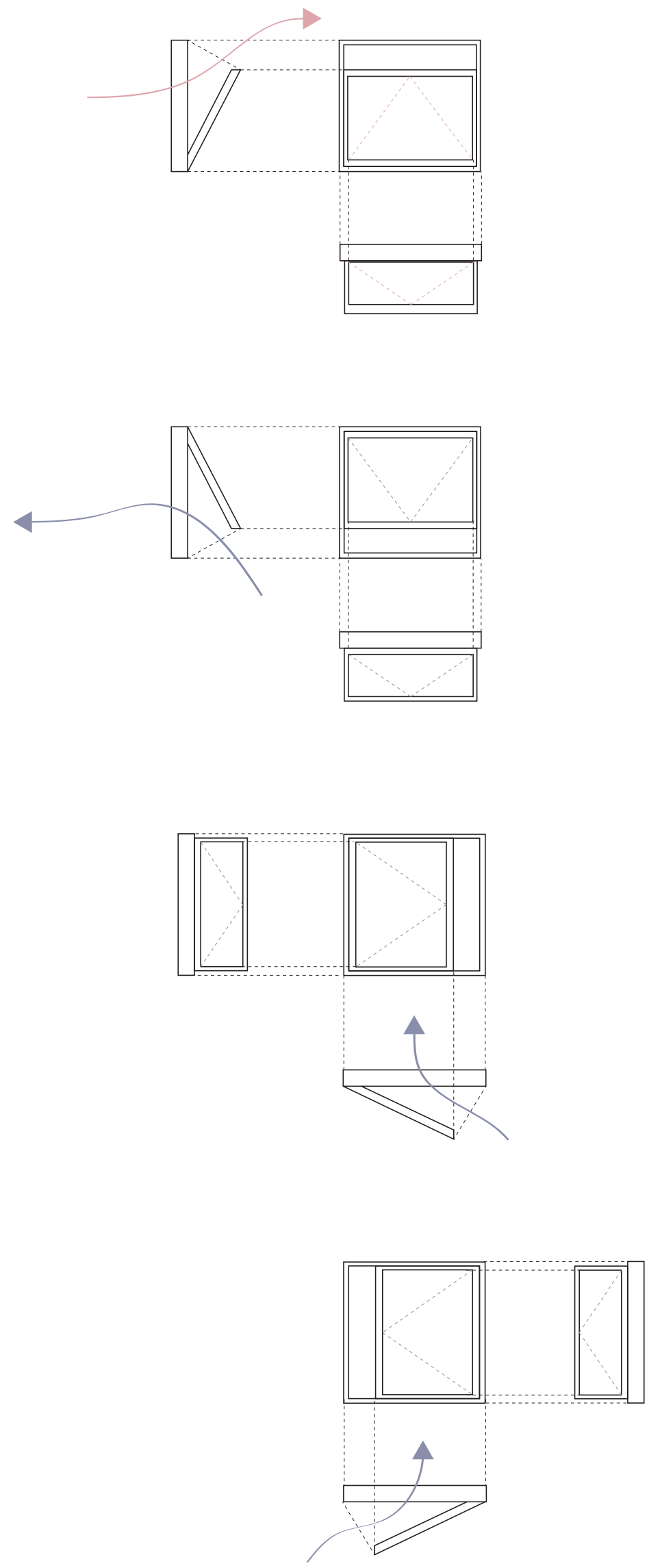
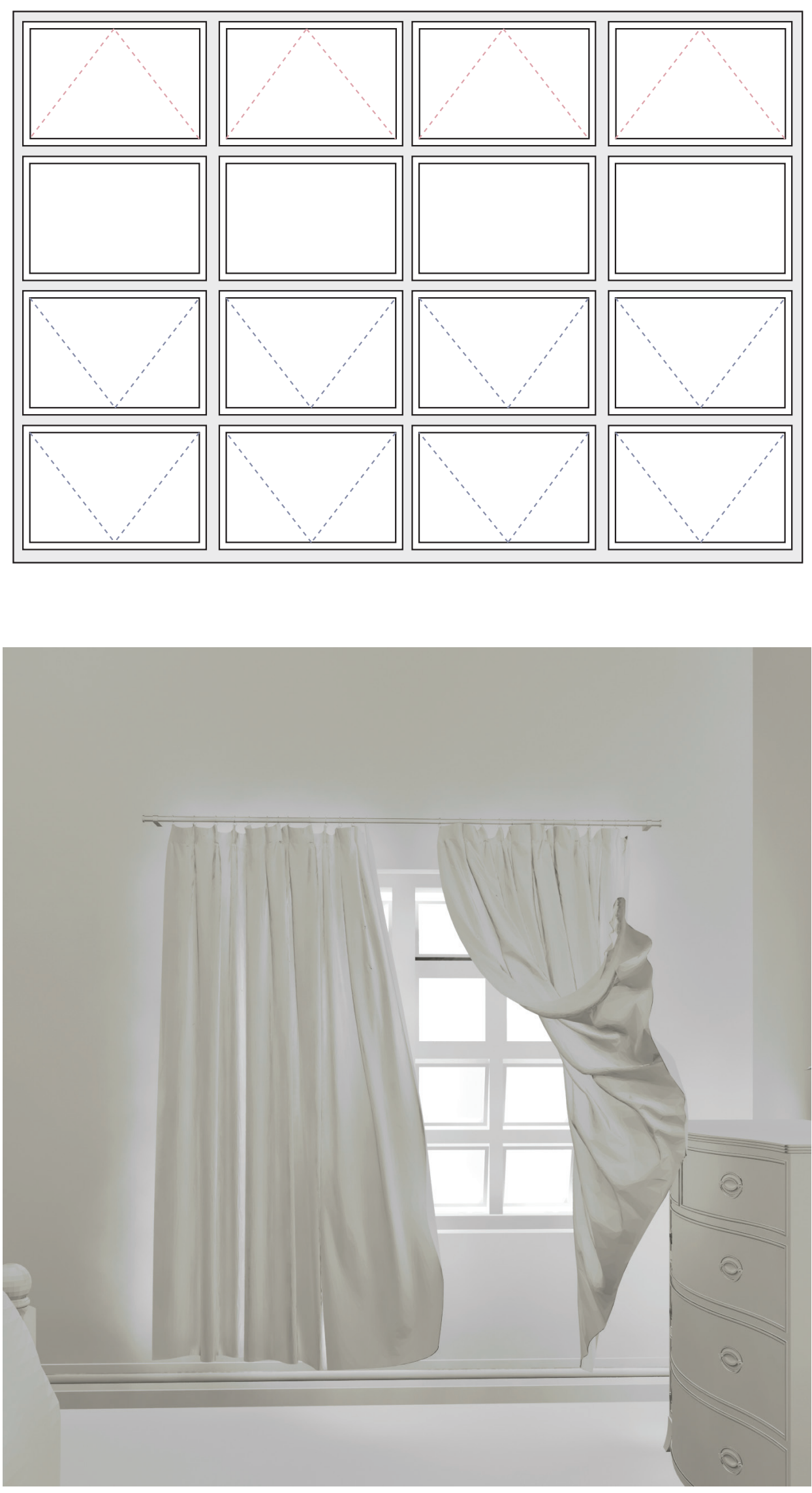

6.5.2 | (above) New window layou 6.5.3 | (above) Air movement 


\subsection{Artificial Lighting}

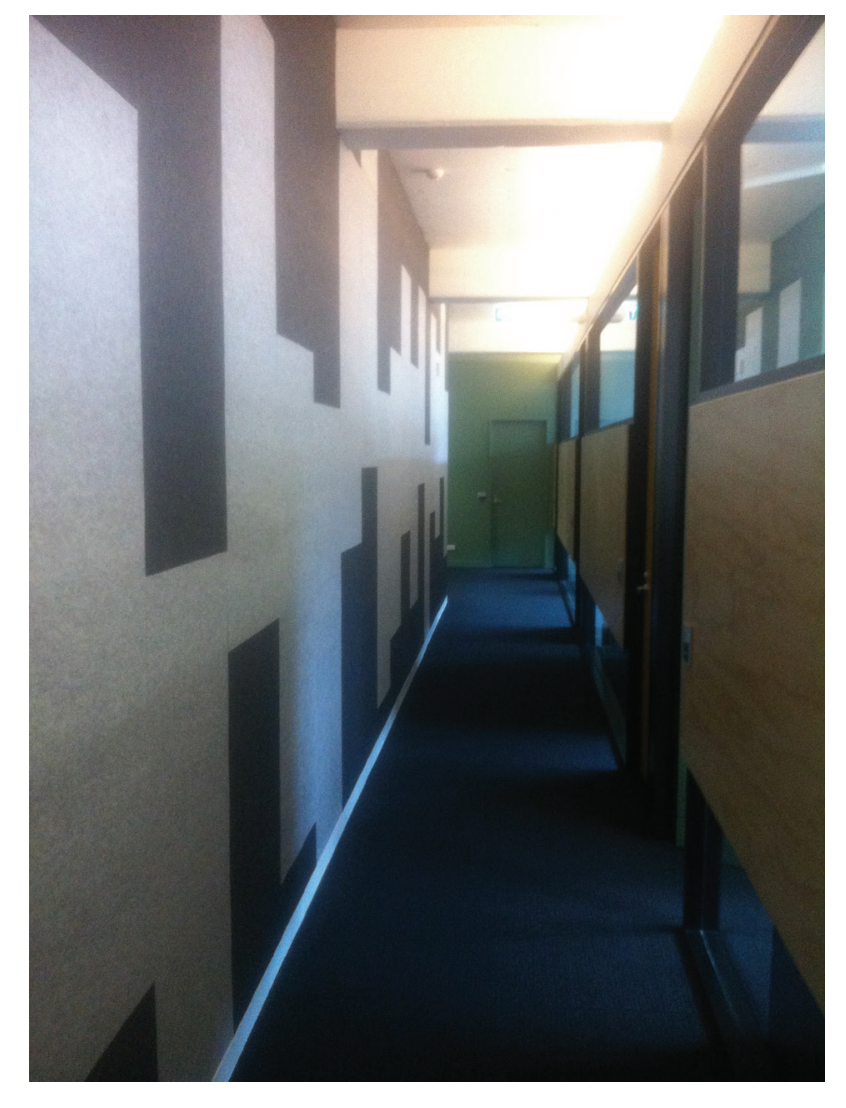

A new feature in leading dementia facilities is light therapy. This is produced through ceiling panels which emit blueish-white light. These are turned on in the morning to reduce agitation later in the day, and allow residents to get better sleep at night. The blue light is often used to slowly wake residents up in the morning as the dimmer automatically increases. Studies have shown that this blue light is most effective in the morning, and reduces bad behavior of a person with dementia.

Visiting a leading research team at Massey University Wellington at Massey University Wellington the light room they created to test light therapy (fig.6.6.1). This to test light therapy (fig.6.6.1). This method of controlled light has been proved to be positive for people with dementia (Gibson).
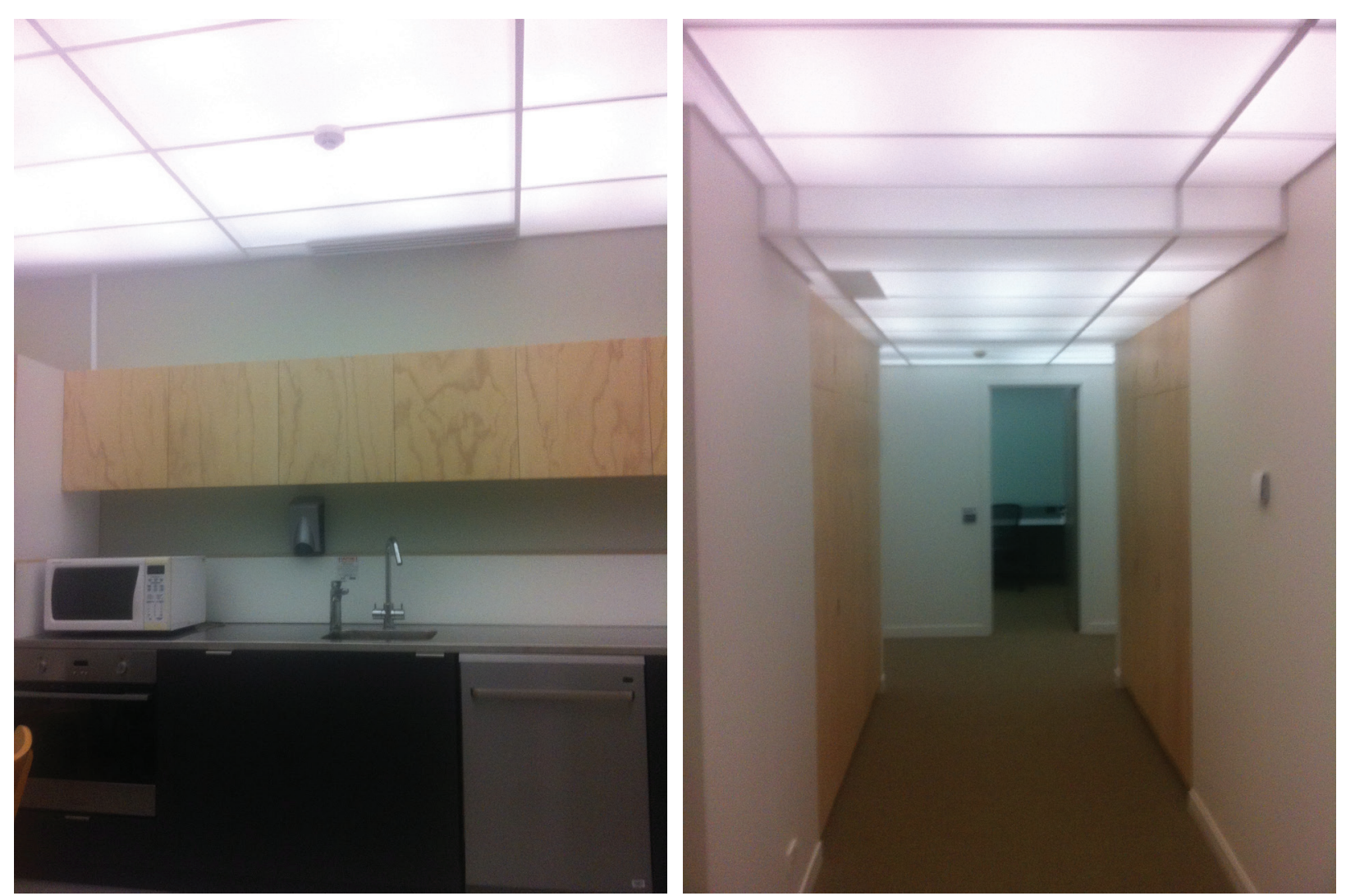
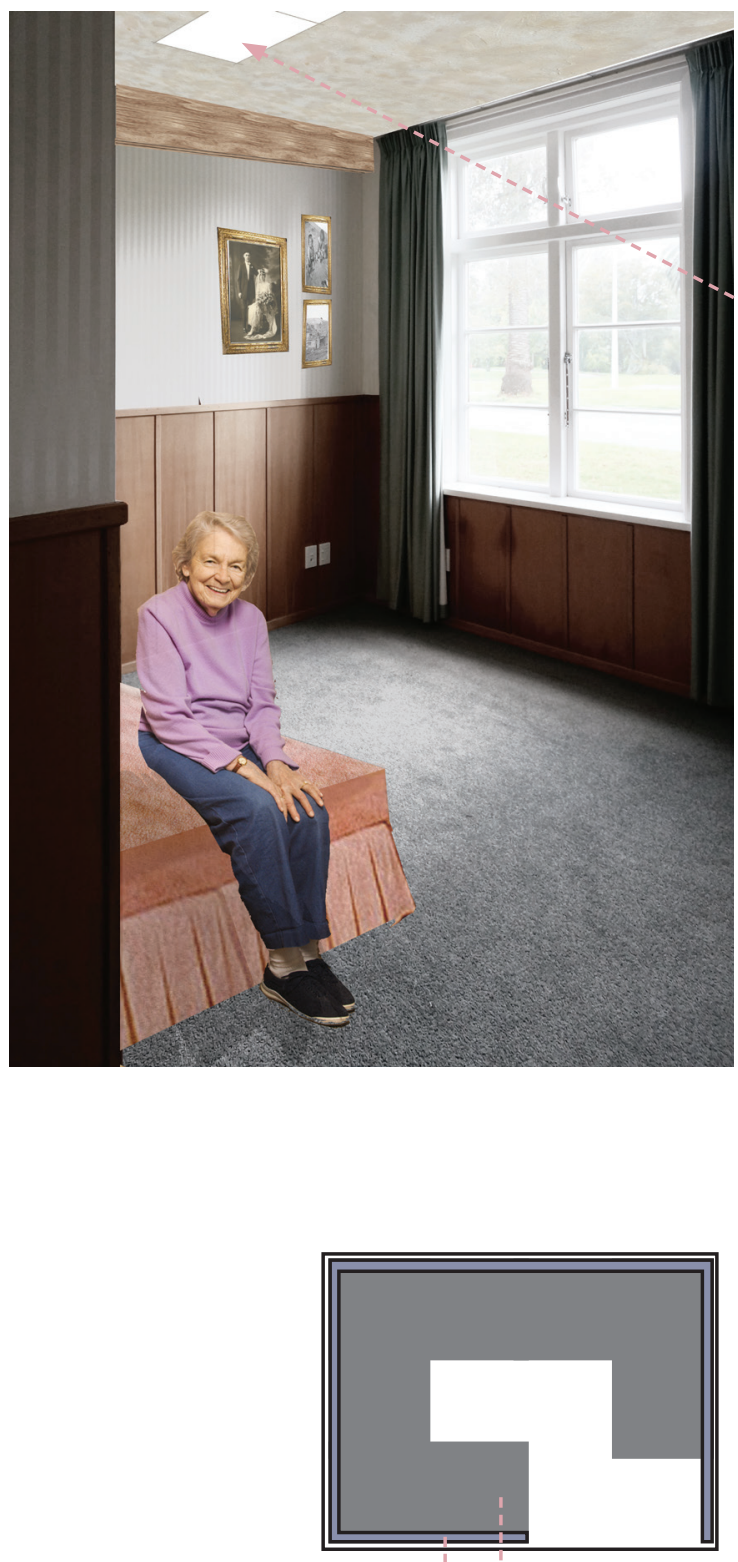

Bed - Movable

Light therapy lighting hidden in scotia This option can offer freedom in the roon layour whing still providing

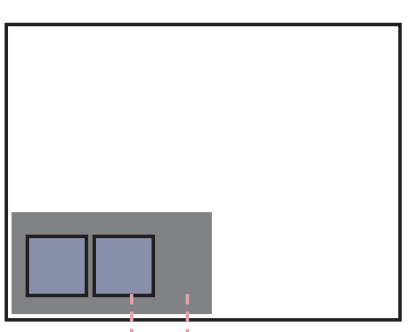

Bed - Fixed

Light therapy panels above bed

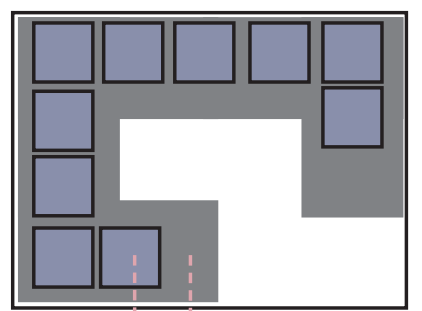

Bed - Movable

Light therapy panels

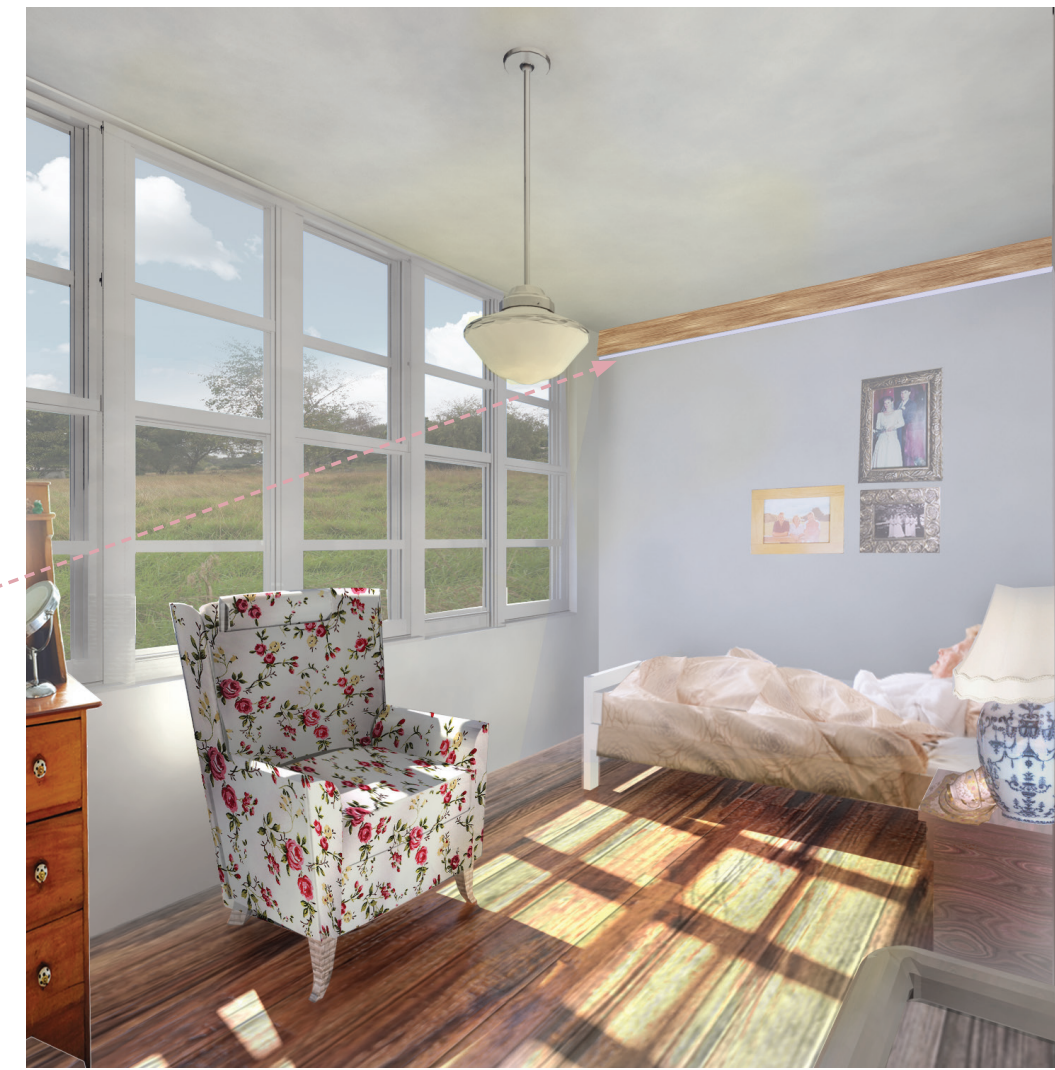

6.6.2 $\mid$ (above) Exploration into non-intrusive artificial lighting 


\subsection{Building Extension}

To establish a better layout, the footprint of the building required further analysis to initiate a design

move that created more space and

circular wandering. The extension of

the building should reflect the initial

design of the existing building, while

providing a unique character of its

own. Various layout possibilities use

the buildings proportions and floor

plan to aid the design of the extension

(see fig.6.7.2).
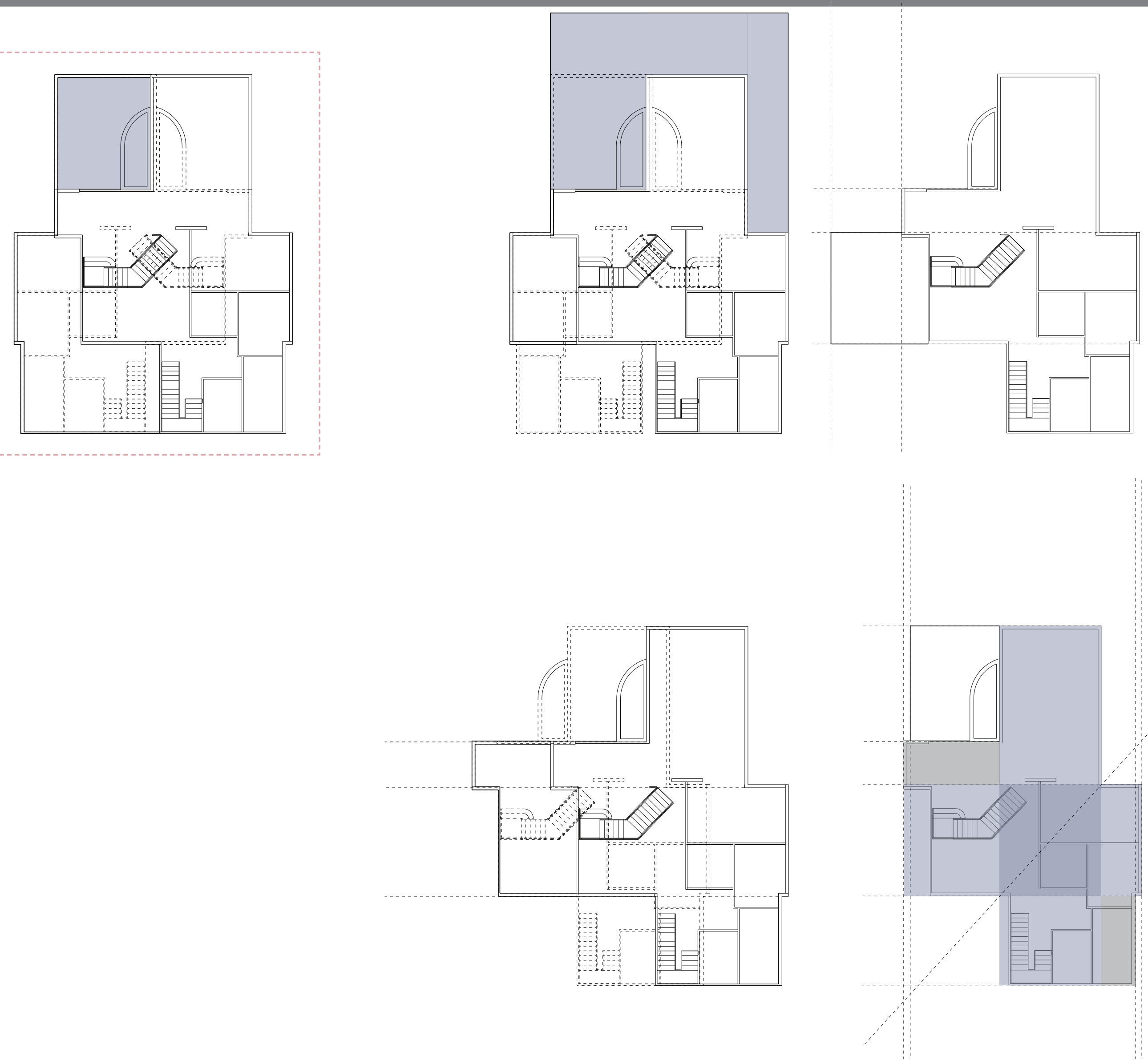


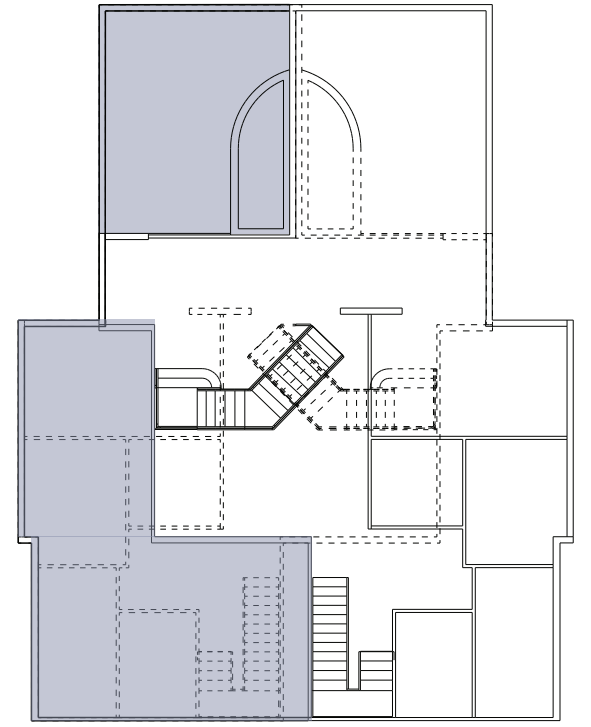

Additional space

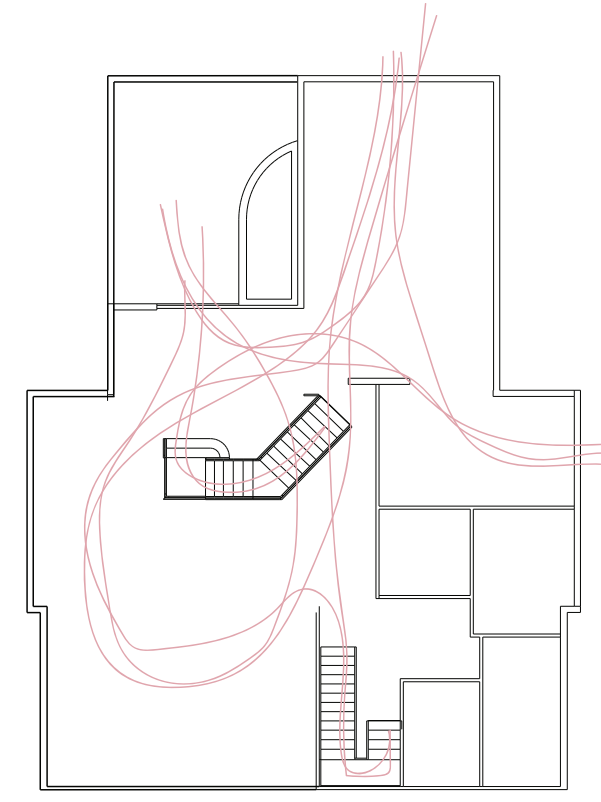

Circular loops

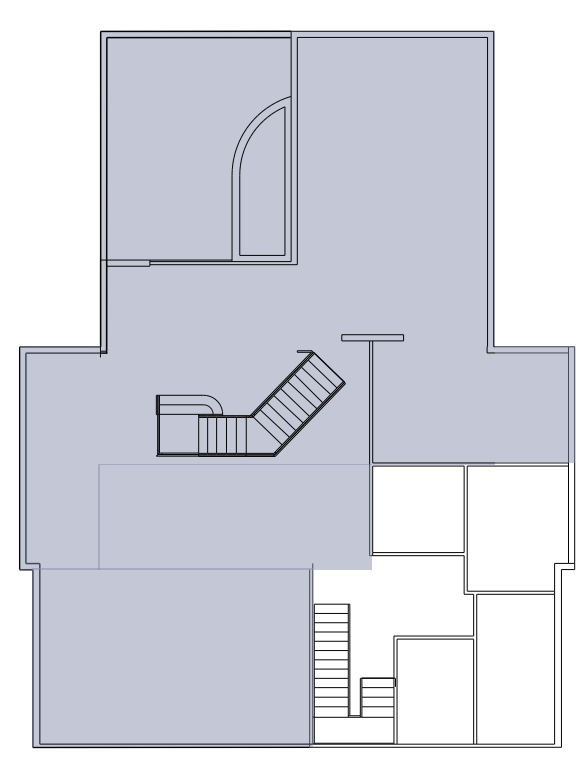

Total public space

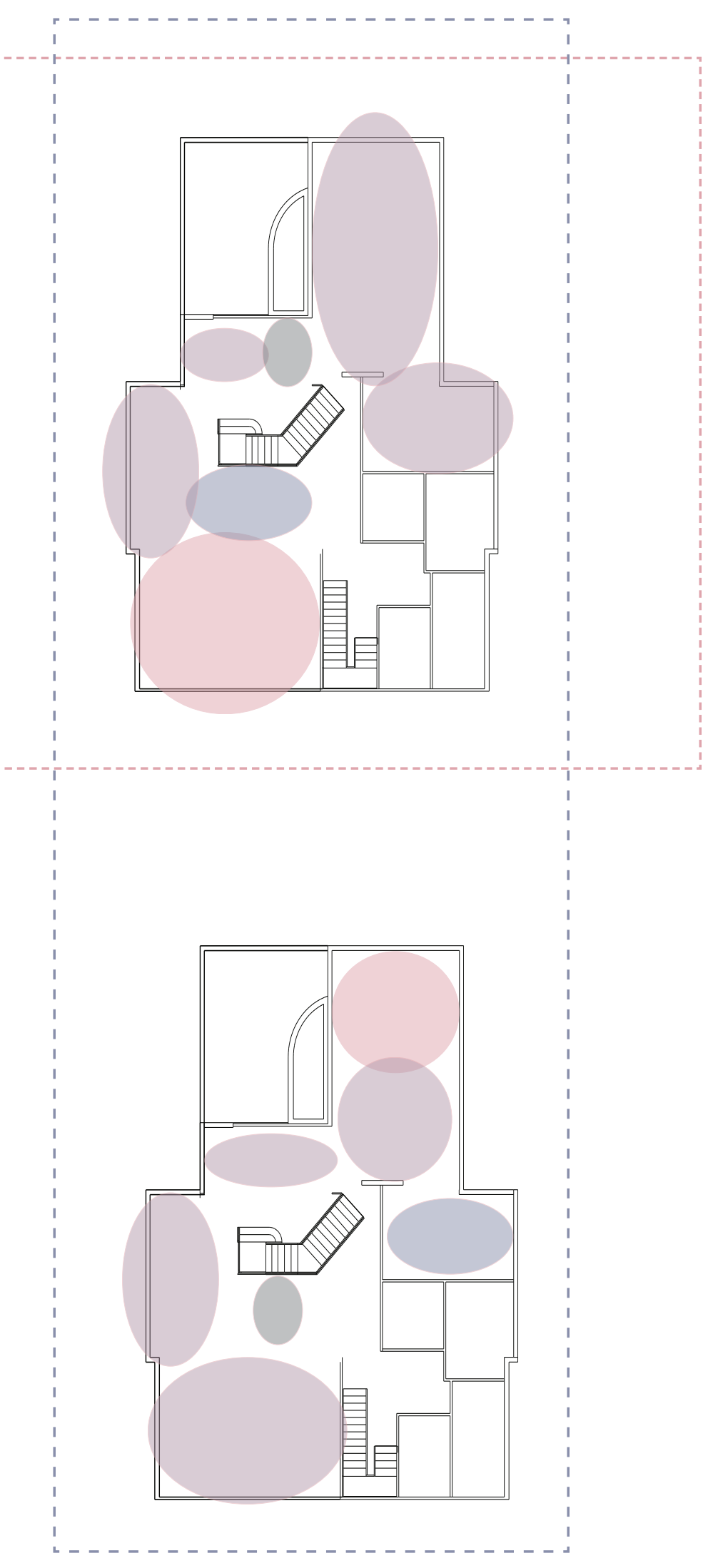

The proposed layout mirrors the existing eastern side of the building making the building footprin symmetrical. This provides additiona interior space as well as creating new exterior area. The extension allows for a continuous loop around the central staircase and a connection across the siche public spaces. The for people with dementa as they deal with dead ends differently to people with full cognitive abilities. Dead ends cause confusion as to where the person was travelling and also pose difficulty for working out how to turn around. To avoid these points of confusion there needs to be a continuous loop which aids in the moventint around space. A continuous loop track also facilitates

\section{Staff facilities}

Kitchen facilities

Seating areas 


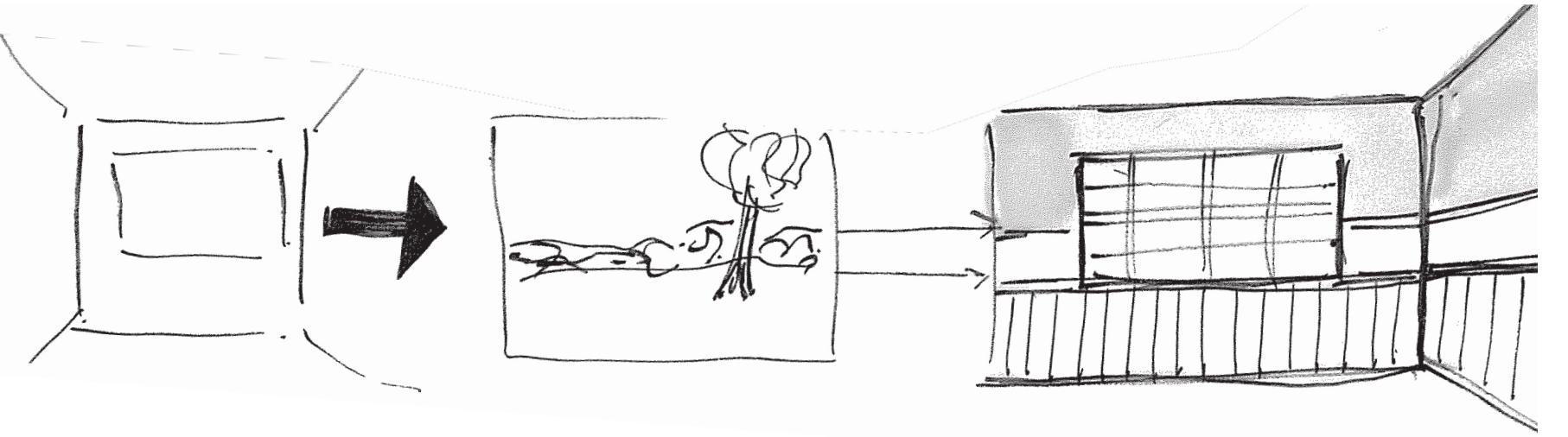

A method of wayfinding has been introduced using pattern on the walls in the corridors that was derived from both nature and historic interior decor. Different patterns or

colours are used to differentiate between spaces. This also creates an opportunity to

hide entryways using the same pattern preventing residents from accessing rooms

that are off bounds, such as staff or nursing rooms. The use of patterns from nature

can create a shift in focus, enhancing concentration and reducing stress. Biophilic design addresses how visual stimulation can reduce the increased agitation in people with dementia (Terrapin Bright Green 38)

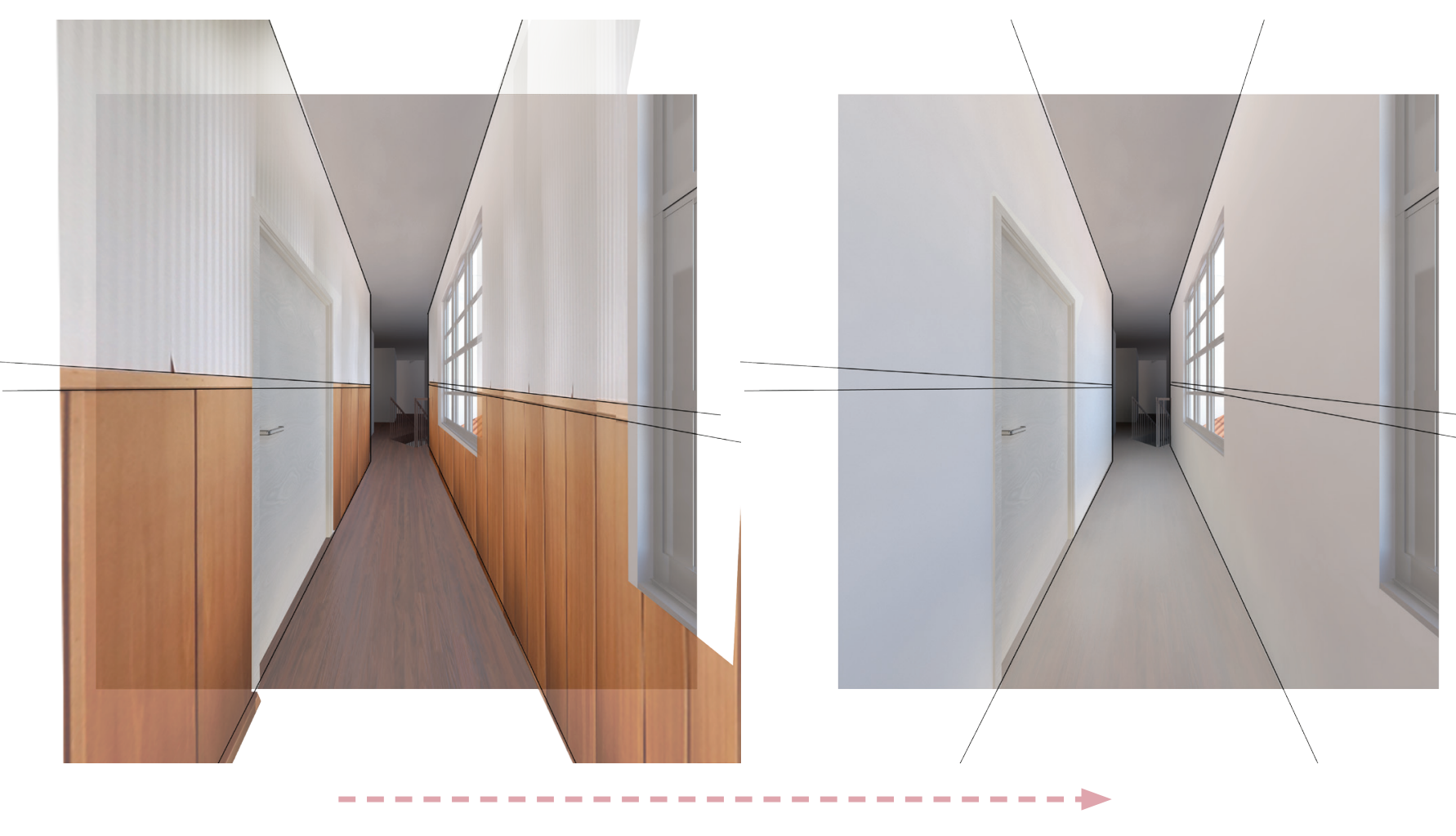



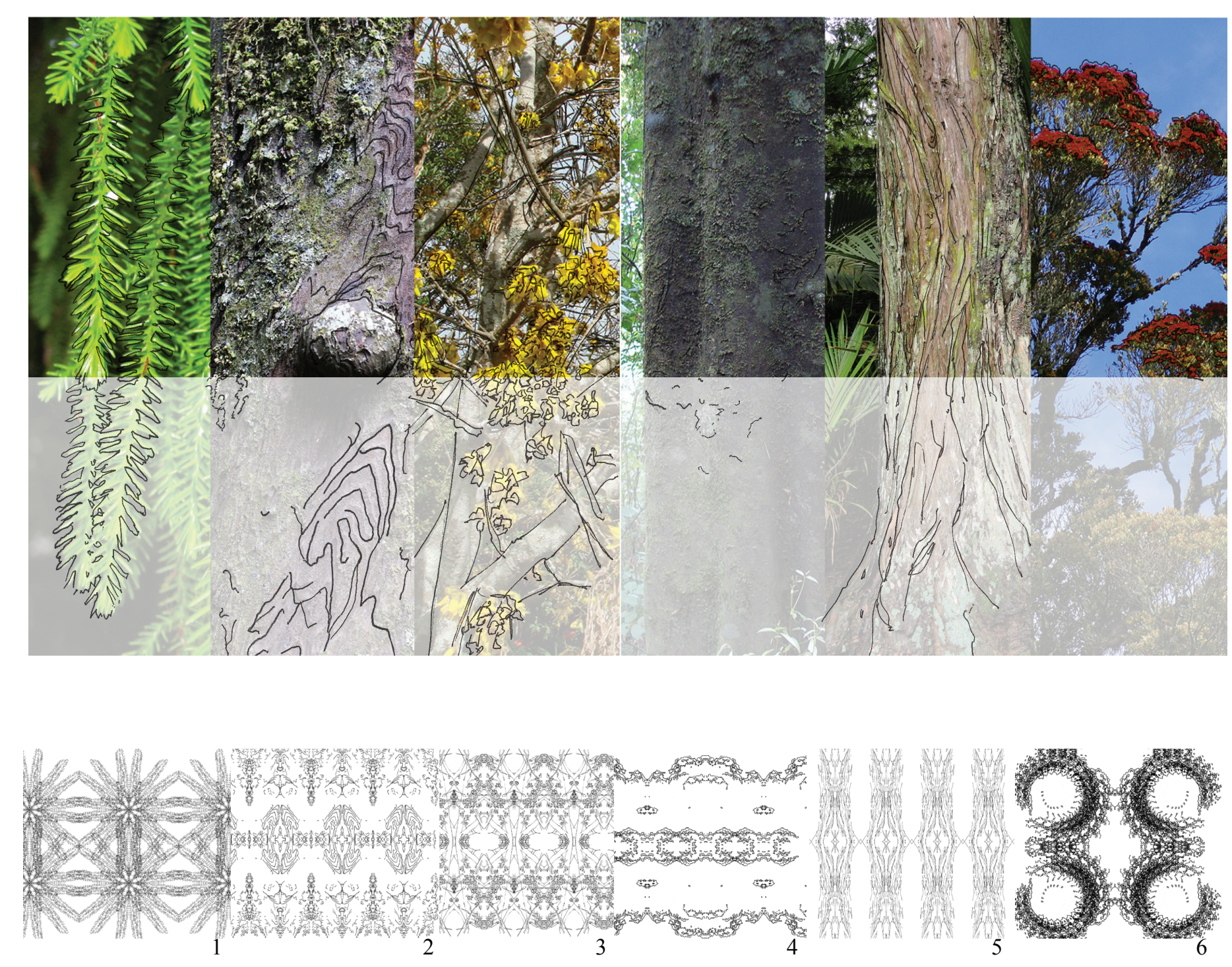
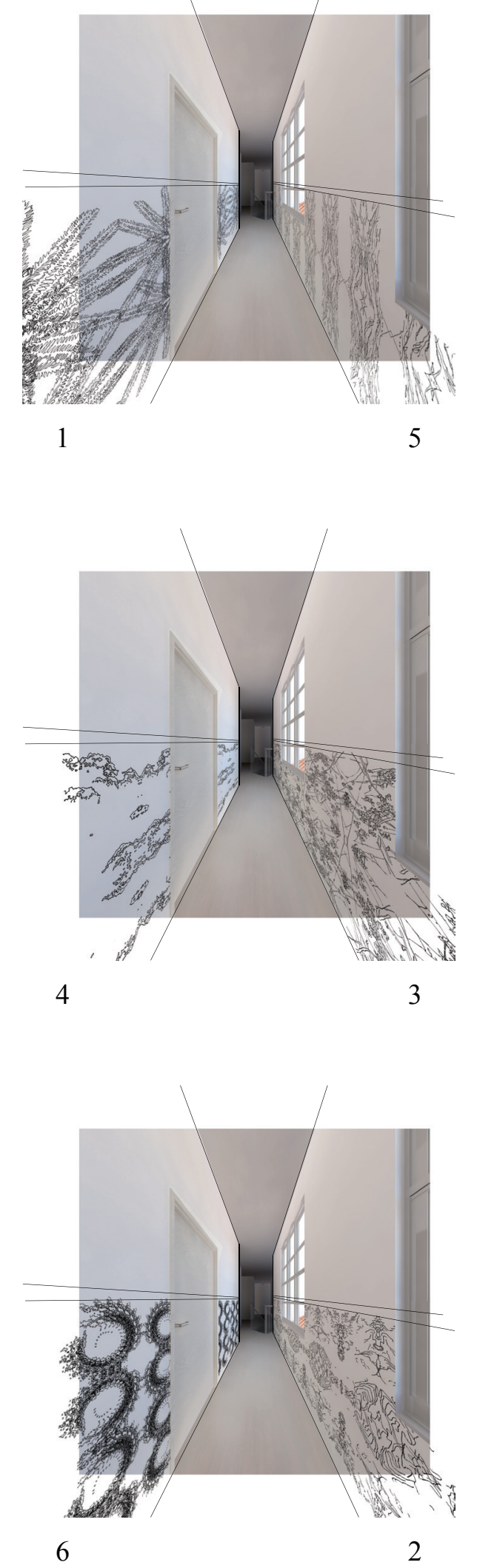

6.8.3| (opposite) New Zealand native plants abstracted $6.8 .4 \mid$ (opposite) Patterns created from overlays $6.8 .5 \mid$ (above) Patterns used as wall feature 

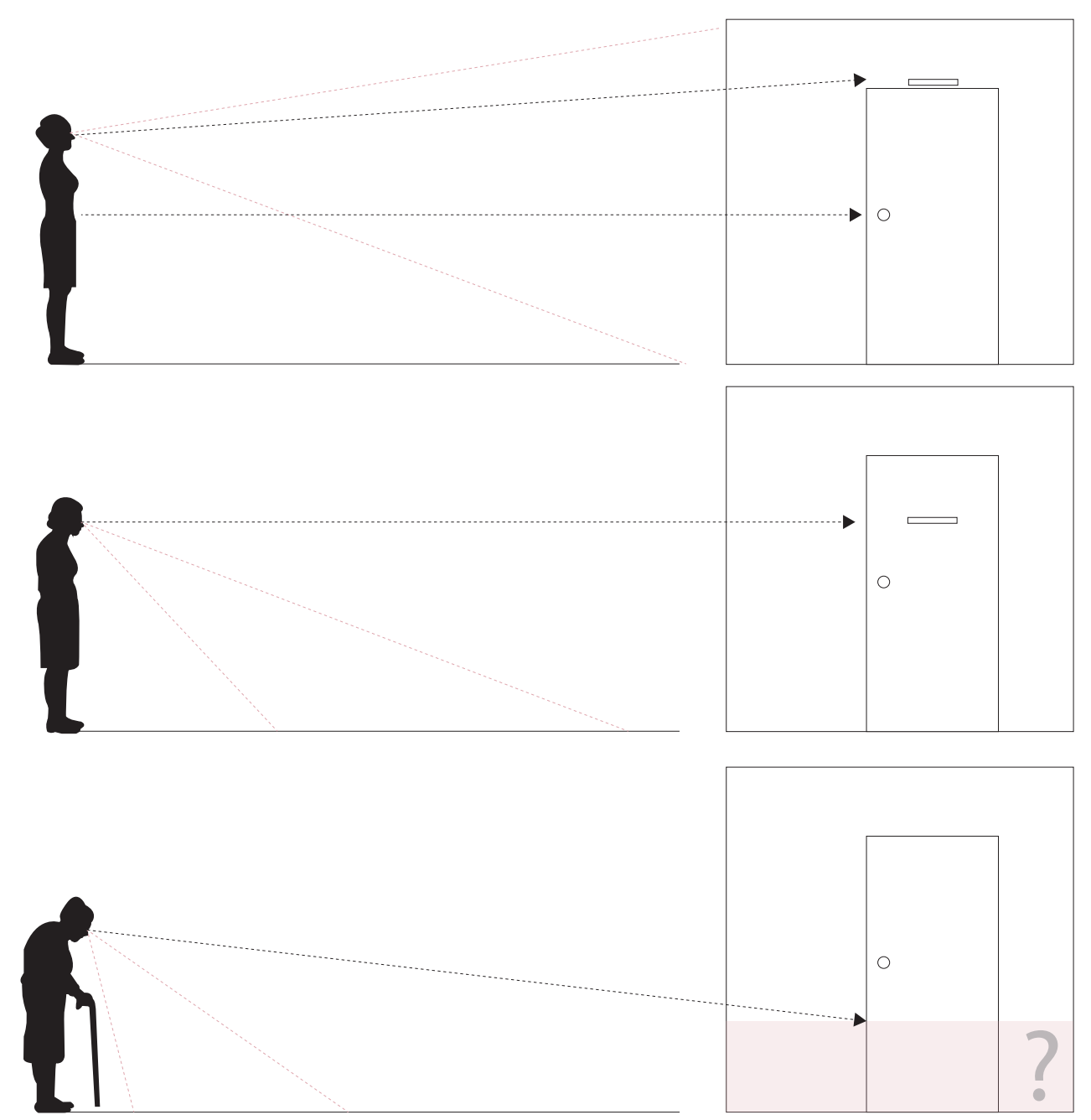

As the eyesight and posture of the residents deteriorates, the typical labeling of both rooms and other spaces becomes harder to see and recognise. There is currently a lost opportunity in the lower section of the wall to enhance way-finding around the facility. This can both reduce any institutional feeling as well as enhance the character of the abstracted wall feature 


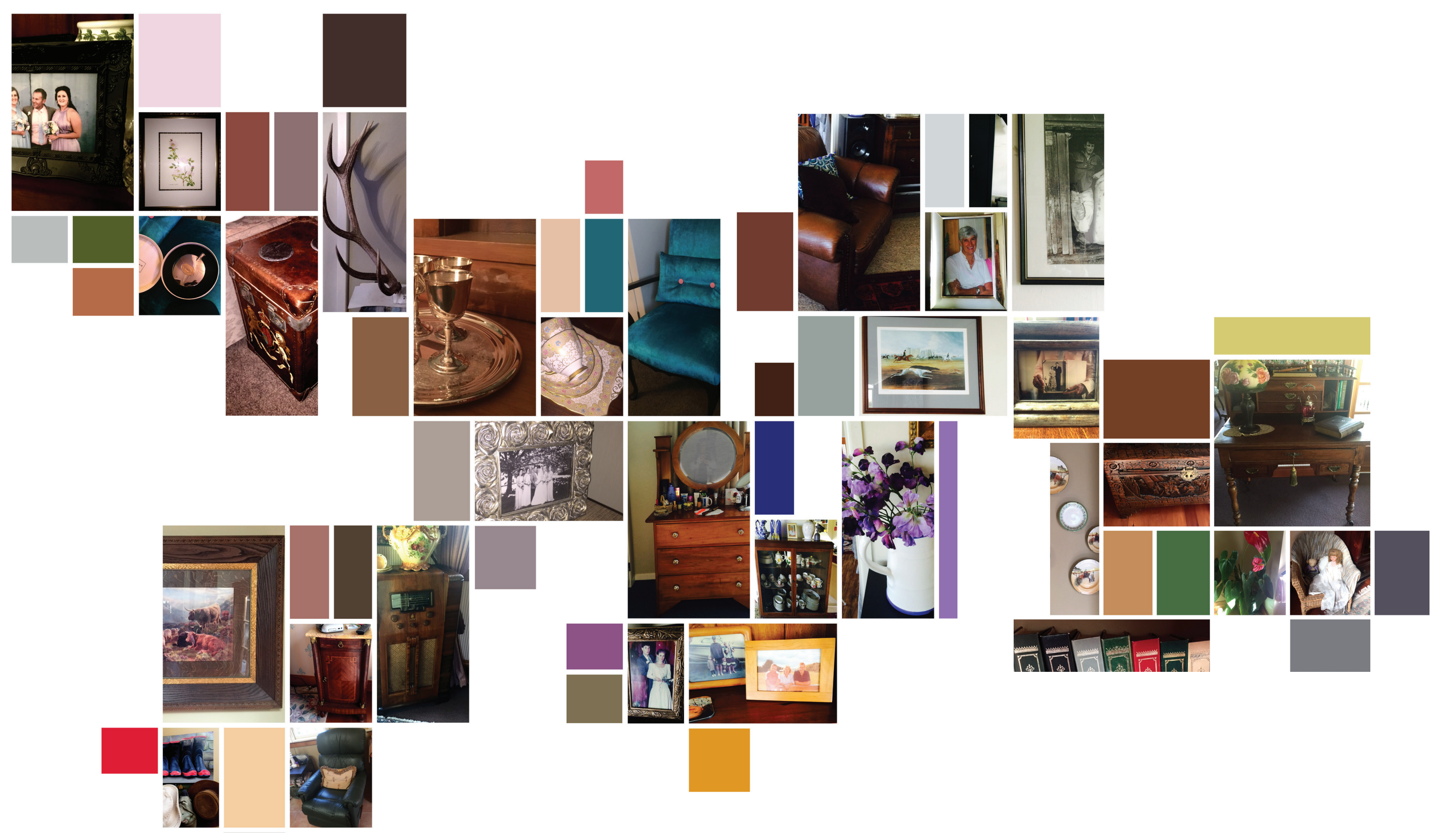



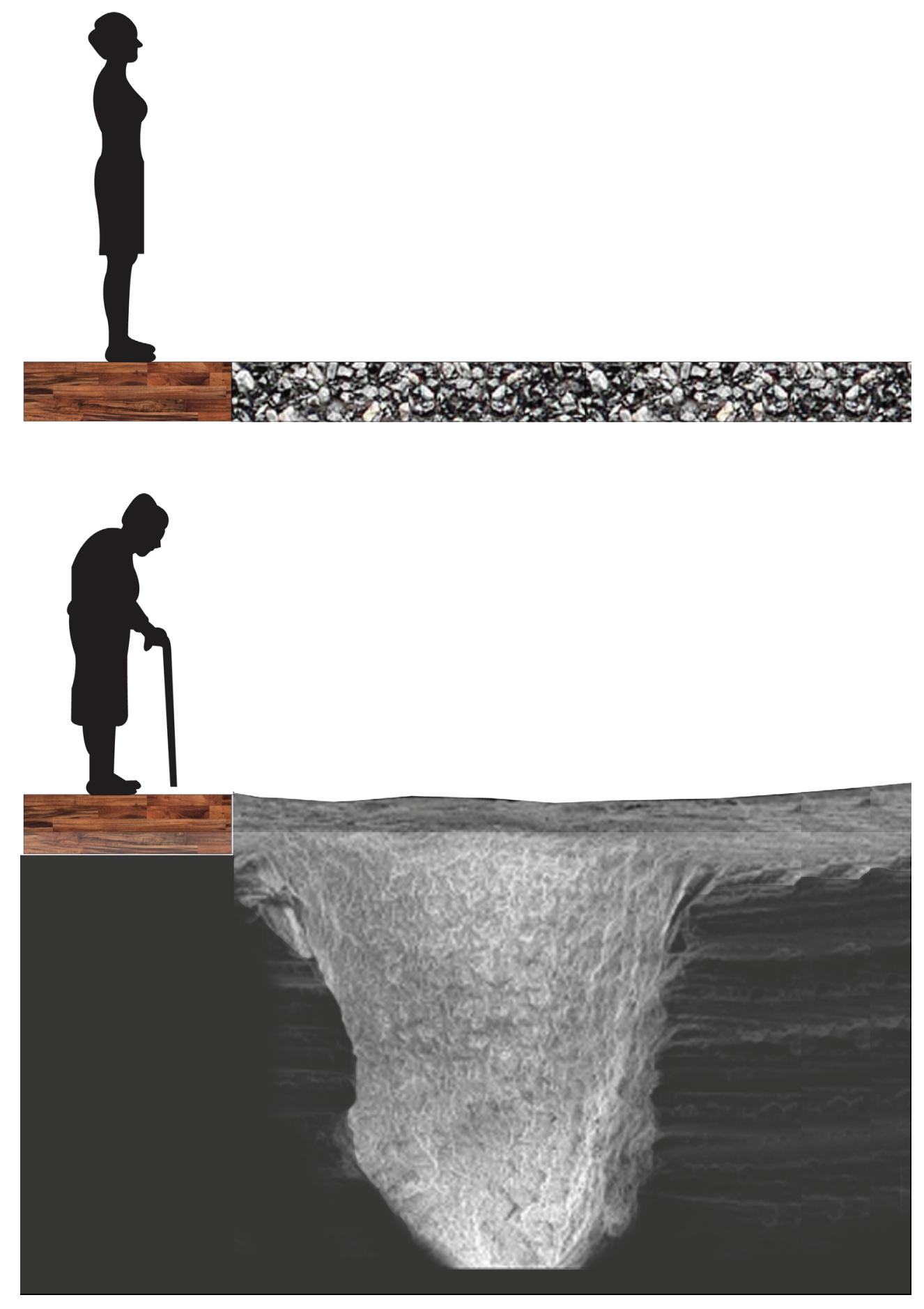

Tiles, or any type of cold flooring are problematic. Some of our people are

hypersensitive especially on the soles of their feet, and become reluctant to stand if they put their feet do and it is cold. We have a gittery shin it in the

- Questionnaire answers

Materials are an important aspect of the interior, both to make a space feel comfortable and home-like and to serve the needs of the residents and the staff of the facility. The flooring material can become quite problematic with the residents diminished eyesight, and cognitive ability. High contrasts of materials should be avoided because residents are unable to understand contrast. They feel as though they are stepping onto something wet, or at a differen level, or even into a big hole (fig. 6.9 .2 ). This can create anxiety for the residents when moving around the facility. A continuous material that doesn't change over the entire facility can help to eliminate this uncertainty for the residents. A material that is familiar as it was commonly used in older rural buildings is wooden flooring. However, the issue with be used as a wet room material. A vinyl or laminate timber look-alike flooring lan cover all spaces of the facility including the bas of the This will also help with the problems associated with incontine as the retention of odours, which is

experienced with carpeting.

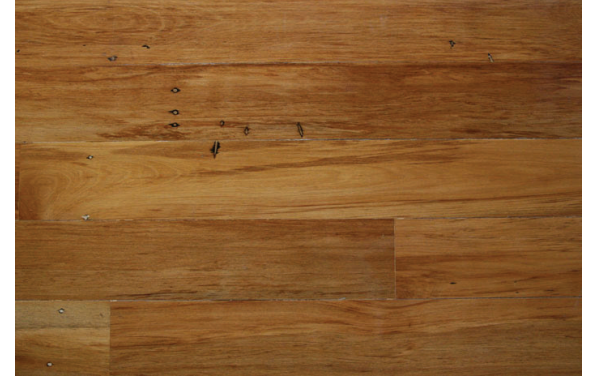

Kauri natural timber flooring

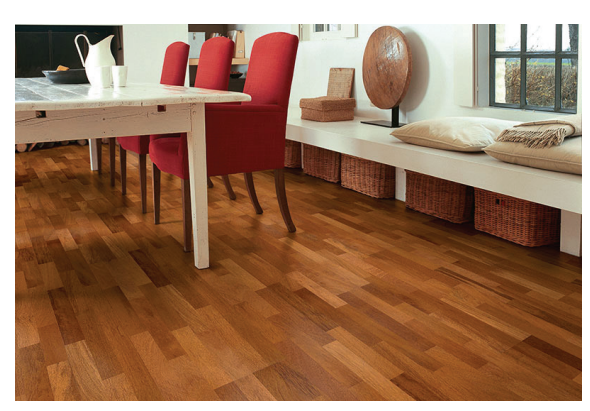

Timber look-alike laminate flooring 


\subsection{Design Phase 2 Interior}
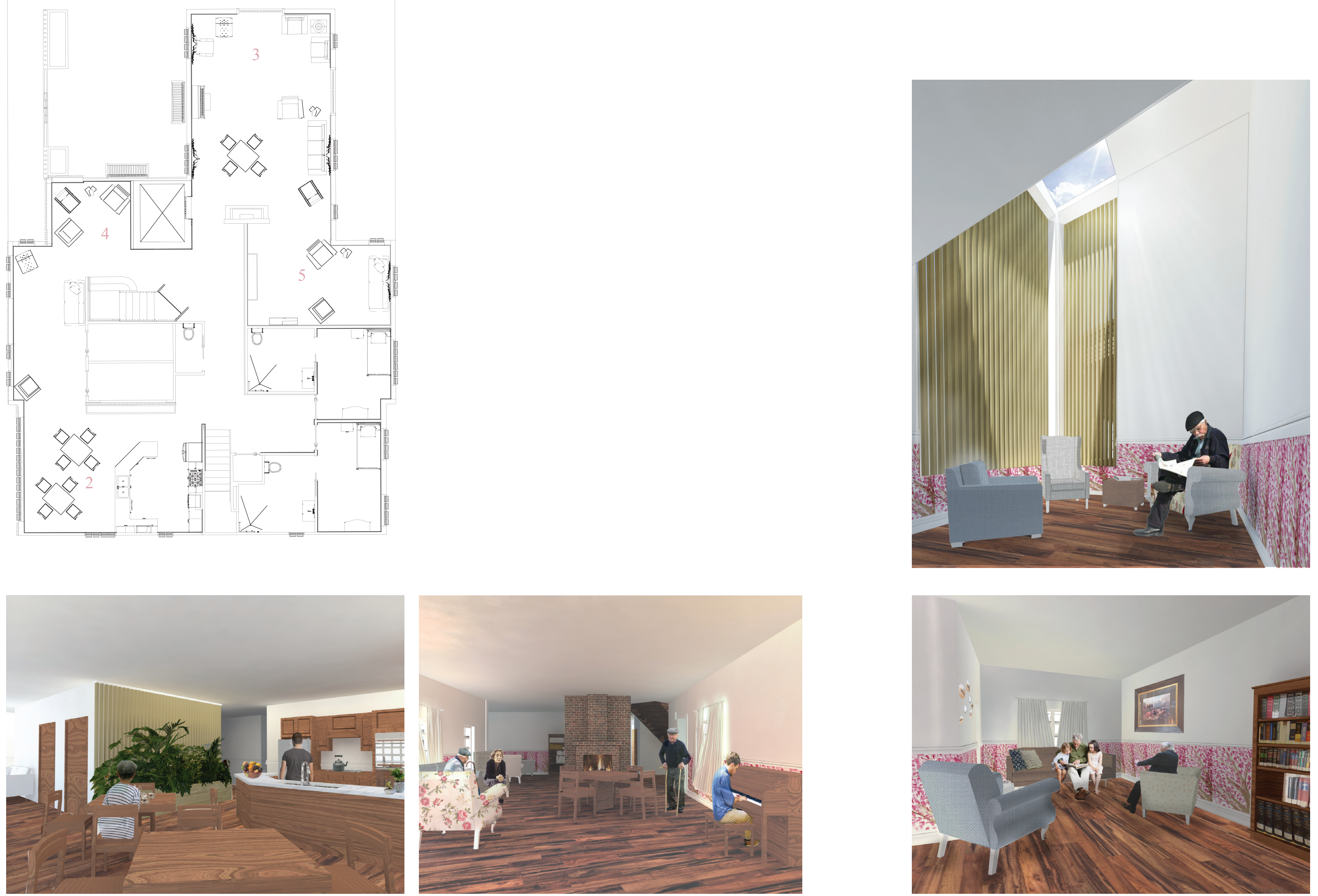

The table shape has been changed to allow one person per side of the table, eliminating confusion as to which food is theirs.

An open kitchen design has been kept to promote self dependency.

Plants have been brought into the area as an aspect of therapy. They promote stimulation to the southern end of the building.

Wooden panelling provides screening to a window which is positioned between the staff room and kitchen for monitoring of residents.

Curtains were chosen for the comfort they provide with privacy and making the .

Wooden louvers control light and heating.

The reading room captures sun in the afternoons.

The wallpaper leaf design is situated in all public areas of the facility.

The plan of level 1 shows a clear circular path between public areas, which promotes circulation and facilitates sundown wandering.

6.10.1 | (above) Level 1 Plan

$6.10 .2 \mid$ (above) Kitchen - dining area 


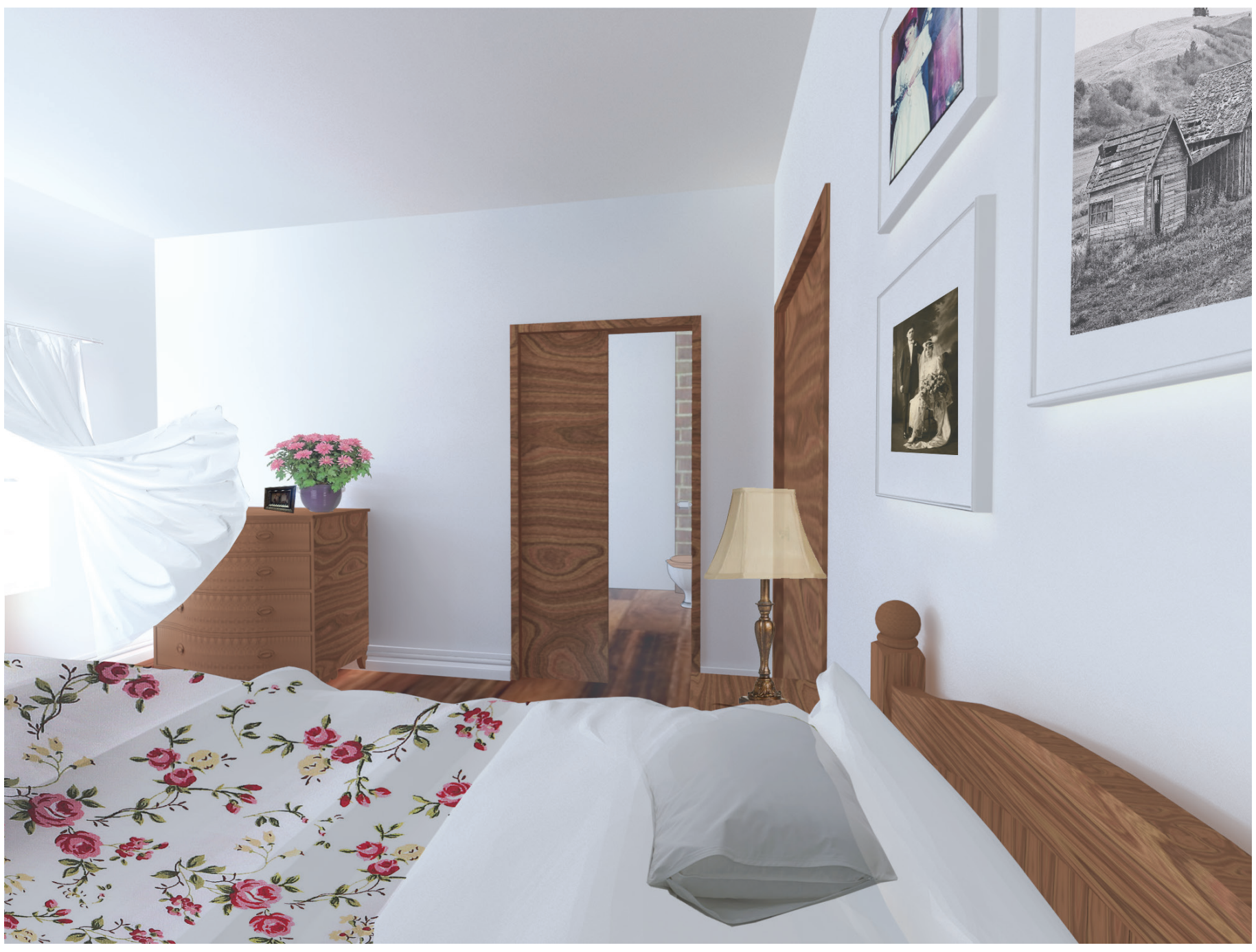

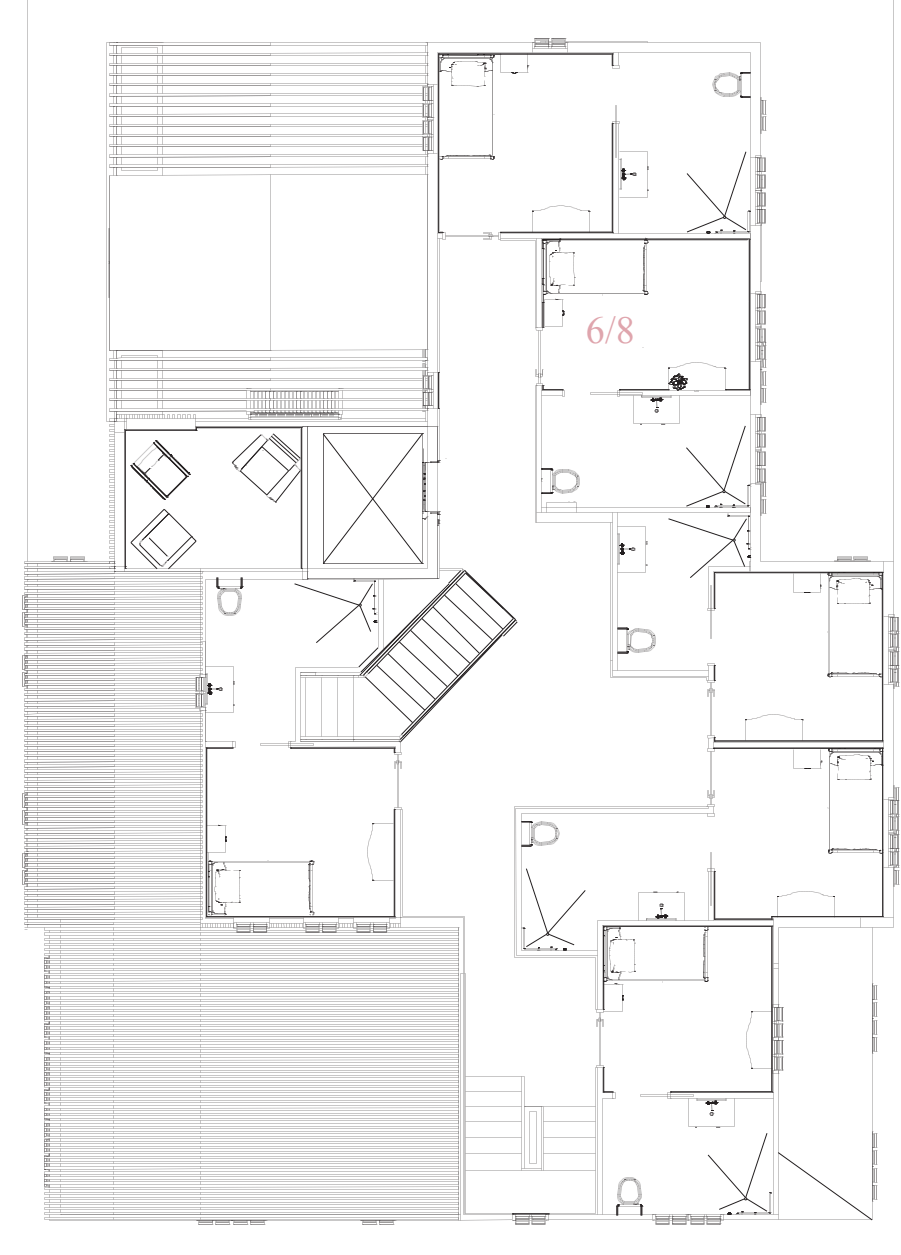

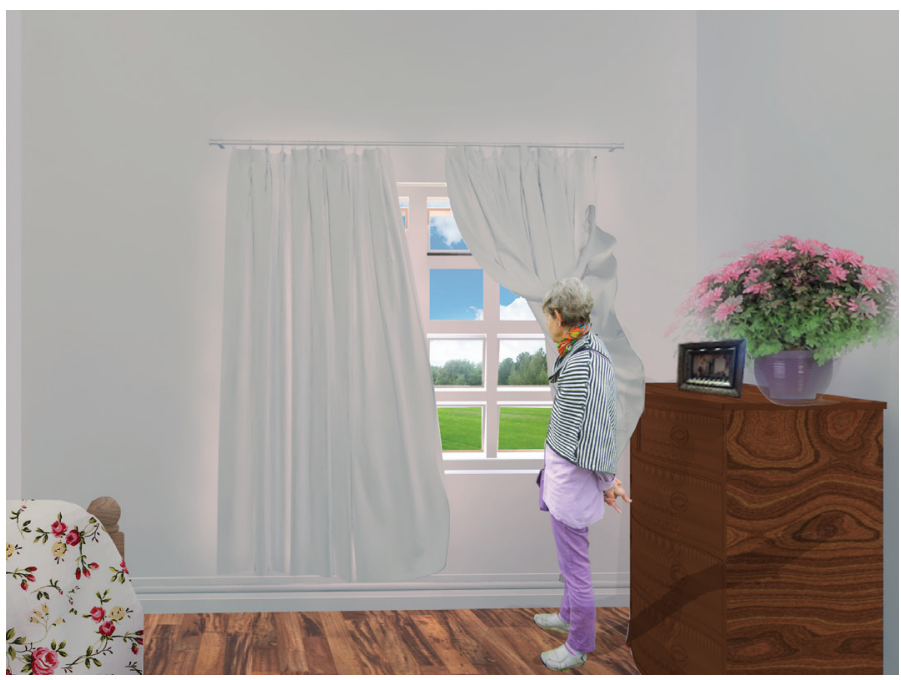

Louvers can be seen from the second level covering the entire new extension.

Curtains make the bedrooms more home-

The additon of personal furniture in the bedroom allows the resident to identifythe room. Familiar objects reduce agitation around being in a foreign place.

The contrast in material in the wooden door makes the opening visible to avoid confusion.

Views to the toilet from the bed are mportant for night time incontenence issues.

Views to surround farm landscape bring comfort for farmers who got up every morich to check the weather, or animals

A timber-framed bed is more home-like han the institutional furniture avalaible in aged-care homes. They are also easily cleaned for sanitary purposes. 
6.11 Exterior - Connecting Site
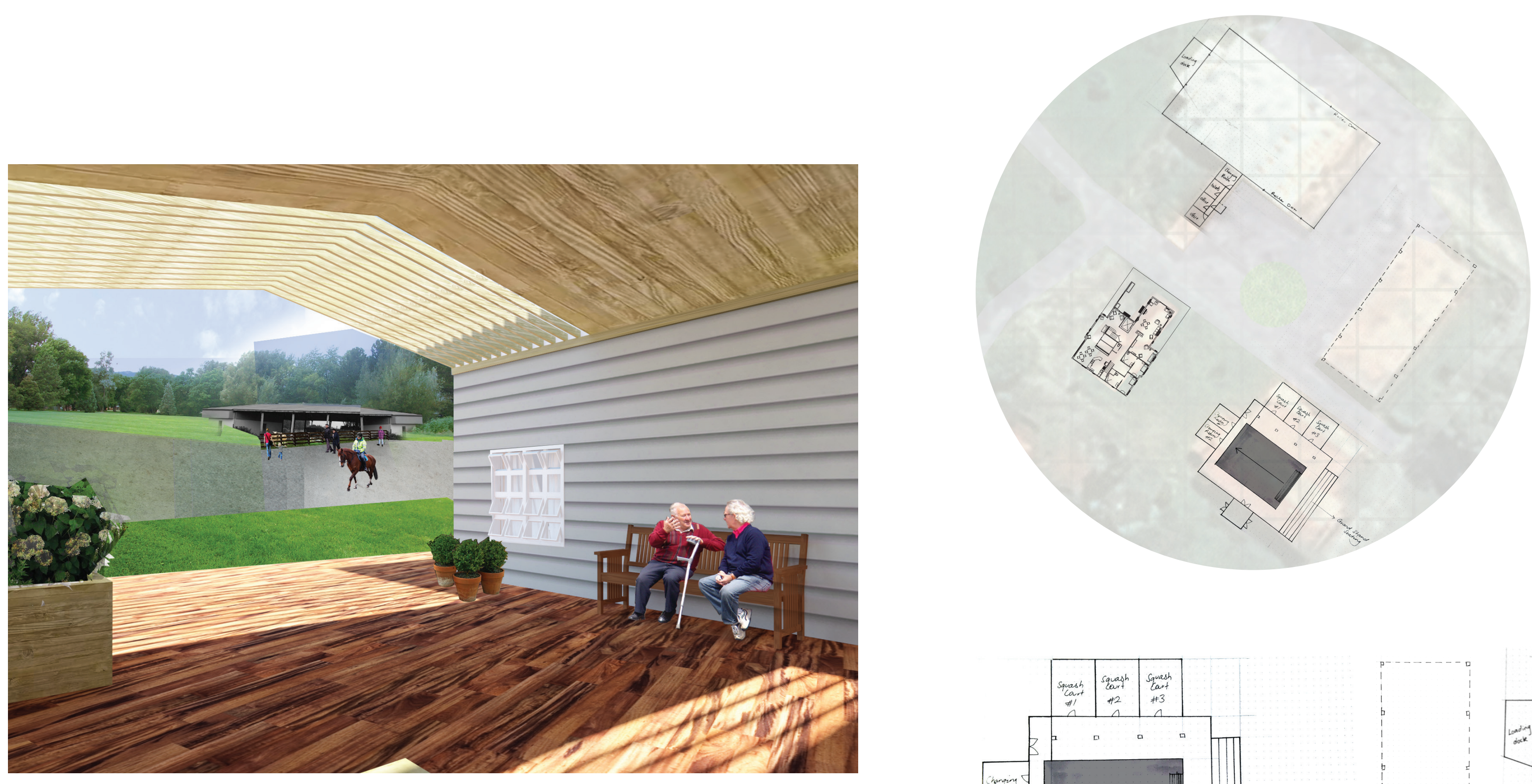

The surrounding buildings were previously used as a swimming pool and farm sheds. Their footprints are perfect for indoor farming activities which could engage both the residents and younger generations.

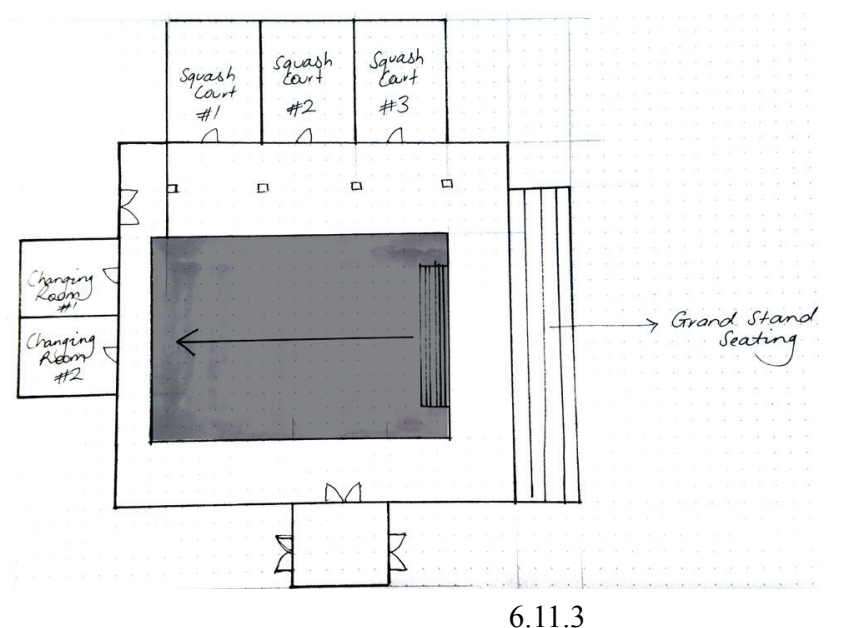

6.11 .3

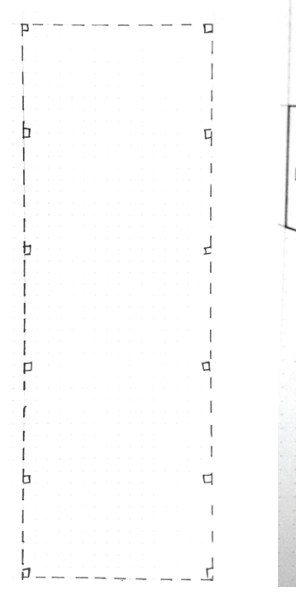

6.11 .4

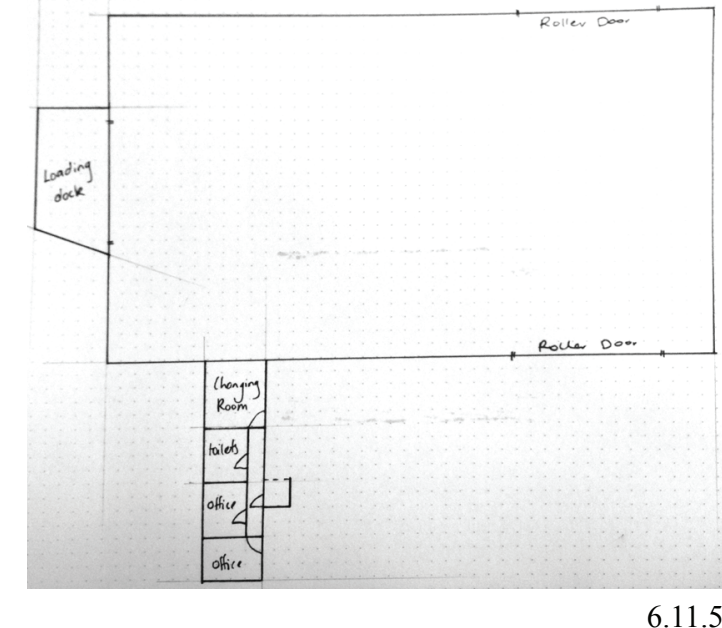

6.11 .2 | (above) Site plan

6.11.3 | (above) Indoor swimming pool and squash court building plan 6.11 .4 | (above) Semi-covered farm shed building plan 6.11.5 | (above) Large fully covered farm shed building plan 


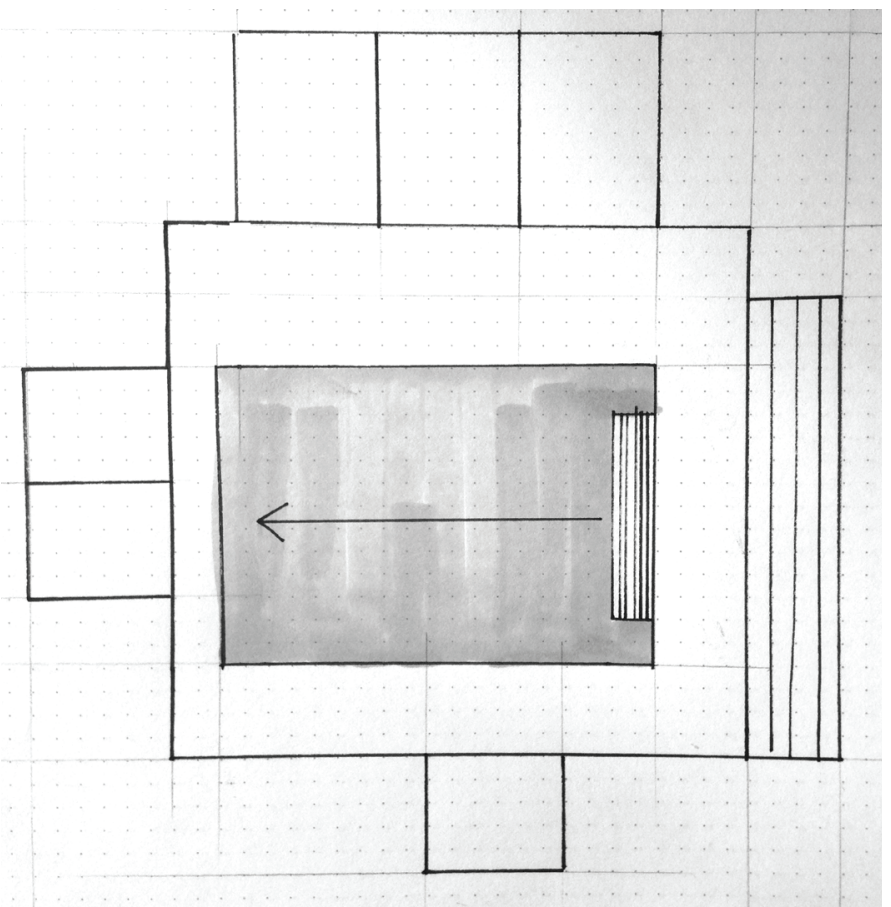

Layout of the swimming pool

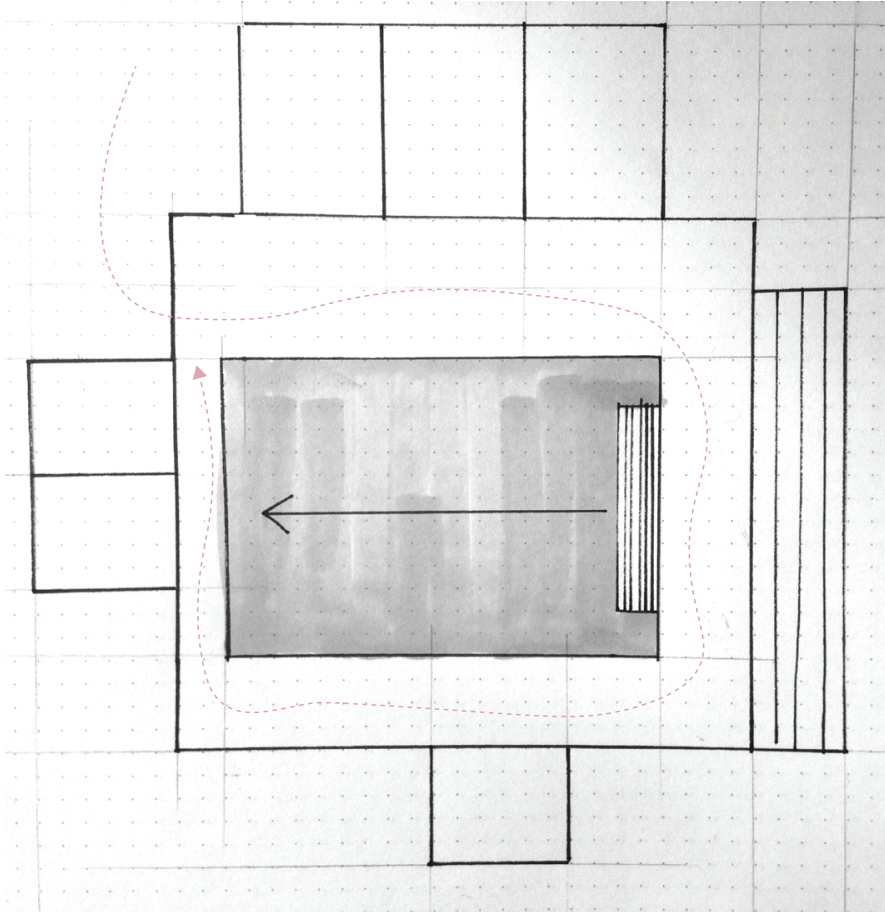

Movement through the building

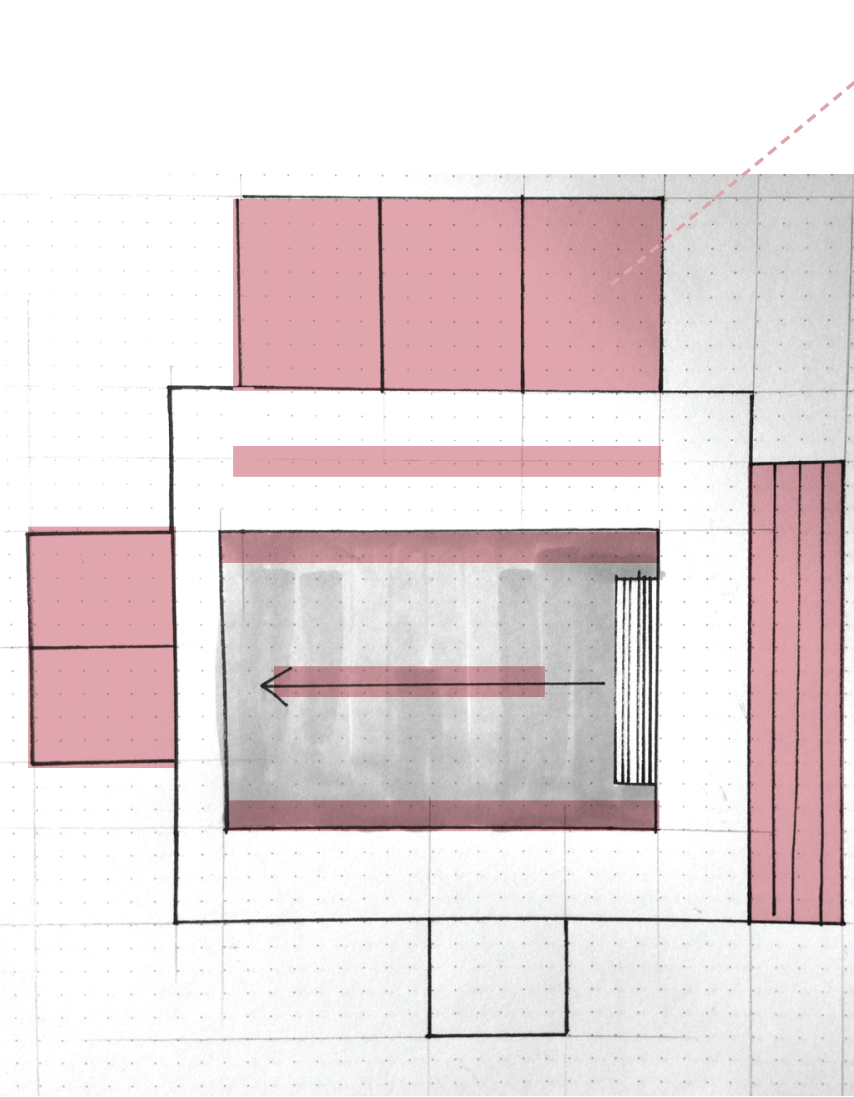

New layout plan 1
Placement of indoor garden beds Indoor pond

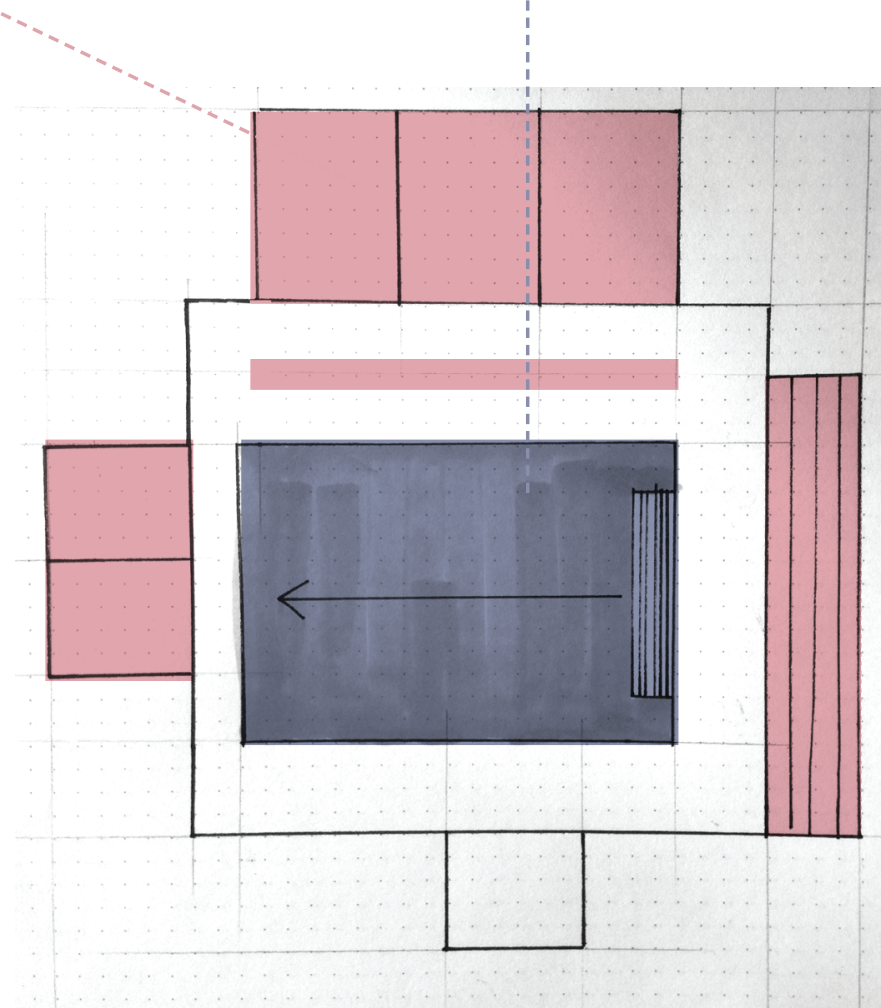

New layout plan 2
The indoor swimming pool provides the perfect setting for an indoor garden. This will allow residents and people visiting the site to wander around and view the plants as they change seasonally. It also provides an activity that family can participate in when visiting their loved ones. The option to leave the dementia facility and wander around the grounds will ensure that family don't feel as though they have placed their family member in a prison-like environment. This is important to both family and resident as it prides a fatigue and perceived vulnerability' (Terrapin Bright Green 44).

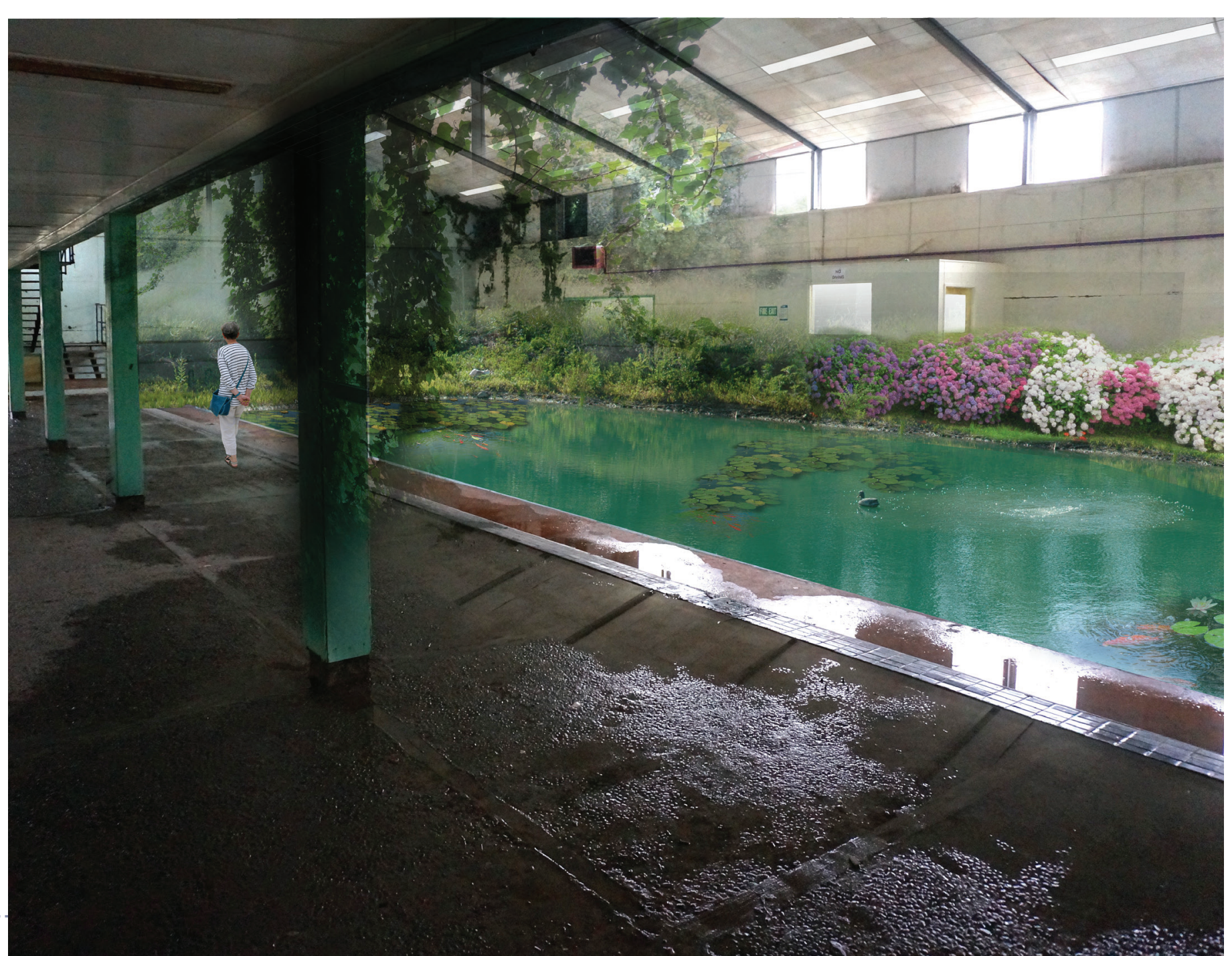




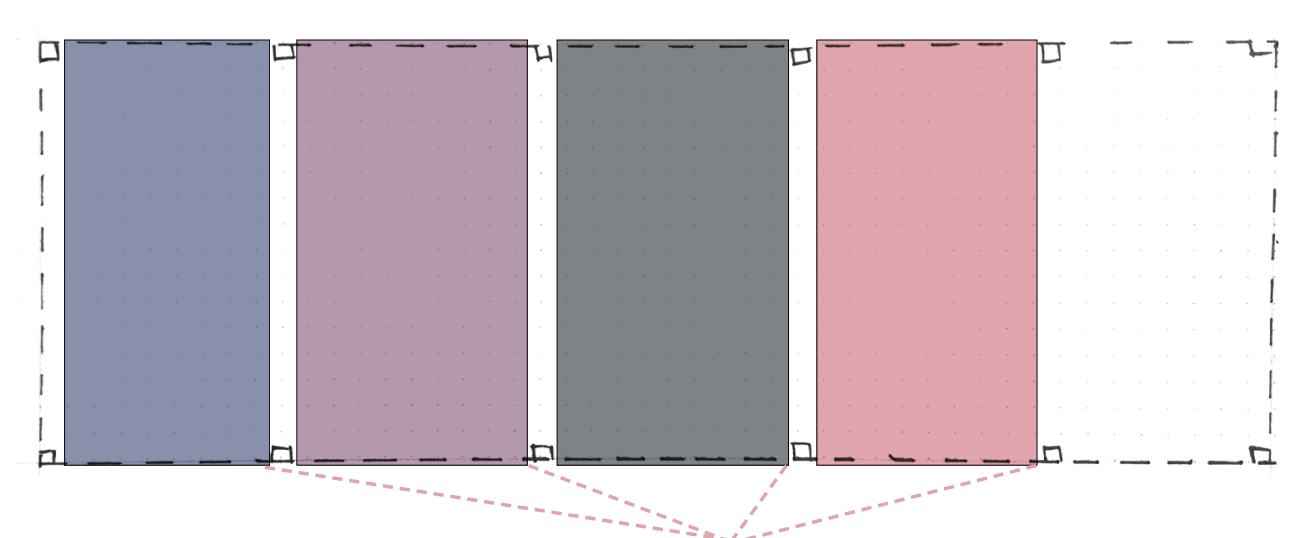

Modular pens hold different types of animals for people to feed and pet most commonly farm animal

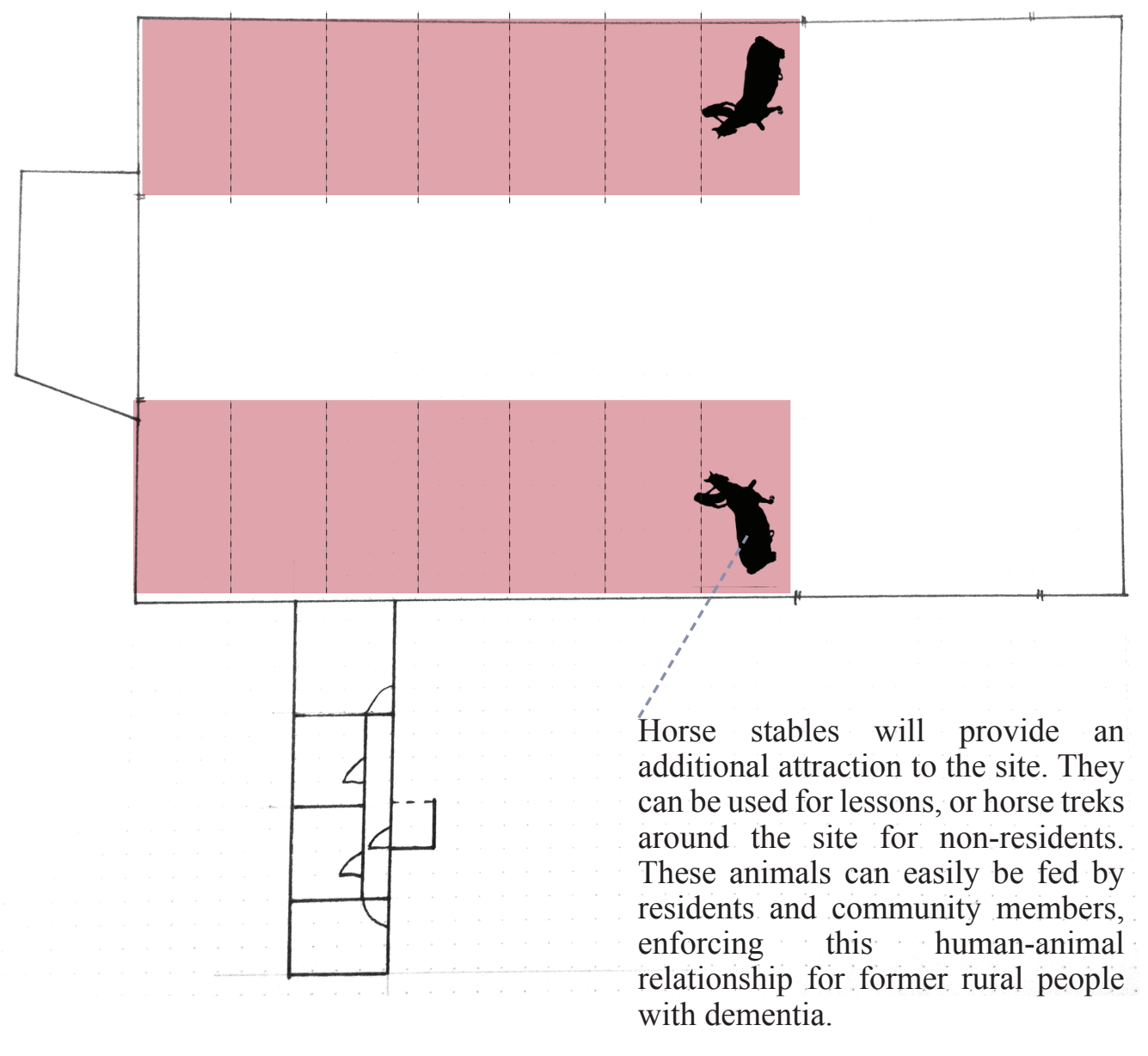

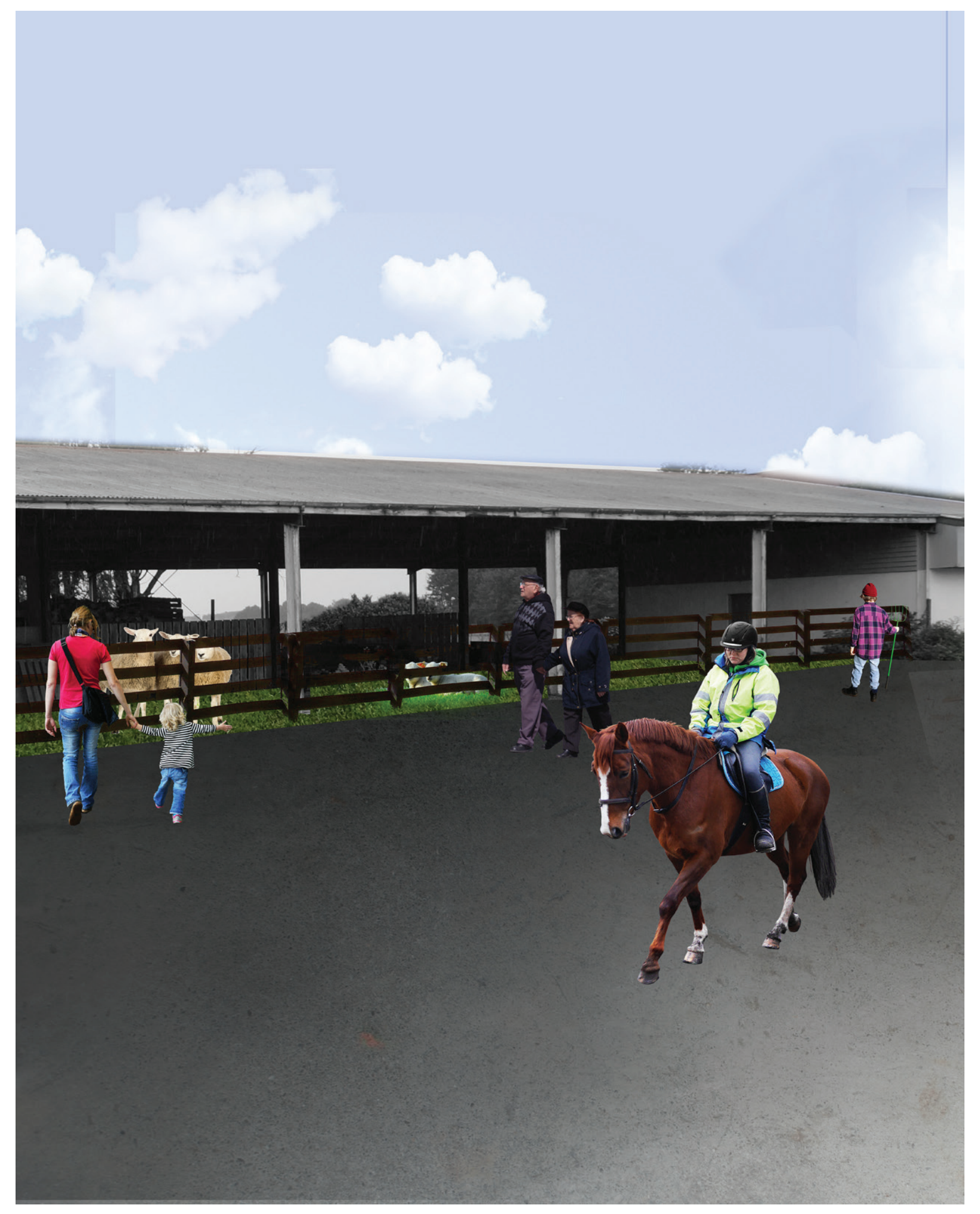

6.11.9| (above) Proposed design 


\subsection{2 Reflection}

This section of design iterations has progressed to incorporate many of the necessary dementia-resident requirements. By considering the resident and how they would experience the building as well as the surrounding landscape, micro and macro design changes have been made to the building to eliminate confusion and enhance familiarity. Wayfinding and therapeutic design knowledge has been drawn on to make design decisions which have advanced this design stage. All aspects of bedroom and interior circulation have been analysed to produce an outcome that benefits the residents and their specific requirements. Landscape aspects of the design have been explored, but community farm attractions need further analysis and detailing.

Positives:

-The notion of allowing one to 'decorate' the space with what was familiar in their own homes/lifestyles is important.

-Familiar interior decor represents rural design.

-Community interaction occurs through farming-specific programmes.

-Detailed analysis of bedroom design has resolved issues identified in dementia research.

-The design places emphasis on view shafts to surrounding landscape and cluster of buildings.

\section{Things to Consider:}

-Explore the notions of sense of place, space, and time.

-Consider colours and finishes related to native New Zealand flora when selecting materials.

-Pay attention to macro detailing within the interiors of the facility and community attractions.

-Consider safety aspects in community buildings for

-Establish clear break-out spaces
within the facility. Design programme-specific spaces.

-Look into wayfinding and feature wall materials. Patterns might be seen as something to pick at.
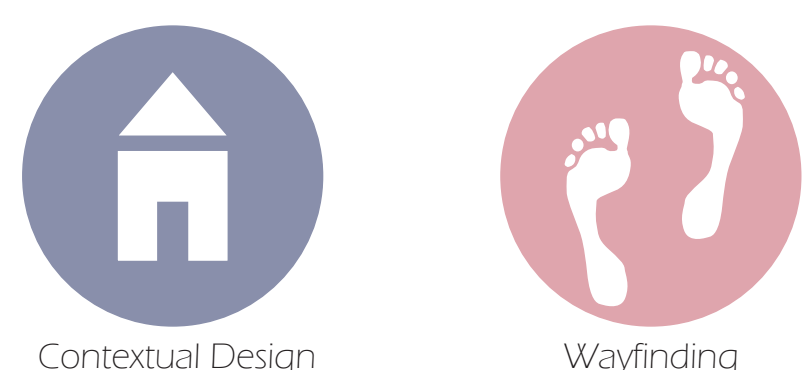

Wayfinding

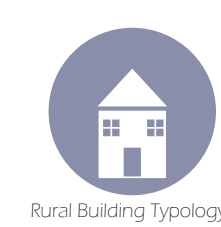

Residential scale
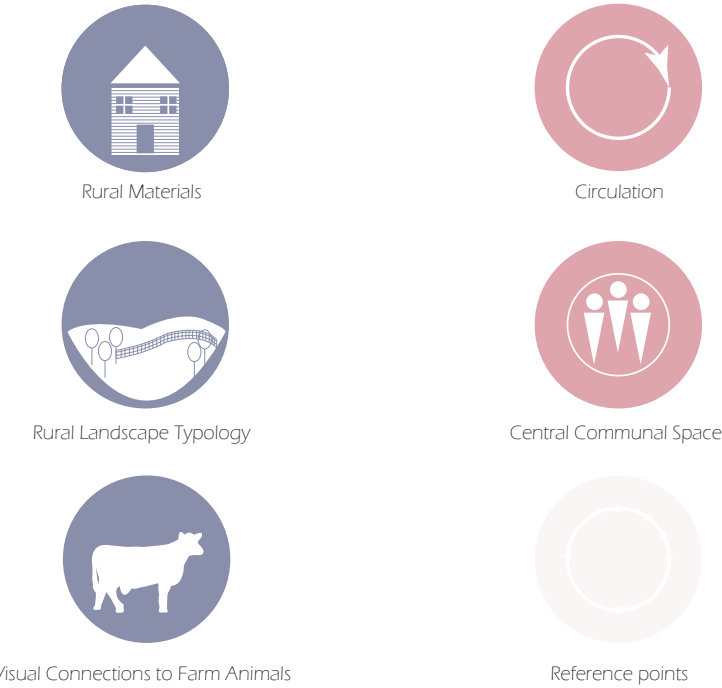

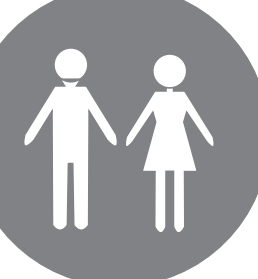

Therapeutic Design
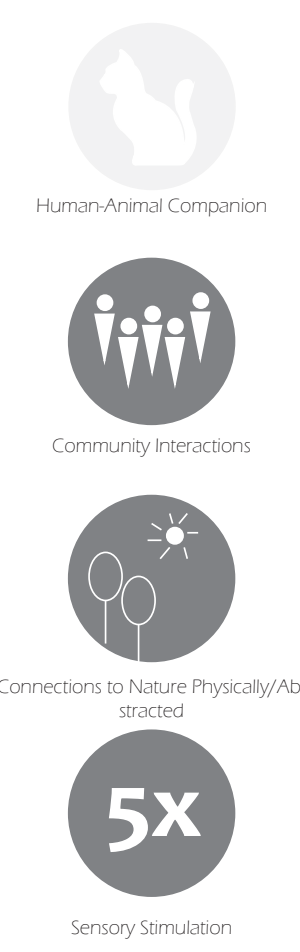

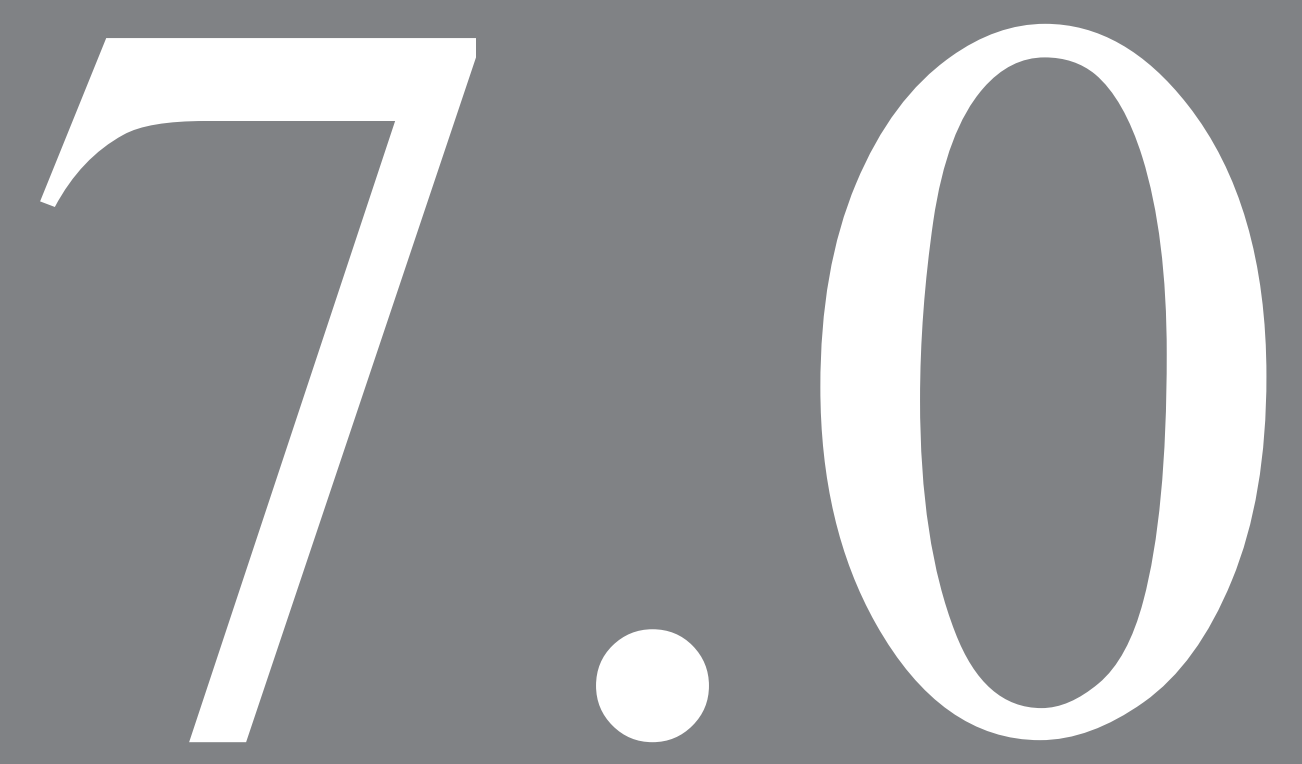

Final Design 
Today is the day.

I have kew starting to forget things these past few months. If seems to get worse as time goes ky. Try daughter has been having or allow how f need to go into a home hufose I cant look after myself. Ism nod sure why she thinks $\mathrm{g}$ am incapable of performing daily d asks. I have beer doing if by myall for years. They have all moved into town, closer to jobs and schools I suppose. But being oud on the farm is where of have spent most of my life. I know In going to mix waking up hew and plodding around looking and tending to my, gardens. Wendy tells me this new place sind much different from home, that they have animals and gardens and I can still look out onto the farm lands. I hope she is rights. I have packed all ry things st is funny hew your endive life can end up fitting ind a sickase. Il el be toking my and a few nick-nacks which I have gotten flam my late husband and children. Fd's the small things that matter now, family and memoirs. The ones that are still there of least. Dol. 
So I set up all my things in my room yesterday. Wendy and her husband Relpet. Its comforting having my things around me. I did neet a few lovely people yeaterday. Edha coas lirought up nol far from old setrool memaries. Il was an enjoyable first day. I do miso Rome lew I'm glad this is mase like a fromo than the place they sent my fieend hancy. It would tie lovely to Rave ker

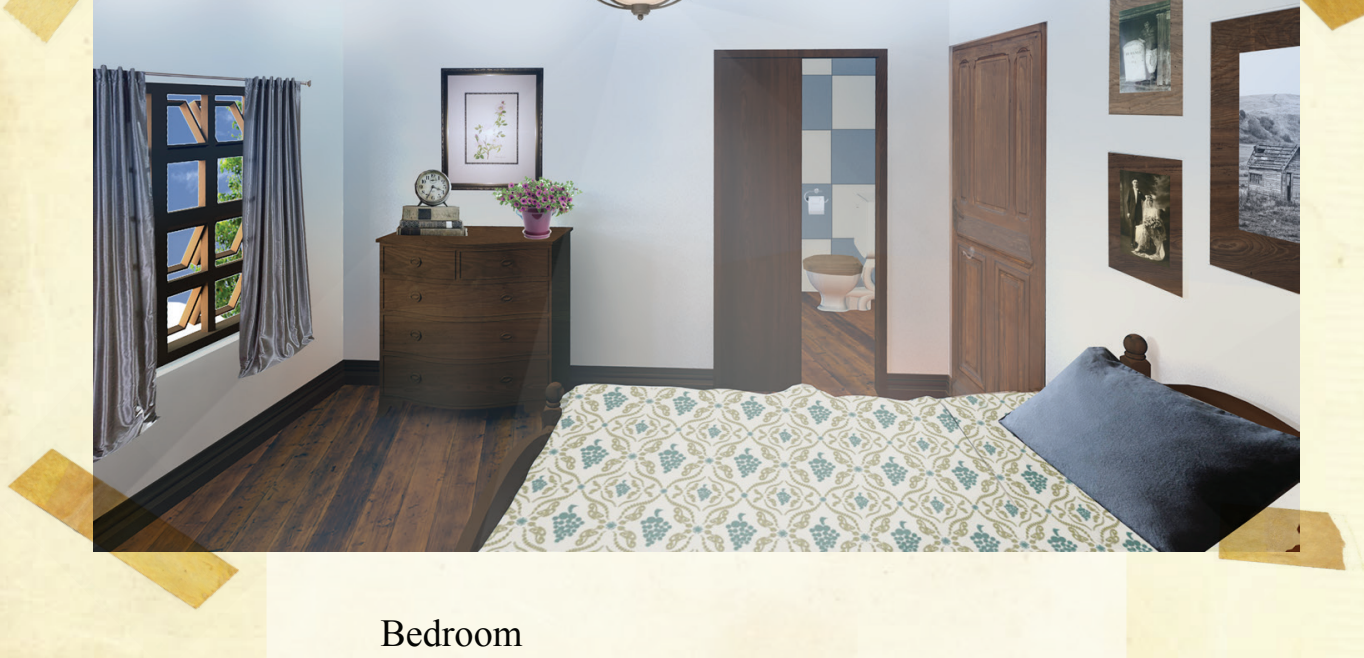

Light therapy from strip lighting hidden in scotia is therapeutic and reduces agitation. This design feature also avoids large ceiling tiles which aren't homelike.

Timber door provide a contrast to the wall materials, making them visible to residents.

Flexible layout allows for the resident to position the bed so that the room has a familiar layout.

Curtains provide a home-like touch.

Continuous flooring from bedroom to bathroom reduces uncertainity with colours and textiles.

A contrasting toilet seat increases the ability to find the toilet in the bathroom. 


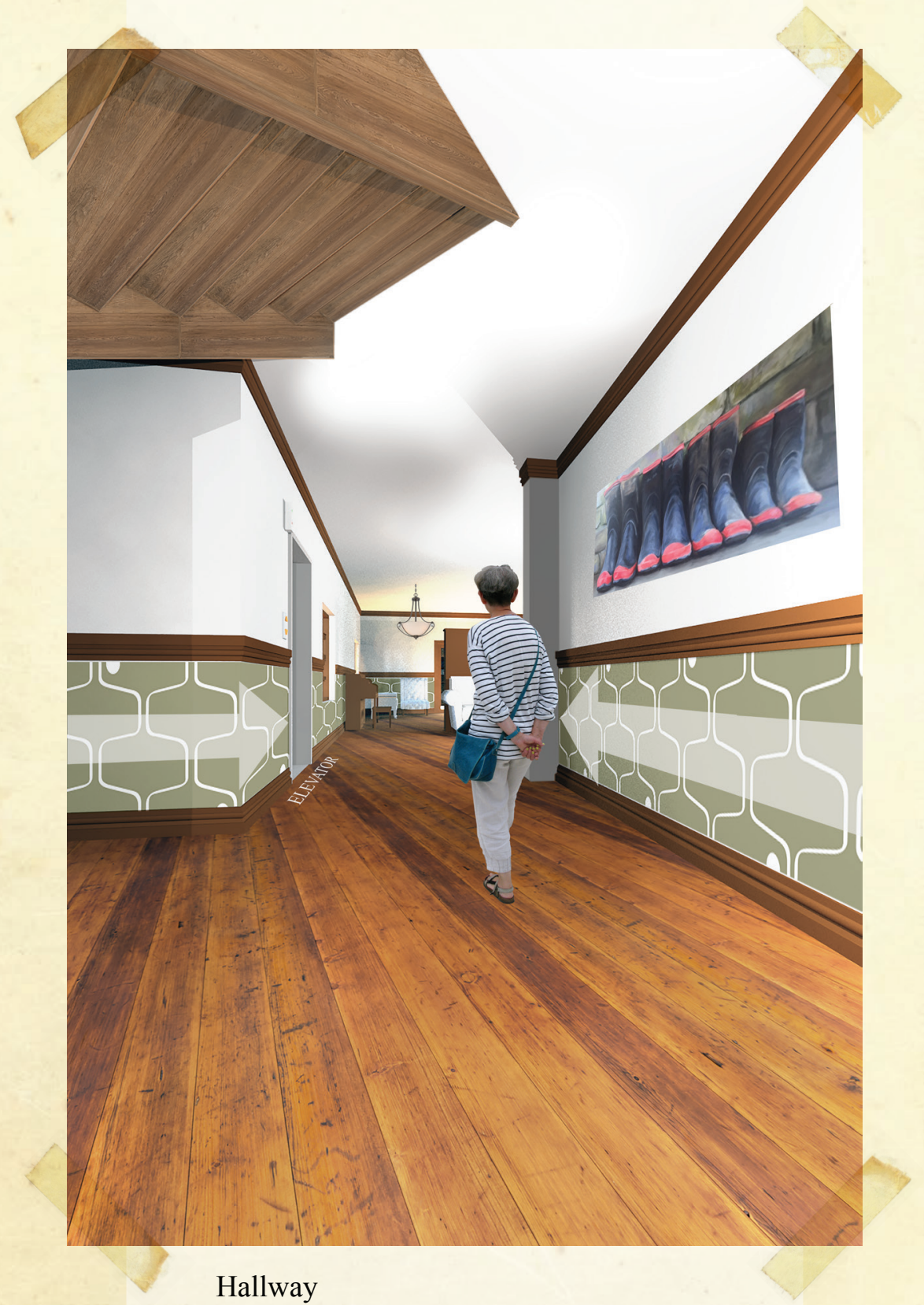

This historic print has been enlarged to create connections to past memories. It is used in all public areas.

An elevator helps with movement between levels.

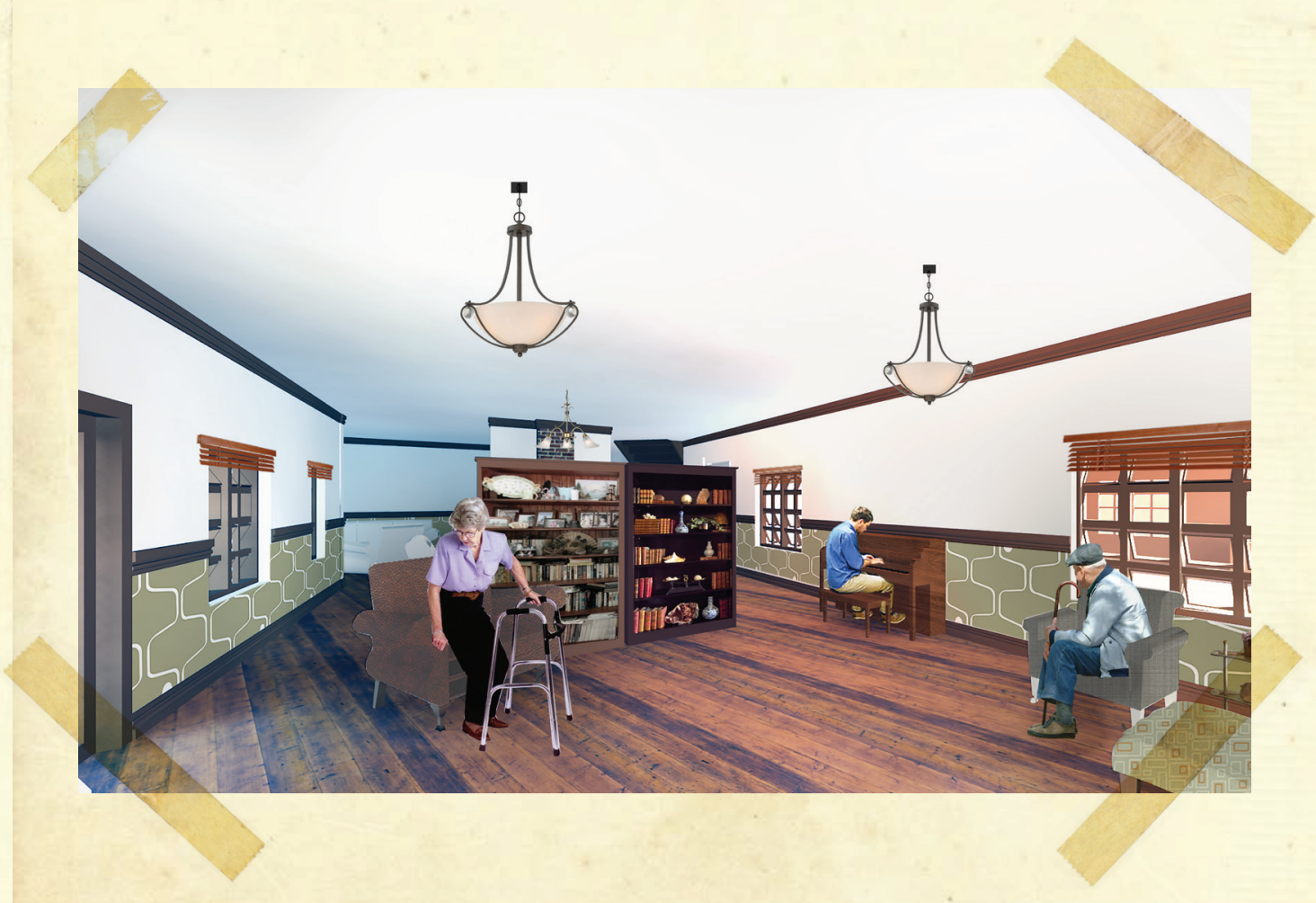

Joday, wre had a young chap in to play ma back to when I did lessons all throught school. I wasint neay good, my fingers seem to fumble coret the keys. Tred a lowely tady today, we sat rest to each other while the piano was bieng played. Her name was Edna. 


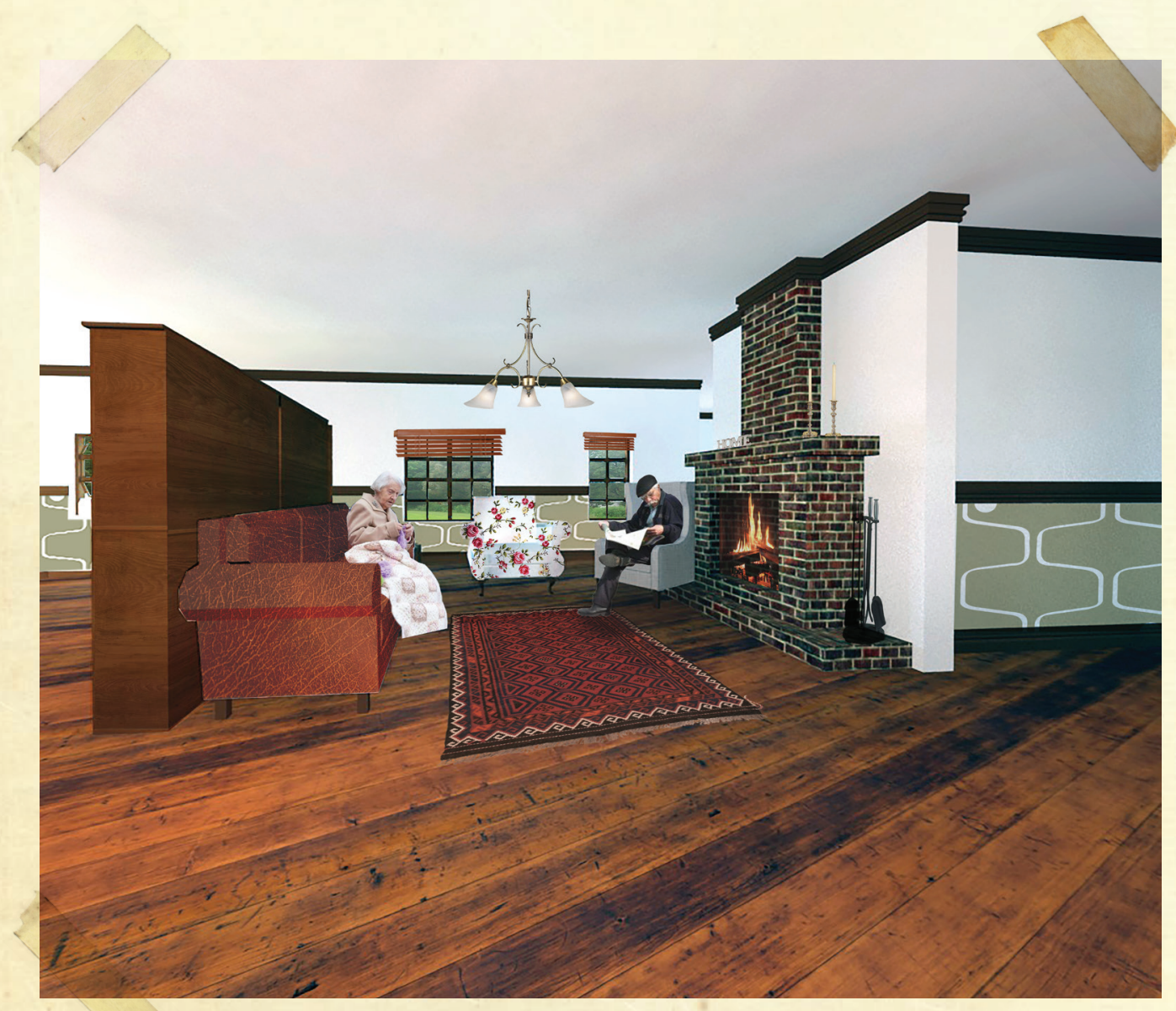

Social spaces

Scotia, commonly used in New Zealand homes, provides a contrast to both wallpaper and walls/ceiling.

Timber flooring laminate flows throughout the facility. It is a material that is easily cleaned and has less traction for people with walkers.

Personal furniture creates a home-like feeling and gives a sense of place to residents.

Room barriers such as the fireplace and bookshelves break up the large space, creating small sitting areas for clusters of people to retreat to rather than going back to their rooms. 
There is a spot I loue to sit in the afternoon. Gim is always sitting there rading the paper. I like to set in the coones in my chair and feel the sin. through the window above, If warno my leack. There is a also a touely rose trush oudside. I enjoy the seend fram my spol. It reminds me of wher I finst planded the gardens sursoundring the house on the farm, Bill and I owned. Thaven't seen Bill around hese very much. He must be away with the animals the ahowed Griesian hulls every year. Won a few dimes doo!!

\section{Sitting room}

The sitting room has a ceiling window to maximise afternoon light.

Timber panels reduce heat and light in summer months. 


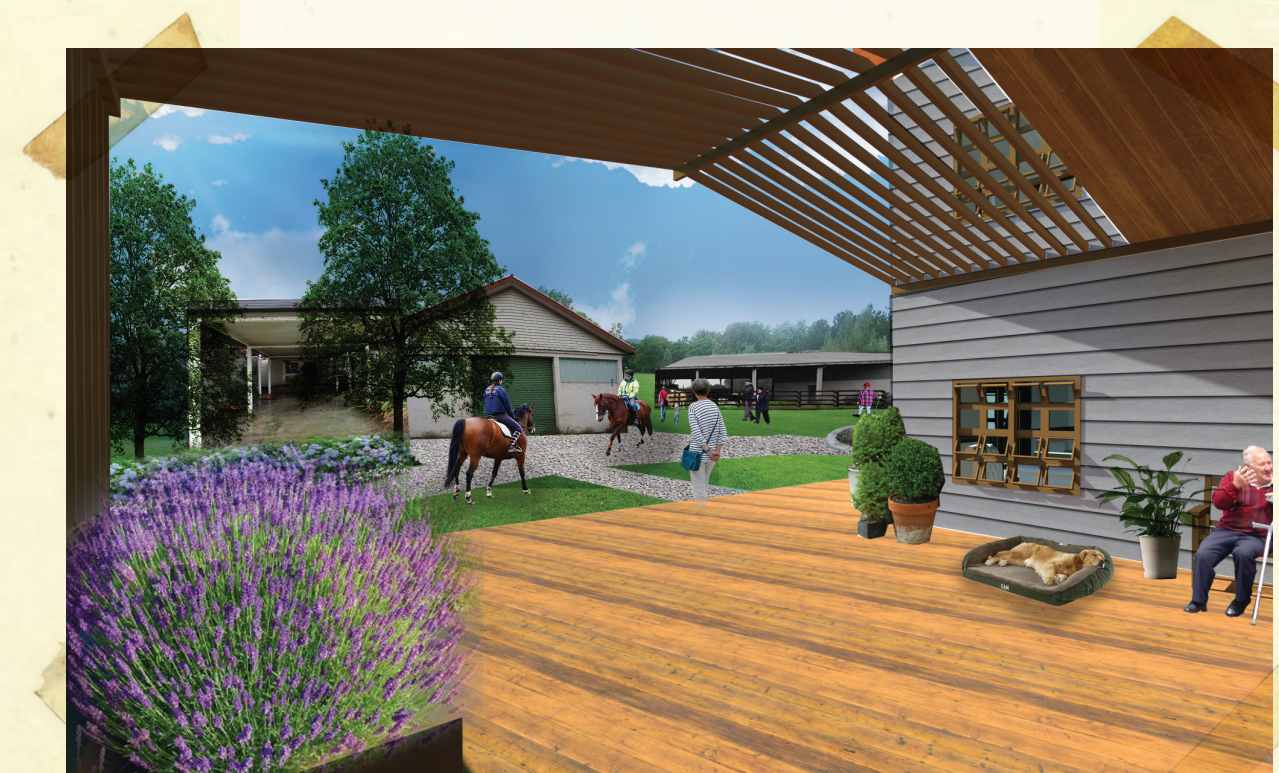

Exterior of facade

Timber panels show exterior building extension and provide shading.

Views to the surrounding community buildings visually engage residents and encourage them to wander outside.

Indoor garden

The indoor garden encourages residents to wander around the site or help with gardening. The garden invites families to go outside together.
Went for a wander to-day with Edna, such a toudy lady. Edna showed me a pretty indoor pond and garden right rest doos? Wo have decided to kelp with the gardening. I do miss my gorden, but this one is nice too hecause it. is indoors. Lets you keep out of the rain in winder, not that it ever hothered me: Sat on the seat for awhile and wotiched the ducks loobling up and dows in the wobter. On the way back to the house picked a deligilful

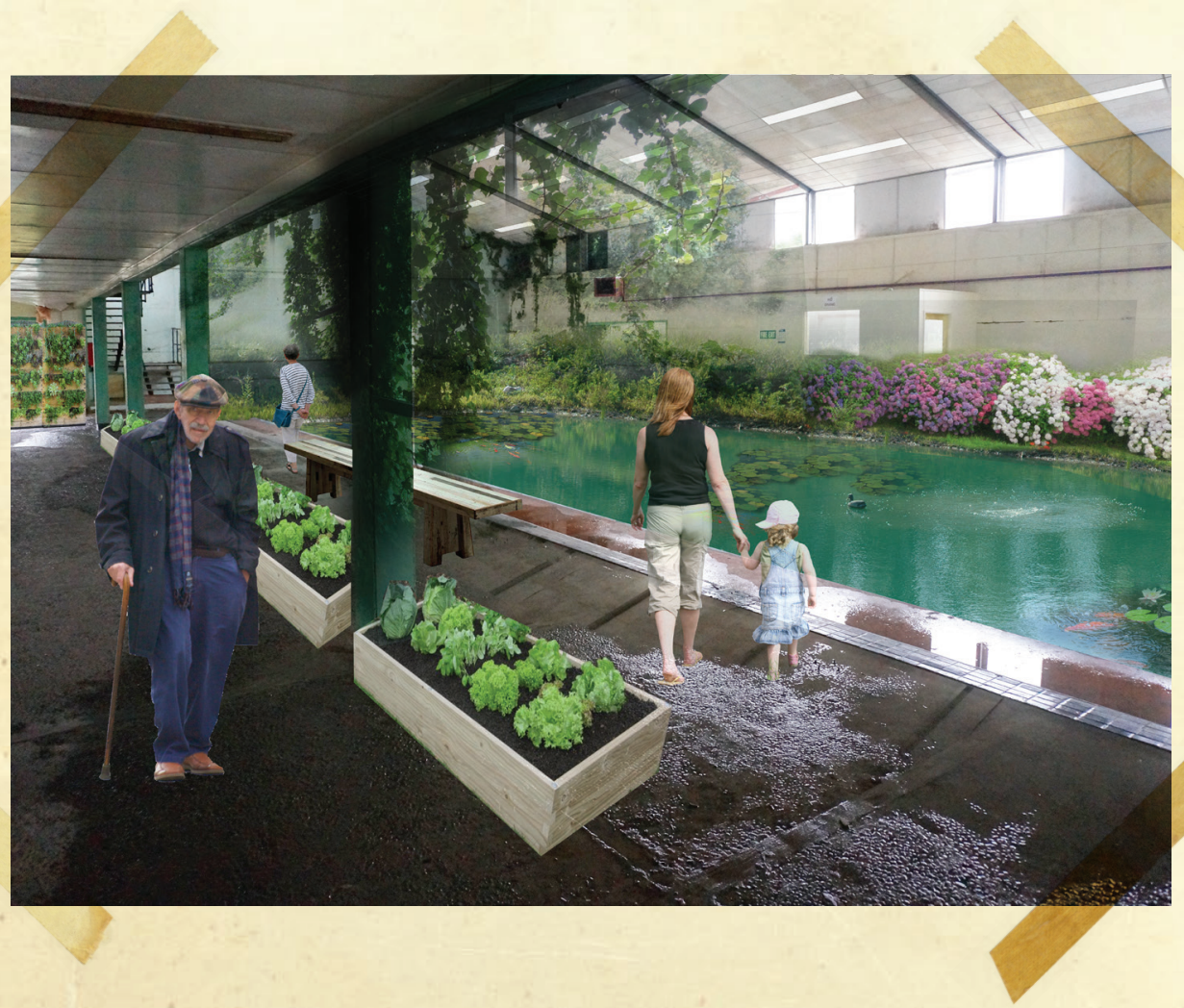




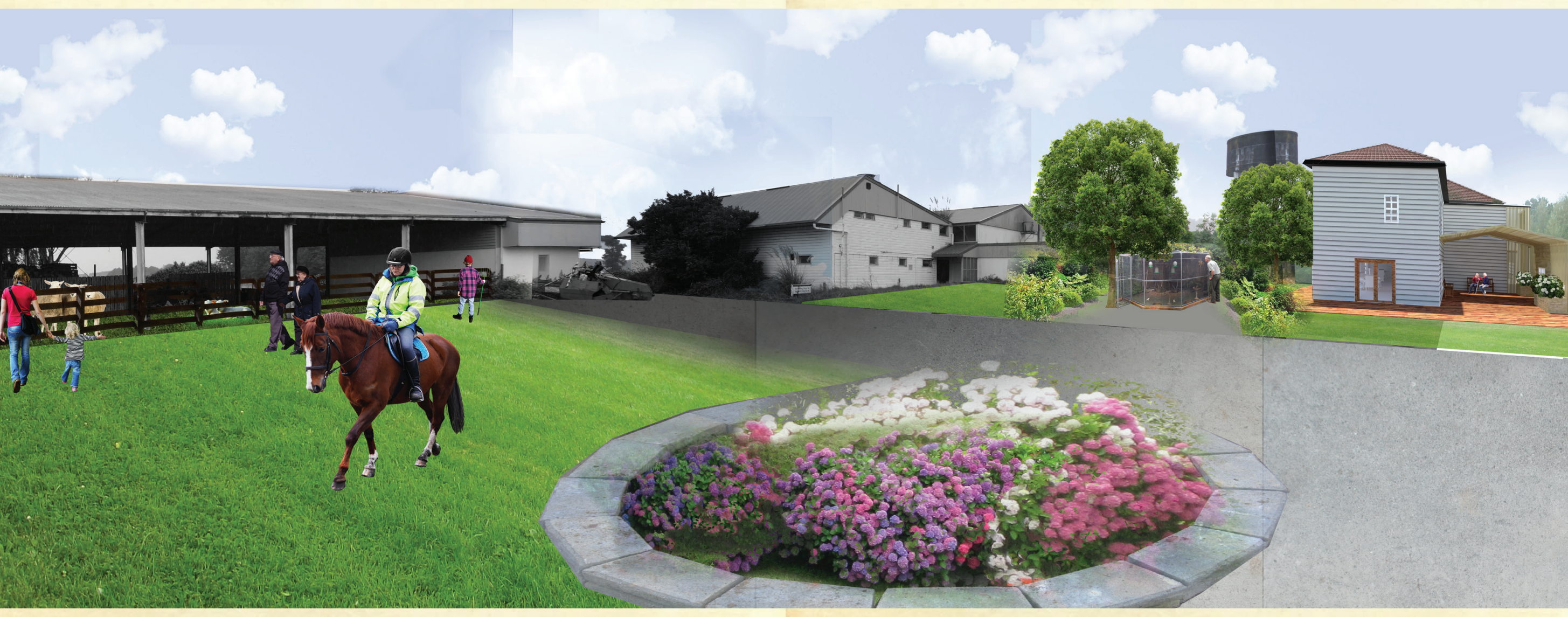


I thought I saw my husband do day. He was oud moving the cows so werd od to see if it was him. If coasint-nod for awhile. In suse hall be home for dirines. Went for a wandes around the reat of the property. Found firm, he was walking the dog and we solood and watched the gives for aubile before walking back to
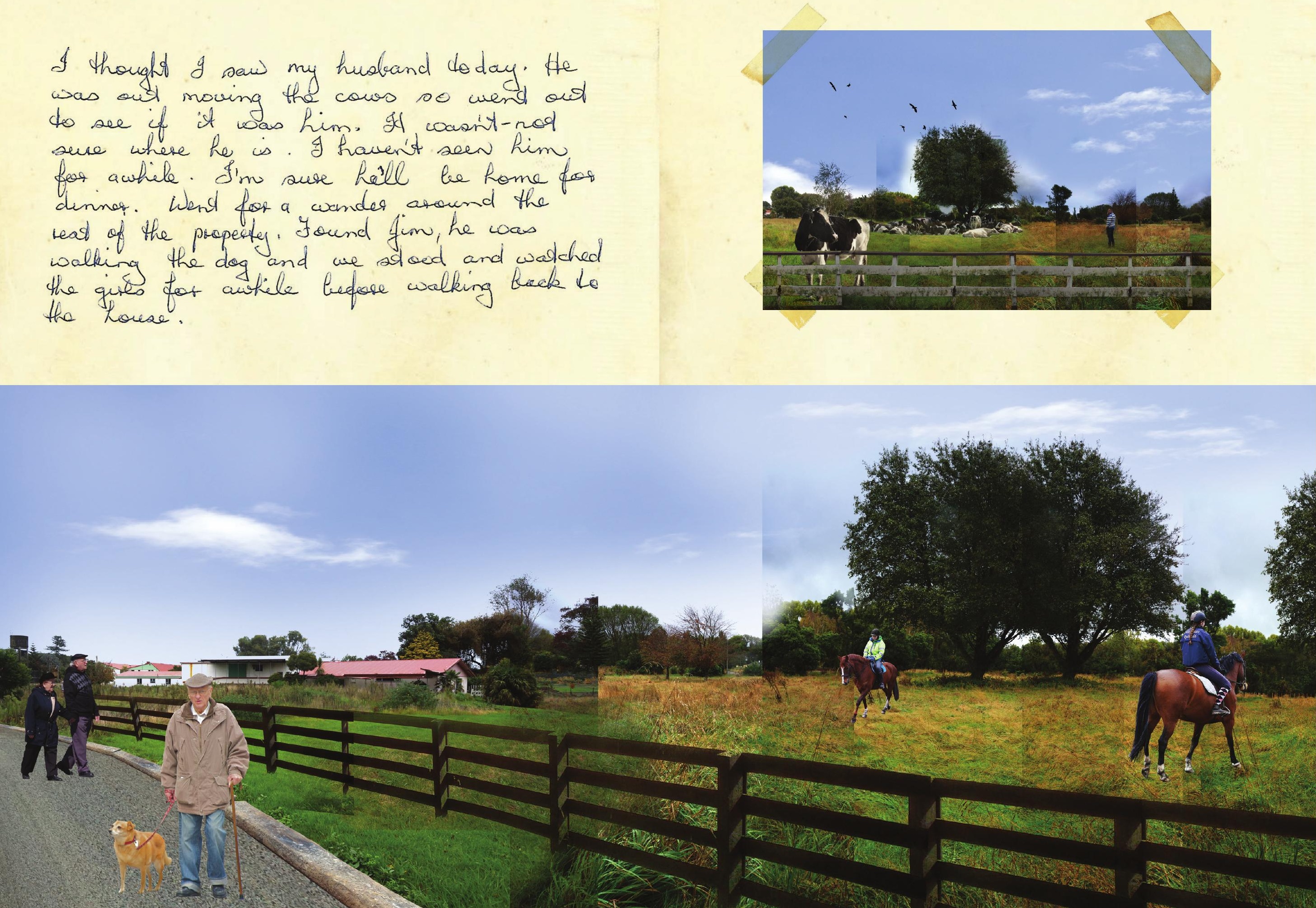


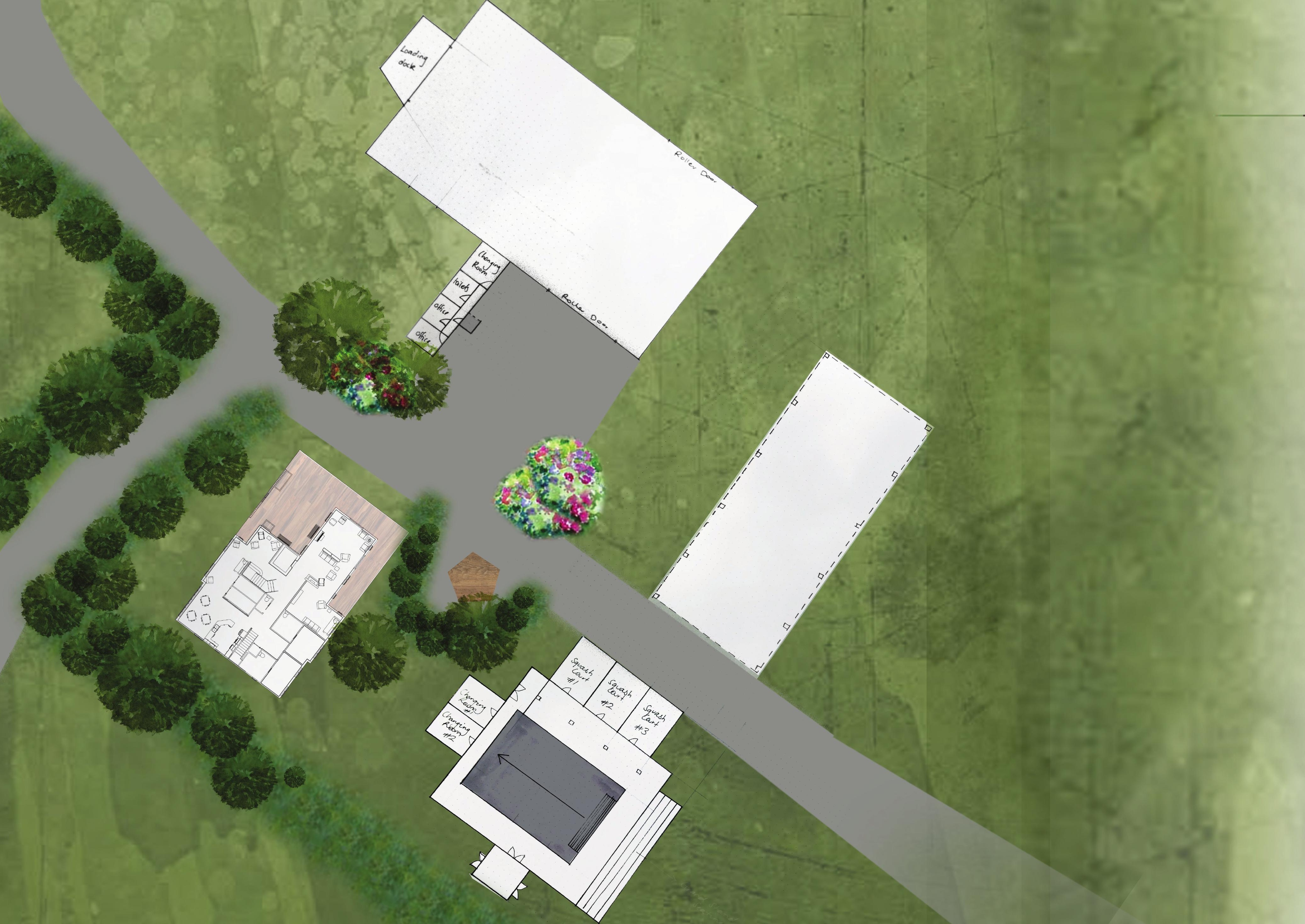




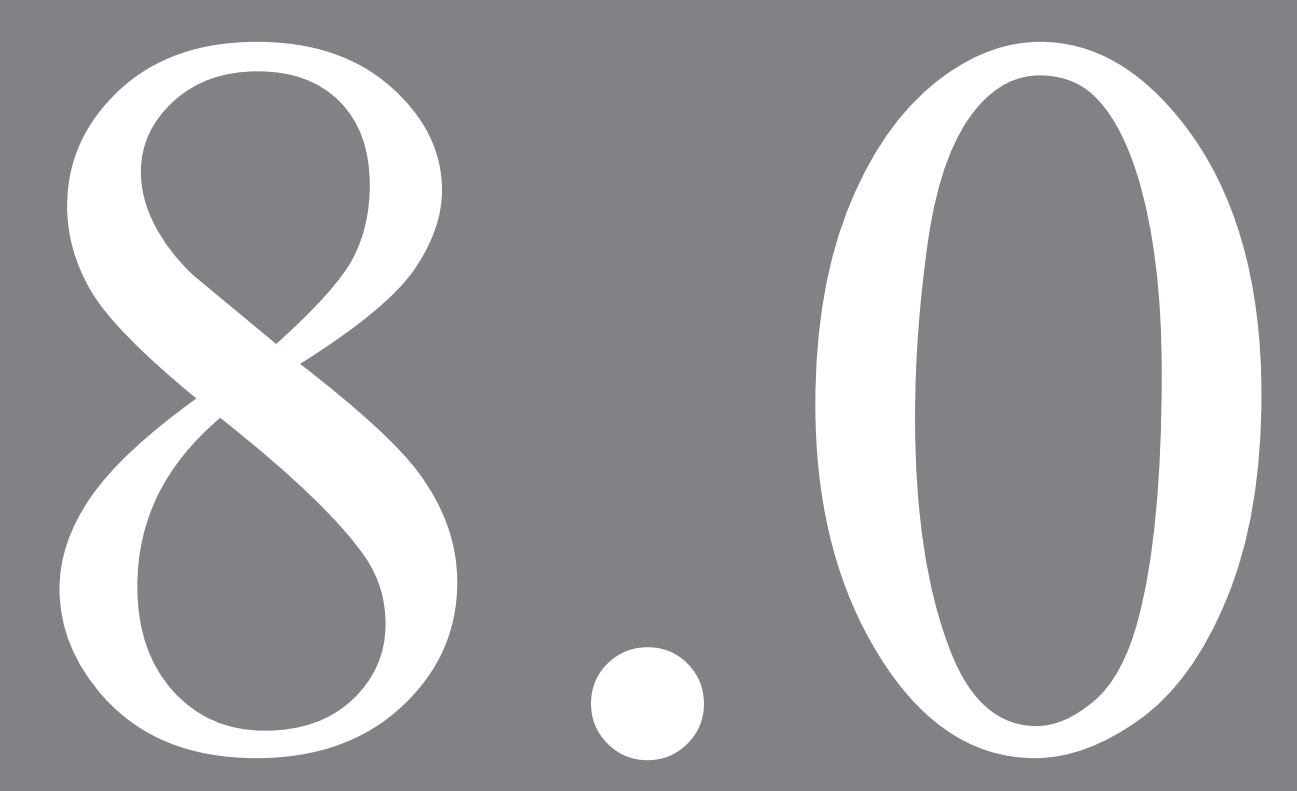

Conclusion 


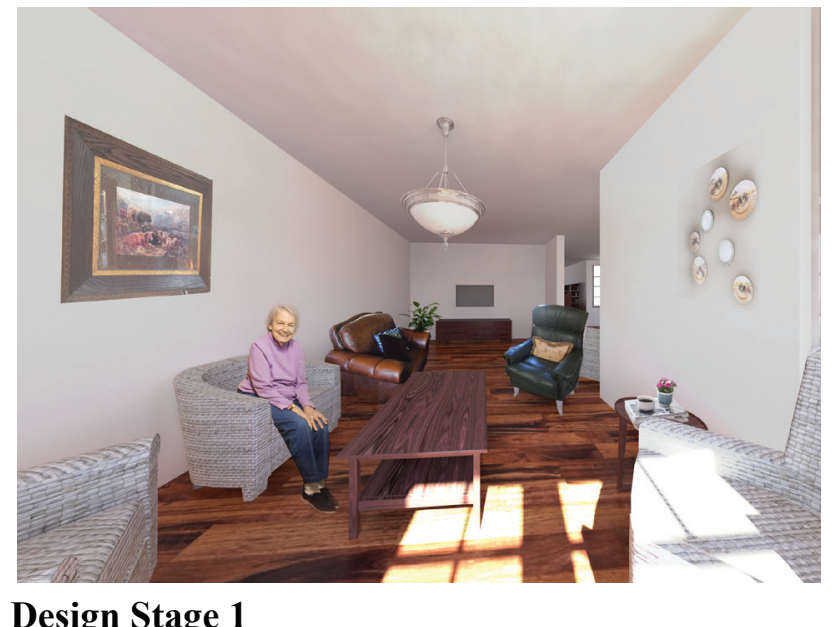

Design Stage 1

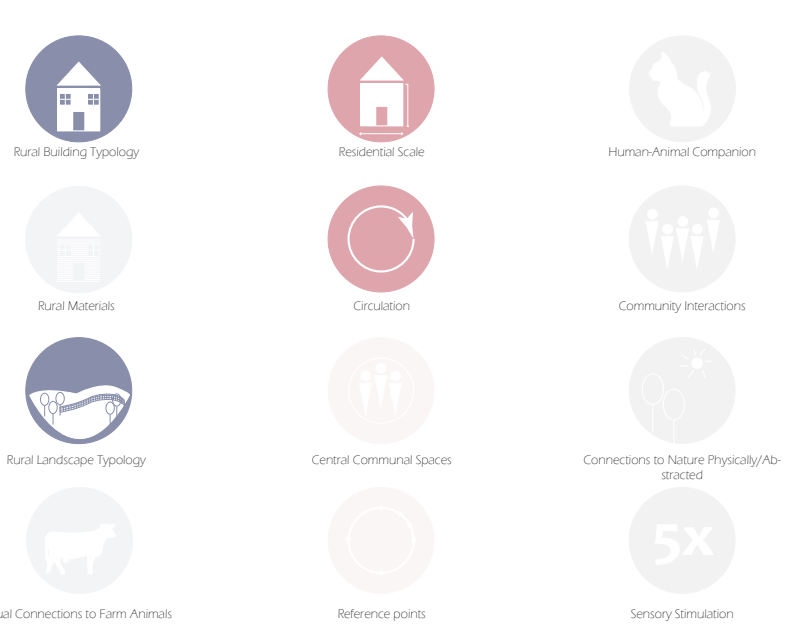

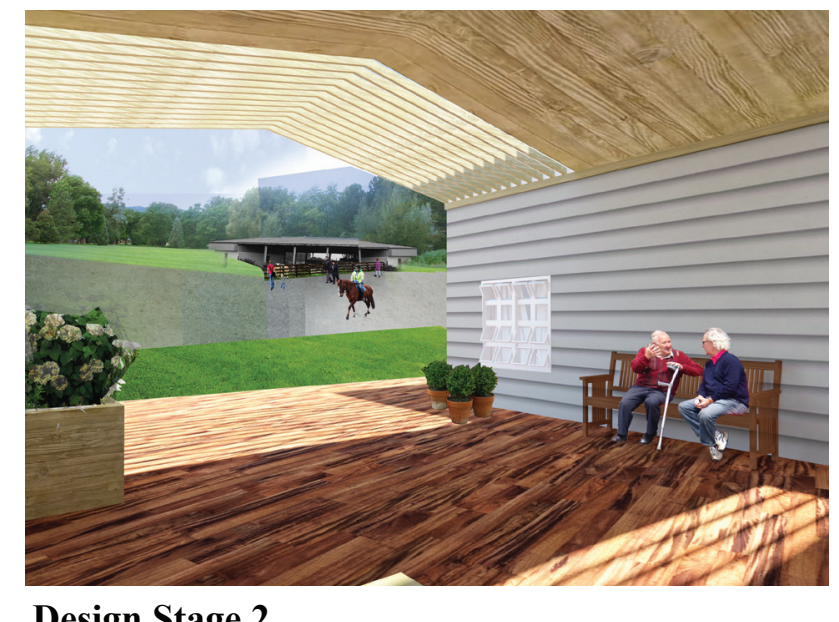

Design Stage 2

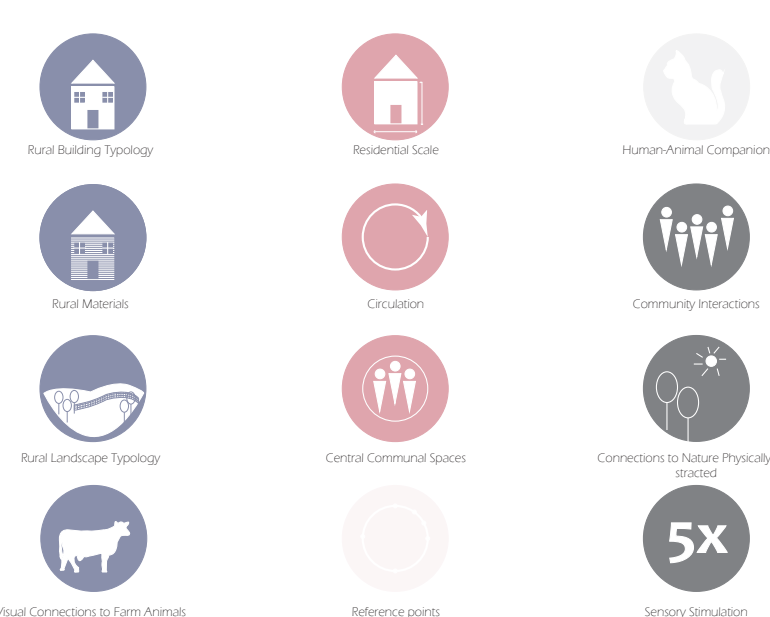

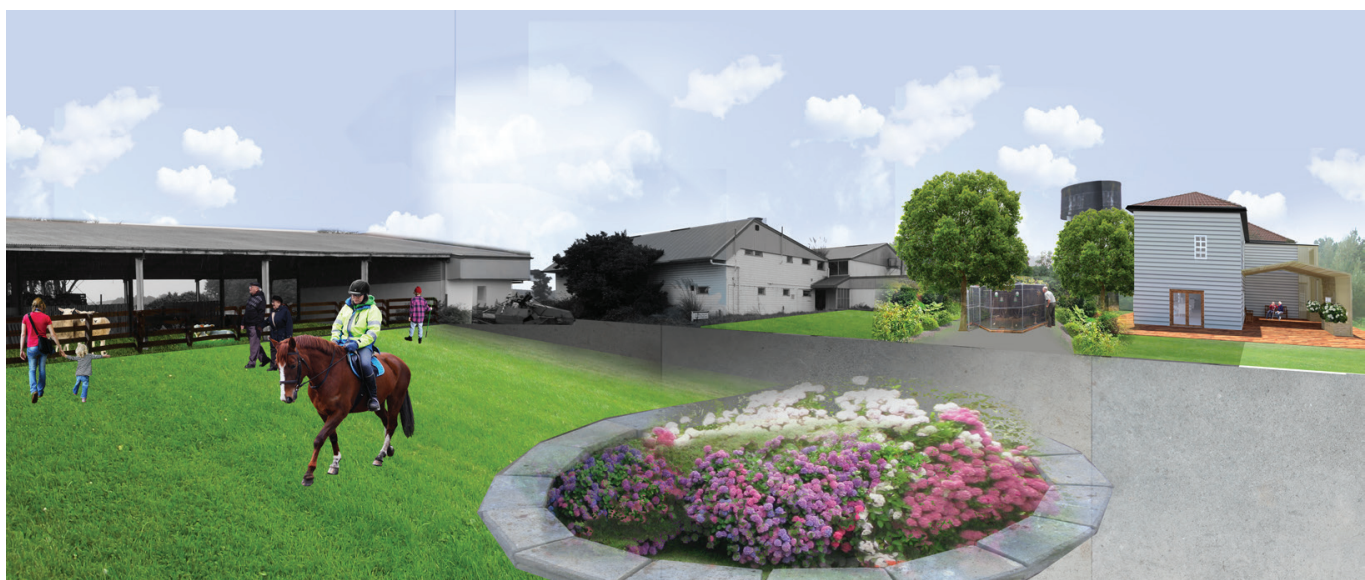

Final Design

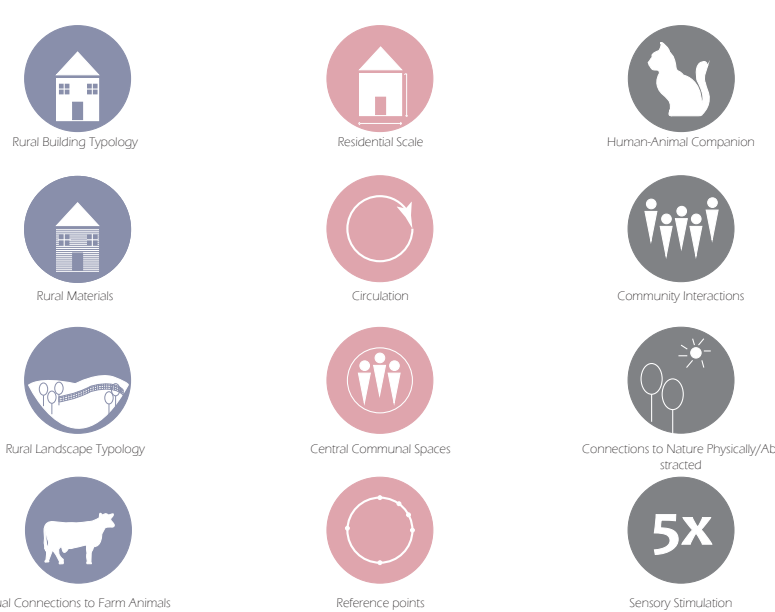


Loss of memory and confusion are becoming a reality for people living with dementia all over New Zealand. As the rate of people with dementia is set to increase, tripling before 2050 , there is a need for many more specialised facilities to accommodate them and to provide them with a reasonable quality of life. Currently specialised facilities ares limited specialised facilities designed to demest

As people with dementia lose their short-term memory and retreat to an earlier time period, modern technologies, newer building typologies, and even landscapes become foreign to them. To date, the focus of aged-care facilities has that are For a cleaned and institutional. For a resident with dementia, this new environment can be confusing, even more so if the person has never lived in a higher density urban environment. Wint the added difficulty that people with dementia are unable to regulate environmenta changes, the environment needs to respond to acconmodate this group of people. With the increased numbers in rural locations, New Zealand has an opportunily to produce adentia centres, drawing on contextual
design, wayfinding, therapy, and how these relate to people with dementia.

Designing a space that is less institutional and draws on homelike features reduces agitation and confusion in residents. This visually congruent design aligned with the lifestyles that people from a rural community have come from can enhance the morale in residents placed in dementia care. Characteristics such as materials, sizing, typology and landscape views are features which differentiate rural design from urban design facilities. The proposed dementia centre takes the site of Flock House on the outskirts of the rural town Bulls, and brings back life to a historically influential former farming institution. The farming typology of the site allows for a wide expanse of views in all directions, and an outlook onto daily farming animals and farmer routines. The addition of this visual connection to prior lifestyles of a rural resident with dementia will provide comfort and entertainment.

Cognitive abilities of people importance of creating an interior which sympathises with aged-care, mobility, wayfinding, and wandering are aspects which will reduce confusion in spatial arrangements. With the input of first hand dementia knowledge through the author's visits to facilities, small details become prominent design features within the interior. Ensuring these features are delivered in a home-like fashion enhances how this

The addition of therapy through influential practices such as Biophilia and the 12 Steps of Eden have Conhanced aspects of the design. and exterior have been explored to create stimuli for the residents, and generate community interaction between site and residents. The importance of human-animal bond is highly regarded as a form of therapy, and relates to the former lifestyle of people from a rural community.

The proposed dementia centre looks at 12 design imperatives based on therapeutic design, which she and the final design was established. As dementi limits a person's abilities, the design outcome has been shaped by this and has resulted in a fully functional healthere facility with the design of a rural homestead. The proposed site and final design has explored all aspects of dementia and seeks to eliminate through design 政 people living with dementia.

The research did not extend into a cost analysis of the final design. As the selected site is rather derelict the costs of renovating buildings and cleaning up the landscape to a high standard could be considerable. With additional time, further analysis into materials and wayfinding aesthetics could enhance the design outcome. 


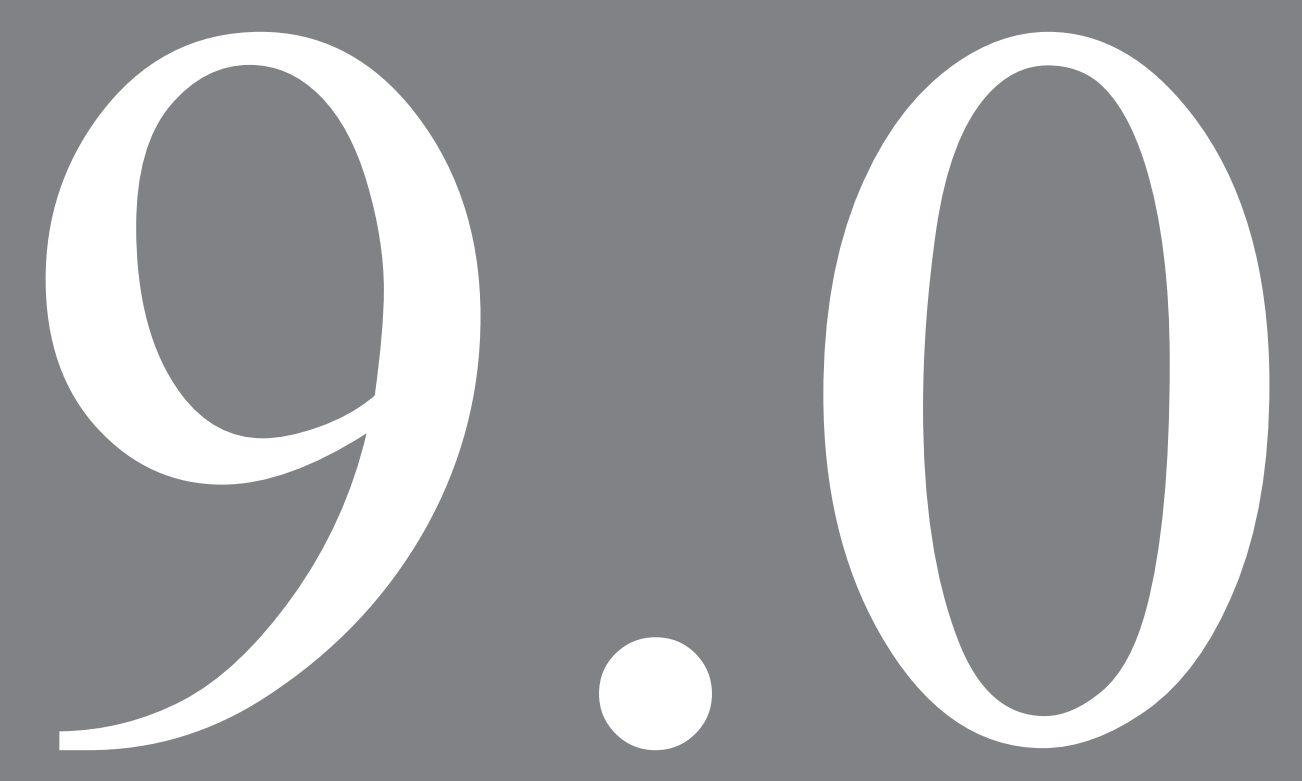

References 
-"Flock House Farm to Be Jointly Run." Radio New Zealand. Web. 2 Nov. 2015.

-"The Royal Children's Hospital by Billard Leece Partnership and Bates Smart Architects, Melbourne.” Architecture And Design. Web. 23 Sept. 2015.

-“Hogeweyk.” Web. 17 June 2015.

-"New Accommodation Facility for Alzheimer's / Philippon-Kalt | ArchDaily.” Web. 24 Apr. 2015

-“Project 'Herbergement Alzheimer a Paris'.” Web. 28 Sept. 2015.

-“Royal Children's Hospital | Australian Design Review.” Web. 23 Sept. 2015.

-"Te Hopai - Rest Home Care. Resthomes and Residential Care in New Zealand. Eldernet - Seniors and Retirement Options.” Web. 20 May 2015.

-“The 5 Stages of Dementia: How Dementia Progresses.” Web. 25 Sept. 2015.

-“The Royal Children's Hospital.” ArchitectureAU. Web. 23 Sept. 2015.

-“The Royal Children's Hospital.” ArchitectureAU. Web. 29 Sept. 2015.

-"Vacancies - Dementia Care (Secure Environment) - MidCentral." Web. 24 Mar. 2015.

Alzheimers New Zealand. "Awareness.” Alzheimers New Zealand. 2012. Web. 17 Mar. 2015.

-Alzheimers New Zealand. "Reports \& Statistics." Alzheimers New Zealand. 2012. Web. 17 Mar. 2015.

-ArchDaily. "Care Housing / Oliver Chapman Architects." Web. 7 Apr. 2015.

-ArchDaily. "Concoret Housing for the Elderly / Nomade Architects." Web. 7 Apr. 2015

-Baun, Mara M., and Barbara W. McCabe. "Companion Animals and Persons With Dementia of the Alzheimer's Type: Therapeutic Possibilities." American Behavioral Scientist 47.1 (2003): 42-51. Web. 23 Apr. 2015.

-City Planning Department. Palmerston North Houses 1880-Present Day. Palmerston North: Swiftprint Centre Ltd, 1986. Print.

-Deloitte Access Economics. Report Updated Dementia Economic Impact Report 2012 New Zealand. 2012. Web. 17 Mar. 2015.

-Dictionary.com Unabridged. "Rural | Define Rural at Dictionary.com.” Web. 3 Nov. 2015

-Eden Alternative Data. 1999. Web. 29 Mar. 2015.

-Eldernet. "Rest Homes, Retirement Villages and Home Services in New Zealand." Eldernet. 2015. Web. 29 Mar. 2015

-Ervin, Kaye, Sarah Finlayson, and Maddalena Cross. "The Management of Behavioural Problems Associated with Dementia in Rural Aged Care." Collegian 19.2 (2012): 85-95. Web. 7 Apr. 201

-FISCHL, GÉZA. "A Psychosocial Approach to Architectural Design.” Division of Engineering Psychology, Department of Human Work Sciences, Luleå University of Technology Web. 15 Apr. 2015
-Passini, Romedi et al "Wayfinding in a Nursing Home for Advanced Dementia of the Alzheimer's Type." Environment and Behavior 32.5 (2000): 684-710. Prin

-Harper, Geoffery M. "Report on the Dysfunctional Provision of Rest Home Care and Funding in New Zealand.” Tauranga: 2011. Web. 19 Feb. 2016

-Haddad, Elie. "Christian Norberg-Schulz's Phenomenological Project In Architecture.” 30 Mar. 2010. Web. 1 Apr. 2015.

-Holtzblatt, Karen, and Hugh Beyer. "Contextual Design." Interraction Design Foundation: A Global Community of the World's Best Designers. Web. 27 Apr. 2015. -Keen, Justine. "Interiors: Architecture in the Lives of People with Dementia." International Journal of Geriatric Psychiatry 4.5 (1989): 255-272. Print.

-Kristen Day, Daisy Cameron, and Cheryl Stump. "The Therapeutic Design of Environments for People With Dementia." Web. 8 Apr. 2015.

-Littlefield, David. "10 - Homes for Older People.” Metric Handbook. Third. Great Britain: Elsevier - Architectural Press, 2008. Web. 5 May 2015.

-Marquardt, Gesine, and Peter Schmieg. "Dementia-Friendly Architecture: Environments That Facilitate Wayfinding in Nursing Homes." American Journal of Alzheimer's Desease \& Other Dementias 24.4 (2009): 333-340. Print.

-Mental Health Foundation of New Zealand, and Janet Peters. "Dementia." Mental Health Foundation. Nov. 2014. Web. 17 Mar. 2015.

-Ministry of Health. New Zealand Framework for Dementia Care. 2013. Web. 17 Mar. 2015.

-Morgan, D. G. et al. "Evaluating Rural Nursing Home Environments: Dementia Special Care Units versus Integrated Facilities." Aging \& Mental Health 8.3 (2004): Web. 7 Apr. 2015

-Patsy McMillan. “Flock House.” Research. Web. 2 Nov. 2015.

-Pop, Dana. "Space Perception and Its Implication in Architectural Design." Acta Technica Napocensis: Civil Engineering \& Architecture 56.2 (2013): 211-221. Print.

-Reynolds, Sandra G., and Julia O. Beamish. "Residential Satisfaction of Older Adults in Age-Segregated Facilities." Housing and Society 30.1 (2003): 33-49. Print. -Statistics New Zealand. "New Zealand Period Life Tables: 2010-12." Statistics New Zealand. 16 Apr. 2013. Web. 17 Mar. 2015.

-Terrapin Bright Green. "14 Patterns of Biophilic Design.” Web. 30 June 2015

-The Eden Alternative. "Mission, Vision, Values, Principles." Eden Alternative. 2015. Web. 29 Mar. 2015.

-Victorian Government Health Information. "Interior Design: Dementia-Friendly Environments.” Interior Design. 16 July 2014. Web. 22 Feb. 2016.

-Walsh, Froma. "Human-Animal Bonds I: The Relational Significance of Companion Animals." Family Process 48.4 (2009): 462-480. Print.

-Wildevuur, Sabine et al. Connect - Design for an Empathic Society. BIS Publishers, 2013. Print. 


$$
10.0
$$


1.0.1 Brain Atrophy in Advanced Alzheimer's Disease. Digital image. Dementia in Elders: A Game Based Rehab. 16 Dec. 2014. Web. Apr. 2015.

3.0.2 Aerial Image of New Zealand. N.d. New Zealand. New Zealand from Space. Web. Nov. 2015.

3.1.1 Corridor. 2012. Wellington. Maycroft Construction. Web. June 2015.

3.1.2 Outdoor courtyard. 2012. Wellington. Maycroft Construction. Web. June 2015.

3.1.3 Interior Sitting Area. N.d. Wellington. Rest Home Care : Te Hopai. Web. Apr. 2015

3.1.4 Landscape. N.d. Wellington. Te Hopai. Web. June 2015.

3.2.1 Williams, Tamara. Bedroom layouts. 2015. JPEG file.

3.2.2 Williams, Tamara. Outdoor garden. 2015. JPEG file.

3.2.3 Williams, Tamara. Interior sitting area. 2015. JPEG file.

3.2.4 Williams, Tamara. Corridor. 2015. JPEG file.

3.2.5 Williams, Tamara. Dining area. 2015. JPEG file.

3.3.1 Kluger, Scott. Lounge area. 2015. JPEG file.

3.3.2 Kluger, Scott. Ceiling panels - Lighting. 2015. JPEG file.

3.3.3 Kluger, Scott. Exterior gardens. 2015. JPEG file.

3.3.4 Kluger, Scott. Outdoor seating area. 2015. JPEG file.

3.3.6 Apollo. The Blue Marble. Digital image. Wikipedia.1972. Web. 2015.

3.4.1 Exterior connections between apartments. Digital image. Dementia Village 'De Hogeweyk' in Weesp. Detail, 19 June 2012. Web. Mar. 2015.

3.4.2 Interactive community aspects. Digital image. Dementia Village 'De Hogeweyk' in Weesp. Detail, 19 June 2012. Web. Mar. 2015.

3.4.3 Interior décor options. Digital image. Dementia Village 'De Hogeweyk' in Weesp. Detail, 19 June 2012. Web. Mar. 2015.

3.5.1 Bremner, Angus, and Paul Zanre. Exterior View of Buildings. 2010. Scotland. Care Housing / Oliver Chapman Architects. Web. Sept. 2015.

3.5.2 3D site image. 2010. Scotland. Care Housing / Oliver Chapman Architects. Web. Sept. 2015.

3.5.3 Bremner, Angus, and Paul Zanre. Exterior view of materiality and landscape. 2010. Scotland. Care Housing / Oliver Chapman Architects. Web. Sept. 2015.

3.5.4 Bremner, Angus, and Paul Zanre. Interior entry way. 2010. Scotland. Care Housing / Oliver Chapman Architects. Web. Sept. 2015.

3.6.1 Boegly, Luc. Overall building image. 2013. France. Concoret Housing for the Elderly / Nomade Architects. Web. Sept. 2015.

3.6.2 Boegly, Luc. Exterior image. 2013. France. Concoret Housing for the Elderly / Nomade Architects. Web. Sept. 2015.
3.6.3 Boegly, Luc. Exterior verandah. 2013. France. Concoret Housing for the Elderly / Nomade Architects. Web. Sept. 2015.

3.6.4 Boegly, Luc. Living area. 2013. France. Concoret Housing for the Elderly / Nomade Architects. Web. Sept. 2015.

3.6.5 Boegly, Luc. Interior corridor. 2013. France. Concoret Housing for the Elderly / Nomade Architects. Web. Sept. 2015.

3.7.1 Abbadie, Herve. Landscape surrounding building. 2013. France. New Accommodation Facility for Alzheimer's / Philippon-Kalt. Web. Sept. 2015.

3.7.2 Abbadie, Herve. Opposite side of the building. 2013. France. New Accommodation Facility for Alzheimer's / Philippon-Kalt. Web. Sept. 2015.

3.7.3 Kalt, Gregoire. Interior colour-coded floor levels. 2013. France. New Accommodation Facility for Alzheimer's / Philippon-Kalt. Web. Sept. 2015.

3.7.4 Abbadie, Herve. Interior entryway. 2013. France. New Accommodation Facility for Alzheimer's / Philippon-Kalt. Web. Sept. 2015.

3.8.1 McGrath, Shannon. Infant medical room. 2012. Melbourne. The Royal Children's Hospital. Web. Sept. 2015

3.8.2 McGrath, Shannon. Interior fish tank. 2012. Melbourne. The Royal Children's Hospital. Web. Sept. 2015

3.8.3 McGrath, Shannon. Private medical rooms. 2012. Melbourne. The Royal Children's Hospital. Web. Sept. 2015

3.8.4 McGrath, Shannon. Reception desk. 2012. Melbourne. The Royal Children's Hospital. Web. Sept. 2015

3.8.5 McGrath, Shannon. Children's room. 2012. Melbourne. The Royal Children's Hospital. Web. Sept. 2015

4.0.4 Kurdulija, Peter. Spring Is When All The Flowers Join The Choir Manawatu. Digital Photographer. Web. Oct. 2015

4.0.5 Wellington Harbour. Wellington. Amora Hotel Wellington. Web. Oct. 2015

4.0.8 House built for a Māori farmer. Wanganui. Te Ara. Web. May. 2015

4.0.9 Rural House, New Zealand. Bachology. Web. May. 2015

4.0.10 Rural self contained Queenstown B\&B. Queenstown. Willowbrook an Surroundings. Web. May. 2015

4.0.11 Hattan, Teresa. House Fire. Waikato. Stuff. Web. May. 2015

6.6.1 Kluger, Scott. Massey University controlled lighting room. 2015. JPEG

6.9.3 Kauri natural timber flooring. Kauri Warehouse. Web. Nov. 2015

6.9.4 Timber look-alike laminate flooring. Kwila (Merbau). Timspec. Web. Nov. 2015 


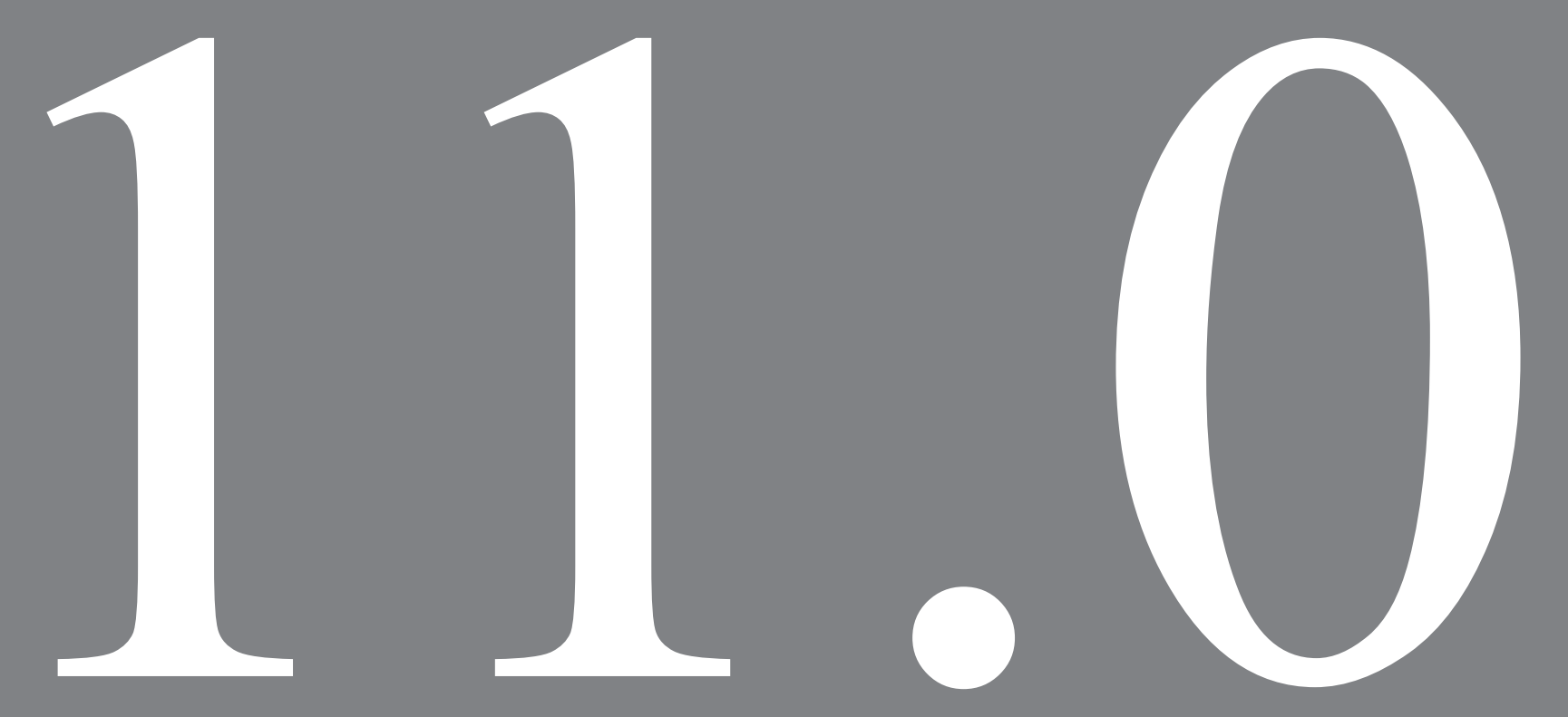

Appendix 


\section{INFORMATION SHEET:}

Participant Information Sheet for a Study of Interior Design related to Dementia Care

\section{Researcher: Sarah Cheetham, School of Architecture and Design, Victoria University of Wellington}

I am a Masters student in Interior Architecture at Victoria University of Wellington. As part of this degree I am undertaking a research project leading to a thesis. The project I am undertaking is examining the difficulties Dementia patients encounter within the realm of Interior Design as the disease progresses. This research project has received approval from the Victoria University Human Ethics Committee.

I am inviting caregivers or people working in dementia facilities to participate in this study. Participants will be asked to complete a short questionnaire, outlining difficulties that Dementia patients encounter in the facilities that they work within.

It is envisaged that the questionnaire will take about half an hour to complete, may be completed in your own time and returned to me personally or via the post. Stamped addressed envelopes will be supplied.

Should any participants feel the need to withdraw from the project, they may do so without question at any time before 30 September 2015. Just let me know at the time.

Responses will form the basis of my research project and will be included in a written report on an anonymous basis. It will not be possible for you to be identified personally. Only grouped responses will be presented in this report, allowing only generalised summaries based on all answers provided. All material collected will be kept confidential. No other person besides me and my supervisor Jacqueline McIntosh will see the questionnaires. The thesis will be submitted for marking to the School of Architecture and Design, and deposited in the University Library. Questionnaires will be destroyed at end of the project.

If you have any further questions or would like to receive further information about the project, please contact me

Sarah Cheetham

Or my supervisor

Jacqueline McIntosh,

At the School or Architecture and Design at Victoria University

Jacqueline.mcintosh@,vuw.ac.nz

\section{CONSENT TO PARTICIPATE IN RESEARCH \\ Title of project: Interiority of a Disconnected Mind}

This thesis topic looks into the interior aspects that Dementia patients find difficult to overcome in aged-care facilities. I have agreed to participate in completing a questionnaire to aid in the research of this thesis. I have been given and have understood an explanation of this research project. I have had an opportunity to ask questions and have them answered to my satisfaction. I understand that I may withdraw myself (or any information I have provided) from this project before 30 September 2015, without having to give reasons.

I understand that any information I provide will be kept confidential to the researcher and the supervisor of the project. I understand the published results will not use my name, and that no opinions will be attributed to me in any way that will identify me.

- I understand that I will have an opportunity to check and modify my answers on the questionnaire before I submit to the researcher.

- I understand that I can leave questions unanswered if I do not feel comfortable answering.

- I understand that the data I provide will not be used for any other purpose or released to others without my written consent.

- I would like to receive a summary of the results of the research when it is completed.

- I understand that the information I have given will be destroyed at the completion of this thesis.

- I agree to take part in this research.

Signed:

Name of participant:

Date:

Researcher:

Sarah Cheetham

cheethsara

nterior Architecture Masters Student

Victoria University of Wellingt 


\section{CAREGIVERS QUESTIONNAIRE:}

\section{Name of Participant:}

Dementia Care Centre:

\section{Researcher:}

Sarah Cheetham

cheethsara(@) myvuw ac nz

nterior Architecture Masters Student

Architecture and Design School

Victoria University of Wellington

\section{Sunlight and Windows:}

1. How do you find the residents react to sunlight?

2. Do you find they prefer more sunlight to less? (more/less)

3. Do residents prefer to sit in front of windows, or sit further into the room?

4. Based on the number of windows present in current environment, would you suggest more or less visual connections (windows) to the exterior? (more/less)

5. What's your biggest concern with large windows and glass doors?

\section{Surface treatments:}

1. What have you found doesn't work where flooring surfaces are concerned?

2. Are there specific surfaces that you have found the patients struggle with?

3. Do you find that surface changes from inside to inhibit outside exploration?

4. If yes, how would you broach this design flaw?

5. Do you find difficulties with surface changes in the bathroom?

6. Are there any specific colours that you have found the patients struggle with?

\section{Personal belongings:}

1. Do many of the residents bring in belongings to personalise their rooms? (yes/no)

2. Can these be moved into the common areas? (yes/no)

3. What is the most typical of objects brought from home?

4. Do the patients seem to connect or associate themselves with these items?

5. Do you find they feel less distressed when surround by things that remind them of their past? (yes/no)

\section{Feel free to explain:}

Interior:

What are aspects of the interior you feel work best for the patients?

What activities are most enjoyed by residents?

Does the corridor system in place work for the residents with respect to wandering? And why?

How often do the residents find their own way into the common areas (lounge, toilets, other)? (0$100 \%)$

5. Do you have a resident animal? (yes/no)

6. Do you find that the residents enjoy the company of this animal? (yes/no)

\section{Exterior:}

列

On a scale of $1-10$, how often would residents decide to venture outside? $(1=$ Never, $10=$ Very Often $)$

3. What issues do they encounter when outside?

4. Do the residents engage in gardening? (yes/no)

5. Would they benefit from a greater connection to the outside? (yes/no)

\section{Comments:}

Do you have any thoughts, comments, ideas that you would like to share? 